\title{
STANDARD \\ TECHNICAL SPECIFICATIONS FOR \\ BABCOCK AND WILCOX PRESSURIZED WATER REACTORS
}

Revision of June 1978

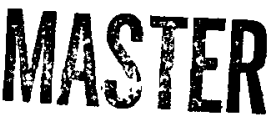

Office of Nuclear Reactor Regulation U. S. Nuclear Regulatory Commission 
Available from

National Technical Information Service

Springfield, Virginia 22161

Price: Printed Copy $\$ 14.00$; Microfiche $\$ 3.00$

The price of this document for requesters outside of the North American Continent can be obtained from the National Technical Information Service. 


\section{DISCLAIMER}

This report was prepared as an account of work sponsored by an agency of the United States Government. Neither the United States Government nor any agency Thereof, nor any of their employees, makes any warranty, express or implied, or assumes any legal liability or responsibility for the accuracy, completeness, or usefulness of any information, apparatus, product, or process disclosed, or represents that its use would not infringe privately owned rights. Reference herein to any specific commercial product, process, or service by trade name, trademark, manufacturer, or otherwise does not necessarily constitute or imply its endorsement, recommendation, or favoring by the United States Government or any agency thereof. The views and opinions of authors expressed herein do not necessarily state or reflect those of the United States Government or any agency thereof. 


\section{DISCLAIMER}

Portions of this document may be illegible in electronic image products. Images are produced from the best available original document. 


\section{STANDARD \\ TECHNICAL SPECIFICATIONS \\ FOR \\ BABCOCK AND WILCOX \\ PRESSURIZED WATER REACTORS}

Revision of June 1978

Supersedes NUREG-0103, REVISION 1

Date Published: June 1978

Division of Operating Reactors Office of Nuclear Reactor Regulation U. S. Nuclear Regulatory Commission Washington, D. C. 20555 


\section{FOREWORD}

The following paragraphs briefly describe the applicability, format and implementation of the Babcock and Wilcox (B\&W) Standard Technical Specification package.

\section{APPLICABILITY}

This Standard Technical Specification (STS) has been structured for the broadest possible use on B\&W NSSS plants currently being reviewed for an Operating License. Two separate and discrete containment specification sections are provided for each of the following containment types: Atmospheric, and Dual. Optional specifications are provided for those features and systems which may be included in individual plant designs but are not generic in their scope of application. Alternate specifications are provided in a limited number of cases to cover situations where alternate specification requirements are necessary on a generic basis because of design differences.

\section{FORMAT}

The format of the STS addresses the categories required by 10 CFR 50 and consists of six section covering the areas of: Definitions, Safety Limits and Limiting Safety System Settings, Limiting Conditions for Operation, Surveillance Requirements, Design Features, and Administrative Controls. The Limiting Conditions for Operation and Surveillance Requirements (Sections $3 \& 4$ ) are presented in a combined format with each LCO appearing at the top of the page followed immediately by the applicable Surveillance Requirements. The combined Section $3 / 4$ is further subdivided into ten subsections covering the areas of:

1. Reactivity Control,

2. Power Distribution,

3. Instrumentation,

4. Reactor Coolant System,

5. Emergency Core Cooling System,

6. Containment Systems,

7. Plant Systems,

8. Electrical Power Systems,

9. Refueling Operations and,

10. Special Test Exceptions. 
The values of those parameters and variables which may vary because of plant design appear as either blanks or parenthesized numbers throughout the STS. The actual value for each parameter will be provided by individual applicants as appropriate for their plants. The values in paratheses are for illustration only.

\section{IMPLEMENTATION}

The implementation of the STS on an individual license application will proceed in three phases. The major steps within each phase are indicated below.

\section{Phase I}

The applicant should:

1. Obtain copies of the STS from the NRC.

2. Select the appropriate containment specification section and set aside the non-applicable containment sections and related bases.

3. Identify and mark those specifications not required because of plant design or other factors. Specifications within this category should be retained in position within the document package for later review and discussion.

4. Identify those areas where specifications are required but are not provided in the STS.

5. Provide the applicable values of the parameters and variables identified by blands or parentheses in the STS. This information must be consistent with the SAR and other supporting documents.

6. Provide the figures, graphs and other information required to complete the STS document package.

\section{Phase II}

1. The Commission staff will review the information provided in the marked up STS document package resulting from the Phase I preparation.

2. An applicant/staff meeting will be held to resolve noted differences of position and other related comments from the applicant, vendor and A.E. 


\section{Phase III}

1. The Commission will provide a Proof and Review edition of the technical specification for final review by all parties based upon the resolution of comments and positions in Phase II.

2. Final comments and corrections will be incorporated into the document as received.

3. The Technical Specifications will be issued by the Commission as Appendix "A" of the Operating License. 
1.0 DEFINITIONS

DEFINED TERMS............................... 1-1

THERMAL POWER................................ $1-1$

RATED THERMAL POWER............................. 1-1

OPERATIONAL MODE.................................. $1-1$

ACTION...................................... 1

OPERABLE - OPERABILITY........................ 1-1

REPORTABLE OCCURENCE........................... $1-2$

CONTAINMENT INTEGRITY.......................... $1-2$

CHANNEL CALIBRATION............................. 1-2

CHANNEL CHECK.................................. 1-2

CHANNEL FUNCTIONAL TEST......................... $1-3$

CORE ALTERATION................................. 1-3

SHUTDOWN MARGIN............................... $1-3$

IDENTIFIED LEAKAGE............................ $1-3$

UNIDENTIFIED LEAKAGE........................... 1-4

PRESSURE BOUNDARY LEAKAGE........................ $1-4$

CONTROLLED LEAKAGE.............................. 1-4

QUADRANT POWER TILT............................ $1-4$

DOSE EQUIVALENT I-131.......................... 1-4

E-AVERAGE DISINTEGRATION ENERGY..................... $1-4$

STAGGERED TEST BASIS......................... $1-5$

FREQUENCY NOTATION.......................... $1-5$

AXIAL POWER IMBALANCE......................... 1-5

SHIELD BUILDING INTEGRITY...................... $1-5$

REACTOR PROTECTION SYSTEM RESPONSE TIME.............. $1-5$

ENGINEERED SAFETY FEATURE RESPONSE TIME.............. 1-6

PHYSICS TESTS................................ 1-6

OPERATIONAL MODES (TABLE 1.1$) \ldots \ldots \ldots \ldots \ldots \ldots \ldots \ldots \ldots . . \ldots 1-7$

FREQUENCY NOTATION (TABLE 1.2$) \ldots \ldots \ldots \ldots \ldots \ldots \ldots \ldots \ldots, 1-8$ 


\section{INDEX}

SAFETY LIMITS AND LIMITING SAFETY SYSTEM SETTINGS

SECTION

PAGE

2.1 SAFETY LIMITS

Reactor Core................................ 2-1

Reactor Coolant System Pressure.................... 2-1

2.2 LIMITING SAFETY SYSTEM SETTINGS

Reactor Protection System Setpoints................ 2-4

BASES

SECTION

PAGE

2.1 SAFETY LIMITS

Reactor Core............................... B 2-1

Reactor Coolant System Pressure.................... B 2-3

2.2 LIMITING SAFETY SYSTEM SETTINGS

Reactor Protection System Setpoints................. B 2-4 
LIMITING CONDITIONS FOR OPERATION AND SURVEILLANCE REQUIREMENTS

SECTION

PAGE

3/4.0 APPLICABILITY.

$3 / 4 \quad 0-1$

3/4.1 REACTIVITY CONTROL SYSTEMS

3/4.1.1 BORATION CONTROL

Shutdown Margin........................... 3/4 1-1

Boron Dilution ......................... 3/4 1-3

Moderator Temperature Coefficient.............. 3/4 1-4

Minimum Temperature for Criticality............. 3/4 1-5

3/4.1.2 BORATION SYSTEMS

Flow Paths - Shutdown...................... 3/4 1-6

Flow Paths - Operating...................... 3/4 1-7

Makeup Pump - Shutdown.................... 3/4 1-9

Makeup Pumps - Operating................... 3/4 1-10

Decay Heat Removal Pump - Shutdown.............. 3/4 1-11

Boric Acid Pump - Shutdown.................. 3/4 1-12

Boric Acid Pumps - Operating.................. 3/4 1-13

Borated Water Sources - Shutdown............... 3/4 1-14

Borated Water Sources - Operating............... 3/4 1-16

3/4.1.3 MOVABLE CONTROL ASSEMBLIES

Group Height - Safety and Regulating Rod Groups..... 3/4 1-18

Group Height - Axial Power Shaping Rod Group....... 3/4 1-21

Position Indicator Channels-Operating ........... 3/4 1-22

Position Indicator Channels-Shutdown............ 3/4 1-24

Rod Drop Time......................... 3/4 1-25

Safety Rod Insertion Limit................. 3/4 1-26

Regulating Rod Insertion Limits.............. 3/4 1-27

Rod Program........................... 3/4 1-33

Xenon Reactivity........................... 3/4 1-36 
SECTION

PAGE

3/4.2 POWER DISTRIBUTION LIMITS

3/4.2.1 AXIAL POWER IMBALANCE..................... $3 / 4$

3/4.2.2 NUCLEAR HEAT FLUX HOT

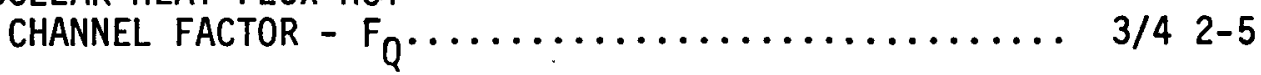

3/4.2.3 NUCLEAR ENTHALPY RISE

HOT CHANNEL FACTOR $-F_{\triangle H}^{N} \ldots \ldots \ldots \ldots \ldots \ldots \ldots \ldots \ldots \ldots \ldots \ldots \ldots, 3 / 4,7$

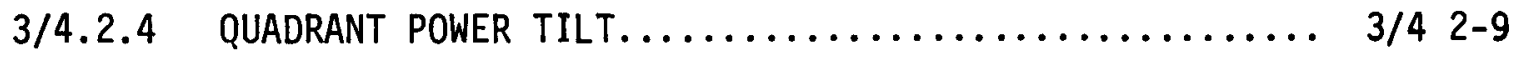

$3 / 4.2 .5$ DNB PARAMETERS......................... $3 / 4$ 2-13

$3 / 4.3$ INSTRUMENTATION

3/4.3.1 REACTOR PROTECTION SYSTEM INSTRUMENTATION......... 3/4 3-1

3/4.3.2 ENGINEERED SAFETY FEATURE ACTUATION SYSTEM

INSTRUMENTATION.......................... $3 / 4 \quad 3-9$

3/4.3.3 MONITORING INSTRUMENTATION

Radiation Monitoring Instrumentation........... 3/4 3-25

Incore Detectors..................... 3/4 3-29

Seismic Instrumentation................... 3/4 3-31

Meteorological Instrumentation............... 3/4 3-34

Remote Shutdown Instrumentation.............. 3/4 3-37

Post-accident Instrumentation................ 3/4 3-40

Chlorine Detection Systems................. 3/4 3-43

Fire Detection Instrumentation.............. 3/4 3-44

3/4.3.4 TURB INE OVERSPEED PROTECTION................ 3/4 3-46

3/4.4 REACTOR COOLANT SYSTEM

3/4.4.1 REACTOR COOLANT LOOPS..................... 3/4 4-1

$3 / 4.4 .2$ SAFETY VALVES - SHUTDOWN................... 3/4 4-3

$3 / 4.4 .3$ SAFETY VALVES - OPERATING................. 3/4 4-4 
3/4.4.4 PRESSURIZER............................ $3 / 4$ 4-5

3/4.4.5 STEAM GENERATORS......................... 3/4 4-6

3/4.4.6 REACTOR COOLANT SYSTEM LEAKAGE

Leakage Detection Systems..................... 3/4 4-13

Operational Leakage....................... 3/4 4-15

3/4.4.7 CHEMISTRY............................. 3/4 4-17

3/4.4.8 SPECIFIC ACTIVITY....................... $3 / 4$ 4-20

3/4.4.9 PRESSURE/TEMPERATURE LIMITS

Reactor Coolant System...................... 3/4 4-24

Pressurizer............................ 3/4 4-28

$3 / 4.4 .10$ STRUCTURAL INTEGRITY...................... 3/4 4-29

3/4.5 EMERGENCY CORE COOLING SYSTEMS (ECCS)

3/4.5.1 CORE FLOODING TANKS........................ 3/4 5-1

$3 / 4.5 .2$ ECCS SUBSYSTEMS - $T_{\text {avg }} \geq(305)^{\circ} \mathrm{F} \ldots \ldots \ldots \ldots \ldots \ldots \ldots \ldots \ldots \ldots \ldots \ldots$

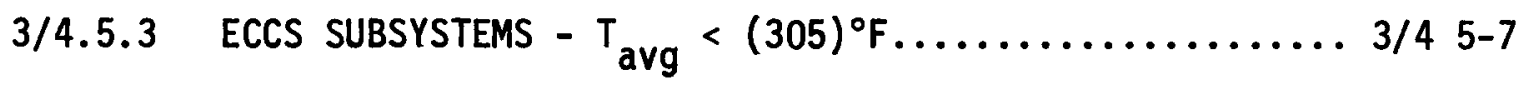

$3 / 4.5 .4$ BORATED WATER STORAGE TANK.................. 3/4 5-8 
-

○

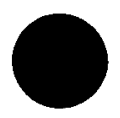




\section{B\&W - ATMOSPHERIC TYPE CONTAINMENT}

$3 / 4.6$ CONTAINMENT SYSTEMS

3/4.6.1 PRIMARY CONTAINMENT

Containment Integrity........................ 3/4 6-1J

Containment Leakage...................... 3/4 6-2J

Containment Air Locks...................... 3/4 6-5J

Containment Isolation Valve and Channel Weld

Pressurization Systems...................... 3/4 6-6J

Internat Pressure.............................. 3/4 6-7J

Air Temperature.............................. $3 / 4$ 6-8

Containment Structural Integrity.............. $3 / 4$ 6-9J

Containment Ventilation System............... $3 / 4$ 6-10 J

3/4.6.2 DEPRESSURIZATION AND COOLING SYSTEMS

Containment Spray System................... 3/4 6-11 J

Spray Additive System.................... $3 / 46-12 \mathrm{~J}$

Containment Cooling System................. 3/4 6-14J

$3 / 4.6 .3$ IODINE CLEANUP SYSTEM...................... 3/4 6-15J

$3 / 4.6 .4$ CONTAINMENT ISOLATION VALVES................ 3/4 6-17J

$3 / 4.6 .5$ COMBUSTIBLE GAS CONTROL

Hydrogen Anaiyzers....................... 3/4 6-20 J

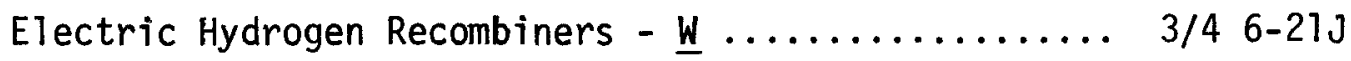

Hydrogen Purge Cleanup System................ 3/4 6-22 J

Hydrogen Mixing System................... 3/4 6-24J

3/4.6.6 PENETRATION ROOM EXHAUST AIR CLEANUP SYSTEM........ 3/4 6-25J

$3 / 4.6 .7$ VACUUM RELIEF VALVES.................... $3 / 4$ 6-28 J 
-

•

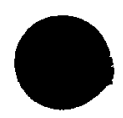


SECTION

PAGE

\section{B\&W - DUAL TYPE CONTAINMENT}

$3 / 4.6$ CONTAINMENT SYSTEMS

3/4.6.1 PRIMARY CONTAINMENT

Containment Integrity..................... 3/4 6-1L

Containment Leakage..................... 3/4 6-2L

Containment Air Locks........................ 3/4 6-6L

Containment Isolation Valve and Channel Weld

Pressurization Systems.................... 3/4 6-7L

Internal Pressure......................... $3 / 46-8 \mathrm{~L}$

Air Temperature............................... 3/4 6-9L

Containment Structural Integrity............... 3/4 6-10L

Containment Ventilation System................. 3/4 6-11L

3/4.6.2 DEPRESSURIZATION AND COOLING SYSTEMS

Containment Spray System.................. 3/4 6-12L

Spray Additive System.................... 3/4 6-13L

Containment Cooling System.................. 3/4 6-15L

$3 / 4.6 .3$ IODINE CLEANUP SYSTEM.................... 3/4 6-16L

$3 / 4.6 .4$ CONTAINMENT ISOLATION VALVES............... 3/4 6-18L

$3 / 4.6 .5$ COMBUSTIBLE GAS CONTROL

Hydrogen Analyzers....................... 3/4 6-21L

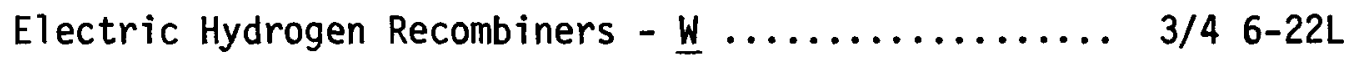

Hydrogen Purge Cleanup System................ 3/4 6-23L

Hydrogen Mixing System................... 3/4 6-25L

3/4.6.6 PENETRATION ROOM EXHAUST AIR CLEANUP SYSTEM........ 3/4 6-26L

$3 / 4.6 .7$ VACUUM RELIEF VALVES.................... $3 / 4$ 6-29L

3/4.6.8 SECONDARY CONTAINMENT

Shield Building Air Cleanup System............. 3/4 6-30L

Shield Building Integrity.................. 3/4 6-33L

Shield Building Structural Integrity............ 3/4 6-34L 
0

O

○ 
LIMITING CONDITIONS FOR OPERATION AND SURVEILLANCE REQUIREMENTS

SECTION

PAGE

3/4.7 PLANT SYSTEMS

3/4.7.1 TURBINE CYCLE

Safety Valves............................. 3/4 7-1

Auxiliary Feedwater System................... 3/4 7-4

Condensate Storage Tank..................... 3/4 7-6

Activity............................... 3/4 7-7

Main Steam Line Isolation Valves................ 3/4 7-9

Secondary Water Chemistry.................... 3/4 7-10

3/4.7.2 STEAM GENERATOR PRESSURE/TEMPERATURE LIMITATION...... 3/4 7-13

$3 / 4.7 .3$ COMPONENT COOLING WATER SYSTEM................. 3/4 7-14

$3 / 4.7 .4$ SERVICE WATER SYSTEM....................... 3/4 7-15

$3 / 4.7 .5$ ULTIMATE HEAT SINK........................ 3/4 7 16

$3 / 4.7 .6$ FLOOD PROTECTION.......................... 3/4 7-17

3/4.7.7 CONTROL ROOM EMERGENCY AIR CLEANUP SYSTEM.......... 3/4 7-18

3/4.7.8 ECCS PUMP ROOM EXHAUST AIR CLEANUP SYSTEM.......... 3/4 7-21

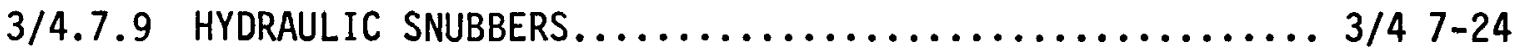

$3 / 4.7 .10$ SEALED SOURCE CONTAMINATION................... 3/4 7-28

3/4.7.11 FIRE SUPPRESSION SYSTEMS

Fire Suppression Water System................. 3/4 7-30

Spray and/or Sprinkler Systems................ 3/4 7-34

Low Pressure $\mathrm{CO}_{2}$ Systems.................... 3/4 7-36

High Pressure $\mathrm{CO}_{2}$ Systems.................. 3/4 7-37

Halon Systems.......................... 3/4 7-38

Fire Hose Stations.......................... 3/4 7-39

3/4.7.12 PENETRATION fire BARRIERS.................. 3/4 7-41

$3 / 4.8$ ELECTRICAL POWER SYSTEMS

3/4.8.1 A.C. SOURCES

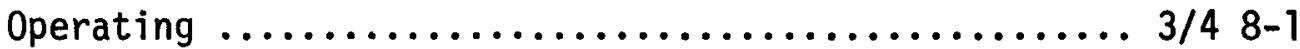

Shutdown................................. 3/4 8-7 


\section{INDEX}

LIMITING CONDITIONS FOR OPERATION AND SURVEILLANCE REQUIREMENTS

SECTION

PAGE

3/4.8.2 ONSITE POWER DISTRIBUTION SYSTEMS

A.C. Distribution - Operating................. 3/4 8-8

A.C. Distribution - Shutdown...................... 3/4 8-9

D.C. Distribution - Operating................. 3/4 8-10

D.C. Distribution - Shutdown................ 3/4 8-12

$3 / 4.9$ REFUELING OPERATIONS

$3 / 4.9 .1$ BORON CONCENTRATION....................... 3/4 9-1

$3 / 4.9 .2$ INSTRUMENTATION............................. $3 / 4$

$3 / 4.9 .3$ DECAY TIME............................... 3/4 9-3

$3 / 4.9 .4$ CONTAINMENT PENETRATIONS...................... $3 / 49.4$

$3 / 4.9 .5$ COMMUNICATIONS............................ $3 / 4$ 9-5

$3 / 4.9 .6$ FUEL HANDLING BRIDGE OPERABILITY............... 3/4 9-6

3/4.9.7 CRANE TRAVEL - SPENT FUEL STORAGE POOL BUILDING...... 3/4 9-7

$3 / 4.9 .8$ COOLANT CIRCULATION......................... 3/4 9-8

$3 / 4.9 .9$ CONTAINMENT PURGE AND EXHAUST ISOLATION SYSTEM....... 3/4 9-9

3/4.9.10 WATER LEVEL - REACTOR VESSEL.................. 3/4 9-10

$3 / 4.9 .11$ STORAGE POOL WATER LEVEL.................... 3/4 9-11

$3 / 4.9 .12$ STORAGE POOL AIR CLEANUP SYSTEM................ 3/4 9-12

3/4.10 SPECIAL TEST EXCEPTIONS

3/4.10.1 GROUP HEIGHT, INSERTION AND

POWER DISTRIBUTION LIMITS.................... $3 / 4$ 10-1

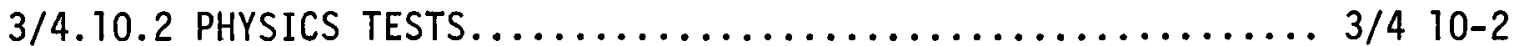

$3 / 4.10 .3$ REACTOR COOLANT LOOPS...................... $3 / 4$ 10-3

$3 / 4.10 .4$ SHUTDOWN MARGIN............................. $3 / 4$ 10-4 
3/4.1 REACTIVITY CONTROL SYSTEMS

3/4.1.1 BORATION CONTROL.......................... B 3/4 1-1

$3 / 4.1 .2$ BORATION SYSTEMS $\ldots \ldots \ldots \ldots \ldots \ldots \ldots \ldots \ldots \ldots \ldots \ldots \ldots \ldots \ldots \ldots \ldots \ldots$, B $3 / 4$ 1-2

$3 / 4.1 .3$ MOVABLE CONTROL ASSEMBLIES $\ldots \ldots \ldots \ldots \ldots \ldots \ldots \ldots \ldots$ B $3 / 4$ 1-3

$3 / 4.2$ POWER DISTRIBUTION LIMITS $\ldots \ldots \ldots \ldots \ldots \ldots \ldots \ldots \ldots \ldots$ B $3 / 4$ 2-1

$3 / 4.3$ INSTRUMENTATION

3/4.3.1 REACTOR PROTECTION SYSTEM INSTRUMENTATION.......... B 3/4 3-1

3/4.3.2 ENGINEERED SAFETY FEATURE ACTUATION SYSTEM

INSTRUMENTATION.......................... B $3 / 43-1$

3/4.3.3 MONITORING INSTRUMENTATION................... B $3 / 4$ 3-2

3/4.4 REACTOR COOLANT SYSTEM

3/4.4.1 REACTOR COOLANT LOOPS..................... B 3/4

$3 / 4.4 .2$ and $3 / 4.4 .3$ SAFETY VALVES................... B 3/4 4 -1

$3 / 4.4 .4$ PRESSURIZER............................. B $3 / 4$ 4-2

$3 / 4.4 .5$ STEAM GENERATORS....................... B $3 / 4$ 4-2

3/4.4.6 REACTOR COOLANT SYSTEM LEAKAGE................ B 3/4 4-4

$3 / 4.4 .7$ CHEMISTRY............................. B 3/4 4-5

$3 / 4.4 .8$ SPECIFIC ACTIVITY....................... B 3/4 4-5

3/4.4.9 PRESSURE/TEMPERATURE LIMITS................ B 3/4 4-6

$3 / 4.4 .10$ STRUCTURAL INTEGRITY....................... B 3/4 4-11 
3/4.5 EMERGENCY CORE COOLING SYSTEMS (ECCS)

3/4.5.1 CORE FLOODING TANKS........................ B 3/4 5-1

$3 / 4.5 .2$ and $3 / 4.5 .3$ ECCS SUBSYSTEMS.................. B $3 / 45-2$

3/4.5.4 BORATED WATER STORAGE TANK.................. B $3 / 4$ 5-3 


\section{B\&W-ATMOSPHERIC TYPE CONTAINMENT}

SECTION

PAGE

$3 / 4.6$ CONTAINMENT SYSTEMS

3/4.6.1 PRIMARY CONTAINMENT...................... B 3/4 6-1J

$3 / 4.6 .2$ DEPRESSURIZATION AND COOLING SYSTEMS........... B $3 / 46-3 \mathrm{~J}$

3/4.6.3 IODINE CLEANUP SYSTEM...................... B 3/4 6-4J

$3 / 4.6 .4$ CONTAINMENT ISOLATION VALVE................ B 3/4 6-5J

$3 / 4.6 .5$ COMBUSTIBLE GAS CONTROL................... B 3/4 6-5J

3/4.6.6 PENETRATION ROOM EXHAUST AIR CLEANUP SYSTEM........ B 3/4 6-5J

$3 / 4.6 .7$ VACUUM RELIEF VALVES................... B $3 / 46-5 \mathrm{~J}$ 
○

○

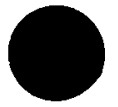




\section{B\&W - DUAL TYPE CONTAINMENT}

SECTION

PAGE

3/4.6 CONTAINMENT SYSTEMS

3/4.6.1 PRIMARY CONTAINMENT..................... B 3/4 6-1L

3/4.6.2 DEPRESSURIZATION AND COOLING SYSTEMS........... B 3/4 6-2L

3/4.6.3 IODINE CLEANUP SYSTEMS................... B 3/4 6-4L

3/4.6.4 CONTAINMENT ISOLATION VALVES............... B $3 / 4$ 6-4L

$3 / 4.6 .5$ COMBUSTIBLE GAS CONTROL.................. B $3 / 4$ 6-5L

3/4.6.6 PENETRATION ROOM EXHAUST AIR CLEANUP SYSTEM....... B 3/4 6-5L

$3 / 4.6 .7$ VACUUM RELIEF VALVES.................... B $3 / 46-5 \mathrm{~L}$

$3 / 4.6 .8$ SECONDARY CONTAINMENT.................... B $3 / 4$ 6-5L 
•

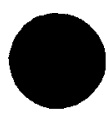

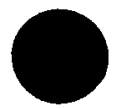


$3 / 4.7$ PLANT SYSTEMS

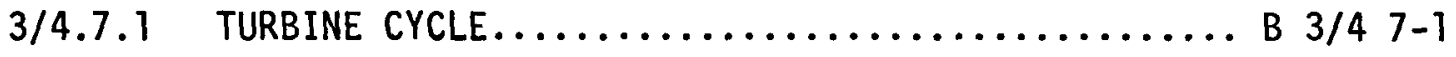

3/4.7.2 STEAM GENERATOR PRESSURE/TEMPERATURE LIMITATION.. B 3/4 7-3

$3 / 4.7 .3$ COMPONENT COOLING WATER SYSTEM.............. B 3/4 7-3

$3 / 4.7 .4$ SERVICE WATER SYSTEM................... B 3/4 7-3

$3 / 4.7 .5$ ULTIMATE HEAT SINK.................... B 3/4 7-4

$3 / 4.7 .6$ FLOOD PROTECTION....................... B 3/4 7-4

3/4.7.7 CONTROL ROOM EMERGENCY AIR CLEANUP SYSTEM....... B 3/4 7-4

3/4.7.8 ECCS PUMP ROOM EXHAUST AIR CLEANUP SYSTEM....... B 3/4 7-5

$3 / 4.7 .9$ HYDRAULIC SNUBBERS..................... B 3/4 7-5

3/4.7.10 SEALED SOURCE CONTAMINATION............... B 3/4 7-6

3/4.7.11 FIRE SUPPRESSION SYSTEMS................. B 3/4 7-6

3/4.7.12 PENETRATION fiRE BARRIERS................ B 3/4 7-6

3/4.8 ELECTRICAL POWER SYSTEMS

3/4.8.1 A.C. SOURCES......................... B $3 / 4$ 8-1

3/4.8.2 ONSITE POWER DISTRIBUTION SYSTEMS............ B 3/4 8-1

3/4.9 REFUELING OPERATIONS

3/4.9.1 BORON CONCENTRATION..................... B 3/4 9-1

3/4.9.2 INSTRUMENTATION........................ В $3 / 4$ 9-1

$3 / 4.9 .3$ DECAY TIME............................ B 3/4 9-1

3/4.9.4 CONTAINMENT PENETRATIONS................... B 3/4 9-1

3/4.9.5 COMMUNICATIONS....................... B 3/4 9-1 
.

-

•

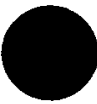


INDEX

BASES

SECTION

PAGE

3/4.9.6 FUEL HANDLING BRIDGE OPERABILITY............... B 3/4 9-2

3/4.9.7 CRANE TRAVEL - SPENT FUEL STORAGE BUILDING........ B 3/4 9-2

$3 / 4.9 .8$ COOLANT CIRCULATION...................... B 3/4 9-2

3/4.9.9 CONTAINMENT PURGE AND EXHAUST ISOLATION SYSTEM..... B 3/4 9-2

3/4.9.10 and 3/4.9.11 WATER LEVEL - REACTOR VESSEL AND

STORAGE POOL WATER LEVEL.................... B 3/4 9-2

$3 / 4.9 .12$ STORAGE POOL AIR CLEANUP SYSTEM................ B 3/4 9-3

$3 / 4.10$ SPECIAL TEST EXCEPTIONS

3/4.10.1 GROUP HEIGHT, INSERTION AND

POWER DISTRIBUTION LIMITS.................. B 3/4 10-1

$3 / 4.10 .2$ PHYSICS TESTS......................... B 3/4 10-1

$3 / 4.10 .3$ REACTOR COOLANT LOOPS.................... B 3/4 10-1

$3 / 4.10 .4$ SHUTDOWN MARGIN......................... B 3/4 10-1 
5.1 SITE

Exclusion Area.............................. 5-1

Low Population Zone.............................

5.2 CONTAINMENT

Configuration.............................. $5-1$

Design Pressure and Temperature.................. 5-4

5.3 REACTOR CORE

Fuel Assemblies............................. $5-4$

Control Rods............................... $5-4$

5.4 REACTOR COOLANT SYSTEM

Design Pressure and Temperature.................. 5-5

volume.................................... $5-5$

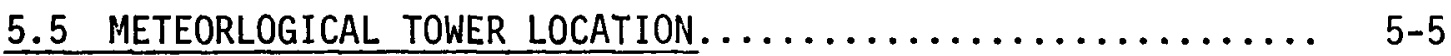

5.6 FUEL STORAGE

Criticality................................ 5-5

Drainage.................................... 5-5

Capacity.................................. $5-6$

5.7 COMPONENT CYCLIC OR TRANSIENT LIMIT $\ldots \ldots \ldots \ldots \ldots \ldots \ldots, 5-6$ 
ADMINISTRATIVE CONTROLS

SECTION

PAGE

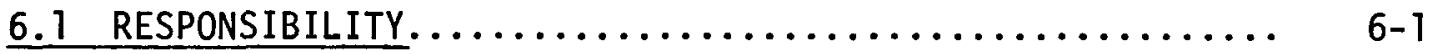

6.2 ORGANIZATION

offsite................................ 6

Unit Staff................................

6.3 UNIT STAFF QUALIFICATIONS $\ldots \ldots \ldots \ldots \ldots \ldots \ldots \ldots \ldots \ldots \ldots \ldots \ldots \ldots, 6-5$

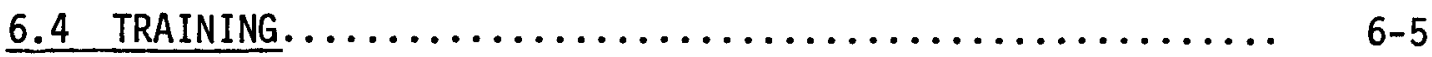

$\underline{6.5}$ REVIEW AND AUDIT

6.5.1 UNIT REVIEW GROUP

Function................................ 6-5

Composition............................. $6-6$

Alternates.............................. $6-6$

Meeting Frequency........................ $6-6$

Quorum................................... $6-6$

Responsibilities........................ $6-6$

Authority............................ $6-7$

Records.............................. $6-8$

6.5.2 COMPANY NUCLEAR REVIEW AND AUDIT GROUP

Function................................ $6-8$

Composition.............................. $6-9$

Alternates.............................. $6-9$

Consultants.......................... $6-9$ 


\section{INDEX}

ADMINISTRATIVE CONTROLS

SECTION

PAGE

Meeting Frequency......................... $6-9$

Quorum................................... $6-9$

Review.................................. $6-10$

Audits..................................... $6-11$

Authority................................. $6-11$

Records................................ $6-12$

6.6 REPORTABLE OCCURRENCE ACTION $. . \ldots \ldots \ldots \ldots \ldots \ldots \ldots \ldots, 6,12$

6.7 SAFETY LIMIT VIOLATION. $\ldots \ldots \ldots \ldots \ldots \ldots \ldots \ldots \ldots \ldots, 6-13$

6.8 PROCEDURES $. \ldots \ldots \ldots \ldots \ldots \ldots \ldots \ldots \ldots \ldots \ldots \ldots \ldots \ldots \ldots \ldots \ldots \ldots \ldots, 6-13$

\subsection{REPORTING REQUIREMENTS}

6.9.1 ROUTINE AND REPORTABLE OCCURRENCES................ 6-14

6.9 .2 SPECIAL REPORTS $\ldots \ldots \ldots \ldots \ldots \ldots \ldots \ldots \ldots \ldots \ldots \ldots \ldots \ldots \ldots, 6-18$

6.10 RECORD RETENTION................................ $6-19$

6.11 RADIATION PROTECTION PROGRAM..................... $6-20$

6.12 HIGH RADIATION AREA. .......................... $6-20$ 
SECTION 1.0

DEFINITIONS 
•

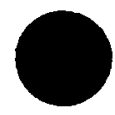

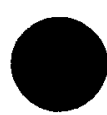


DEFINED TERMS

1.1 The DEFINED TERMS of this section appear in capitalized type and are applicable throughout these Technical Specifications.

THERMAL POWER

1.2 THERMAL POWER shall be the total reactor core heat transfer rate to the reactor coolant.

RATED THERMAL POWER

1.3 RATED THERMAL POWER shall be a total reactor core heat transfer rate to the reactor coolant of MWt.

OPERATIONAL MODE - MODE

1.4 An OPERATIONAL MODE (i.e. Mode) shall correspond to any one inclusive combination of core reactivity condition, power level and average reactor coolant temperature specified in Table 1.1.

ACTION

1.5 ACTION shall be those additional requirements specified as corollary statements to each principle specification and shall be part of the specifications.

OPERABLE - OPERABILITY

1.6 A system, subsystem, train, component or device shall be OPERABLE or have OPERABILITY when it is capable of performing its specified function(s). Implicit in this definition shall be the assumption that all necessary attendant instrumentation, controls, normal and emergency electrical power sources, cooling or seal water, lubrication or other auxiliary equipment, that are required for the system, subsystem, train, component or device to perform its function(s), are also capable of performing their related support function(s). 
REPORTABLE OCCURRENCE

1.7 A REPORTABLE OCCURRENCE shall be any of those conditions specified in Specifications 6.9.1.8 and 6.9.1.9. CONTAINMENT INTEGRITY

1.8 CONTAINMENT INTEGRITY shal1 exist when:

a. All penetrations required to be closed during accident conditions are either:

1. Capable of being closed by an OPERABLE containment automatic isolation system, or

2. Closed by manual valves, blind flanges, or deactivated automatic valves secured in their closed positions, except as provided in Table (3.6-1) of Specification (3.6.3.1).

b. All equipment hatches are closed and sealed.

c. Each airlock is OPERABLE pursuant to Specification $(3.6 .1 .3)$.

d. The containment leakage rates are within the limits of Specification (3.6.1.2).

e. The sealing mechanism associated with each penetration (e.g. welds, bellows or 0-rings) is OPERABLE.

CHANNEL CALIBRATION

1.9 A CHANNEL CALIBRATION shall be the adjustment, as necessary, of the channel output such that it responds with necessary range and accuracy to known values of the parameter which the channel monitors. The CHANNEL CALIBRATION shall encompass the entire channel including the sensor and alarm and/or trip functions, and shall include the CHANNEL FUNCTIONAL TEST. CHANNEL CALIBRATION may be performed by any series of sequential, overlapping or total channel steps such that the entire channel is calibrated.

\section{CHANNEL CHECK}

1.10 A CHANNEL CHECK shall be the qualitative assessment of channe1 behavior during operation by observation. This determination shall include, where possible, comparison of the channel indication and/or status with other indications and/or status derived from independent instrument channels measuring the same parameter. 
CHANNEL FUNCTIONAL TEST

1.11 A CHANNEL FUNCTIONAL TEST shal1 be:

a. Analog channels - the injection of a simulated signal into the channel as close to the sensor as practicable to verify OPERABILITY including alarm and/or trip functions.

b. Bistable channels - the injection of a simulated signal into the sensor to verify OPERABILITY including alarm and/or trip functions.

\section{CORE ALTERATION}

1.12 CORE ALTERATION shall be the movement or manipulation of any component within the reactor pressure vessel with the vessel head removed and fuel in the vessel. Suspension of CORE ALTERATIONS shall not preclude completion of movement of a component to a safe conservative position.

SHUTDOWN MARGIN

1.13 SHUTDOWN MARGIN shall be the instantaneous amount of reactivity by which the reactor is subcritical or would be subcritical from its present condition assuming:

a. No change in axial power shaping rod position.

b. All control rod assemblies (safety and regulating) are fully inserted except for the single rod assembly of highest reactivity worth which is assumed to be fully withdrawn.

\section{IDENT IFIED LEAKAGE}

1.14 IDENTIFIED LEAKAGE shal1 be:

a. Leakage (except CONTROLLED LEAKAGE) into closed systems, such as pump seal or valve packing leaks that are captured and conducted to a sump or collecting tank.

b. Leakage into the containment atmosphere from sources that are both specifically located and known either not to interfere with the operation of leakage detection systems or not to be PRESSURE BOUNDARY LEAKAGE. 
c. Reactor coolant system leakage through a steam generator to the secondary system.

UNIDENTIFIED LEAKAGE

1.15 UNIDENTIFIED LEAKAGE shall be all leakage which is not IDENTIFIED LEAKAGE or CONTROLLED LEAKAGE.

PRESSURE BOUNDARY LEAKAGE

1.16 PRESSURE BOUNDARY LEAKAGE shall be leakage (except steam generator tube leakage) through a non-isolable fault in a Reactor Coolant System component body, pipe wall or vessel wall.

CONTROLLED LEAKAGE

1.17 CONTROLLED LEAKAGE shal1 be that seal water flow supplied to the reactor coolant pump seals.

QUADRANT POWER TILT

1.18 QUADRANT POWER TILT is defined by the following equation and is expressed in percent.

QUADRANT POWER TILT $=$

100 ( $\frac{\text { Power in any core quadrant }}{\text { Average power of a11 quadrants }}-1$ )

DOSE EQUIVALENT I-131

1.19 DOSE EQUIVALENT I-131 shall be that concentration of I-131 ( $\mu \mathrm{Ci} / \mathrm{gram}$ ) which alone would produce the same thyroid dose as the quantity and isotopic mixture of I-131, I-132, I-133, I-134 and I-135 actually present. The thyroid dose conversion factors used for this calculation shall be those listed in Table III of TID-14844, "Calculation of Distance Factors for Power and Test Reactor Sites."

\section{$\bar{E}$ - AVERAGE DISINTEGRATION ENERGY}

1.20 $\bar{E}$-AVERAGE DISINTEGRATION ENERGY shall be the average (weighted in proportion to the concentration of each radionuclide in the reactor coolant at the time of sampling) of the sum of the average beta and gamma energies 
per disintegration (in MeV) for isotopes, other than iodines, with half 1 ives greater than 15 minutes, making up at 1 east $95 \%$ of the total noniodine activity in the coolant.

\section{STAGGERED TEST BASIS}

1.21 A STAGGERED TEST BASIS sha11 consist of:

a. A test schedule for $n$ systems, subsystems, trains or designated components obtained by dividing the specified test interval into $n$ equal subintervals.

b. The testing of one system, subsystem, train or designated components at the beginning of each subinterval.

\section{FREQUENCY NOTATION}

1.22 The FREQUENCY NOTATION specified for the performance of Surveillance Requirements shall correspond to the intervals defined in Table 1.2.

AXIAL POWER IMBALANCE

1.23 AXIAL POWER IMBALANCE shall be the THERMAL POWER in the top half of the core expressed as a percentage of RATED THERMAL POWER minus the THERMAL POWER in the bottom half of the core expressed as a percentage of RATED THERMAL POWER.

\section{SHIELD BUILDING INTEGRITY}

\subsection{SHIELD BUILDING INTEGRITY shal1 exist when:}

a. Each door in each access opening is closed except when the access opening is being used for normal transit entry and exit, then at least one door shall be closed.

b. The shield building filtration system is OPERABLE.

c. The sealing mechanism associated with each penetration (e.g. welds, bellows or 0-rings) is OPERABLE.

REACTOR PROTECTION SYSTEM RESPONSE TIME

1.25 The REACTOR PROTECTION SYSTEM RESPONSE TIME shall be that time interval from when the monitored parameter exceeds its trip setpoint at the channel sensor until power interruption at the control rod drive breaker undervoltage coils. 


\section{DEFINITIONS}

ENGINEERED SAFETY FEATURE RESPONSE TIME

1.26 The ENGINEERED SAFETY FEATURE RESPONSE TIME shall be that time interval from when the monitored parameter exceeds its ESF actuation setpoint at the channel sensor until the ESF equipment is capable of performing its safety function (i.e., the valves travel to their required positions, pump discharge pressures reach their required values, etc.). Times shall include diesel generator starting and sequence loading delays where applicable.

\section{PHYSICS TESTS}

1.27 PHYSICS TESTS shall be those tests performed to measure the fundamental nuclear characteristics of the reactor core and related instrumentation and 1) described in Chapter (14.0) of the FSAR, 2) authorized under the provisions of 10 CFR 50.59, or 3) otherwise approved by the Commission. 
TABLE 1.1

OPERATIONAL MODES

MODE

1. POWER OPERATION

2. STARTUP

3. HOT STANDBY

4. HOT SHUTDOWN

5. COLD SHUTDOWN

6. RL:FUELING**
REACTIVITY CONDITION, $K_{\text {eff }}$

$\geq 0.99$

$\geq 0.99$

$<0.99$

$<0.99$

$<0.99$

$\leq 0.95$
\%RATED THERMAL POWER*

$>5 \%$

$\leq 5 \%$

0

0

0

0
AVERAGE COOLANT TEMPERATURE

$\geq(305)^{\circ} \mathrm{F}$

$\geq(305)^{\circ} \mathrm{F}$

$\geq(305)^{\circ} \mathrm{F}$

$(305)^{\circ} \mathrm{F}>\mathrm{T}_{\mathrm{avg}}>200^{\circ} \mathrm{F}$

$\leq 200^{\circ} \mathrm{F}$

$\leq 140^{\circ} \mathrm{F}$

${ }_{\star \star \star}^{\star}$ Excluding decay heat.

${ }^{\star *}$ Reactor vessel head unbolted or removed and fuel in the vessel. 
TABLE 1.2

\section{FREQUENCY NOTATION}

NOTATION

S

D

$W$

M

Q

SA

$\mathrm{R}$

$S / U$

N.A.

\section{FREQUENCY}

At least once per 12 hours.

At least once per 24 hours.

At least once per 7 days.

At least once per 31 days.

At least once per 92 days.

At least once per 184 days.

At least once per 18 months.

Prior to each reactor startup.

Not applicable. 


\section{SECTION 2.0 \\ SAFETY LIMITS \\ AND}

LIMITING SAFETY SYSTEM SETTINGS 
-

O

○ 


\subsection{SAFETY LIMITS}

REACTOR CORE

2.1.1 The combination of the reactor coolant core outlet pressure and outlet temperature shall not exceed the safety limit shown in Figure 2.1-1.

APPLICABILITY: MODES 1 and 2.

ACTION:

Whenever the point defined by the combination of reactor coolant core outlet pressure and outlet temperature has exceeded the safety limit, be in HOT STANDBY within one hour.

REACTOR CORE

2.1.2 The combination of reactor THERMAL POWER and AXIAL POWER IMBALANCE shall not exceed the safety limit shown in Figure 2.1-2 for the various combinations of two, three and four reactor coolant pump operation.

APPLICABILITY: MODE 1 .

ACTION:

Whenever the point defined by the combination of Reactor Coolant System flow, AXIAL POWER IMBALANCE and THERMAL POWER has exceeded the appropriate safety limit, be in HOT STANDBY within one hour.

REACTOR COOLANT SYSTEM PRESSURE

2.1.3 The Reactor Coolant System pressure shall not exceed 2750 psig. APPLICABILITY: MODES $1,2,3,4$ and 5.

ACTION:

MODES 1 and 2 - Whenever the Reactor Coolant System pressure has exceeded 2750 psig, be in HOT STANDBY with the Reactor Coolant System pressure within its limit within one hour.

MODES 3, 4 - Whenever the Reactor Coolant System pressure has and 5 exceeded $2750 \mathrm{psig}$, reduce the Reactor Coolant System pressure to within its limit within 5 minutes. 


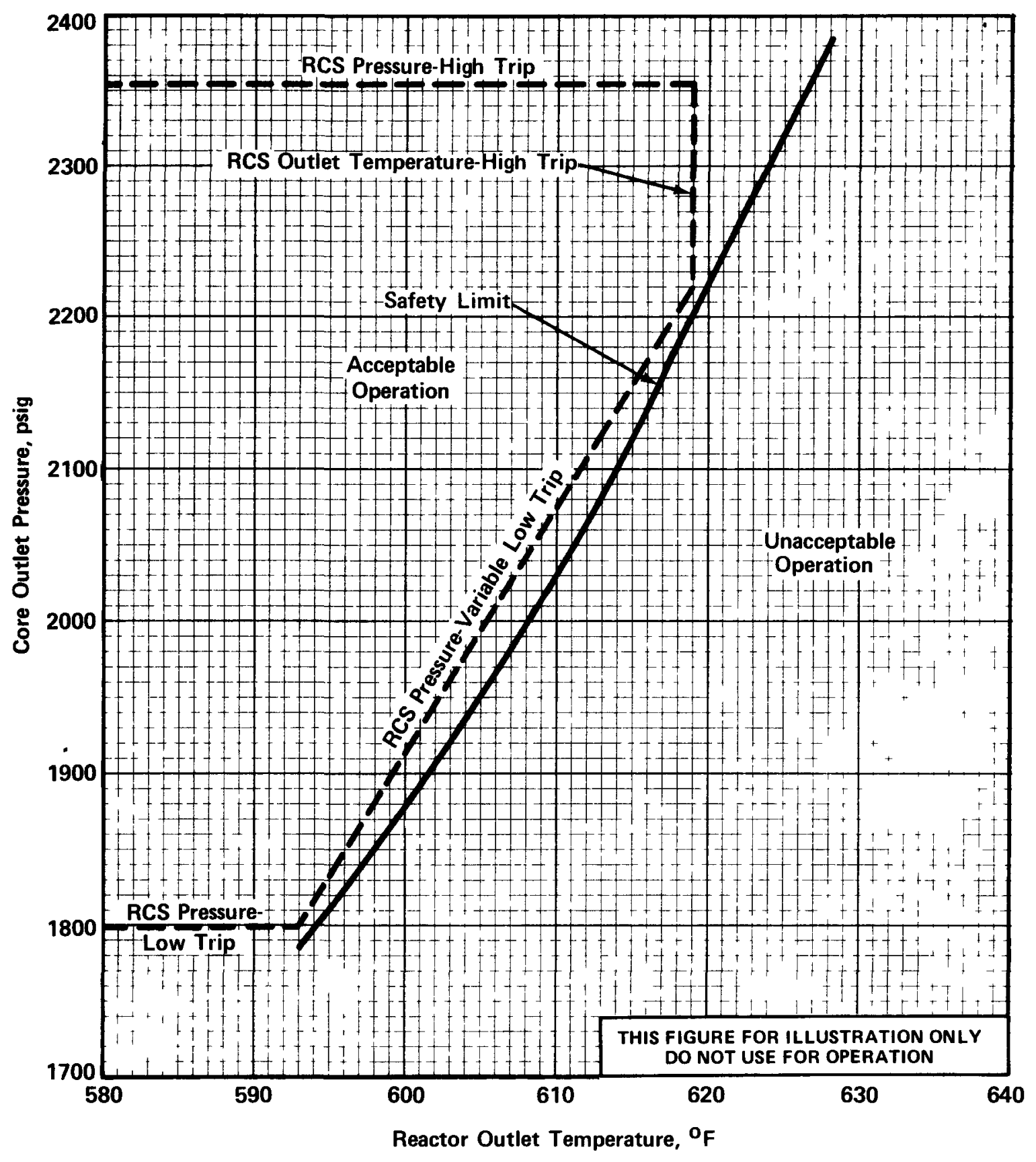

Figure 2.1-1

Reactor Core Safety Limit 


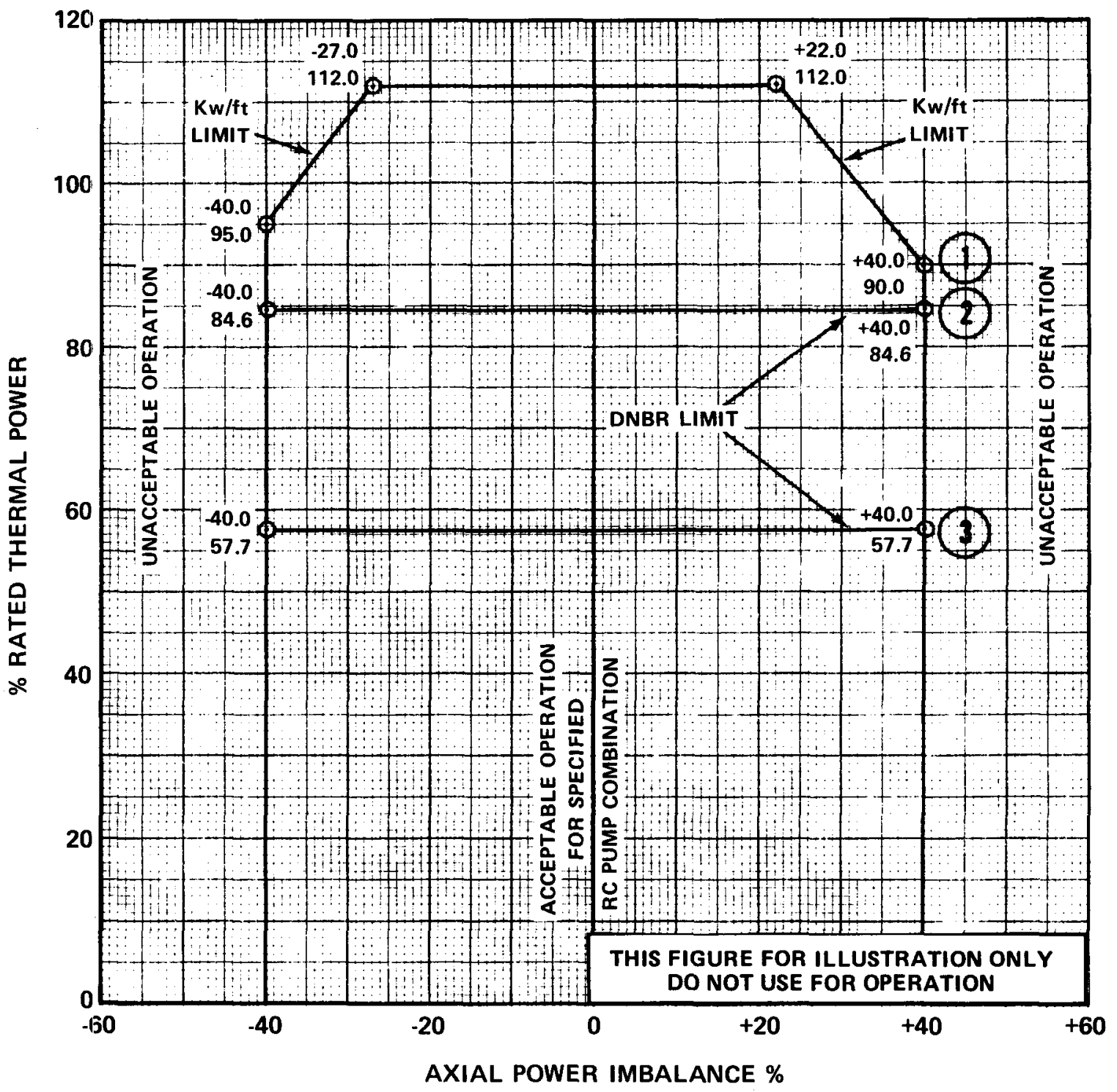

$\begin{array}{cc}\text { CURVE } & \text { REACTOR COOLANT FLOW }(1 \mathrm{~b} / \mathrm{hr}) \\ 1 & 131.3 \times 10^{6} \\ 2 & 98.1 \times 10^{6} \\ 3 & 64.4 \times 10^{6}\end{array}$

Figure 2.1-2

Reactor Core Safety Limit 


\subsection{LIMITING SAFETY SYSTEM SETTINGS}

REACTOR PROTECTION SYSTEM SETPOINTS

2.2.1 The Reactor Protection System instrumentation setpoints shall be set consistent with the Trip Setpoint values shown in Table 2.2-1.

APPLICABILITY: As shown for each channel in Table 3.3-1.

ACTION:

With a Reactor Protection System instrumentation setpoint less conservative than the value shown in the Allowable Values column of Table 2.2-1, declare the channel inoperable and apply the applicable ACTION statement requirement of Specification 3.3.1.1 until the channel is restored to OPERABLE status with its trip setpoint adjusted consistent with the Trip Setpoint value. 
TABLE 2.2-1

\section{REACTOR PROTECTION SYSTEM INSTRUMENTATION TRIP SETPOINTS}

\section{FUNCTIONAL UNIT}

1. Manual Reactor Trip

2. Nuclear Overpower

\section{TRIP SETPOINT}

Not Applicable

$<(\quad) \%$ of RATED THERMAL POWER

with four pumps operating

$\leq$ ( )\% of RATED THERMAL POWER

with three pumps operating

$\leq() \%$ of RATED THERMAL POWER with one pump operating in each loop

3. RCS Outlet Temperature-High $\leq(619)^{\circ} \mathrm{F}$

4. Nuclear Overpower Based on RCS Flow and (1) AXIAL POWER IMBLANCE

5. RCS Pressure-Low (1)

6. RCS Pressure-High

7. RCS Pressure-Variable Low $(1)$
Trip Setpoint not to exceed the limit line of Figure 2.2-1.

$\geq(1800)$ psig

$\leq(2355)$ psig

$\geq\left((16.25) \mathrm{T}_{\text {out }}{ }^{\circ} \mathrm{F}-(7838)\right) \mathrm{psig}$
ALLOWABLE VALUES

Not Applicable

$\leq(\quad) \%$ of RATED THERMAL POWER with four pumps operating

$\leq(\quad) \%$ of RATED THERMAL POWER with three pumps operating

$\leq(\quad) \%$ of RATED THERMAL POWER with one pump operating in each loop

$\leq()^{\circ} \mathrm{F}$

Allowable Values not to exceed the limit line of Figure 2.2-2.

$$
\begin{aligned}
& \geq(\quad) \text { psig } \\
& \leq(\quad) \text { psig } \\
& \geq\left((16.25) \text { Tout }^{\circ} \mathrm{F}-(\quad)\right) \text { psig }
\end{aligned}
$$


TABLE 2.2-1 (Continued)

REACTOR PROTECTION SYSTEM INSTRUMENTATION TRIP SETPOINTS

\section{FUNCTION UNIT}

8. Nuclear Overpower based on Pump Monitors $(1)$

ก̃

9. Reactor Containment Vessel

\section{TRIP SETPOINT}

$\leq(\quad) \%$ of RATED THERMAL POWER

with three pumps operating

$<(\quad) \%$ of RATED THERMAL POWER with one pump operating in each loop

$\leq(\quad) \%$ of RATED THERMAL POWER with two pump operating in one loop and no pump operating in the other loop

$\leq(\quad) \%$ of RATED THERMAL POWER with $\overrightarrow{\text { no }}$ pumps operating or only one pump operating

\section{ALLOWABLE VALUES}

$<(\quad) \%$ of RATED THERMAL POWER with three pumps operating

$<(\quad) \%$ of RATÉD THERMAL POWER with one pump operating in each loop

$<(\quad) \%$ of RATED THERMAL POWER with two pumps operating in one loop and no pump operating in the other loop

$\leq() \%$ of RATED THERMAL POWER with no pumps operating or only one pump operating

$\leq(\quad)$ psig

(1) Trip may be manually bypassed when RCS pressure $\leq$ (1720) psig by actuating Shutdown Bypass provided that:

a. The Nuclear Overpower Trip Setpoint is $\leq 5 \%$ of RATED THERMAL POWER

b. The Shutdown Bypass RCS Pressure - High Trip Setpoint of $\leq$ (1720) psig is imposed, and

c. The Shutdown Bypass is removed when RCS Pressure $>(1800)$ psig. 


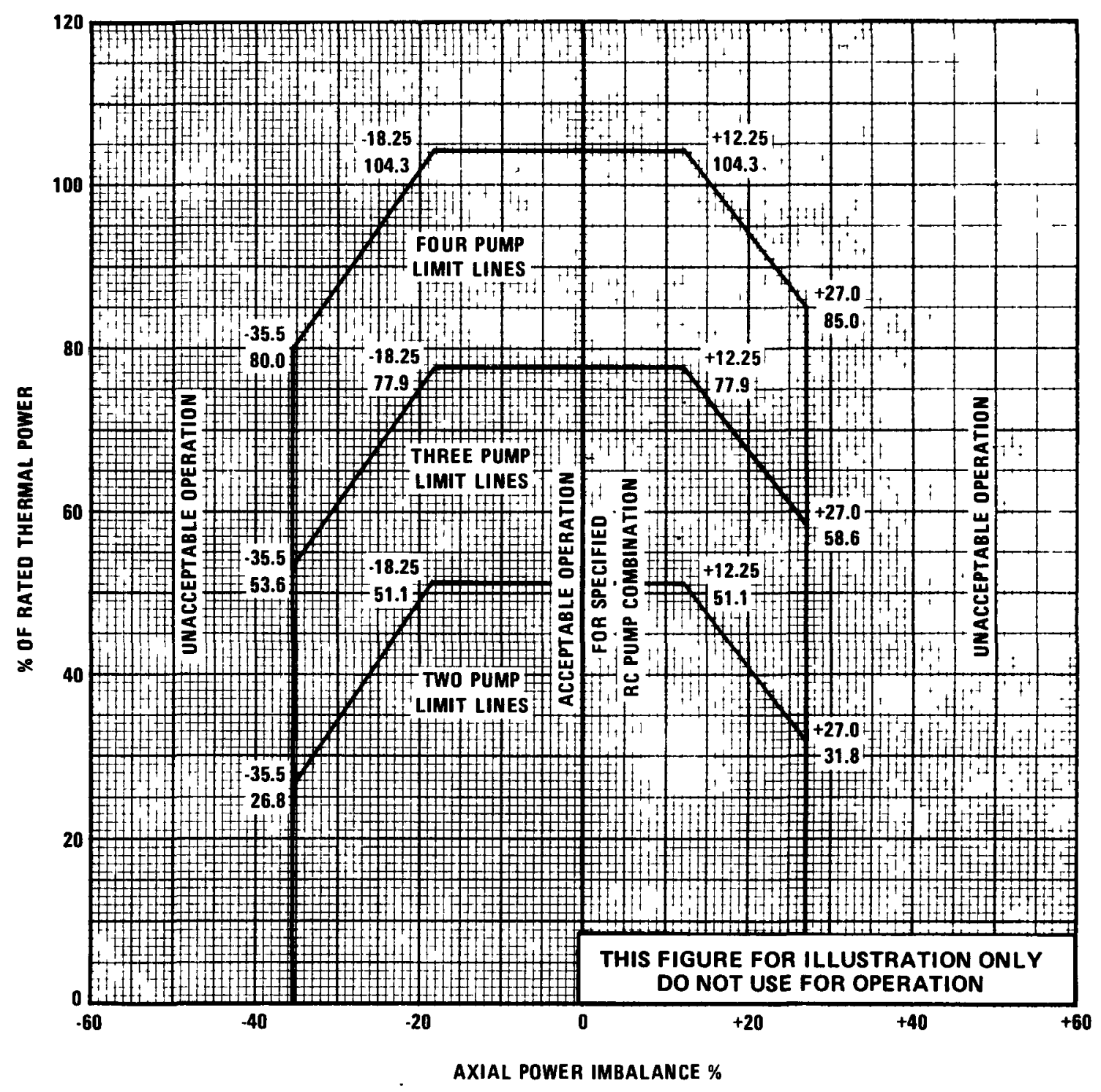

Figure 2.2-1

Trip Setpoint For Nuclear Overpower Based On RCS Flow and AXIAL POWER IMBALANCE 


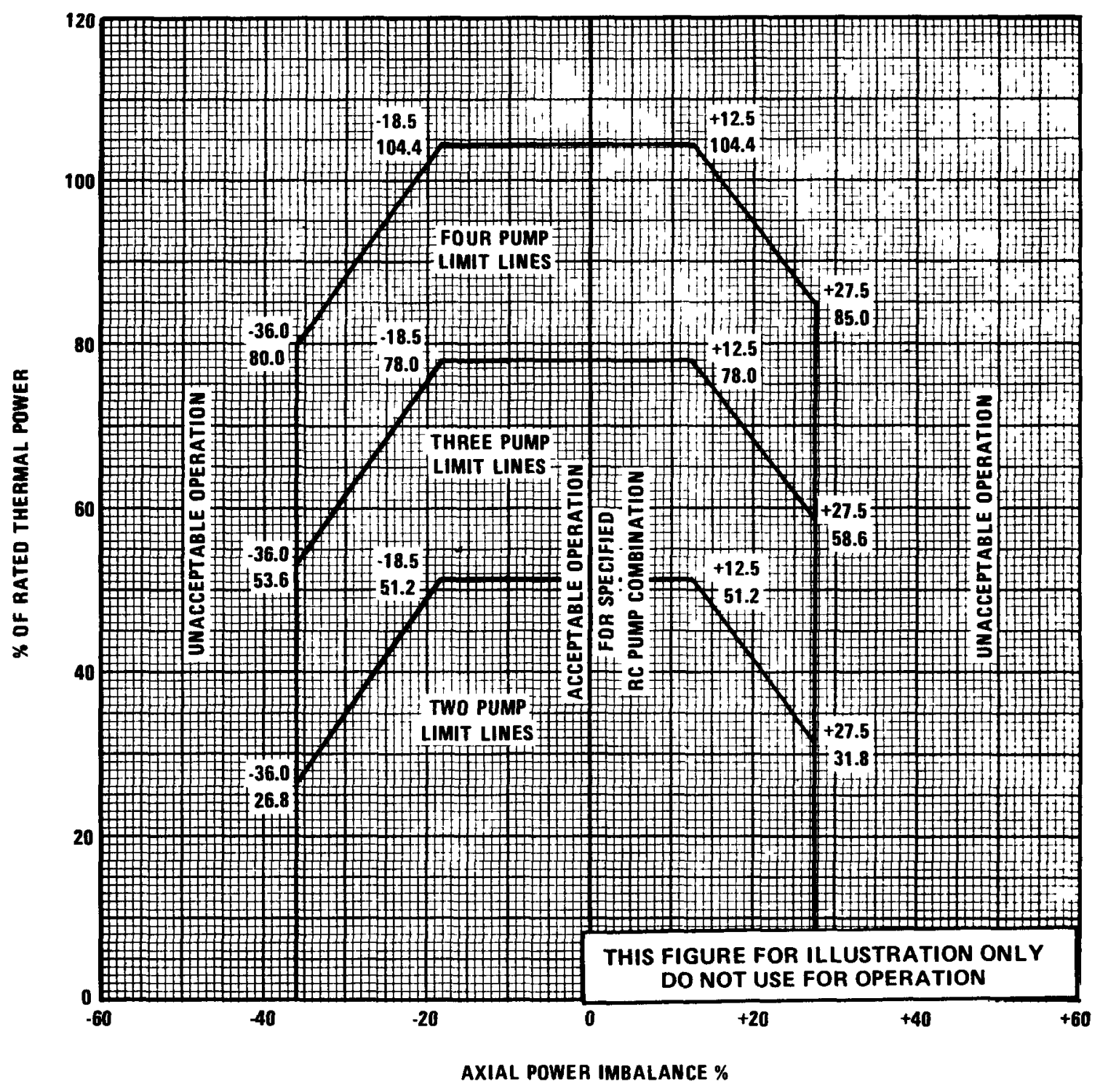

Figure 2.2-2

Allowable Value For Nuclear Overpower Based On RCS

Flow and AXIAL POWER IMBALANCE 


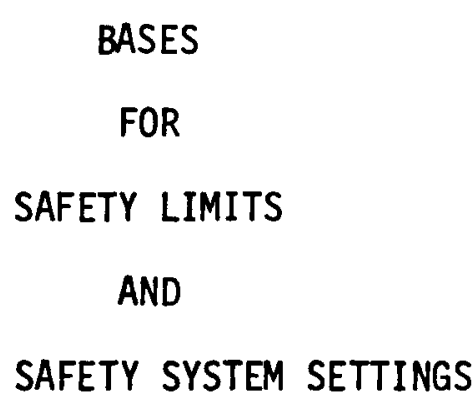


-

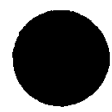

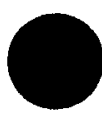




\section{NOTE}

The summary statements contained in this section provide the bases for the specifications of Section 2.0 and are not considered a part of these technical

specifications as provided in 10 CFR 50.36. 
-

○

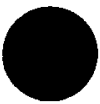




\subsection{SAFETY LIMITS}

BASES

\subsection{1 and 2.1.2 REACTOR CORE}

The restrictions of this safety limit prevent overheating of the fuel cladding and possible cladding perforation which would result in the release of fission products to the reactor coolant. Overheating of the fuel cladding is prevented by restricting fuel operation to within the nucleate boiling regime where the heat transfer coefficient is large and the cladding surface temperature is slightly above the coolant saturation temperature.

Operation above the upper boundary of the nucleate boiling regime would result in excessive cladding temperatures because of the onset of departure from nucleate boiling (DNB) and the resultant sharp reduction in heat transfer coefficient. DNB is not a directly measurable parameter during operation and therefore THERMAL POWER and Reactor Coolant Temperature and Pressure have been related to DNB through the (B\&W-2/W-3) DNB correlation. The DNB correlation has been developed to predict the DNB flux and the location of DNB for axially uniform and non-uniform heat flux distributions. The local DNB heat flux ratio, DNBR, defined as the ratio of the heat flux that would cause DNB at a particular core location to the local heat flux, is indicative of the margin to DNB.

The minimum value of the DNBR during steady state operation, normal operational transients, and anticipated transients is limited to $(1.30)$. This value corresponds to a (95) percent probability at a (99) percent confidence level that DNB will not occur and is chosen as an appropriate margin to DNB for all operating conditions.

The curve presented in Figure 2.1-1 represents the conditions at which a minimum DNBR of $(1.32 / 1.30)$ is predicted for the maximum possible thermal power (112)\% when the reactor coolant flow is $\left(131.3 \times 10^{6}\right) \mathrm{lbs} / \mathrm{hr}$, which is the design flow rate for four operating reactor coolant pumps. This curve is based on the following nuclear power peaking factors with potential fuel densification effects:

$$
F_{Q}^{N}=(2.67) ; \quad F_{\Delta H}^{N}=(1.78) ; \quad F_{Z}^{N}=(1.50)
$$

The design limit power peaking factors are the most restrictive calculated at full power for the range from all control rods fully withdrawn to minimum allowable control rod withdrawal, and form the core DNBR design basis. 
The reactor trip envelope appears to approach the safety limit more closely than it actually does because the reactor trip pressures are measured at a location where the indicated pressure is about () psi less than core outlet pressure, providing a more conservative margin to the safety limit.

The curves of Figure 2.1-2 are based on the more restrictive of two thermal limits and include the effects of potential fuel densification:

1. The (1.32/1.30) DNBR limit produced by a nuclear power peaking factor of $F_{Q}^{N}=(2.67)$ or the combination of the radial peak, axial peak and position of the axial peak that yields no less than a $(1.32 / 1.30)$ DNBR.

2. The combination of radial and axial peak that causes central fuel melting at the hot spot. The limit is (19.7) $\mathrm{kw} / \mathrm{ft}$.

Power peaking is not a directly observable quantity and therefore limits have been established on the basis of the reactor power imbalance produced by the power peaking.

The specified flow rates for curves 1,2, and 3 of Figure 2.1-2 correspond to the expected minimum flow rates with four pumps, three pumps, and one pump in each loop, respectively.

The curve of Figure 2.1-1 is the most restrictive of all possible reactor coolant pump-maximum thermal power combinations shown in BASES Figure 2.1. The curves of BASES Figure 2.1 represent the conditions at which a minimum DNBR of $(1.32 / 7.30)$ is predicted at the maximum possible thermal power for the number of reactor coolant pumps in operation or the local quality at the point of minimum DNBR is equal to $(22 / 15) \%$, whichever condition is more restrictive.

Using a local quality limit of $(22 / 15) \%$ at the point of minimum DNBR as a basis for curve 3 of BASES Figure 2.1 is a conservative criterion even though the quality at the exit is higher than the quality at the point of minimum DNBR.

The DNBR as calculated by the (B\&W-2/W-3) DNB correlation continually increases from point of minimum DNBR, so that the exit DNBR is always higher. Extrapolation of the correlation beyond its published quality range of $(+22 / 15) \%$ is justified on the basis of experimental data. 
SAFETY LIMITS

BASES

For each curve of BASES Figure 2.1, a pressure-temperature point above and to the left of the curve would result in a DNBR greater than $(1.32 / 1.30)$ or a local quality at the point of minimum DNBR less than $(22 / 15) \%$ for that particular reactor coolant pump situation. The $(1.32 / 1.30)$ DNBR curve for four pump operation is more restrictive than any other reactor coolant pump situation because any pressure/temperature point above and to the left of the four pump curve will be above and to the left of the other curves.

\subsubsection{REACTOR COOLANT SYSTEM PRESSURE}

The restriction of this Safety Limit protects the integrity of the Reactor Coolant System from overpressurization and thereby prevents the release of radionuclides contained in the reactor coolant from reaching the containment atmosphere.

The reactor pressure vessel and pressurizer are designed to Section III of the ASME Boiler and Pressure Vessel Code which permits a maximum transient pressure of $110 \%, 2750 \mathrm{psig}$, of design pressure. The Reactor Coolant System piping, valves and fittings, are designed to ANSI B 31.7, Edition, which permits a maximum transient pressure of $110 \%, 2750$

$\overline{p s i g}$, of component design pressure. The Safety Limit of 2750 psig is therefore consistent with the design criteria and associated code requirements.

The entire Reactor Coolant System is hydrotested at 3125 psig, $125 \%$ of design pressure, to demonstrate integrity prior to initial operation. 


\subsection{LIMITING SAFETY SYSTEM SETTINGS}

BASES

\subsubsection{REACTOR PROTECTION SYSTEM INSTRUMENTATION SETPOINTS}

The Reactor Protection System Instrumentation Trip Setpoint specified in Table 2.2-1 are the values at which the Reactor Trips are set for each parameter. The Trip Setpoints have been selected to ensure that the reactor core and reactor coolant system are prevented from exceeding their safety limits during normal operation and design basis anticipated operational occurrences and to assist the Engineered Safety Feature Actuation System in mitigating the consequences of accidents. Operation with a trip setpoint less conservative than its Trip Setpoint but within its specified Arlowable Value is acceptable on the basis that the difference between each Trip Setpoint and the Allowable Value is equal to or less than the drift allowance assumed for each trip in the safety analyses.

The Shutdown Bypass provides for bypassing certain functions of the Reactor Protection System in order to permit control rod drive tests, zero power PHYSICS TESTS and certain startup and shutdown procedures. The purpose of the Shutdown Bypass RCS Pressure-High trip is to prevent normal operation with Shutdown Bypass activated. This high pressure trip setpoint is lower than the normal low pressure trip setpoint so that the reactor must be tripped before the bypass is initiated. The Nuclear Overpower Trip Setpoint of $\leq 5.0 \%$ prevents any significant reactor power from being produced. Sufficient natural circulation would be available to remove $5.0 \%$ of RATED THERMAL POWER if none of the reactor coolant pumps were operating.

\section{Manual Reactor Trip}

The Manual Reactor Trip is a redundant channel to the automatic Reactor Protection System instrumentation channels and provides manual reactor trip capability.

\section{Nuc lear Overpower}

A Nuclear Overpower trip at high power level (neutron flux) provides reactor core protection against reactivity excursions which are too rapid to be protected by temperature and pressure protective circuitry.

During normal station operation, reactor trip is initiated when the reactor power level reaches $(105.5) \%$ of rated power. Due to calibration and instrument errors, the maximum actual power at which a trip would be actuated could be (112)\%, which was used in the safety analysis. 
LIMITING SAFETY SYSTEM SETTINGS

BASES

RCS Outlet Temperature - High

The RCS Outlet Temperature High trip $\leq(619)^{\circ} \mathrm{F}$ prevents the reactor outlet temperature from exceeding the design limits and acts as a backup trip for all power excursion transients.

Nuclear Overpower Based on RCS Flow and AXIAL POWER IMBALANCE

The power level trip setpoint produced by the reactor coolant system flow is based on a flux-to-flow ratio which has been established to accomodate flow decreasing transients from high power where protection is not provided by the Nuclear Overpower Based on Pump Monitors channels.

The power level trip setpoint produced by the power-to-flow ratio provides both high power level and low flow protection in the event the reactor power level increases or the reactor coolant flow rate decreases. The power level setpoint produced by the power-to-flow ratio provides overpower DNB protection for all modes of pump operation. For every flow rate there is a maximum permissible power level, and for every power level there is a minimum permissible low flow rate. Typical power level and low flow rate combinations for the pump situations of Table 2.2-1 are as follows:

1. Trip would occur when four reactor coolant pumps are operating if power is $(108.0) \%$ and reactor flow rate is $100 \%$, or flow rate is $(92.6) \%$ and power level is $100 \%$.

2. Trip would occur when three reactor coolant pumps are operating if power is $(80.7) \%$ and reactor flow rate is $(74.7) \%$, or flow rate is $(69.4) \%$ and power is $(75) \%$.

3. Trip would occur when one reactor coolant pump is operating in each loop (total of two pumps operating) if the power is $(52.9) \%$ and reactor flow rate is $(49.0) \%$ or flow rate is $(45.4) \%$ and the power level is $(49.0) \%$.

For safety calculations the maximum calibration and instrumentation errors for the power level were used. 
The AXIAL POWER IMBALANCE boundaries are established in order to prevent reactor thermal 1 imits from being exceeded. These therma 1 limits are either power peaking $\mathrm{kw} / \mathrm{ft}$ Timits or DNBR Timits. The AXIAL POWER IMBALANCE reduces the power level trip produced by the flux-toflow ratio such that the boundaries of Figure 2.2-1 are produced. The flux-to-flow ratio reduces the power level trip and associated reactor power-reactor power-imbalance boundaries by $(1.08) \%$ for a $1 \%$ flow reduction.

RCS Pressure - Low, High and Variable Low

The High and Low trips are provided to limit the pressure range in which reactor operation is permitted.

During a slow reactivity insertion startup accident from low power or a slow reactivity insertion from high power, the RCS Pressure-High setpoint is reached before the Nuclear Overpower Trip Setpoint. The trip setpoint for RCS Pressure-High, (2355) psig, has been established to maintain the system pressure below the safety limit, (2750) psig, for any design transient. The RCS Pressure-High trip is backed up by the pressurizer code safety valves for RCS over pressure protection, and is therefore set lower than the set pressure for these valves, (2500) psig. The RCS Pressure-High trip also backs up the Nuclear Overpower trip.

The RCS Pressure-Low, (1800) psig, and RCS Pressure-Variable Low, [(16.25) T $\left.{ }^{\circ} \mathrm{F}-(7838)\right]$ psig, Trip Setpoints have been established to maintain the DNB ratio greater than or equal to $(1.32 / 1.30)$ for those design accidents that result in a pressure reduction. It also prevents reactor operation at pressures below the valid range of DNB correlation limits, protecting against DNB.

Due to the calibration and instrumentation errors, the safety analysis used a RCS Pressure-Variable Low Trip Setpoint of $[(16.25)$ $T_{\text {out }}{ }^{\circ} \mathrm{F}-(7923)$ ] psig.

Nuclear Overpower Based on Pump Monitors

In conjunction with the power/imbalance/flow trips the Nuclear Overpower Based On Pump Monitors trip prevents the minimum core DNBR from decreasing below $(1.32 / 1.30)$ by tripping the reactor due to the loss of reactor coolant pump(s). The pump monitors also restrict the power level for the number of pumps in operation. 


\section{LIMITING SAFETY SYSTEM SETTINGS}

\section{BASES}

Reactor Containment Vessel Pressure - High

The Reactor Containment Vessel Pressure-High Trip Setpoint $\leq$ (4) psig, 1 provides positive assurance that a reactor trip will occur in the unlikely event of a steam line failure in the containment vessel or a loss-ofcoolant accident, even in the absence of a RCS Pressure -Low trip. 


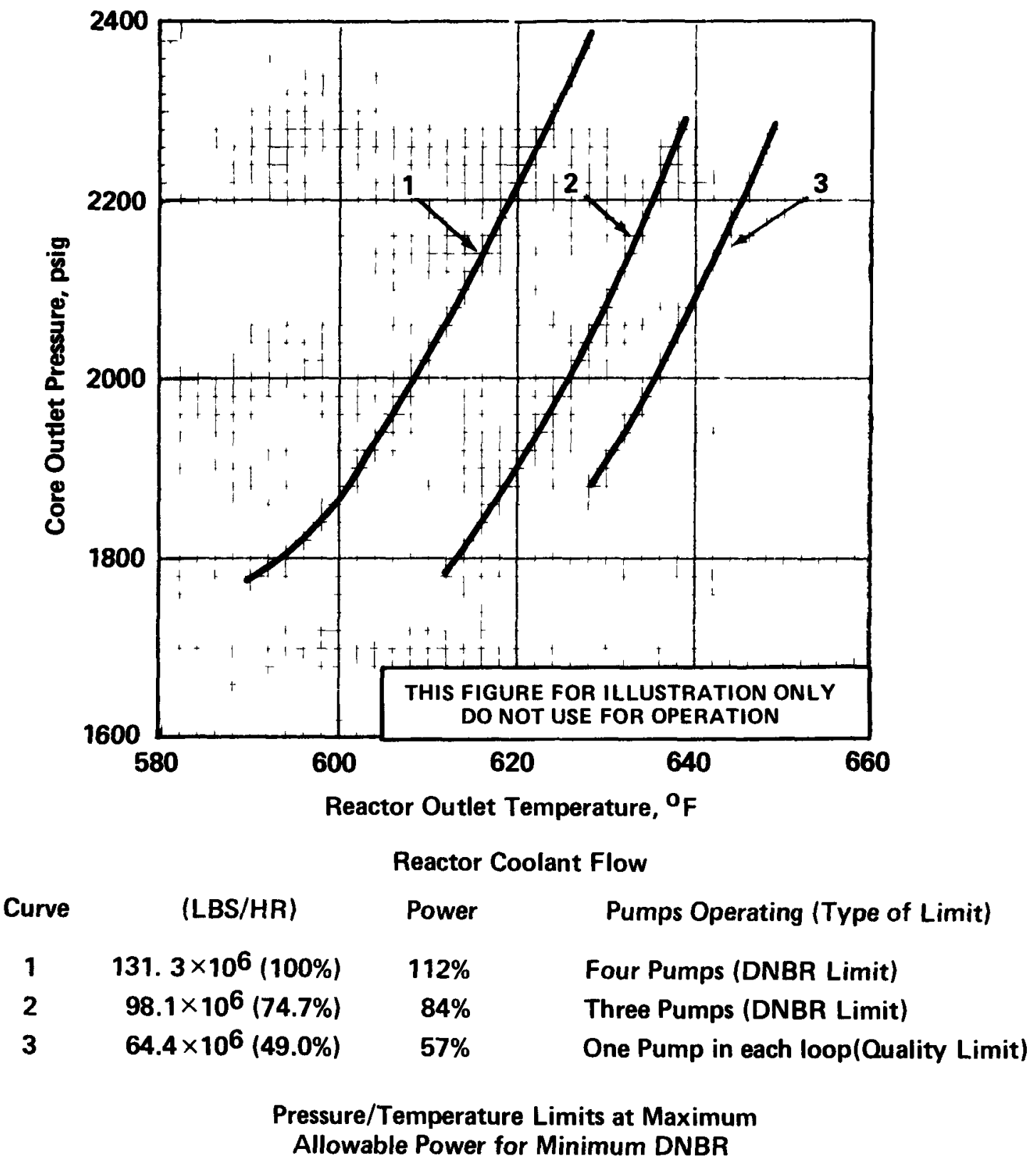

BASES Figure 2.1 
SECTIONS 3.0 AND 4.0

LIMITING CONDITIONS FOR OPERATION

AND

SURVEILLANCE REQUIREMENTS 
•

•

$\bullet$ 
3/4.0 APPLICABILITY

LIMITING CONDITION FOR OPERATION

3.0.1 Limiting Conditions for Operation and ACTION requirements shall be applicable during the OPERATIONAL MODES or other conditions specified for each specification.

3.0.2 Adherence to the requirements of the Limiting Condition for Operation and/or associated ACTION within the specified time interval shall constitute compliance with the specification. In the event the Limiting Condition for Operation is restored prior to expiration of the specified time interval, completion of the ACTION statement is not required.

3.0.3 In the event a Limiting Condition for Operation and/or associated ACTION requirements cannot be satisfied because of circumstances in excess of those addressed in the specification, the facility shall be placed in at least HOT STANDBY within 1 hour and in COLD SHUTDOWN within the following 30 hours unless corrective measures are completed that permit operation under the permissible ACTION statements for the specified time interval as measured from initial discovery. Exceptions to these requirements shall be stated in the individual specifications.

3.0.4 Entry into an OPERATIONAL MODE or other specified applicability condition shall not be made unless the conditions of the Limiting Condition for Operation are met without reliance on provisions contained in the ACTION statements unless otherwise excepted. This provision shall not prevent passage through OPERATIONAL MODES as required to comply with ACTION statements.

\section{SURVEILLANCE REQUIREMENTS}

4.0.1 Surveillance Requirements shall be applicable during the OPERATIONAL MODES or other conditions specified for individual Limiting Conditions for Operation unless otherwise stated in an individual Surveillance Requirement.

4.0.2 Each Surveillance Requirement shall be performed within the specified time interval with:

a. A maximum allowable extension not to exceed $25 \%$ of the surveillance interval, and

b. A total maximum combined interval time for any 3 consecutive tests not to exceed 3.25 times the specified survelllance interval. 
APPLICABILITY

SURVEILLANCE REQUIREMENTS (Continued)

4.0.3 Performance of a Surveillance Requirement within the specified time interval shall constitute compliance with OPERABILITY requirements for a Limiting Condition for Operation and associated ACTION statements unless otherwise required by the specification. Surveillance Requirements do not have to be performed on inoperable equipment.

4.0.4 Entry into an OPERATIONAL MODE or other specified applicability condition shall not be made unless the Surveillance Requirement(s) associated with the Limiting Condition for Operation have been performed within the stated surveillance interval or as otherwise specified.

4.0.5 Surveillance Requirements for inservice inspection and testing of ASME Code Class 1,2 and 3 components shall be applicable as follows:

a. During the time period:

1. From issuance of the Facility Operating License to the start of facility commercial operation, inservice testing of ASME Code Class 1,2 and 3 pumps and valves shall be performed in accordance with Section XI of the ASME Boiler and Pressure Vesel Code $(*)$ Edition, and Addenda through $(*)$, except where specific written relief has been granted by the Commission.

2. Following start of facility commercial operation, inservice inspection of ASME Code Class 1,2 and 3 components and inservice testing of ASME Code Class 1,2 and 3 pumps and valves shall be performed in accordance with Section XI of the ASME Boiler and Pressure Vessel Code and applicable Addenda as required by 10 CFR 50 , Section $50.55 \mathrm{a}(\mathrm{g})$, except where specific written relief has been granted by the Commission pursuant to 10 CFR 50, Section $50.55 \mathrm{a}(\mathrm{g})(6)(i)$.

b. Surveillance intervals specified in Section XI of the ASME Boiler and Pressure Vessel Code and applicable Addenda for the inservice inspection and testing activities required by the ASME Boiler and Pressure Vessel Code and applicable Addenda shall be applicable as follows in these Technical Specifications:

*Specific Code Edition and Addenda are to be specified consistent with 10 CFR $50.55 \mathrm{a}(\mathrm{b})$. 
ASME Boiler and Pressure Vessel Code and applicable Addenda terminology for inservice inspection and testing criteria

Weekly Monthiy

Quarterly or every 3 months

Semiannually or every 6 months Every 9 months

Yearly or annually
Required frequencies

for performing inservice inspection and testing activities

At least once per 7 days At least once per 31 days At least once per 92 days At least once per 184 days At least once per 276 days At least once per 366 days

c. The provisions of Specification 4.0.2 are applicable to the above required frequencies for performing inservice inspection and testing activities.

d. Performance of the above inservice inspection and testing activities shall be in addition to other specified Surveillance Requirements.

e. Nothing in the ASME Boiler and Pressure Vessel Code shall be construed to supersede the requirements of any Technical Specification. 
•

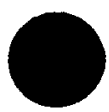

○ 


\section{3/4.1 REACTIVITY CONTROL SYSTEMS}

3/4.1.1 BORATION CONTROL

SHUTDOWN MARGIN

LIMITING CONDITION FOR OPERATION

3.1.1.1 The SHUTDOWN MARGIN shall be $\geq 1 \% \Delta k / k$.

APPLICABILITY: MODES $1,2^{*}, 3,4$ and 5 .

ACTION:

With the SHUTDOWN MARGIN $<1 \% \Delta \mathrm{k} / \mathrm{k}$, immediately initiate and continue boration at $>\quad \mathrm{gpm}$ of ( ) ppm boron or its equivalent, until the required SHUTDOWN MARGIN is restored.

SURVEILLANCE REQUIREMENTS

4.1.1.1.1 The SHUTDOWN MARGIN shall be determined to be $\geq 1 \% \Delta k / k$ :

a. Within one hour after detection of an inoperable control $\operatorname{rod}(s)$ and at least once per 12 hours thereafter while the $\operatorname{rod}(s)$ is inoperable. If the inoperable control rod is immovable or untrippable, the above required SHUTDOWN MARGIN shall be verified acceptable with an increased allowance for the withdrawn I worth of the immovable or untrippable control $\operatorname{rod}(s)$.

b. When in MODES 1 or $2^{\#}$, at least once per 12 hours, by verifying that regulating rod groups withdrawal is within the limits of Specification (3.1.3.7).

c. When in MODE $2^{\# \#}$, within 4 hours prior to achieving reactor criticality by verifying that the predicted critical control rod position is within the limits of Specification (3.1.3.7).

d. Prior to initial operation above 5\% RATED THERMAL POWER after each fuel loading by consideration of the factors of $e$. below, with the regulating rod groups at the maximum insertion limit of Specification (3.1.3.7).

\#ith $K_{\text {eff }} \geq 1.0$.

\#\#ith $K_{\text {eff }}<1.0$.

* See Special Test Exception 3.10.4. 
e. When in MODES 3,4 or 5 , at least once per 24 hours by consideration of the following factors:

1. Reactor coolant system boron concentration.

2. Control rod position.

3. Reactor coolant system average temperature.

4. Fuel burnup based on gross thermal energy generation.

5. Xenon concentration.

6. Samarium concentration.

4.1.1.1.2 The overall core reactivity balance shall be compared to predicted values to demonstrate agreement within $+1 \% \Delta \mathrm{k} / \mathrm{k}$ at least once per 31 Effective Full Power Days (EFPD). This comparison shall consider at least those factors stated in Specification (4.1.1.1.1.e), above.

The predicted reactivity values shall be adjusted (normalized) to correspond to the actual core conditions prior to exceeding a fuel burnup of 60 Effective Ful1 Power Days after each fuel loading. 


\section{REACTIVITY CONTROL SYSTEMS \\ BORON DILUTION \\ LIMITING CONDITION FOR OPERATION}

3.1.1.2 The flow rate of reactor coolant through the Reactor Coolant System shall be $\geq(2800) \mathrm{gpm}$ whenever a reduction in Reactor Coolant System boron concentration is being made.

APPLICABILITY: A11 MODES.

ACTION:

With the flow rate of reactor coolant through the Reactor Coolant System < $(2800) \mathrm{gpm}$, immediately suspend all operations involving a reduction in boron concentration of the Reactor Coolant System.

SURVEILLANCE REQUIREMENTS

4.1.1.2 The flow rate of reactor coolant through the Reactor Coolant System shall be determined to be $\geq(2800) \mathrm{gpm}$ within one hour prior to the start of and at least once per hour during a reduction in the Reactor Coolant System boron concentration by either:

a. Verifying at least one reactor coolant pump is in operation, or

b. Verifying that at least one DHR pump is in operation and supplying $\geq(2800) \mathrm{gpm}$ through the Reactor Coolant System. 
REACTIVITY CONTROL SYSTEMS

MODERATOR TEMPERATURE COEFFICIENT

LIMITING CONDITION FOR OPERATION

3.1.1.3 The moderator temperature coefficient (MTC) shall be:

a. Less positive than $(0.5) \times 10^{-4} \Delta \mathrm{k} / \mathrm{k} /{ }^{\circ} \mathrm{F}$ whenever THERMAL POWER is $<(95) \%$ of RATED THERMAL POWER.

b. Less positive than $(0.0) \times 10^{-4} \Delta \mathrm{k} / \mathrm{k} /{ }^{\circ} \mathrm{F}$ whenever THERMAL POWER is $\geq(95) \%$ of RATED THERMAL POWER.

c. Less negative than $(-0.2) \times 10^{-4} \Delta k / k /{ }^{\circ} \mathrm{F}$ at RATED THERMAL POWER.

APPLICABILITY: MODES 1 and $2^{* \#}$.

ACTION:

With the moderator temperature coefficient outside any of the above limits, be in at least HOT STANDBY within 6 hours.

SURVEILLANCE REQUIREMENTS

4.1.1.3.1 The MTC shall be determined to be within its limits by confirmatory measurements. MTC measured values shall be extrapolated and/or compensated to permit direct comparison with the above 1 imits.

4.1.1.3.2 The MTC shall be determined at the following frequencies and THERMAL POWER Conditions during each fuel cycle.

a. Prior to initial operation above $5 \%$ of RATED THERMAL POWER, after each fuel loading.

b. At any THERMAL POWER, within 7 days after reaching a RATED THERMAL POWER equilbrium boron concentration of $(300) \mathrm{ppm}$.

*With Keff $\geq 1.0$.

\#See Special Test Exception 3.10.2. 
REACTIVITY CONTROL SYSTEMS

MINIMUM TEMPERATURE FOR CRITICALITY

LIMITING CONDITION FOR OPERATION

3.1.1.4 The Reactor Coolant System lowest loop temperature $\left(T_{\text {avg }}\right)$ shall be $\geq(525)^{\circ} \mathrm{F}$.

APPLICABILITY: MODES 1 and $2^{*}$.

ACTION:

With a Reactor Coolant System loop temperature $(T)<(525)^{\circ} \mathrm{F}$, restore $T$ to within its limit within 15 minutes or be $9 \mathrm{~g}^{\mathrm{H} O T}$ STANDBY within the next 15 minutes.

\section{SURVEILLANCE REQUIREMENTS}

4.1.1.4 The RCS temperature ( $T_{\text {avg }}$ ) shall be determined to be $\geq(525)^{\circ} \mathrm{F}$ :

a. Within 15 minutes prior to achieving reactor criticality.

b. At least once per 30 minutes when the reactor is critical and the Reactor Coolant System $\mathrm{T}_{\text {avg }}$ is less than $(535)^{\circ} \mathrm{F}$.

With $K_{\text {eff }} \geq 1.0$ 
REACTIVITY CONTROL SYSTEMS

3/4.1.2 BORATION SYSTEMS

FLOW PATHS - SHUTDOWN

LIMITING CONDITION FOR OPERATION

3.1.2.1 At least one of the following boron injection flow paths shall be OPERABLE:

a. A flow path from the concentrated boric acid storage system via a boric acid pump and a makeup or decay heat removal (DHR) pump to the Reactor Coolant System, if only the boric acid storage system in Specification (3.1.2.8a) is OPERABLE, or

b. A flow path from the borated water storage tank via a makeup or DHR pump to the Reactor Coolant System if only the borated water storage tank in Specification (3.1.2.8b) is OPERABLE.

APPLICABILITY: MODES 5 and 6.

ACTION:

With none of the above flow paths OPERABLE, suspend all operations involving CORE ALTERATIONS or positive reactivity changes until at least one injection path is restored to OPERABLE status.

SURVEILLANCE REQUIREMENTS

4.1.2.1 At least one of the above required flow paths shall be demonstrated OPERABLE:

a. At least once per 7 days by verifying that the pipe temperature of the heat traced portion of the flow path is $\geq(105)^{\circ} \mathrm{F}$ when a flow path from the concentrated boric acid storage system is used.

b. At least once per 31 days by verifying that each valve (manual, power operated or automatic) in the flow path that is not locked, sealed or otherwise secured in position is in its correct position. 
REACTIVITY CONTROLS SYSTEMS

FLOW PATHS - OPERATING

LIMITING CONDITION FOR OPERATION

3.1.2.2 Each of the following boron injection flow paths shall be OPERABLE:

a. A flow path from the concentrated boric acid storage system via a boric acid pump and makeup or decay heat removal (DHR) pump to the Reactor Coolant System.

b. A flow path from the borated water storage tank via makeup or DHR pump to the Reactor Coolant System.

APPLICABILITY: MODES $1,2,3$ and 4.

ACTION:

a. With the flow path from the concentrated boric acid storage system inoperable, restore the inoperable flow path to OPERABLE status within 72 hours or be in at least HOT STANDBY and borated to a SHUTDOWN MARGIN equivalent to $1 \% \triangle \mathrm{k} / \mathrm{k}$ at $200^{\circ} \mathrm{F}$ within the next 6 hours; restore the flow path to OPERABLE status within the next 7 days or be in COLD SHUTDOWN within the next 30 hours.

b. With the flow path from the borated water storage tank inoperable, restore the flow path to OPERABLE status within one hour or be in at least HOT STANDBY within the next 6 hours and in COLD SHUTDOWN within the following 30 hours.

SURVIELLANCE REQUIREMENTS

4.1.2.2 Each of the above required flow paths shall be demonstrated OPERABLE:

a. At least once per 7 days by verifying that the pipe temperature of the heat traced portion of the flow path from the concentrated boric acid storage system is $\geq(105)^{\circ} \mathrm{F}$. 
b. At least once per 31 days by verifying that each valve (manual, power operated or automatic) in the flow path that is not locked, sealed, or otherwise secured in position, is in its correct position.

c. At least once per 18 months, during shutdown, by verifying that each automatic valve in the flow path actuates to its correct position on a boron injection test signal. 


\section{REACTIVITY CONTROL SYSTEMS \\ MAKEUP PUMP - SHUTDOWN}

LIMITING CONDITION FOR OPERATION

3.1.2.3 At least one makeup pump in the boron injection flow path required by Specification (3.1.2.1) shall be OPERABLE and capable of being powered from an OPERABLE emergency bus.

APPLICABILITY: MODE $5 *$.

ACTION:

With no makeup pump OPERABLE, suspend all operations involving positive reactivity changes until at least one makeup pump is restored to OPERABLE status.

4.1.2.3 At least the above required makeup pump shall be demonstrated OPERABLE by verifying, that on recirculation flow, the pump develops a discharge pressure of $\geq$ 4.0.5. psig when tested pursuant to Specification

${ }^{\star}$ RCS Pressure $\geq($ ) psig. 
REACTIVITY CONTROL SYSTEMS

MAKEUP PUMPS - OPERATING

LIMITING CONDITION FOR OPERATION

3.1.2.4 At least two makeup pumps shall be OPERABLE.

APPLICABILITY: MODES $1,2,3$ and $4^{*}$.

ACTION:

With only one makeup pump OPERABLE, restore at least two makeup pumps to OPERABLE status within 72 hours or be in at least HOT STANDBY and borated to a SHUTDOWN MARGIN equivalent to $1 \% \Delta \mathrm{k} / \mathrm{k}$ at $200^{\circ} \mathrm{F}$ within the next 6 hours; restore at least two makeup pumps to OPERABLE status within the next 7 days or be in COLD SHUTDOWN within the next 30 hours.

SURVEILLANCE REQUIREMENTS

4.1.2.4 At least two makeup pumps shall be demonstrated OPERABLE by verifying, that on recirculation flow, each pump develops a discharge pressure $\geq$ psig when tested pursuant to Specification 4.0.5.

ॠith RCS pressure $\geq($ ) psig. 
REACTIVITY CONTROL SYSTEMS

DECAY HEAT REMOVAL PUMP - SHUTDOWN

LIMITING CONDITION FOR OPERATION

3.1.2.5 At least one decay heat removal (DHR) pump in the boron injection flow path required by Specification (3.1.2.1) or (3.1.2.2) shall be OPERABLE and capable of being powered from an OPERABLE emergency bus.

APPLICABILITY: MODES $4 *, 5^{*}$ and 6.

ACTION:

With no DHR pump OPERABLE, suspend all operations involving CORE ALTERATIONS or positive reactivity changes until at least one DHR pump is restored to OPERABLE status.

SURVEILLANCE REQUIREMENTS

4.1.2.5 At least the above required decay heat removal pump shall be demonstrated OPERABLE by verifying, that on recirculation flow, the pump develops a discharge pressure of $\geq$ Specification 4.0.5. psig when tested pursuant to

${ }^{\star}$ RCS Pressure < ( ) psig. 
REACTIVITY CONTROL SYSTEMS

BORIC ACID PUMP - SHUTDOWN

LIMITING CONDITION FOR OPERATION

3.1.2.6 At least one boric acid pump shall be OPERABLE and capable of being powered from an OPERABLE emergency bus if only the flow path through the boric acid pump in Specification (3.1.2.1a) is OPERABLE.

APPLICABILITY: MODES 5 and 6.

ACTION:

With no boric acid pump OPERABLE as required to complete the flow path of Specification (3.1.2.1a), suspend all operations involving CORE ALTERATIONS or positive reactivity changes until at least one boric acid pump is restored to OPERABLE status.

SUIRVEILLANCE REQUIREMENTS

4.1.2.6 At least the above required boric acid pump shall be demonstrated OPERABLE by verifying, that on recirculation flow, the pump develops a discharge pressure of $\geq$ 4.0.5. psig when tested pursuant to Specification 
BORIC ACID PUMPS - OPERATING

LIMITING CONDITION FOR OPERATION

3.1.2.7 At least one boric acid pump in the boron injection flow path required by Specification $(3.1 .2 .2 a)$ shall be OPERABLE and capable of being powered from an OPERABLE emergency bus if the flow path through the boric acid pump in Specification (3.1.2.2a) is required to be OPERABLE.

APPLICABILITY: MODES $1,2,3$ and 4.

ACTION:

With no boric acid pump OPERABLE, restore at least one boric acid pump to OPERABLE status within 72 hours or be in at least HOT STANDBY and borated to a SHUTDOWN MARGIN equivalent to $1 \% \Delta k / k$ at $200^{\circ} \mathrm{F}$ within the next 6 hours; restore at least one boric acid pump to OPERABLE status within the next 7 days or be in COLD SHUTDOWN within the next 30 hours.

SURVEILLANCE REQUIREMENTS

4.1.2.7 At least the above required boric acid pump shall be demonstrated OPERABLE by verifying, that on recirculation flow, the pump develops a discharge pressure of $\geq \ldots$ psig when tested pursuant to Specification 4.0.5. 
REACTIVITY CONTROL SYSTEMS

BORATED WATER SOURCES - SHUTDOWN

LIMITING CONDITION FOR OPERATION

3.1.2.8 As a minimum, one of the following borated water sources shall be OPERABLE:

a. A concentrated boric acid storage system and associated heat tracing with:

1. A minimum contained borated water volume of gallons.

2. Between _ and _ ppm of boron.

3. A minimum solution temperature of $(105)^{\circ} \mathrm{F}$.

b. The borated water storage tank (BWST) with:

1. A minimum contained borated water volume of $(25,000)$ gallons.

2. A minimum boron concentration of (1800) ppm.

3. A minimum solution temperature of $(35)^{\circ} \mathrm{F}$.

APPLICABILITY: MODES 5 and 6.

ACTION:

With no borated water sources OPERABLE, suspend all operations involving CORE ALTERATION or pOsitive reactivity changes until at least one borated water source is restored to OPERABLE status.

\section{SURVEILLANCE REQUIREMENTS}

4.1.2.8 The above required borated water source shall be demonstrated OPERABLE:

a. At least once per 7 days by:

1. Verifying the boron concentration of the water.

2. Verifying the contained borated water volume of the tank. 
REACTIVITY CONTROL SYSTEMS

SURVEILLANCE REQUIREMENTS (Continued)

3. Verifying the concentrated boric acid storage system solution temperature when it is the source of borated water.

b. At least once per 24 hours by verifying the BWST temperature when it is the source of borated water and the (outside) air temperature is $<35^{\circ} \mathrm{F}$. 
REACTIVITY CONTROL SYSTEMS

BORATED WATER SOURCES - OPERATING

LIMITING CONDITION FOR OPERATION

3.1.2.9 Each of the following borated water sources shall be OPERABLE:

a. The concentrated boric acid storage system and associated heat tracing with:

1. A minimum contained borated water volume of gallons.

2. Between __ and __ ppm of boron.

3. A minimum solution temperature of $(105)^{\circ} \mathrm{F}$.

b. The borated water storage tank (BWST) with:

1. A contained borated water volume of between and gallons.

2. Between _ and p ppm of boron.

3. A minimum solution temperature of $(35)^{\circ} \mathrm{F}$.

APPLICABILITY: MODES $1,2,3$ and 4.

ACTION:

a. With the concentrated boric acid storage system inoperable, restore the storage system to OPERABLE status within 72 hours or be in at least HOT STANDBY and borated to a SHUTDOWN MARGIN equivalent to $1 \% \Delta \mathrm{k} / \mathrm{k}$ at $200^{\circ} \mathrm{F}$ within the next 6 hours; restore the concentrated boric acid storage system to OPERABLE status within the next 7 days or be in COLD SHUTDOWN within the next 30 hours.

b. With the borated water storage tank inoperable, restore the tank to OPERABLE status within one hour or be in at least HOT STANDBY within the next 6 hours and in COLD SHUTDOWN within the following 30 hours. 
REACTIVITY CONTROL SYSTEMS

SURVEILLANCE REQUIREMENTS

4.1.2.9 Each borated water source shall be demonstrated OPERABLE:

a. At least once per 7 days by:

1. Verifying the boron concentration in each water source.

2. Verifying the contained borated water volume of each water source.

3. Verifying the concentrated boric acid storage system solution temperature.

b. At least once per 24 hours by verifying the BWST temperature when the (outside) air temperature is $<35^{\circ} \mathrm{F}$. 


\section{REACTIVITY CONTROL SYSTEMS \\ 3/4.1.3 MOVABLE CONTROL ASSEMBLIES \\ GROUP HEIGHT - SAFETY AND REGULATING ROD GROUPS \\ LIMITING CONDITION FOR OPERATIONS}

3.1.3.1 All control (safety and regulating) rods shall be OPERABLE and positioned within $\pm 6.5 \%$ (indicated position) of their group average height.

APPLICABILITY: MODES $1^{*}$ and $2 *$.

ACTION:

a. With one or more control rods inoperable due to being immovable as a result of excessive friction or mechanical interference or known to be untrippable, determine that the SHUTDOWN MARGIN requirement of Specjfication 3.1.1.1 is satisfied within one hour and be in at least HOT STANDBY within 6 hours.

b. With more than one control rod inoperable or misaligned from its group average height by more than $\pm 6.5 \%$ (indicated position), be in at least HOT STANDBY within 6 hours.

c. With one control rod inoperable due to causes other than addressed in ACTION a, above, or misaligned from its group average height by more than $\pm 6.5 \%$ (indicated position), POWER OPERATION may continue provided that within one hour either:

1. The control rod is restored to OPERABLE status within the above alignment requirements, or

2. The control rod is declared inoperable and the SHUTDOWN MARGIN requirement of Specification 3.1.1.1 is satisfied. POWER OPERATION may then continue provided that:

a) A reevaluation of each accident analysis of Table 3.1-1 is performed within 5 days; this reevaluation shall confirm that the previously analyzed results of these accidents remain valid for the duration of operation under these conditions.

b) The SHUTDOWN MARGIN requirement of Specification 3.1.1.1 is determined at least once per 12 hours.

FSee Special Test Exceptions 3.10.1 and 3.10.2. 
REACTIVITY CONTROL SYSTEMS

ACTION: (Continued)

c) A power distribution map is obtained from the incore detectors and $F_{0}$ and $F \Delta$ are verified to be within their limits within $72^{\Delta}$ hours.

d) Either the THERMAL POWER level is reduced to $\leq(60) \%$ of the THERMAL POWER allowable for the reactor coolant pump combination within one hour and within the next 4 hours the Nuclear Overpower Trip Setpoint is reduced to $<(70) \%$ of the THERMAL POWER allowable for the reactor coolant pump combination, or

e) The remainder of the rods in the group with the inoperable rod are aligned to within $+6.5 \%$ of the inoperable rod within one hour while maintaining the rod sequence, insertion and overlap limits of Figures $3.1-1,3.1-2,3.1-3,3.1-4$ and $3.1-5$; the THERMAL POWER level shall be restricted pursuant to Specification (3.1.3.7) during subsequent operation.

SURVEILLANCE REQUIREMENTS

4.1.3.1.1 The position of each control rod shall be determined to be within the group average height limit by verifying the individual rod positions at least once per 12 hours except during time intervals when the Asymmetric Rod Monitor is inoperable, then verify the individual rod positions at least once per 4 hours.

4.1.3.1.2 Each control rod not fully inserted shall be determined to be OPERABLE by movement of at least (3)\% in any one direction at least once every 31 days. 


\section{TABLE $3.1-1$}

ACCIDENT ANALYSES REQUIRING REEVALUATION IN THE EVENT OF AN INOPERABLE CONTROL ROD

Control Rod Assembly Insertion Characteristics

Control Rod Assembly Misalignment

Loss of Reactor Coolant From Small Ruptured

Pipes Or From Cracks In Large Pipes Which

Actuates The Emergency Core Cooling System

Single Control Rod Assembly Withdrawal At Full

Power

Major Reactor Coolant System Pipe Ruptures (Loss of Coolant Accident)

Major Secondary System Pipe Rupture

Rupture of a Control Rod Drive Mechanism Housing (Control Rod Assembly Ejection) 
REACTIVITY CONTROL SYSTEMS

GROUP HEIGHT - AXIAL POWER SHAPING ROD GROUP

LIMITING CONDITION FOR OPERATION

3.1.3.2 All axial power shaping rods (APSR) shall be OPERABLE, unless fully withdrawn, and shall be positioned within $\pm 6.5 \%$ (indicated position) of their group average height.

APPLICABILITY: MODES $1^{\star}$ and $2 *$.

ACTION:

With a maximum of one APSR inoperable or misaligned from its group average height by more than $\pm 6.5 \%$ (indicated position), operation may continue provided that within 2 hours:

a. The APSR group is positioned such that the misaligned rod is restored to within limits for the group average height, or

b. It is determined that the imbalance limits of Specification 3.2.1 are satisfied and movement of the APSR group is prevented while the rod remains inoperable or misaligned.

SURVEILLANCE REQUIREMENTS

4.1.3.2.1 The position of each APSR rod shall be determined to be within the group average height limit by verifying the individual rod positions at least once per 12 hours except during time intervals when the Asymmetric Control Rod Monitor is inoperable, then verify the individual rod positions at least once per 4 hours.

4.1.3.2.2 Unless all APSR are fully withdrawn, each APSR shall be determined to be OPERABLE by moving the individual rod at least (3)\% at least once every 31 days.

\#See Special Test Exceptions 3.10.1 and 3.10.2. 
REACTIVITY CONTROL SYSTEMS

POSITION INDICATOR CHANNELS - SHUTDOWN

LIMITING CONDITION FOR OPERATION

3.1.3.4 At least one reed switch rod position indicator channel or one pulse stepping rod position indicator channel shall be OPERABLE for each safety, regulating or axial power shaping rod not fully inserted.

APPLICABILITY: MODES $3 *, 4 *$ and $5 *$.

ACTION:

With less than the above required rod position indicator channel(s)

OPERABLE, immediately open the Control Rod Drive Trip Breakers.

SURVEILLANCE REQUIREMENTS

4.1.3.4 Each of the above required rod position indicator channel(s) shall be determined to be OPERABLE by performance of a CHANNEL FUNCTIONAL TEST at least once each 18 months.

* With the Control Rod Drive Trip Breakers in the closed position. 
REACTIVITY CONTROL SYSTEMS

ROD DROP TIME

LIMITING CONDITION FOR OPERATION

3.1.3.5 The individual safety and regulating rod drop time from the fully withdrawn position shall be $\leq()$ seconds from power interruption at the control rod drive breaker undervoltage coils to ( ) insertion (" position) with:

a. $T_{\text {avg }} \geq(525)^{\circ} \mathrm{F}$.

b. A11 reactor coolant pumps operating.

APPLICABILITY: MODES 1 and 2.

ACTION:

a. With the drop time of any safety or regulating rod determined to exceed the above 1 imit, restore the rod drop time to within the above 1 imit prior to proceeding to MODE 1 and 2 .

b. With the rod drop times within limits but determined with less than 4 reactor coolant pumps operating, operation may proceed provided that THERMAL POWER is restricted to less than or equal to the THERMAL POWER allowable for the reactor coolant pump combination operating at the time of rod drop time measurement.

SURVEILLANCE REQUIREMENTS

4.1.3.5 The rod drop time of safety and regulating rods shall be demonstrated through measurement prior to reactor criticality:

a. For all rods following each removal of the reactor vessel head.

b. For specifically affected individual rods following any maintenance on or modification to the control rod drive system which could affect the drop time of those specific rods.

c. At least once every 18 months. 
Figure 3.1-3

Regulating Rod Group Insertion Limits for 4 Pump Operation After $400 \pm 10$ EFPD 
Figure 3.1-4

Regulating Rod Group Insertion Limits for 3 and 2 Pump Operation up to Control Rod Interchange $250 \pm 10$ EFPD 
Figure 3.1.5

Regulating Rod Group Insortion Limits for 3 and 2 Pump

Operation after Control Rod Interchange $(250 \pm 10$ EPPD) 
REACTIVITY CONTROL SYSTEMS

ROD PROGRAM

LIMITING CONDITION FOR OPERATION

3.1.3.8 Each control rod (safety, regulating and APSR) shall be programmed to operate in the core position and rod group specified in

Figure $(3.1-6)$ or $(3.1-7)$.

APPLICABILITY: MODES $7^{*}$ and $2^{*}$.

ACTION:

With any control rod not programmed to operate as specified above, be in HOT STANDBY within 1 hour.

SURVEILLANCE REQUIREMENTS

4.1 .3 .8

a. Each control rod shall be demonstrated to be programmed to operate in the specified core position and rod group by:

1. Selection and actuation from the control room and verification of movement of the proper rod as indicated by both the absolute and relative position indicators:

a) For all control rods, after the control rod drive patches are locked subsequent to test, reprogramming or maintenance within the panels.

b) For specifically affected individual rods, following maintenance, test, reconnection or modification of power or instrumentation cables from the control rod drive control system to the control rod drive.

2. Verifying that each cable that has been disconnected has been properly matched and reconnected to the specified control rod drive.

b. At least once each 7 days, verify that the control rod drive patch panels are locked.

*See Special Test Exceptions 3.10.1 and 3.10.2.

B\&W-STS

$3 / 4 \quad 1-33$

January 1, 1977 


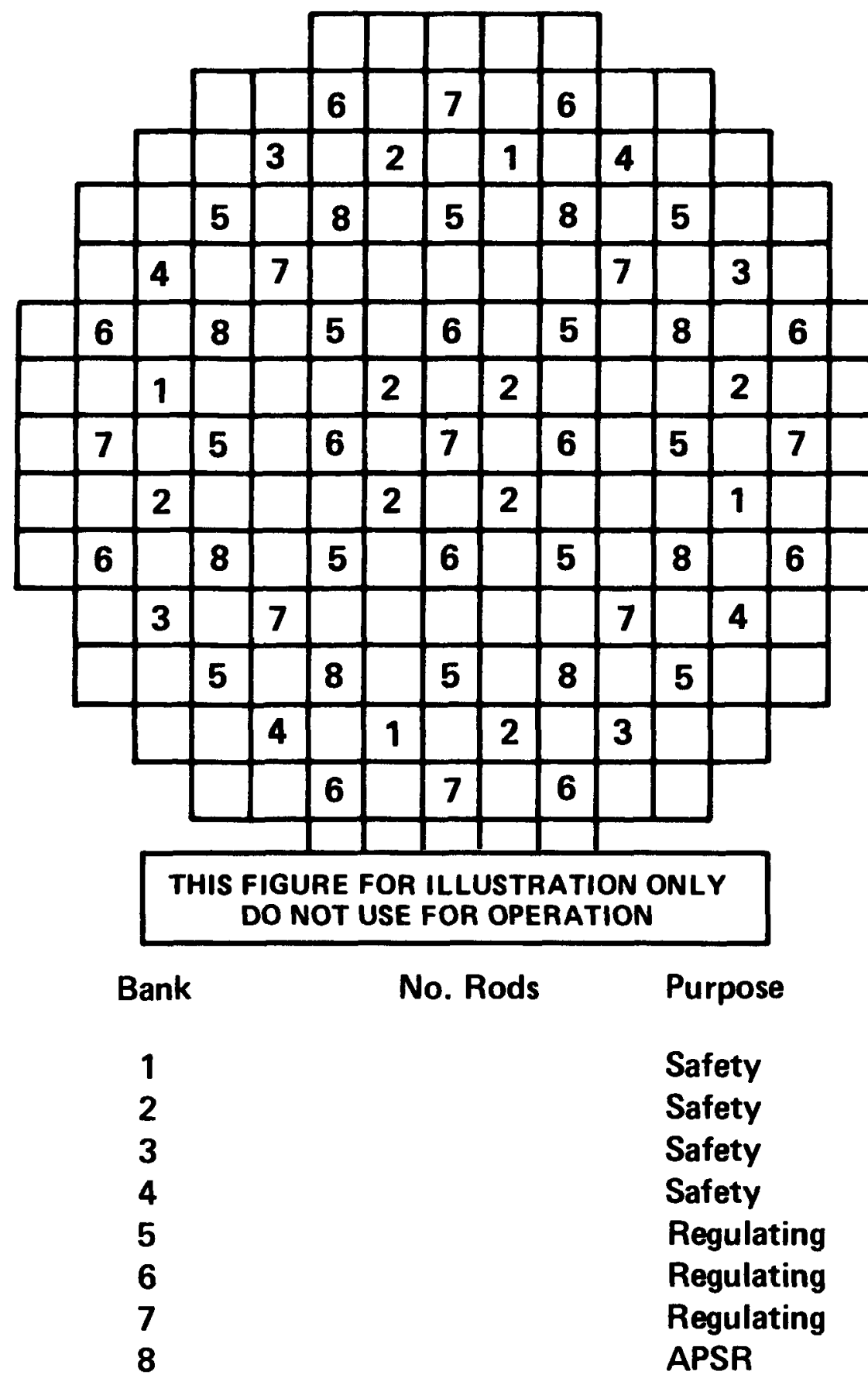

Figure 3.1-6

Control Rod Core Location and

Group Assignments up to $(250 \pm 10)$ EFPD 


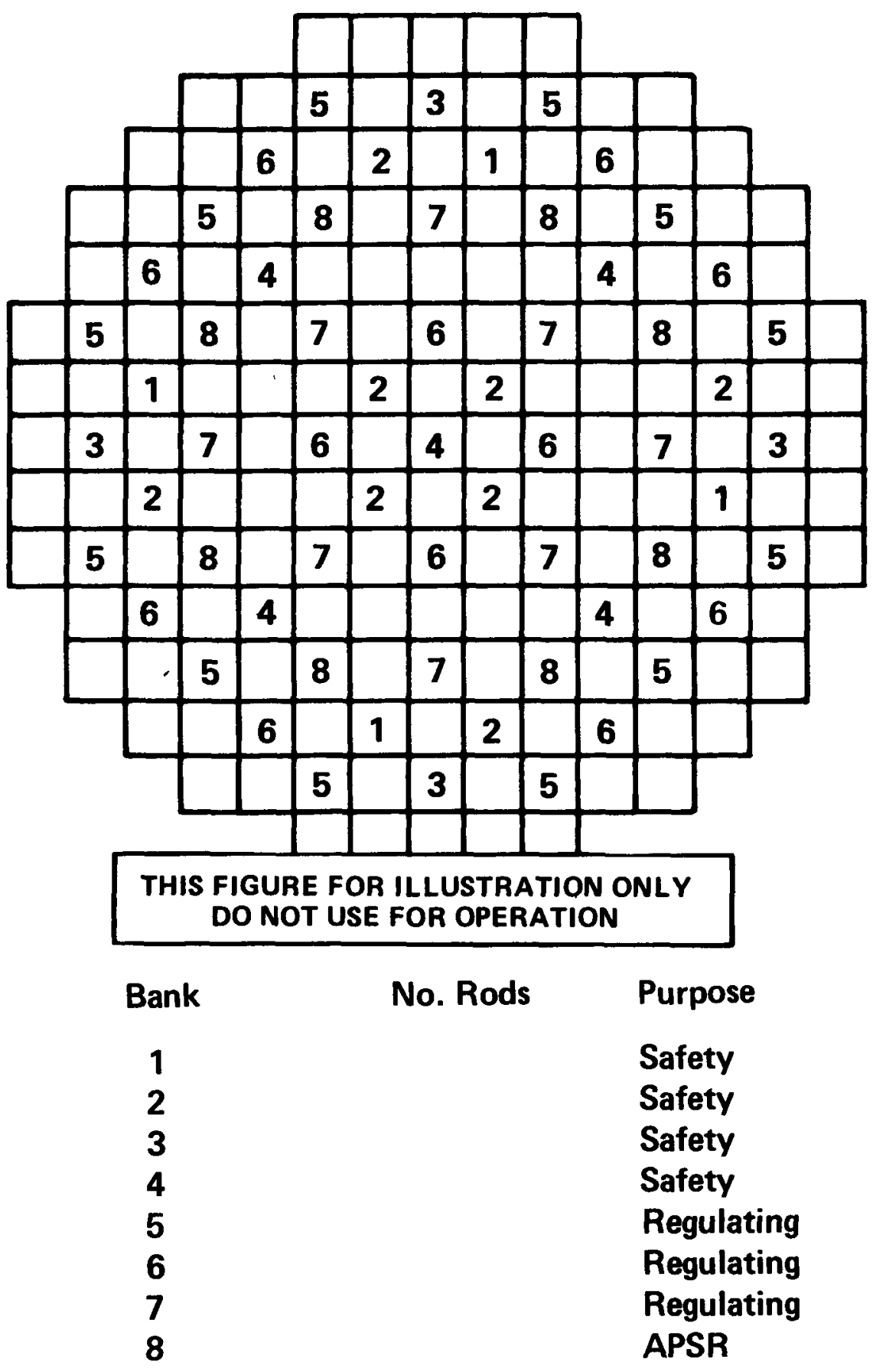

Figure 3.1-7

Control Rod Core Location and Group

Assignments after $(250 \pm 10)$ EFPD 
3.1.3.9 THERMAL POWER shall not be increased above the power level cutoff specified in Figures $3.1-1,3.1-2$, and $3.1-3$ unless one of the following conditions is satisfied:
a. Xenon reactivity is within 10 percent of the equilibrium value for RATED THERMAL POWER and is approaching stability*, or
b. THERMAL POWER has been within a range of $(1)$ to $($ ) percent of RATED THERMAL POWER for a period exceeding 2 hours in the soluble poison control mode, excluding xenon free start-ups.

APPLICABILITY: MODE 1.

ACTION:

With the requirements of the above specification not satisfied, reduce THERMAL POWER to less than or equal to the power level cutoff within 15 minutes.

\section{SURVEILLANCE REQUIREMENTS}

4.1.3.9 Xenon reactivity shall be determined to be within $10 \%$ of the equilibrium value for RATED THERMAL POWER and to be approaching stability or it shall be determined that the THERMAL POWER has been in the range of () to ( ) \% of RATED THERMAL POWER for $\geq 2$ hours, prior to increasing THERMAL POWER above the power level cutoff.

*In the case of short duration power level reductions Xenon reactivity need not be approaching stability provided that throughout the period of the reduction it has not deviated more than $10 \%$ from the equilibrium value for RATED THERMAL POWER. 
3/4.2 POWER DISTRIBUTION LIMITS

AXIAL POWER IMBALANCE

LIMITING CONDITION FOR OPERATION

3.2.1 AXIAL POWER IMBALANCE shall be maintained within the limits shown on Figures $3.2-1,3.2-2$ and 3.2-3.

APPLICABILITY: MODE 1 above $40 \%$ of RATED THERMAL POWER.* ACTION:

With AXIAL POWER IMBALANCE exceeding the limits specified above, either:

a. Restore the AXIAL POWER IMBALANCE to within its limits within 15 minutes, or

b. Be in at least HOT STANDBY within 2 hours.

SURVEILLANCE REQUIREMENTS

4.2.1 The AXIAL POWER IMBALANCE shall be determined to be within limits at least once every 12 hours when above $40 \%$ of RATED THERMAL POWER except when an AXIAL POWER IMBALANCE monitor is inoperable, then calculate the AXIAL POWER IMBALANCE at least once per hour.

ॠ See Special Test Exception 3.10.1. 


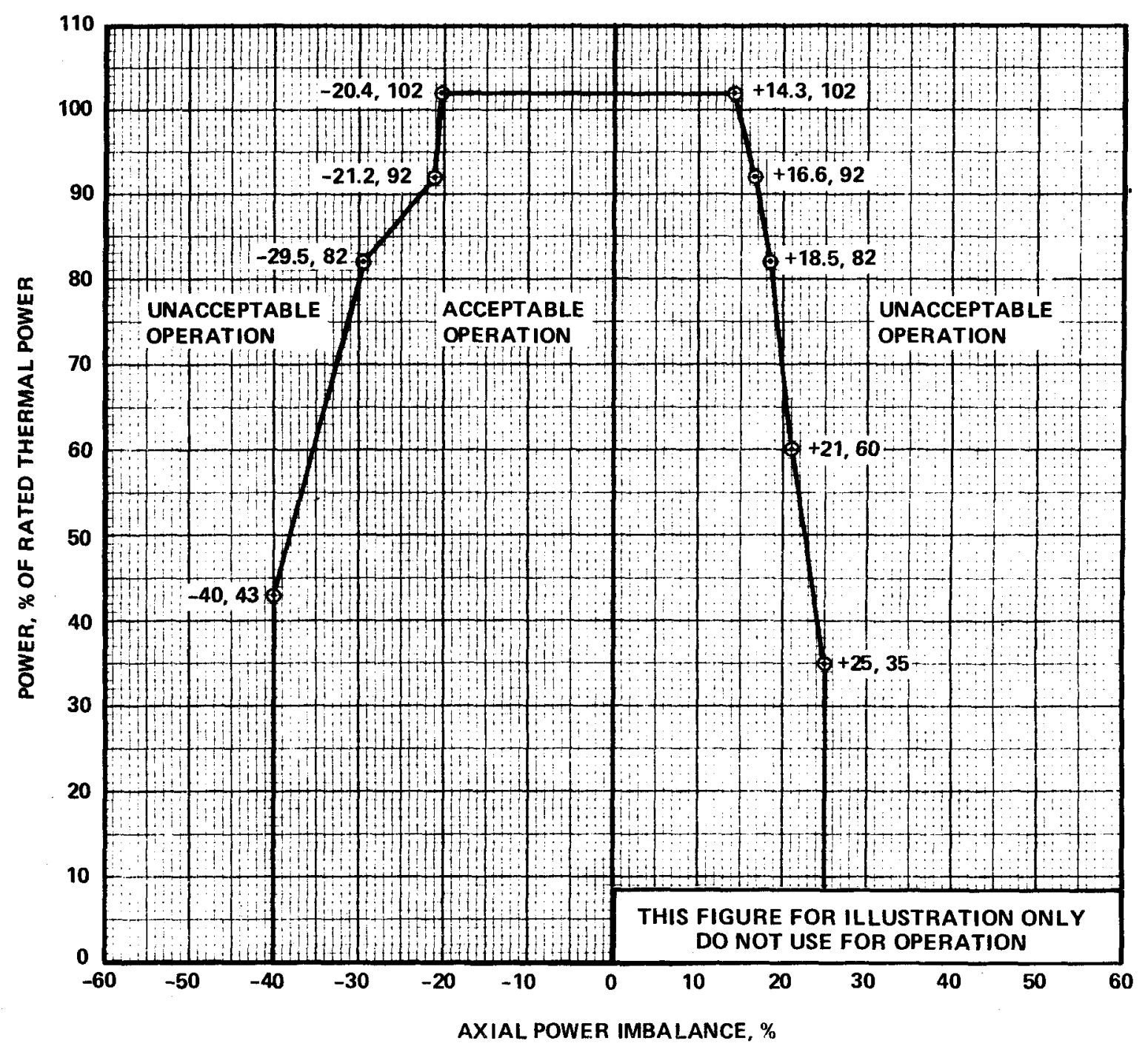

Figure 3.2-1 AXIAL POWER IMBALANCE Envelope for 4 Pump Operation 


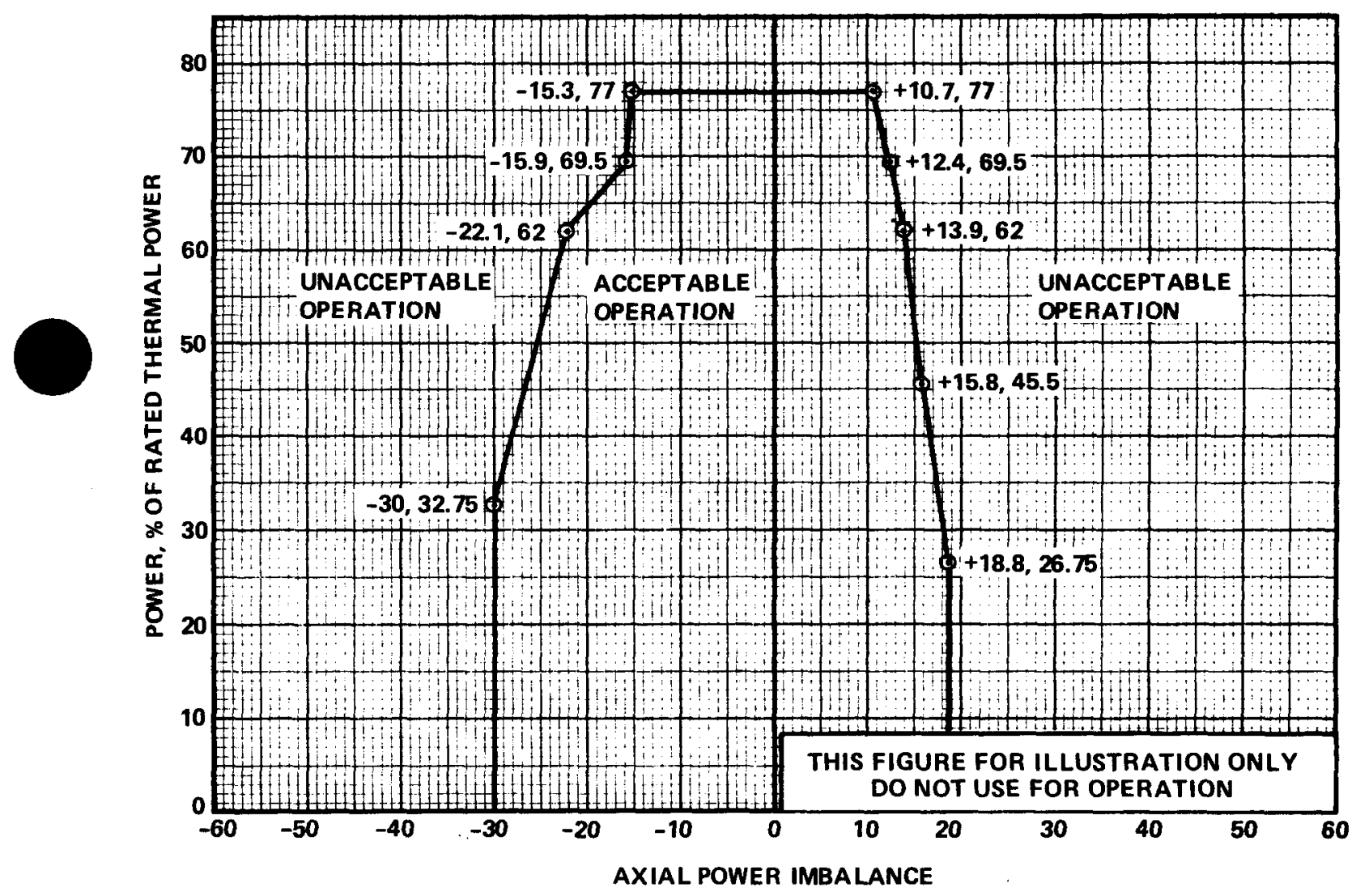

Figure 3.2-2 AXIAL POWER IMBALANCE Envelope for 3 Pump Operation 


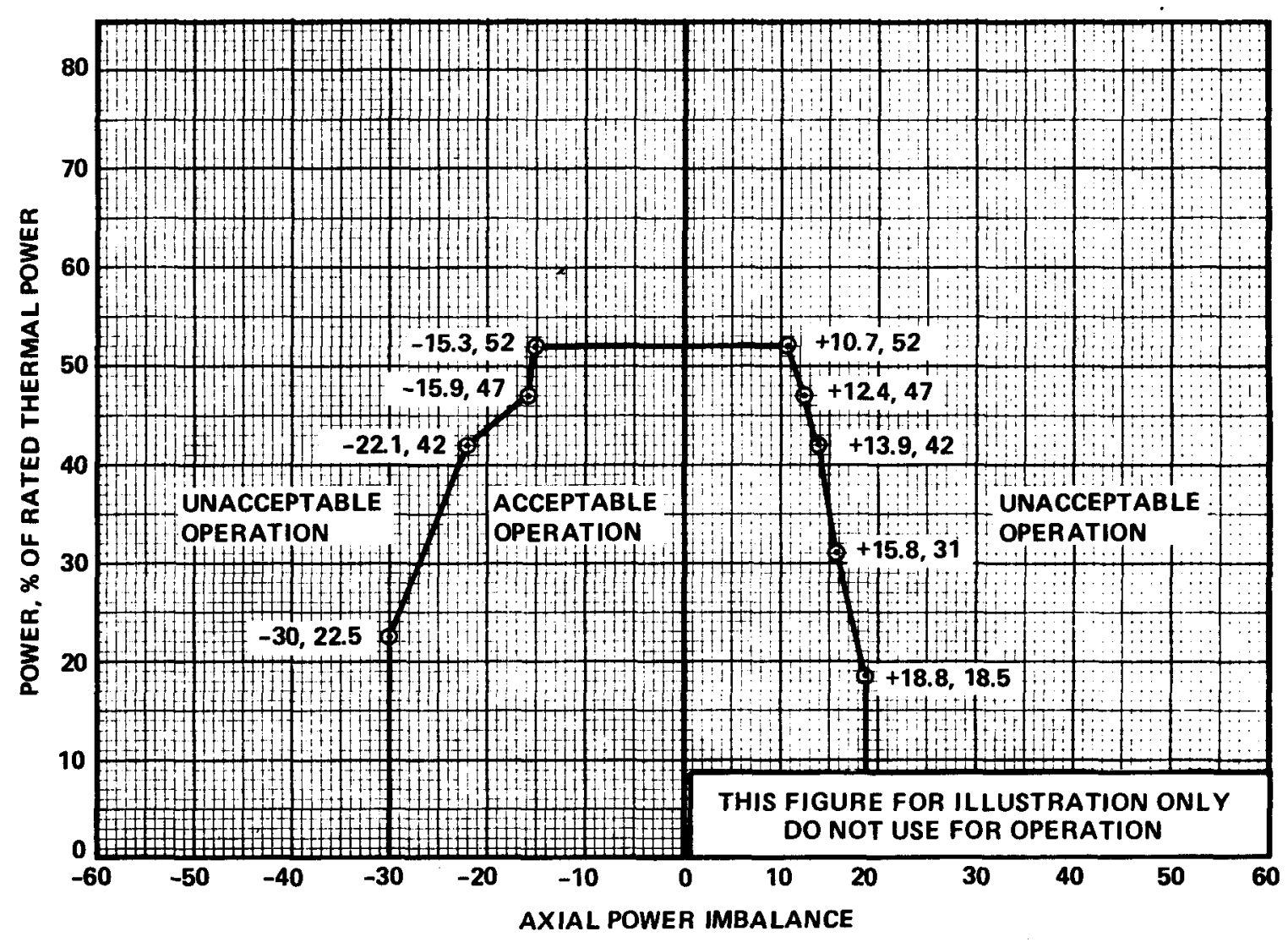

Figure 3.2-3 AXIAL POWER IMBALANCE Envelope for 2 Pump Operation 
POWER DISTRIBUTION LIMITS

NUCLEAR HEAT FLUX HOT CHANNEL FACTOR $-\mathrm{F}_{\mathrm{Q}}$

LIMITING CONDITION FOR OPERATION

3.2.2 $F_{Q}$ shall be limited by the following relationships:

$$
\begin{aligned}
& F_{Q} \leq \frac{\left(\frac{1}{P} \text { for } P>0.5\right.}{F_{Q} \leq 2() \text { for } P \leq 0.5}
\end{aligned}
$$

where $P=\frac{\text { THERMAL POWER }}{\text { RATED THERMAL POWER }}$ and $P \leq 1.0$.

APPLICABILITY: MODE 1 .

ACTION:

With $F_{Q}$ exceeding its limit:

a. Reduce THERMAL POWER at least $1 \%$ for each $1 \% \mathrm{~F}_{\text {g }}$ exceeds the 1 imit within 15 minutes and similarly reduce the Nuclear Overpower Trip Setpoint and Nuclear Overpower based on RCS Flow and AXIAL POWER IMBALANCE Trip Setpoint within 4 hours.

b. Demonstrate through in-core mapping that $F_{0}$ is within its limit within 24 hours after exceeding the limit or reduce THERMAL POWER to less than 5\% of RATED THERMAL POWER within the next 2 hours.

c. Identify and correct the cause of the out of limit condition prior to increasing THERMAL POWER above the reduced limit required by $a$ or $b$, above; subsequent POWER OPERATION may proceed provided that $F_{0}$ is demonstrated through in-core mapping to be within its limit at a nominal $50 \%$ of RATED THERMAL POWER prior to exceeding this THERMAL POWER, at a nominal $75 \%$ of RATED THERMAL POWER prior to exceeding this THERMAL POWER and within 24 hours after attaining 95\% or greater RATED THERMAL POWER.

SURVEILLANCE REQUIREMENTS

4.2.2.1 $F_{0}$ shall be determined to be within its limit by using the incore detectors to obtain a power distribution map: 


\section{POWER DISTRIBUTION LIMITS}

SURVEILLANCE REQUIREMENTS (Continued)

a. Prior to initial operation above 75 percent of RATED THERMAL POWER after each fuel loading.

b. At least once per 31 Effective Full Power Days.

c. The provisions of Specification 4.0.4 are not applicable.

4.2.2.2 The measured $F_{0}$ of 4.2 .2 .1 above, shall be increased by (3)\% to account for manufacturing tolerances and further increased by $(5) \%$ to account for measurement uncertainty. 
POWER DISTRIBUTION LIMITS

NUCLEAR ENTHALPY RISE HOT CHANNEL FACTOR - $\mathrm{F}_{\Delta H}^{\mathrm{N}}$

LIMITING CONDITION FOR OPERATION

3.2.3 $F_{\Delta H}^{N}$ shall be limited by the following relationship:

$$
\begin{aligned}
& \mathrm{F}_{\Delta H}^{\mathrm{N}} \leq(\quad)[1+0.2(1-\mathrm{P})] \\
& \text { where } \mathrm{P}=\frac{\text { THERMAL POWER }}{\text { RATED THERMAL POWER }}
\end{aligned}
$$

and $P \leq 1.0$.

APPLICABILITY: MODE 1 .

ACTION:

With $F_{\Delta H}^{N}$ exceeding its limit:

a. Reduce THERMAL POWER at least $1 \%$ for each $1 \%$ that $\mathrm{F}^{\mathrm{N}}$ exceeds the 7 imit within 15 minutes and similarly reduce the Nuctear Overpower Trip Setpoint and Nuclear Overpower based on RCS Flow and AXIAL POWER IMBALANCE Trip Setpoint within 4 hours.

b. Demonstrate through in-core mapping that $\mathrm{F}^{N}$ is within its limit within 24 hours after exceeding the limit of reduce THERMAL POWER to less than 5\% of RATED THERMAL POWER within the next 2 hours.

c. Identify and correct the cause of the out of limit condition prior to increasing THERMAL POWER above the reduced limit required by $a$ or $b$, aboye; subsequent POWER OPERATION may proceed provided that $F^{N}$ is demonstrated through in-core mapping to be within its limit at a nominal $50 \%$ of RATED THERMAL POWER prior to exceeding this THERMAL POWER, at a nominal $75 \%$ of RATED THERMAL POWER prior to exceeding this THERMAL POWER and within 24 hours after attaining 95\% or greater RATED THERMAL POWER. 


\section{POWER DISTRIBUTION LIMITS}

SURVEILLANCE REQUIREMENTS

4.2.3.1 $F^{N}$ shall be determined to be within its limit by using the incore detectors to obtain a power distribution map:

a. Prior to operation above 75 percent of RATED THERMAL POWER after each fuel loading.

b. At least once per 31 Effective Full Power Days.

c. The provisions of Specification 4.0.4 are not applicable.

4.2.3.2 The measured $F^{N}$ of 4.2 .3 .1 above, shall be increased by $(4) \%$ for measurement uncertaithy. 
POWER DISTRIBUTION LIMITS

QUADRANT POWER TILT

LIMITING CONDITION FOR OPERATION

3.2.4 THE QUADRANT POWER TILT shall not exceed the Steady State Limit of Table 3.2-1.

APPLICABILITY: MODE 1 above 15\% of RATED THERMAL POWER.*

ACTION:

a. Wi th the QUADRANT POWER TILT determined to exceed the Steady State Limit but less than or equal to the Transient Limit of Table 3.2-1:

1. Within 2 hours:

a) Either reduce the QUADRANT POWER TILT to within its Steady State Limit, or

b) Reduce THERMAL POWER so as not to exceed THERMAL POWER, including power level cutoff, allowable for the reactor coolant pump combination less at least $2 \%$ for each $1 \%$ of QUADRANT POWER TILT in excess of the Steady State Limit and within 4 hours, reduce the Nuclear Overpower Trip Setpoint and the Nuclear Overpower Based on RCS Flow and AXIAL POWER IMBALANCE Trip Setpoint at least $2 \%$ for each $1 \%$ of QUADRANT POWER TILT in excess of the Steady State Limit.

2. Verify that the QUADRANT POWER TILT is within its Steady State Limit within 24 hours after exceeding the Steady State Limit or reduce THERMAL POWER to less than $60 \%$ of THERMAL POWER allowable for the reactor coolant pump combination within the next 2 hours and reduce the Nuclear Overpower Trip Setpoint to $\leq 65.5 \%$ of THERMAL POWER allowable for the reactor coolant pump combination within the next 4 hours.

3. Identify and correct the cause of the out of limit condition prior to increasing THERMAL POWER; subsequent POWER OPERATION above $60 \%$ of THERMAL POWER allowable for the reactor coolant pump combination may proceed provided that the QUADRANT POWER TILT is verified within its Steady State Limit at least once per hour for 12 hours or until verified acceptable at $95 \%$ or greater RATED THERMAL POWER.

ॠSee Special Test Exception 3.10.1. 
POWER DISTRIBUTION LIMITS

LIMITING CONDITION FOR OPERATION (Continued)

b. With the QUADRANT POWER TILT determined to exceed the Transient Limit but less than the Maximum Limit of Table 3.2-1, due to misalignment of either a safety, regulating or axial power shaping rod:

1. Reduce THERMAL POWER at least $2 \%$ for each $1 \%$ of indicated QUADRANT POWER TILT in excess of the Steady State Limit within 30 minutes.

2. Verify that the QUADRANT POWER TILT is within its Transient Limit within 2 hours after exceeding the Transient Limit or reduce THERMAL POWER to less than $60 \%$ of THERMAL POWER allowable for the reactor coolant pump combination within the next 2 hours and reduce the Nuclear Overpower Trip Setpoint to $<65.5 \%$ of THERMAL POWER al lowable for the reactor coolant pump combination within the next 4 hours.

3. Identify and correct the cause of the out of limit condition prior to increasing THERMAL POWER; subsequent POWER OPERATION above $60 \%$ of THERMAL POWER allowable for the reactor coolant pump combination may proceed provided that the QUADRANT POWER TILT is verified within its Steady State Limit at least once per hour for 12 hours or until verified acceptable at $95 \%$ or greater RATED THERMAL POWER.

c. With the QUADRANT POWER TILT determined to exceed the Transient Limit but less than the Maximum Limit of Table 3.2-1, due to causes other than the misalignment of either a safety, regulating or axial power shaping rod:

1. Reduce THERMAL POWER to less than $60 \%$ of THERMAL POWER allowable for the reactor coolant pump combination within 2 hours and reduce the Nuclear Overpower Trip Setpoint to $<65.5 \%$ of THERMAL POWER al lowable for the reactor cooTant pump combination within the next 4 hours.

2. Identify and correct the cause of the out of limit condition prior to increasing THERMAL POWER; subsequent POWER OPERATION above $60 \%$ of THERMAL POWER allowable for the reactor coolant pump combination may proceed provided that the QUADRANT POWER TILT is verified within its Steady State Limit at least once per hour for 12 hours or until verified at $95 \%$ or greater RATED THERMAL POWER. 
POWER DISTRIBUTION LIMITS

LIMITING CONDITION FOR OPERATION (Continued)

ACTION: (Continued)

d. With the QUADRANT POWER TILT determined to exceed the Maximum Limit of Table $3.2-1$, reduce THERMAL POWER to $\leq 15 \%$ of RATED THERMAL POWER within 2 hours.

SURVEILLANCE REQUIREMENTS

4.2.4 The QUADRANT POWER TILT shall be determined to be within the 1 imits at least once every 7 days during operation above $15 \%$ of RATED THERMAL POWER except when the QUADRANT POWER TILT monitor is inoperable, then the QUADRANT POWER TILT shall be calculated at least once per 12 hours. 
TABLE 3.2-1

QUADRANT POWER TILT LIMITS

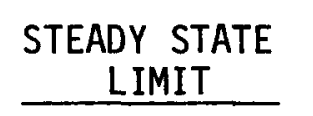

Measurement Independent QUADRANT POWER TILT

QUADRANT POWER TILT aS

Measured by:

Symmetrical Incore

Detector System

Power Range Channels

Minimum Incore Detector System
(4.92)

$(11.07)$

$(20.0)$

(4.01)

(2.04)

$(2.82)$
$(9.51)$

$(20.0)$

(7.04)

$(20.0)$

(8. 32)

$(20.0)$
MAXIMUM

LIMIT 


\section{POWER DISTRIBUTION LIMITS \\ DNB PARAMETERS}

LIMITING CONDITION FOR OPERATION

3.2.5 The following DNB related parameters shall be maintained within the limits shown on Table 3.2-2:

a. Reactor Coolant Hot Leg Temperature.

b. Reactor Coolant Pressure.

c. Reactor Coolant Flow Rate.

APPLICABILITY: MODE 1 .

ACTION:

With any of the above parameters exceeding its limit, restore the parameter to within its limit within 2 hours or reduce THERMAL POWER to Tess than $5 \%$ of RATED THERMAL POWER within the next 4 hours.

SURVEILLANCE REQUIREMENTS

4.2.5.1 Each of the parameters of Table $3.2-2$ shall be verified to be within their limits at least once per 12 hours.

4.2.5.2 The Reactor Coolant System total flow rate shall be determined to be within its limit by measurement at least once per 18 months. 
TABLE 3.2-2

\section{DNB MARGIN}

\section{$\underline{\text { LIMITS }}$}

Four Reactor

Coolant Pumps Operating

Three Reactor

Coolant Pumps

One Reactor

Coolant Pump

Parameter Operating

Operating in Each Loop

Reactor Coolant Hot Leg

Temperature, $\mathrm{T}_{H}{ }^{\circ} \mathrm{F}$

$\leq(605.2)$

$\leq(605.2)^{(1)}$

$\leq(605.2)$

Reactor Coolant Pressure, psig(2)

$\geq(2062.7)$

$\geq(2058.9)^{(1)}$

$\geq(2092.5)$

$\stackrel{\omega}{\infty}$ Reactor Coolant Flow Rate, gpm

$\geq(369,600)$

$\geq(276,091)$

$\geq(181,843)$

$\frac{N}{D}$

(T) Applicable to the loop with 2 Reactor Coolant Pumps Operating.

(2) Limit not applicable during either a THERMAL POWER ramp increase in excess of $5 \%$ of RATED THERMAL POWER per minute or a THERMAL POWER step increase of greater than $10 \%$ of RATED THERMAL POWER. 


\section{$3 / 4.3$ INSTRUMENTATION}

3/4.3.1 REACTOR PROTECTION SYSTEM INSTRUMENTATION

LIMITING CONDITION FOR OPERATION

3.3.1.1 As a minimum, the Reactor Protection System instrumentation channels and bypasses of Table 3.3-1 shall be OPERABLE with RESPONSE TIMES as shown in Table 3.3-2.

APPLICABILITY: As shown in Table 3.3-1.

ACTION:

As shown in Table 3.3-1.

SURVEILLANCE REQUIREMENTS

4.3.1.1.1 Each Reactor Protection System instrumentation channel shall be demonstrated OPERABLE by the performance of the CHANNEL CHECK, CHANNEL CALIBRATION and CHANNEL FUNCTIONAL TEST operations for the MODES and at the frequencies shown in Table 4.3-1.

4.3.1.1.2 The total bypass function shall be demonstrated OPERABLE at least once per 18 months during CHANNEL CALIBRATION testing of each channel affected by bypass operation.

4.3.1.1.3 The REACTOR PROTECTION SYSTEM RESPONSE TIME of each reactor trip function shall be demonstrated to be within its limit at least once per 18 months. Each test shall include at least one channel per function such that all channels are tested at least once every $\mathrm{N}$ times 18 months where $\mathrm{N}$ is the total number of redundant channels in a specific reactor trip function as shown in the "Total No. of Channels" column of Table $3.3-1$. 
TABLE $3.3-1$

变

\section{FUNCTIONAL UNIT}

1. Manual Reactor Trip

2. Nuclear Overpower

3. RCS Outlet Temperature--High

4. Nuclear Overpower Based on RCS Flow and AXIAL POWER IMBALANCE

5. RCS Pressure--Low

6. RCS Pressure--High

7. Variable Low RCS Pressure

8. Nuclear Overpower Based on Pump Monitor

9. Reactor Containment Pressure--High

10. Intermediate Range, Neutron Flux and Rate

11. Source Range, Neutron Flux and Rate
A. Startup
B. Shutdown

12. Control Rod Drive Trip Breakers

13. Reactor Trip Module

14. Shutdown Bypass RCS Pressure-High

OF C

TOTAL NO. CHANNELS CHANNELS

OF CHANNELS TO TRIP

APPLICABLE MODES

ACTION

2

4

4

1

2

2

4

$2(a)(b)$

2(a)

2

4

2(a)

$2(a)(b)$

2

0

2

1, 2 and *

1,2

1,2

1,2

1,2

1,2

1,2

1,2

1,2

1, 2 and *

2

2\#\# and *

3,4 and 5

1

1, 2 and * 2 per

2 per trip system

2 per trip system

1 per trip system

1 per trip system

2 per 1,2 and * trip system

2
3
1 2\#
4 $4 * \star, 5 * \star$ 


\section{TABLE 3.3-1 (Continued)}

\section{TABLE NOTATION}

* With the control rod drive trip breakers in the closed position and the control rod drive system capable of rod withdrawal.

**When Shutdown Bypass is actuated.

\#The provisions of Specification 3.0.4 are not applicable.

\#\#High voltage to detector may be de-energized above $10^{-10}$ amps on both Intermediate Range channels.

(a) Trip may be manually bypassed when RCS pressure $\leq(1720)$ psig by actuating Shutdown Bypass provided that:

(1) The Nuclear Overpower Trip Setpoint is $\leq 5 \%$ of RATED THERMAL POWER.

(2) The Shutdown Bypass RCS Pressure--High Trip Setpoint of $\leq$ (1720) psig is imposed.

(3) The Shutdown Bypass is removed when RCS pressure $>(1800)$ psig.

(b) Trip may be bypassed during testing pursuant to Special Test Exception 3.10.3.

\section{ACTION STATEMENTS}

ACTION 1 - With the number of channels OPERABLE one less than required by the Minimum Channels OPERABLE requirement, restore the inoperable channel to OPERABLE status within 48 hours or be in at least HOT STANDBY within the next 6 hours and/or open the control rod drive trip breakers.

ACTION 2 - With the number of OPERABLE channels one less than the Total Number of Channels STARTUP and/or POWER OPERATION may proceed provided all of the following conditions are satisfied:

a. The inoperable channel is placed in the tripped condition within one hour.

b. The Minimum Channels OPERABLE requirement is met; however, one additional channel may be bypassed for up to 2 hours for surveillance testing per Specification 4.3.1.1.1, 
TABLE 3.3-1 (Continued)

ACTION STATEMENTS (Continued)

and the inoperable channel above may be bypassed for up to 30 minutes in any 24 hour period when necessary to test the trip breaker associated with the logic of the channel being tested per Specification 4.3.1.1.1.

c. Either, THERMAL POWER is restricted to $\leq(75) \%$ of RATED THERMAL POWER and the Nuclear Overpower Trip Setpoint is reduced to $\leq(85) \%$ of RATED THERMAL POWER within 4 hours or the QUADRANT POWER TILT is monitored at least once per 12 hours.

ACTION 3 - With the number of OPERABLE channels one less than the Total Number of Channels STARTUP and POWER OPERATION may proceed provided both of the following conditions are satisfied:

a. The inoperable channel is placed in the tripped condition within one hour.

b. The Minimum Channels OPERABLE requirement is met; however, one additional channel may be bypassed for up to 2 hours for surveillance testing per Specification 4.3.1.1.1, and the inoperable channel above may be bypassed for up to 30 minutes in any 24 hour period when necessary to test the trip breaker associated with the logic of the channel being tested per Specification 4.3.1.1.1.

ACTION 4 - With the number of channels OPERABLE one less than required by the Minimum Channels OPERABLE requirement and with the THERMAL Power leve1:

a. $\leq 5 \%$ of RATED THERMAL POWER restore the inoperable channe1 to OPERABLE status prior to increasing THERMAL POWER above $5 \%$ of RATED THERMAL POWER.

b. $>5 \%$ of RATED THERMAL POWER, POWER OPERATION may continue. 


\section{TABLE 3.3-1 (Continued)}

\section{ACTION STATEMENTS (Continued)}

ACTION 5 - With the number of channels OPERABLE one less than required by the Minimum Channels OPERABLE requirement and with the THERMAL POWER level:

a. $\leq 10^{-10}$ amps on the Intermediate Range (IR) instrumentation, restore the inoperable channel to OPERABLE $\{$ tatus prior to increasing THERMAL POWER above $10^{-10^{-}}$amps on the IR instrumentation.

b. $>10^{-10}$ amps on the IR instrumentation, operation may continue.

ACTION 6 - With the number of channels OPERABLE one less than required by the Minimum Channels OPERABLE requirement, verify compliance with the SHUTDOWN MARGIN requirements of Specification 3.1.1.1 within one hour and at least once per 12 hours thereafter.

ACTION 7 - With the number of OPERABLE channels one less than the Total Number of Channels STARTUP and/or POWER OPERATION may proceed provided all of the following conditions are satisfied:

a. Within 1 hour:

1. Place the inoperable channel in the tripped condition, or

2. Remove power supplied to the control rod trip device associated with the inoperative channel.

b. One additional channel may be bypassed for up to 2 hours for surveillance testing per Specification 4.3.1.1.1, and the inoperable channel above may be bypassed for to 30 minutes in any 24 hour period when necessary to test the trip breaker associated with the logic of the channel being tested per Specification 4.3.1.1.1. The inoperable channel above 1 may not be bypassed to test the logic of a channel of the trip system associated with the inoperable channel.

ACTION 8 - With the number of channels OPERABLE less than required by the Minimum Channels OPERABLE requirement, be in at least HOT STANDBY within 6 hours. 
TABLE 3.3-2

\section{FUNCTIONAL UNIT}

1. Manual Reactor Trip

2. Nuclear Overpower*

3. RCS Outlet Temperature--High

4. Nuclear Overpower Based on RCS Flow and AXIAL POWER IMBALANCE*

5. RCS Pressure--Low

6. RCS Pressure--High

7. Variable Low RCS Pressure

8. Nuclear Overpower Based on Pump Monitor*

9. Reactor Containment Pressure--High

\section{RESPONSE TIMES}

Not Applicable

$\leq \ldots$ seconds

$\leq-$ seconds

$\leq \ldots$ seconds

$\leq \ldots$ seconds

$\leq \ldots$ seconds

$\leq \ldots$ seconds

$\leq \ldots$ seconds

$\leq \ldots$ seconds

c. Neutron detectors are exempt from response time testing. Response time of the neutron flux s signal portion of the channel shall be measured from detector output or input of first electronic component in channel. 
TABLE 4.3-1

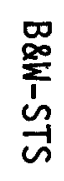

\section{REACTOR PROTECTION SYSTEM INSTRUMENTATION SURVEILLANCE REQUIREMENTS}

\section{FUNCTIONAL UNIT}

1. Manual Reactor Trip

2. Nuclear Overpower

3. RCS Outlet Temprature--High

4. Nuclear Overpower Based on RCS Flow and AXIAL POWER IMBALANCE

$\stackrel{\omega}{\infty}$

5. RCS Pressure--Low

6. RCS Pressure--High

$\stackrel{\omega}{v}$

章

7. Variable Low RCCS Pressure

8. Nuclear Overpower Based on Pump Monitor

10. Intermediate Range, Neutron Flux and Rate

11. Source Range, Neutron Flux and Rate

12. Control Rod Drive Trip Breaker

13. Reactor Trip Module

14. Shutdown Bypass RCS Pressure-High

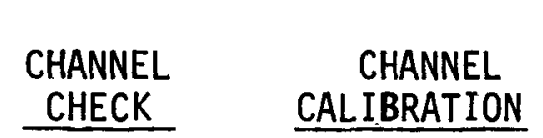

N.A.

$\mathrm{S}$

$S$

9. Reactor Containment Pressure--High $S$
S

S

\section{$S(4)$}

$S$

S

S

S

(n)

s

N.A.

N.A.

$\mathrm{S}$

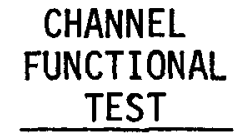

N.A.

$D(2)$ and $Q(6)$

$\mathrm{R}$

$S / U(1)$

$\mathrm{M}$

M

$M(3)$ and $Q(6,7) \quad M$

$R$

$R$

R

$R$

R

$R(6)$

$R(6)$

N.A.

N.A.

$\mathrm{R}$
MODES IN WHICH SURVEILANCE REQUIRED

N.A.

1,2

1,2

1,2

1,2

1,2

1,2

1,2

1,2

1,2 and *

$2,3,4$ and 5

1,2 and *

1,2 , and *

$2 * \star, 3 * \star, 4 * \star, 5 * \star$ 


\section{TABLE 4.3-1 (Continued)}

NOTATION

* - With any control rod drive trip breaker closed.

** - When Shutdown Bypass is actuated.

(1) - If not performed in previous 7 days.

(2) - Heat balance only, above 15\% of RATED THERMAL POWER. Adjust channel if absolute difference $\geq$ (2) percent.

(3) - Compare incore to out-of-core measured AXIAL POWER IMBALANCE above $15 \%$ of RATED THERMAL POWER. Recalibrate if absolute difference $\geq(2)$ percent.

(4) - AXIAL POWER IMBALANCE and loop flow indications only.

(5) - Verify at least one decade overlap if not verified in previous 7 days.

(6) - Neutron detectors may be excluded from CHANNEL CALIBRATION.

(7) - Flow rate measurement sensors may be excluded from CHANNEL CALIBRATION. However, each flow measurement sensor shall be calibrated at least once per 18 months. 
INSTRUMENTATION

3/4.3.2 ENGINEERED SAFETY FEATURE ACTUATION SYSTEM INSTRUMENTATION

LIMITING CONDITION FOR OPERATION

3.3.2.1 The Engineered Safety Feature Actuation System (ESFAS) instrumentation channels shown in Table 3.3-3 shall be OPERABLE with their trip setpoints set consistent with the values shown in the Trip Setpoint column of Table 3.3-4 and with RESPONSE TIMES as shown in Table 3.3-5.

APPLICABILITY: As shown in Table 3.3-3.

ACTION:

a. With an ESFAS instrumentation channel trip setpoint less conservative than the value shown in the Allowable Values column of Table 3.3-4, declare the channel inoperable and apply the applicable ACTION requirement of Table 3.3-3 until the channel is restored to OPERABLE status with the trip setpoint adjusted consistent with the Trip Setpoint Value.

b. With an ESFAS instrumentation channel inoperable, take the action shown in Table 3.3-3.

SURVEILLANCE REQUIREMENTS

4.3.2.1.1 Each ESFAS instrumentation channel shall be demonstrated OPERABLE by the performance of the CHANNEL CHECK, CHANNEL CALIBRATION and CHANNEL FUNCTIONAL TEST operations for the MODES and at the frequencies shown in Table 4.3-2.

4.3.2.1.2 The logic for the bypasses shall be demonstrated OPERABLE during the at power CHANNEL FUNCTIONAL TEST of channels affected by bypass operation. The total bypass function shall be demonstrated OPERABLE at least once per 18 months during CHANNEL CALIBRATION testing of each channel affected by bypass operation.

4.3.2.1.3 The ENGINEERED SAFETY FEATURES RESPONSE TIME of each ESFAS function shall be demonstrated to be within the limit at least once per 18 months. Each test shall include at least one channel per function such that all channels are tested at least once every $\mathrm{N}$ times 18 months where $N$ is the total number of redundant channels in a specific ESFAS function as shown in the "Total No. of Channels" Column of Table 3.3-3. 
1. SAFETY INJECTION

\begin{tabular}{lll} 
TOTAL NO. & CHANNELS & CHANNELS \\
OF CHANNELS & TO TRIP & OPERABLE \\
\hline
\end{tabular}

a. High Pressure Injection
1) Manual Initiation
2) Containment Pressure- High
3) RCS Pressure-Low
4) Automatic Actuation Logic

2
$4\left(^{1}(3)^{1}\right.$
2

1

2

2

1

$\underset{\omega}{\omega}$

b. Low Pressure Injection

$\frac{\omega}{0}$

1) Manual Initiation

2) Containment PressureHigh

3) RCS Pressure--

Low-Low

4) Automatic Actuation Logic

2. CONTAINMENT SPRAY

a. Manual Initiation

2

4 (3)

3 (2)

2

$1,2,3,4$

$3(2)^{1}$

$1,2,3$

3 (2)

$1,2,3 *$

2

$1,2,3,4$

$1,2,3,4$

$1,2,3,4$

10

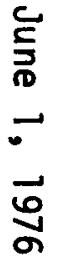

2

2

$1,2,3,4$

12

b. Containment Pressure-High-High

$1,2,3$

c. Automatic Actuation Logic 2

$1,2,3,4$

10

3 channel systems. 
TABLE 3.3-3 (Continued)

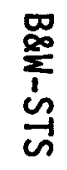

\section{ENGINEERED SAFETY FEATURE ACTUATION SYSTEMS INSTRUMENTATION}

FUNCTIONAL UNIT

\begin{tabular}{cll} 
TOTAL NO. & MINIMUM \\
OF CHANNELS & TO TRIP & CHANNELS \\
\hline
\end{tabular}

APPLICABLE

MODES

ACTION

3. CONTAINMENT ISOLATION

a. Containment Isolation

$\begin{array}{lllllll}\text { 1) } \begin{array}{l}\text { Manual Initiation } \\ \text { Containment Pressure- }\end{array} & 2 & 1 & 2 & 1,2,3,4 & 12 & \text { | } \\ \begin{array}{l}\text { High } \\ \text { Automatic Actuation }\end{array} & 4(3) & 2 & 3(2) & 1,2,3 & 9 \#(9) \# \text { | } \\ \begin{array}{l}\text { Logic } \\ \text { Logic }\end{array} & 2 & 1 & 2 & 1,2,3,4 & 10\end{array}$

b. Containment Purge and Exhaust Isolation

1) Manual Initiation

2) Containment PressureHigh

3) Containment

Radioactivity-High

4) Automatic Actuation Logic

$2 \quad 1$

4 (3)

2

$1,2,3,4$

$11 \#$

$3(2)$

$1,2,3$

$11 \#$

4 (3)

3 (2)

$1,2,3,4$

$11 \#$

2

$1,2,3,4$

$11 \#$

4. CONTAINMENT COOLING
a. Manual Initiation
b. Containment Pressure- High
c. Automatic Actuation Logic

2

2

$1,2,3,4$

12

$3(2)$

$1,2,3$

9\# (9)\#

2

2

$1,2,3,4$

10 
TABLE 3.3-3 (Continued)

FUNCTIONAL UNIT

$\begin{array}{cll}\text { TOTAL NO. } & \text { CHANNELS } & \text { MINIMUM } \\ \text { OF CHANNELS } & \text { TO TRIP } & \text { OPERABLE }\end{array}$

APPLICABLE

5. MAIN STEAM ISOLATION
a. Manual Initiation
2
b. Containment Pressure- High
$4(3)$
4 (3)
c. RCS Pressure-Low
d. Automatic Actuation Logic 2

2

2

1

6. CONTAINMENT EMERGENCY SUMP SUCTION
a. Manual Initiation
b. Borated Water Storage
Tank-Low
c. Automatic Actuation Logic

2

$4(3)$

2

$3(2)$

$1,2,3$

9\# (9)\#

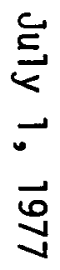

7. LOSS OF POWER

a. $416 \mathrm{Kv}$ Emergency Bus Undervoltage (Loss of Voltage)

4(3)/Bus

2/Bus

2

$1,2,3,4$

10

b. $4.16 \mathrm{Kv}$ Emergency Bus Undervoltage (Degraded Voltage

4(3)/Bus 2/Bus

$3(2)$ /Bus $1,2,3$

$9 \#(9) \#$

ACTION

$3(2) \quad 1,2,3 * \star * \quad 9 \#(9) \#$

$2(2) \quad 1,2,3 * \star * * \quad 9 \#(9) \#$

$2 \quad 1,2,3,4 \quad 10$ 


\section{TABLE 3.3-3 (Continued)}

\section{TABLE NOTATION}

*Trip function may be bypassed in this MODE with RCS pressure below (1600) psig. Bypass shall be automatically removed when RCS pressure exceeds (1800) psig.

**Trip function may be bypassed in this MODE with RCS pressure below (400) psig. Bypass shall be automatically removed when RCS pressure exceeds (600) psig.

***Trip function may be bypassed in this MODE with steam generator pressure below (725) psig. Bypass shall be automatically removed when steam generator pressure exceeds (725) psig.

\#The provisions of Specification 3.0.4 are not applicable.

\section{ACTION STATEMENTS}

ACTION 9 - With the number of OPERABLE channels one less than the Total Number of Channels operation may proceed provided both of the following conditions are satisfied:
a. The inoperable channel is placed in the tripped condition within one hour.
b. The Minimum Channels OPERABLE requirement is met; however, one additional channel may be bypassed for up to 2 hours for surveillance testing per Specification 4.3.2.1.1.

ACTION (9) - With the number of OPERABLE Channels one less than the Total Number of Channels operation may proceed until performance of the next required CHANNEL FUNCTIONAL TEST provided the inoperable channel is placed in the tripped condition within 1 hour.

ACTION 10 - With the number of OPERABLE channels one less than the Total Number of Channels, be in at least HOT STANDBY within 6 hours and in COLD SHUTDOWN within the next 30 hours; however, one channel may be bypassed for up to 1 hour for surveillance testing per Specification 4.3.2.1.1.

ACTION 11 - With less than the Minimum Channels OPERABLE, operation may continue provided the containment purge and exhaust valves are maintained closed. 
TABLE 3.3-3 (Continued)

\section{ACTION STATEMENTS (Continued)}

ACTION 12 - With the number of OPERABLE Channels one less than the Total Number of Channels, restore the inoperable channel to OPERABLE status within 48 hours or be in at least HOT STANDBY within the next 6 hours and in COLD SHUTDOWN within the following 30 hours.

ACTION 13 - With the number of OPERABLE Channels one less than the Total Number of Channels operation may proceed provided the inoperable channel is placed in the bypassed condition and the minimum channels OPERABLE requirement is demonstrated within 1 hour; one additional channel may be bypassed for up to 2 hours for Surveillance testing per Specification 4.3.2.1.1. 
TABLE 3.3-4

1. SAFETY INJECTION

a. High Pressure Injection

1) Manual Initiation

2) Containment Pressure-High

3) RCS Pressure-Low

4) Automatic Actuation Logic

b. Low Pressure Injection
1) Manual Initiation
2) Containment Pressure-High
3) RCS Pressure--Low-Low
4) Automatic Actuation Logic

2. CONTAINMENT SPRAY
a. Manual Initiation
b. Containment Pressure--High-High
c. Automatic Actuation Logic

3. CONTAINMENT ISOLATION

a. Containment Isolation

1) Manual Initiation

2) Containment Pressure-High

3) Automatic Actuation Logic
Not Applicable

$<$ (5) psig

$\overline{>}(1600)$ psig

Not Applicable

Not Applicable

$<$ (5) psig

$>(400)$ psig

Not Applicable

Not Applicable $<$ (30) psig

Not Applicable

Not Applicable

$<$ (5) psig

Not Applicable
Not Applicable

$\leq()$ psig

Not Applicable

Not Applicable

$\leq(\quad)$ psig

Not Applicable

Not Applicable

$<$ ( ) psig

Not Applicable

Not Applicable

$<$ ( ) psig

N̄ot Applicable 
TABLE 3.3-4 (Continued)

\section{ENGINEERED SAFETY FEATURE ACTUATION SYSTEMS INSTRUMENTATION TRIP SETPOINTS}

b. Containment Purge and Exhaust Isolation

1) Manual Initiation

2) Containment Pressure-High

3) Containment Radiation-High

4) Automatic Actuation Logic

4. CONTAINMENT COOLING

$\underset{\omega}{\omega}$

$\frac{\omega}{a}$

a. Manual Initiation

b. Containment Pressure-High

c. Automatic Actuation Logic

5. MAIN STEAM ISOLATION
a. Manual Initiation
b. Containment Pressure-High
c. RCS Pressure-Low
d. Automatic Actuation Logic

6. CONTAINMENT EMERGENCY SUMP SUCTION
Not Applicable

$\leq$ (5) psig

$<(25) \mathrm{mr} / \mathrm{hr}$

Not Applicable
Not Applicable

$\leq\left(\int \mathrm{psig}\right.$

$<$ ) $\mathrm{mr} / \mathrm{hr}$

Not Applicable
Not Applicable < (5) psig Not Applicable

Not Applicable $\leq$ (5) psig $\overline{>}(1600)$ psig Not Applicable

Not Applicable $>$ (3) feet Not Applicable
Not Applicable $<($ ) psig

Not Applicable

Not Applicable

$\leq\{\quad$ ) psig

Not Applicable

Not Applicable

$>($ ) feet

Not Applicable

b. Borated Water Storage Tank-Low

c. Automatic Actuation Logic 
TABLE 3.3.4 (Continued)

\section{ENGINEERED SAFETY FEATURE ACTUATION SYSTEM INSTRUMENTATION TRIP VALUES}

FUNCTION UNIT

7. LOSS OF POWER

a. $4.16 \mathrm{kv}$ Emergency Bus Undervoltage (Loss of Voltage)

b. $4.16 \mathrm{kv}$ Emergency Bus Undervoltage (Degraded Voltage)

\section{TRIP VALUE}

$( \pm)$ volts with a

$( \pm)$ second time delay

$(+)$ volts with a

$( \pm)$ second time delay
ALLOWABLE

VALUES

$\omega$
$\stackrel{\omega}{\omega}$
$\stackrel{\omega}{v}$

空

$\underset{\infty}{\infty}$ 
TABLE 3.3-5

ENGINEERED SAFETY FEATURES RESPONSE TIMES

INITIATING SIGNAL AND FUNCTION

RESPONSE TIME IN SECONDS

1. Manual

a. Emergency Core Cooling

High Pressure Injection NA

Low Pressure Injection NA

Component Cooling Water System NA

Service Water System NA

b. Containment Depressurization Systems

Containment Spray NA

Containment Cooling NA

c. Containment Isolation Systems

Containment Isolation NA

Containment Purge and Exhaust Isolation NA

2. Containment Pressure-High

High Pressure Injection

Low Pressure Injection

$\leq(\quad) * /(\quad) * *$

Main Steam Isolation

$\leq() * /() * *$

Containment Isolation

$\leq() * /() * *$

Emergency Ventilation

Containment Purge and Exhaust Isolation

$\leq() * /() * *$

$\leq() * /(\quad) * *$

Containment Cooling

Component Cooling Water System

$\leq() * /() * *$

$\leq() * /(\quad) * *$

Service Water System

$\leq() * /(\quad) * \star$

$\leq() * /(\quad) * *$ 
TABLE 3.3-5 (Continued)

ENGINEERED SAFETY FEATURES RESPONSE TIMES

INITIATING SIGNAL AND FUNCTION

3. Containment Pressure--High-High Containment Spray

4. Reactor Coolant Pressure-Low

High Pressure Injection

Main Steam Isolation

Component Cooling Water System

Service Water System

5. Reactor Coolant Pressure--Low-Low

Low Pressure Injection

6. Containment Radioactivity-High

Containment Purge and Exhaust Isolation

Emergency Ventilation

7. Borated Water Storage Tank-Low

Containment Emergency Sump Suction
RESPONSE TIME IN SECONDS

$$
\begin{aligned}
& \leq() * /() * * \\
& \leq() * /() * * \\
& \leq() \\
& \leq() * /() * * \\
& \leq() * /() * * \\
& \leq() * /() * * \\
& \leq()^{\star \star *} \\
& \leq() * * \\
& \leq()
\end{aligned}
$$




\section{TABLE 3.3-5 (Continued)}

\section{TABLE NOTATION}

*Diesel generator starting and sequence loading delays included. Response time limit includes movement of valves and attainment of pump or blower discharge pressure.

**Diesel generator starting and sequence loading delays not included. Offsite power available. Response time limit includes movement of valves and attainment of pump or blower discharge pressure. 


\section{TABLE 4.3-2}

$\frac{\sum_{\infty}^{\infty}}{i}$

ENGINEERED SAFETY FEATURE ACTUATION SYSTEMS INSTRUMENTATION SURVEILLANCE REQUIREMENTS

FUNCTIONAL UNIT

CHANNEL

CHANNEL

MODES IN WHICH

CHECK

CHANNEL

FUNCTIONAL

SURVEILLANCE

1. SAFETY INJECTION

a. High Pressure Injection

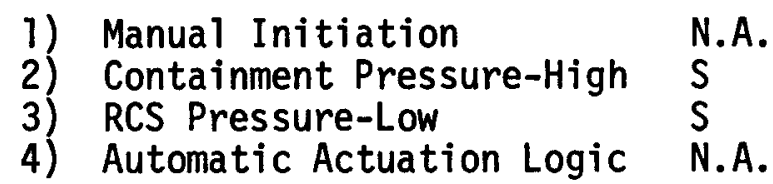

N.A.
R
R
N.A.

$M(1)$

$M(3)$

$M$

N.A. $\quad M(2)$

REQUIRED

b. Low Pressure Injection

$\stackrel{\omega}{\Lambda}$

$\begin{array}{ll}\text { 1) Manual Initiation } & \text { N.A. } \\ \text { 2) Containment Pressure-High } & \text { S } \\ \text { 3) RCS Pressure--Low-Low } & \text { S } \\ \text { 4) Automatic Actuation Logic } & \text { N.A. }\end{array}$

N.A.

$R$

$R$

N.A.

TEST

2. CONTAINMENT SPRAY
a. Manual Initiation
N.A.
N.A.
$M(1)$
$1,2,3,4$
b. Containment Pressure--
High-High
$S$
R
$M(3)$
$1,2,3$
c. Automatic Actuation Logic
N.A.
N.A.
$M(2)$
$1,2,3,4$ 
TABLE 4.3-2 (Continued)

FUNCTIONAL UNIT

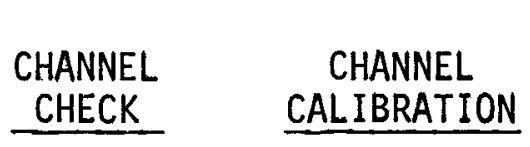

CHANNEL

FUNCTIONAL

MODES IN WHICH SURVEILLANCE

3. CONTAINMENT ISOLATION

a. Containment Isolation
1) Manual Initiation
N.A.
N.A.
$M(1)$
$1,2,3,4$
2) Containment Pressure- High
$S$
3) Automatic Actuation Logic
$\mathrm{R}$
N.A.
$M(3)$
$1,2,3$
N.A.
$M(2)$
$1,2,3,4$

b. Containment Purge and Exhaust Isolation
1) Manual Initiation
N.A.
2) Containment Pressure-High
$S$
3) Containment Radioactivity- High
4) Automatic Actuation Logic
S.A.

N.A.

$\mathrm{R}$

$M(1)$

$1,2,3,4$

$\mathrm{R}$

N.A.

$M$

$M(2)$

$1,2,3$

$1,2,3,4$

$1,2,3,4$

4. CONTAINMENT COOLING

a. Manual Initiation

b. Containment Pressure-High

c. Automatic Actuation Logic

5. MAIN STEAM ISOLATION
a. Manual Initiation
b. Containment Pressure-High
c. RCS Pressure-Low
d. Automatic Actuation Logic

N.A.

$S$

N.A.
N.A.

$R$

N.A.

$M(1)$
$M(3)$

$M(2)$

$1,2,3,4$

$1,2,3$

$1,2,3,4$
N.A.

$\mathrm{R}$

$\mathrm{R}$

N.A.

$M(1)$
$M(3)$
$M$
$M(2)$

$1,2,3$

$1,2,3$

$1,2,3$

N.A.

$M(2)$

$1,2,3$ 
TABLE 4.3-2 (Continued)

CHANNEL

CHECK

6. CONTAINMENT EMERGENCY SUMP SUCTION

a. Manual Initiation

b. Borated Water Storate Tank-Low

c. Automatic Actuation Logic

N.A.

$S$

N.A.

7. LOSS OF POWER

a. $4.16 \mathrm{kv}$ Emergency Bus Undervoltage (Loaa of Voltage)

S

$\stackrel{\omega}{\rho}$

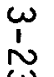

b. $4.16 \mathrm{kv}$ Emergency Bus Undervol tage (Degraded Voltage)

\section{CHANNEL}

CAL IBRATION

CHANNEL

FUNCTIONAL

TEST

MODES IN WHICH

SURVEILLANCE

REQUIRED
N.A.

$R$

N.A.

$M(1)$

$M(2)$

$1,2,3,4$

$1,2,3$

$1,2,3,4$
R

M

$1,2,3$

R

M

$1,2,3$ 


\section{TABLE 4.3-2 (Continued)}

TABLE NOTATION

(1) Manual actuation switches shall be tested at least once per 18 months during shutdown. A11 other circuitry associated with manual safeguards actuation shall receive a CHANNEL FUNCTIONAL TEST at least once per 31 days.

(2) Each train or logic channel shall be tested at least every other 31 days.

(3) The CHANNEL FUNCTIONAL TEST shall include exercising the transmitter by applying either vacuum or pressure to the appropriate side of the transmitter. 
INSTRUMENTATION

3/4.3.3 MONITORING INSTRUMENTATION

RADIATION MONITORING INSTRUMENTATION

LIMITING CONDITION FOR OPERATION

3.3.3.1 The radiation monitoring instrumentation channels shown in Table 3.3-6 shall be OPERABLE with their alarm/trip setpoints within the specified limits.

APPLICABILITY: As shown in Table 3.3-6.

ACTION:

a. With a radiation monitoring channel alarm/trip setpoint exceeding the value shown in Table $3.3-6$, adjust the setpoint to within the limit within 4 hours or declare the channel inoperable.

b. With one or more radiation monitoring channels inoperable, take the ACTION shown in Table 3.3-6.

c. The provisions of Specifications 3.0.3 and 3.0.4 are not applicable.

SURVEILLANCE REQUIREMENTS

4.3.3.1 Each radiation monitoring instrumentation channel shall be demonstrated OPERABLE by the performance of the CHANNEL CHECK, CHANNEL CALIBRATION and CHANNEL FUNCTIONAL TEST operations during the modes and at the frequencies shown in Table 4.3-3. 
TABLE 3.3-6

\section{RADIATION MONITORING INSTRUMENTATION}

INSTRUMENT

MINIMUM

CHANNELS

OPERABLE

APPLICABLE

ALARM/TRIP

MEASUREMENT

MODES

SETPOINT

1. AREA MONITORS

a. Fuel Storage Pool Area

i. Criticality Monitor

ii. Ventilation System

Isolation

$\star$

$\leq 15 \mathrm{mR} / \mathrm{hr}$

$\left(10^{-1}-10^{4}\right) \mathrm{mR} / \mathrm{hr}$

$\leq(2 \times$ background $)$

$\left(1-10^{5}\right) \mathrm{cpm}$

b. Containment
i. Purge \& Exhaust Isolation

$\leq(2 \times$ background $) \quad\left(1-10^{5}\right) \mathrm{cpm}$

2. PROCESS MONITORS

a. Fuel Storage Pool Area

i. Gaseous Activity Ventilation System Isolation

ii. Particulate Activity Ventilation System Isolation

$\star \star$

$\leq(2 \times$ background $) \quad\left(1-10^{5}\right) \mathrm{cpm}$

$\leq(2 \times$ background $) \quad\left(1-10^{5}\right) \mathrm{cpm}$

b. Containment

i. Gaseous Activity

a) Purge \& Exhaust

b) RCS Leakage Detection(1)

ii. Particulate Activity
a) Purge \& Exhaust

Isolation

b) RCS Leakage Detection(1)

$1,2,3 \& 4$

$\leq(2 \times$ background $)$ Not applicable

$\leq(2 \times$ background $) \quad\left(1-10_{5}^{5}\right) \mathrm{cpm}$ 


\section{TABLE 3.3-6 (Continued)}

TABLE NOTATION

ACTION 14 - With the number of channels OPERABLE less than required by the Minimum Channels OPERABLE requirement, comply with the ACTION requirements of Specification $(3.4 .6 .1)$.

ACTION 15 - With the number of channels OPERABLE less than required by the Minimum Channels OPERABLE requirement, comply with the ACTION requirements of Specification (3.9.12).

ACTION 16 - With the number of channels OPERABLE less than required by the Minimum Channels OPERABLE requirement, comply with the ACTION requirements of Specification (3.9.9).

ACTION 17 - With the number of channels OPERABLE less than required by the Minimum Channels OPERABLE requirement, perform area surveys of the monitored area with portable monitoring instrumentation at least once per 24 hours. 
TABLE 4.3-3

RADIATION MONITORING INSTRUMENTATION SURVEILLANCE REQUIREMENTS

\begin{tabular}{|c|c|c|c|c|}
\hline INSTRUMENT & $\begin{array}{l}\text { CHANNEL } \\
\text { CHECK }\end{array}$ & $\begin{array}{c}\text { CHANNEL } \\
\text { CALIBRATION }\end{array}$ & $\begin{array}{c}\text { CHANNEL } \\
\text { FUNCTIONAL } \\
\text { TEST } \\
\end{array}$ & $\begin{array}{c}\text { MODES IN WHICH } \\
\text { SURVEILLANCE } \\
\text { REQUIRED } \\
\end{array}$ \\
\hline
\end{tabular}

1. AREA MONITORS

a. Fuel Storage Pool Area

i.
ii.
$\begin{gathered}\text { Ventiliation System } \\ \text { Isolation }\end{gathered}$

$S$

$R$

M

*

$\mathbf{R}$

M

b. Containment

i. Purge \& Exhaust Isolation

S

$\mathrm{R}$

M

6

2. PROCESS MONITORS

a. Fuel Storage Pool Area

i. Gaseous Activity -

Ventilation System Isolation

ii. Particulate Activity Ventilation System

Isolation $\mathrm{S}$

$\mathrm{R}$

M

R

M

b. Containment

$\frac{\complement}{\stackrel{5}{D}}$

i. Gaseous Activity

a) Purge \& Exhaust Isolation

b) RCS Leakage Detection

$S$

$\mathrm{S}$

R

R

M

6

ii. Particulate Activity

a) Purge \& Exhaust

b) RCS Leakage Detection

S

5

$R$

M

6

M

$1,2,3, \& 4$

- With fuel in the storage pool or building

** With irradiated fuel in the storage pool 
INSTRUMENTATION

INCORE DETECTORS

LIMITING CONDITION FOR OPERATION

3.3.3.2 As a minimum, the incore detectors shall be OPERABLE as specified below.

a. For AXIAL POWER IMBALANCE measurements:

1. Nine detectors shall be arranged such that there are three detectors in each of three strings and there are three detectors lying in the same axial plane with one plane at the core mid-plane and one plane in each axial core half.

2. The axial planes in each core half shall be symmetrical about the core mid-plane.

3. The detector strings shall not have radial symmetry.

b. For QUADRANT POWER TILT measurements with the Minimum Incore Detector System:

1. Two sets of 4 detectors shall lie in each core half. Each set of detectors shall lie in the same axial plane. The two sets in the same core half may lie in the same axial plane.

2. Detectors in the same plane shall have quarter core radial symmetry.

c. For QUADRANT POWER TILT, $F_{A H}^{N}$ and $F_{0}$ measurements with the Symmetric Incore Detector 5 stem at least $(75) \%$ of the detectors in each core quadrant shall be OPERABLE.

APPLICABILITY: When the incore detection system is used for surveillance of:

a. The AXIAL POWER IMBALANCE.

b. The QUADRANT POWER TILT.

c. $F_{\Delta H}^{N}$ and $F_{Q}$.

ACTION:

With less than the specified minimum incore detector arrangement OPERABLE, do not use incore detectors for the applicable monitoring functions. The provisions of Specifications 3.0.3 and 3.0.4 are not applicable. 


\section{INSTRUMENTATION}

SURVEILLANCE REQUIREMENTS

4.3.3.2 The incore detector system shall be demonstrated OPERABLE:

a. By performance of a CHANNEL CHECK within 7 days prior to its use for measurement of the AXIAL POWER IMBALANCE or the QUADRANT POWER TILT.

b. At least once per 18 months by performance of a CHANNEL CALIBRATION which does not include the neutron detectors. 
INSTRUMENTATION

SEISMIC INSTRUMENTATION*

LIMITING CONDITION FOR OPERATION

3.3.3.3 The seismic monitoring instrumentation shown in Table 3.3-7 sha11 be OPERABLE.

APPLICABILITY: At all times.

ACTION:

a. With one or more seismic monitoring instruments inoperable for more than 30 days, prepare and submit a Special Report to the Commission pursuant to Specification 6.9.2 within the next 10 days outlining the cause of the malfunction and the plans for restoring the instrument(s) to OPERABLE status.

b. The provisions of Specifications 3.0 .3 and 3.0.4 are not applicable.

SURVEILLANCE REQUIREMENTS

4.3.3.3.1 Each of the above seismic monitoring instruments shall be demonstrated OPERABLE by the performance of the CHANNEL CHECK, CHANNEL CALIBRATION and CHANNEL FUNCTIONAL TEST operations at the frequencies shown in Table 4.3-4.

4.3.3.3.2 Each of the above seismic monitoring instruments actuated during a seismic event shall be restored to OPERABLE status within 24 hours and a CHANNEL CALIBRATION performed within 5 days following the seismic event. Data shal1 be retrieved from actuated instruments and analyzed to determine the magnitude of the vibratory ground motion. A Special Report shall be prepared and submitted to the Commission pursuant to Specification 6.9.2 within 10 days describing the magnitude, frequency spectrum and resultant effect upon facility features important to safety.

*This specification not required for additional units at a common site provided at least one unit has seismic instrumentation and corresponding technical specifications meeting the recommendations of Regulatory Guide 1.12, April 1974. 
TABLE 3.3-7

SEISMIC MONITORING INSTRUMENTATION

INSTRUMENTS AND SENSOR LOCATIONS

MEASUREMENT
RANGE $\quad \begin{gathered}\text { MINIMUM } \\ \text { INSTRUMENT } \\ \text { OPERABLE }\end{gathered}$

1. Triaxial Time-History Accelerographs
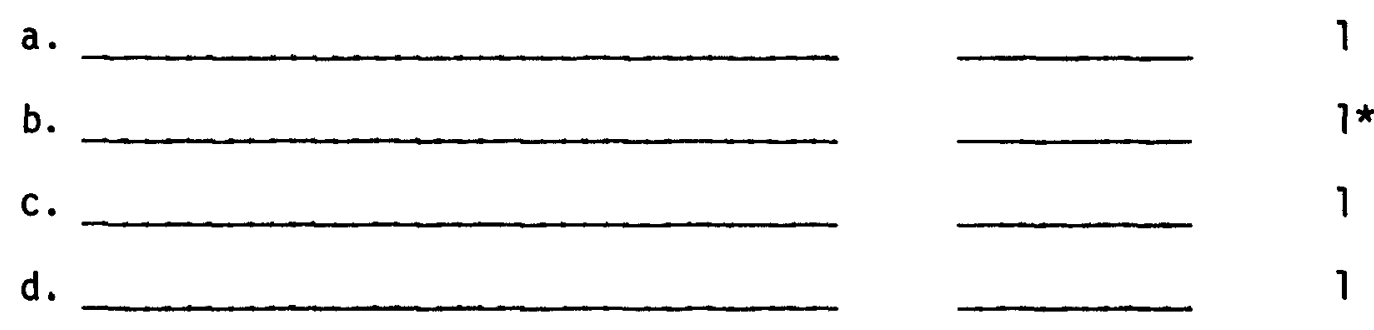

2. Triaxial Peak Accelerographs
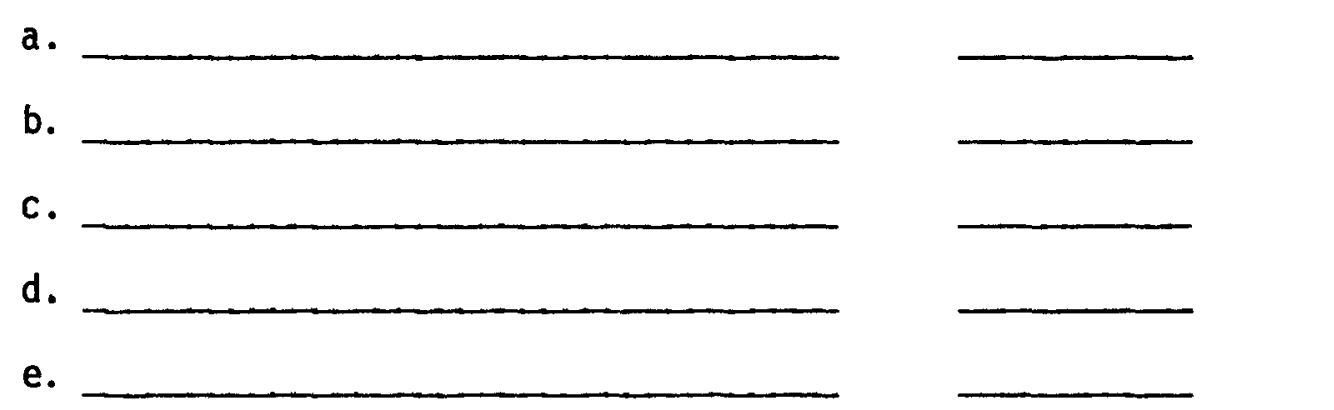

3. Triaxial Seismic Switches
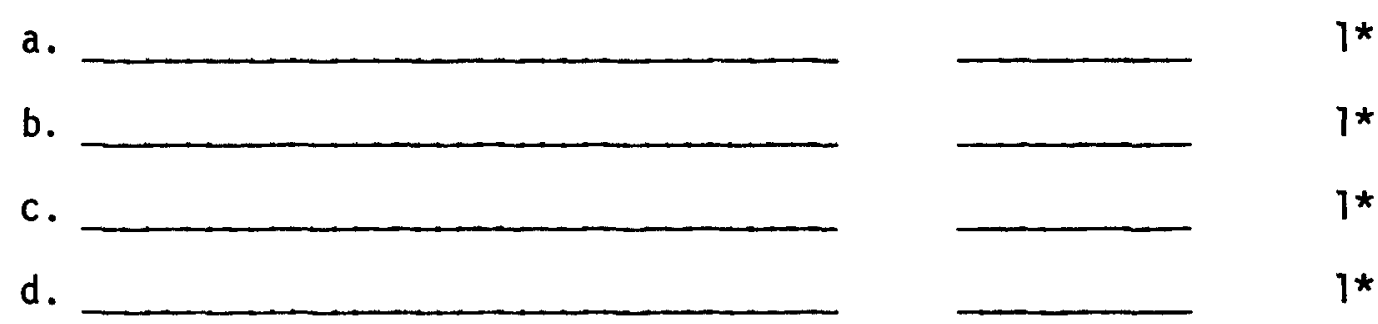

4. Triaxial Response-Spectrum Recorders
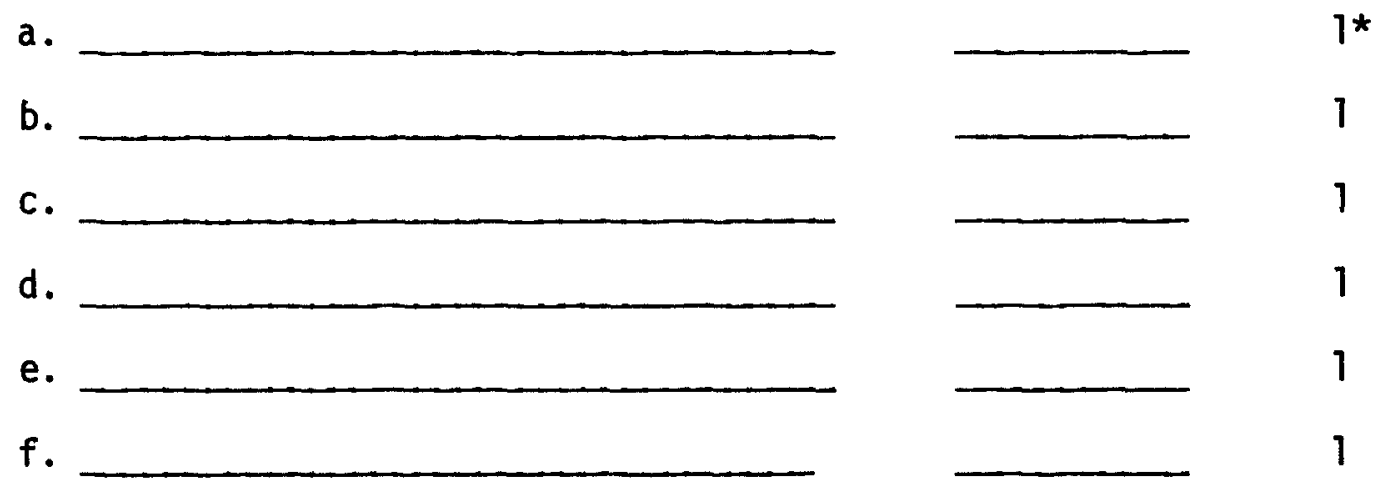

* With reactor control room indication B\&W-STS 
TABLE 4.3-4

SEISMIC MONLTORING INSTRUMENTATION SURVEILLANCE REQUIREMENTS

INSTRUMENTS AND SENSOR LOCATIONS

1. Triaxial Time-History Accelerographs

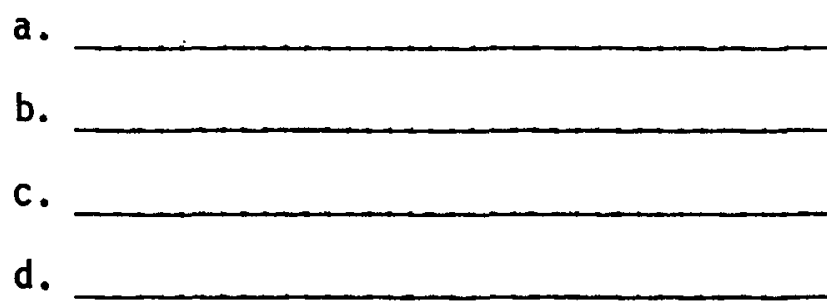

2. Triaxial Peak Accelerographs

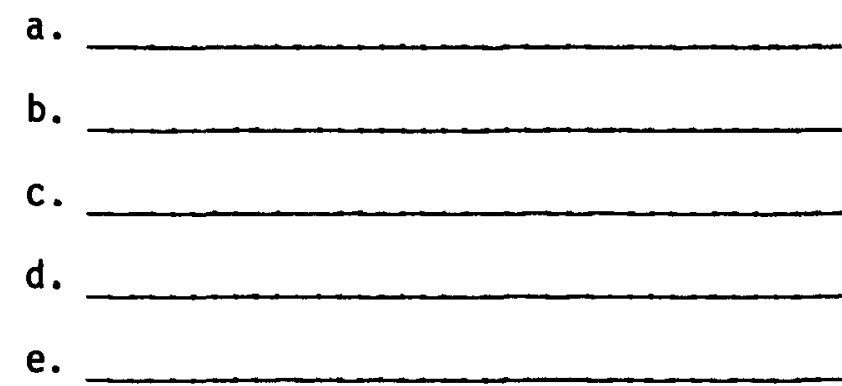

3. Triaxial Seismic Switches

a.

b.

c.

d.

4. Triaxial Response-Spectrum Recorders

$$
\text { a. }
$$

b.

c.

d.

e.

f.

* Except seismic trigger

With reactor control room indication
CHANNEL CHANNEL FUNCTIONAL CHECK CALIBRATION TEST
SA

$S A$

SA

SA

NA

NA

NA

NA

NA

$M * \star$

$M^{* *}$

$M \star \star$

$M \star \star$

$M^{* *}$

R

SA

NA

R

SA

NA

SA

NA

R

SA

NA

R

SA

NA

R

SA 
INSTRUMENTATION

METEOROLOGICAL INSTRUMENTATION

LIMITING CONDITION FOR OPERATION

3.3.3.4 The meteorological monitoring instrumentation channels shown in Table 3.3-8 shall be OPERABLE.

APPLICABILITY: At all times.

ACTION:

a. With one or more required meteorological monitoring channels inoperable for more than 7 days, prepare and submit a Special Report to the Commission pursuant to Specification 6.9 .2 within the next 10 days outiining the cause of the malfunction and the plans for restoring the channel(s) to OPERABLE status.

b. The provisions of Specifications 3.0.3 and 3.0.4 are not applicable.

SURVEILLANCE REQUIREMENTS

4.3.3.4 Each of the above meteorological monitoring instrumentation channels shall be demonstrated OPERABLE by the performance of the CHANNEL CHECK and CHANNEL CALIBRATION operations at the frequencies shown in Table 4.3-5. 
TABLE 3.3-8

METEOROLOGICAL MONITORING INSTRUMENTATION

INSTRUMENT

$$
\text { LOCATION }
$$

1. WIND SPEED
MINIMUM

OPERABLE
a. Nominal Elev.
1
b. Nominal Elev.
1

2. WIND DIRECTION
a. Nominal Elev.
1
b. Nominal Elev.
1

3. AIR TEMPERATURE - DELTA T
a. Nominal Elev.
b. Nominal Elev.

1

1 
TABLE 4.3-5

1. WIND SPEED
a. Nominal
Elev.
b. Nominal
ETev.

D

SA

D

SA

2. WIND DIRECTION
a. Nominal

Elev.

b. Nominal Elev.

3. AIR TEMPERATURE - DELTA T
a. Nominal
Elev.
b. Nominal
Elev.

$\frac{C}{5}$ 
REMOTE SHUTDOWN INSTRUMENTATION

LIMITING CONDITION FOR OPERATION

3.3.3.5 The remote shutdown monitoring instrumentation channels shown in Table 3.3-9 shall be OPERABLE with readouts displayed external to the control room.

APPLICABILITY: MODES 1,2 and 3.

ACTION:

a. With the number of OPERABLE remote shutdown monitoring channels less than required by Table 3.3-9, either restore the inoperable channel to OPERABLE status within 30 days, or be in HOT SHUTDOWN within the next 12 hours.

b. The provisions of Specification 3.0.4 are not applicable.

4.3.3.5 Each remote shutdown monitoring instrumentation channel shall be demonstrated OPERABLE by performance of the CHANNEL CHECK and CHANNEL CALIBRATION operations at the frequencies shown in Table 4.3-6. 
TABLE 3.3-9

$\frac{0}{2}$

REMOTE SHUTDOWN MONITORING INSTRUMENTATION

INSTRUMENT

1. Power Range Nuclear Flux

2. Intermediate Range Nuclear Flux

3. Source Range Nuclear Flux

4. Control Rod Drive Trip Breaker Indication

5. Reactor Coolant Temperature Average

$\stackrel{\omega}{\infty}$

$\stackrel{\omega}{\omega}$

6. Reactor Coolant Flow Rate

7. Pressurizer Pressure

8. Pressurizer Level

9. Steam Generator Pressure

10. Steam Generator Leve1

c 11. Control Rod Position

仿 Limit Switches

미 12. DHR Flow Rate

13. DHR Temperature

14. Auxiliary Feedwater Flow Rate

\begin{tabular}{lc} 
READOUT & MEASUREMENT \\
LOCATION & RANGE \\
\hline
\end{tabular}

MINIMUM

CHANNELS OPERABLE

1

1

1

OPEN-CLOSE

1/trip breaker

1

1

1

1

$1 /$ steam generator

1/steam generator

1 insertion limit switch/rod

1

1

1 


\section{TABLE 4.3-6}

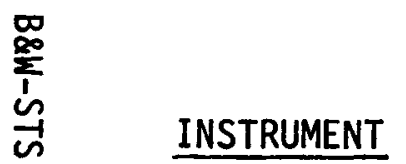

1. Power Range Nuclear Flux

2. Intermediate Range Nuclear Flux

3. Source Range Nuclear Flux

4. Control Rod Drive Trip Breaker Indication $M$

5. Reactor Coolant Temperature-Average $M$

6. Reactor Coolant Flow Rate

7. Pressurizer Pressure

$\stackrel{\omega}{\infty}$

w

$\omega$

8. Pressurizer Leve1

9. Steam Generator Leve]

10. Steam Generator Pressure

11. Control Rod Position Limit Switches

12. DHR Flow Rate

离
$\overrightarrow{0}$
$\frac{\infty}{}$
13. DHR Temperature

14. Auxiliary Feedwater Flow Rate

\begin{tabular}{l} 
CHANNEL \\
CHECK \\
\hline
\end{tabular}

$M$

$M$

$M$

$M$

$M$

$M$

$M$

$M$

$M$

$M$

$M$

$M$

$M$

$M$
CHANNEL

CALIBRATION

Q*

$Q^{*}$

$Q^{*}$

N.A.

R

R

R

R

R

R

R

R

$R$

$R$

*Neutron detectors may be excluded from CHANNEL CALIBRATION. 
INSTRUMENTATION

POST-ACCIDENT INSTRUMENTATION

LIMITING CONDITION FOR OPERATION

3.3.3.6 The post-accident monitoring instrumentation channels shown in Table 3.3-10 shall be OPERABLE.

APPLICABILITY: MODES 1, 2 and 3.

ACTION:

a. With the number of OPERABLE post-accident monitoring channels less than required by Table 3.3-10, either restore the inoperable channel to OPERABLE status within 30 days, or be in HOT SHUTDOWN within the next 12 hours.

b. The provisions of Specification 3.0.4 are not applicable.

SURVE ILLANCE REQUIREMENTS

4.3.3.6 Each post-accident monitoring instrumentation channel shall be demonstrated OPERABLE by performance of the CHANNEL CHECK and CHANNEL CALIBRATION operations at the frequencies shown in Table 4.3-10. 
TABLE $3.3-10$

\section{POST-ACCIDENT MONITORING INSTRUMENTATION}

\section{INSTRUMENT}

1. Power Range Nuclear Flux

2. Reactor Building Pressure

3. Source Range Nuclear Flux

4. Reactor Coolant Outlet Temperature

$\stackrel{\omega}{\Phi}$

$\stackrel{\omega}{\omega}$

5. Reactor Coolant Total Flow Rate

6. RC Loop Pressure

7. Pressurizer Leve1

8. Steam Generator Outlet Pressure

9. Steam Generator Level

E 10. Borated Water Storage Tank Level

$\overrightarrow{0} \quad$ 11. Startup Feedwater Flow Rate
MINIMUM

CHANNELS

OPERABLE

2

2

2

2

2

2

2

2/steam generator

$2 /$ steam generator

2

2 


\section{POST-ACCIDENT MONITORING INSTRUMENTATION SURVEILLANCE REQUIREMENTS}

INSTRUMENT

1. Power Range Nuclear Flux

2. Reactor Building Pressure

3. Source Range Nuclear Flux

4. Reactor Coolant Outlet Temperature

5. Reactor Coolant Total Flow Rate

$\underset{f}{\omega}$

$\underset{1}{1}$

6. RC Loop Pressure

7. Pressurizer Level

8. Steam Generator Outlet Pressure

9. Steam Generator Leve1

10. Borated Water Storage Tank Leve1

至 11 . Startup Feedwater Flow Rate

\begin{tabular}{ccc}
$\begin{array}{c}\text { CHANNEL } \\
\text { CHECK }\end{array}$ & & $\begin{array}{c}\text { CHANNEL } \\
\text { CALIBRATION }\end{array}$ \\
\cline { 1 - 1 }$M$ & & $Q^{*}$ \\
$M$ & $R$ \\
$M$ & $Q^{*}$ \\
$M$ & $R$ \\
$M$ & $R$ \\
$M$ & $R$ \\
$M$ & $R$ \\
$M$ & $R$ \\
$M$ & $R$ \\
$M$ & $R$ \\
$M$ & $R$
\end{tabular}

$\stackrel{\vec{\varphi}}{\infty}$

Neutron detectors may be excluded from CHANNEL CALIBRATION. 
INSTRUMENTATION

CHLORINE DETECTION SYSTEMS

LIMITING CONDITION FOR OPERATION

3.3.3.7 Two independent chlorine detection systems, with their alarm/trip setpoints adjusted to actuate at a chlorine concentration of $\leq 5 \mathrm{ppm}$, shall be OPERABLE.

APPLICABILITY: $1,2,3$ and 4.

ACTION:

a. With one chlorine detection system inoperable, restore the inoperable detection system to OPERABLE status within 7 days or within the next 6 hours initiate and maintain operation of the control room emergency ventilation system in the recirculation mode of operation.

b. With no chlorine detection system OPERABLE, within 1 hour initiate and maintain operation of the control room emergency ventilation system in the recirculation mode of operation.

c. The provisions of Specification 3.0.4 are not applicable.

SURVEILLANCE REQUIREMENTS

4.3.3.7 Each chlorine detection system shall be demonstrated OPERABLE by performance of a CHANNEL CHECK at least once per 12 hours, a CHANNEL FUNCTIONAL TEST at least once per 31 days, and a CHANNEL CALIBRATION at least once per 18 months. 
INSTRUMENTATION

FIRE DETECTION INSTRUMENTATION

LIMITING CONDITION FOR OPERATION

3.3.3.8 As a minimum, the fire detection instrumentation for each fire detection zone shown in Table 3.3-11 shal1 be OPERABLE.

APPLICABILITY: Whenever equipment in that fire detection zone is required to be OPERABLE.

\section{ACTION:}

With one or more of the fire detection instrument(s) shown in Table 3.3-11. inoperable:

a. Within 1 hour establish a fire watch patrol to inspect the zone(s) with the inoperable instrument(s) at least once per hour, and

b. Restore the inoperable instrument(s) to OPERABLE status within 14 days or, in lieu of any other report required by Specification 6.9.1, prepare and submit a Special Report to the Commission pursuant to Specification 6.9 .2 within the next 30 days outlining the action taken, the cause of the inoperability and the plans and schedule for restoring the instrument(s) to OPERABLE status.

c. The provisions of Specifications 3.0.3 and 3.0.4 are not applicable.

SURVEILLANCE REQUIREMENTS

4.3.3.8.1 Each of the above required fire detection instruments shall be demonstrated OPERABLE at least once per 6 months by performance of a CHANNEL FUNCTIONAL TEST.

4.3.3.8.2 The NFPA Code 72D Class A supervised circuits supervision associated with the detector alarms of each of the above required fire detection instruments shal1 be demonstrated OPERABLE. at least once per 6 months.

4.3.3.8.3 The non-supervised circuits between the local panels in Specification 4.3.3.8.2 and the control room shall be demonstrated OPERABLE at least once per 31 days. 


\section{FIRE DETECTION INSTRUMENTS}

\section{INSTRUMENT LOCATION (II lustrative) *}

1. Containment

$$
\begin{array}{ll}
\text { Zone } 1 & \text { Elevation } \\
\text { Zone } 2 & \text { Elevation }
\end{array}
$$

2. Control Room

3. Cable Spreading

$$
\begin{array}{ll}
\text { Zone } 1 & \text { Elevation } \\
\text { Zone } 2 & \text { Elevation }
\end{array}
$$

4. Computer Room

5. Switchgear Room

6. Remote Shutdown Panels

7. Station Battery Rooms

$$
\begin{array}{ll}
\text { Zone } 1 & \text { Elevation } \\
\text { Zone } 2 & \text { Elevation }
\end{array}
$$

8. Turbine

$$
\begin{array}{ll}
\text { Zone } 1 & \text { Elevation } \\
\text { Zone } 2 & \text { Elevation }
\end{array}
$$

9. Diesel Generator

$$
\begin{array}{ll}
\text { Zone } 1 & \text { Elevation } \\
\text { Zone } 2 & \text { Elevation }
\end{array}
$$

10. Diesel Fuel Storage

11. Safety Related Pumps

$$
\begin{array}{ll}
\text { Zone } 1 & \text { Elevation } \\
\text { Zone } 2 & \text { Elevation }
\end{array}
$$

12. Fuel Storage

$$
\begin{array}{ll}
\text { Zone } 1 & \text { Elevation } \\
\text { Zone } 2 & \text { Elevation }
\end{array}
$$

\footnotetext{
*List all detectors in areas required to insure the OPERABILITY of safety related equipment.
} 
INSTRUMENTATION

3/4.3.4 TURB INE OVERSPEED PROTECTION

LIMITING CONDITION FOR OPERATION

3.3.4.1 At least one turbine overspeed protection s.ystem shall be OPERABLE.

APPLICABILITY: MODES 1,2 and 3.

ACTION:

a. With one stop valve or one control valve per high pressure turbine steam lead inoperable or with one reheat stop valve or one reheat intercept valve per low pressure turbine steam lead inoperable, operation may continue for up to 72 hours provided the inoperable valve(s) is restored to OPERABLE status or at least one valve in the affected steam lead is closed; otherwise, isolate the turbine from the steam supply within the next 6 hours.

b. With the above required turbine overspeed protection system otherwise inoperable, within 6 hours either restore the system to OPERABLE status or isolate the turbine from the steam supply.

SURVEILLANCE REQUIREMENTS

4.3.4.1.1 The provisions of Specification 4.0.4 are not applicable.

4.3.4.1.2 The above required turbine overspeed protection system shall be demonstrated OPERABLE:

a. At least once per 7 days by cycling each of the following valves through at least one complete cycle from the running position.

1. (Four) high pressure turbine stop valves.

2. (Four) high pressure turbine control valves.

3. (Four) low pressure turbine reheat stop valves.

4. (Four) low pressure turbine reheat intercept valves. 
b. At least once per 31 days by direct observation of the movement of each of the above valves through one complete cycle from the running position.

c. At least once per 18 months by performance of a CHANNEL CALIBRATION on the turbine overspeed protection systems.

d. At least once per 40 months by disassembling at least one of each of the above valves and performing a visual and surface inspection of valve seats, disks and stems and verifying no unacceptable flaws or corrosion. 
-

○

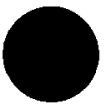




\section{$3 / 4.4$ REACTOR COOLANT SYSTEM \\ REACTOR COOLANT LOOPS}

LIMITING CONDITION FOR OPERATION

3.4.1 Both reactor coolant loops and both reactor coolant pumps in each loop shall be in operation.

APPLICABILITY: As noted below, but excluding MODE 6.*

ACTION:

MODES 1 and 2:

a. With one reactor coolant pump not in operation, STARTUP and POWER OPERATION may be initiated and may proceed provided THERMAL POWER is restricted to less than ( )\% of RATED THERMAL POWER and within 4 hours the setpoints for the following trips have been reduced to the values specified in Specification 2.2.1 for operation with three reactor coolant pumps operating:

1. (Nuclear Overpower).

2. (Nuclear Overpower based on RCS flow and AXIAL POWER IMBALANCE).

3. (Nuclear Overpower based on pump monitors).

b. With one reactor coolant pump in each loop not in operation, STARTUP and POWER OPERATION may be initiated and may proceed provided THERMAL POWER is restricted to less than ( )\% of RATED THERMAL POWER and within 4 hours the setpoints for the following trips have been reduced to the values specified in Specification 2.2.1 for operation with one reactor coolant pump operating in each loop:

1. (Nuclear Overpower).

2. (Nuclear Overpower based on RCS flow and AXIAL POWER IMBALANCE).

3. (Nuclear Overpower Based on pump monitors).

See Special Test Exception 3.10.3. 
REACTOR COOLANT SYSTEM

LIMITING CONDITION FOR OPERATION (Continued)

MODES 3,4 and 5:

a. Operation may proceed provided at least one reactor coolant loop is in operation with an associated reactor coolant pump or decay heat removal pump.

b. The provisions of Specifications 3.0 .3 and 3.0 .4 are not applicable. I

4.4.1 The Reactor Protective Instrumentation channels specified in the applicable ACTION statement above shall be verified to have had their trip setpoints changed to the values specified in Specification 2.2.1 for the applicable number of reactor coolant pumps operating either:

a, Within 4 hours after switching to a different pump combination if the switch is made while operating, or

b. Prior to reactor criticality if the switch is made while shutdown. 
REACTOR COOLANT SYSTEM

SAFETY VALVES - SHUTDOWN

LIMITING CONDITION FOR OPERATION

3.4.2 A minimum of one pressurizer code safety valve shall be OPERABLE with a lift setting of 2500 PSIG $\pm 1 \%$.

APPLICABILITY: MODES 4 and 5.

ACTION:

With no pressurizer code safety valve OPERABLE, immediately suspend all operations involving positive reactivity changes and place an OPERABLE DHR loop into operation in the shutdown cooling mode.

SURVEILLANCE REQUIREMENTS

4.4.2 No additional Surveillance Requirements other than those required by Specification 4.0.5.

*The lift setting pressure shall correspond to ambient conditions of the valve at nominal operating temperature and pressure. 
REACTOR COOLANT SYSTEM

SAFETY VALVES - OPERATING

LIMITING CONDITION FOR OPERATION

3.4.3 All pressurizer code safety valves shall be OPERABLE with a lift setting of 2500 PSIG $\pm 1 \% *$.

APPLICABILITY: MODES 1,2 and 3.

ACTION:

With one pressurizer code safety valve inoperable, either restore the inoperable valve to OPERABLE status within 15 minutes or be in HOT SHUTDOWN within 12 hours.

SURVEILLANCE REQUIREMENTS

4.4.3 No additional Surveillance Requirements other than those required by Specification 4.0 .5 .

*The lift setting pressure shall correspond to ambient conditions of the valve at nominal operating temperature and pressure. 
REACTOR COOLANT SYSTEM

PRESSURIZER

LIMITING CONDITION FOR OPERATION

3.4.4 The pressurizer shall be OPERABLE with:

a. A steam bubble.

b. A water volume between ( ) and ( ) cubic feet.

APPLICABILITY: MODES 1,2 and 3.

ACTION:

With the pressurizer inoperable, be in at least HOT SHUTDOWN with the control rod drive trip breakers open within 12 hours.

SURVEILLANCE REQUIREMENTS

4.4.4 The pressurizer shall be demonstrated OPERABLE by verifying pressurizer level to be within limits at least once per 12 hours. 


\section{REACTOR COOLANT SYSTEM \\ STEAM GENERATORS}

LIMITING CONDITION FOR OPERATION

3.4.5 Each steam generator shall be OPERABLE with a water level between () and $($ ) inches.

APPLICABILITY: MODES $1,2,3$ and 4 .

ACTION:

a. With one or more steam generators inoperable due to steam generator tube imperfections, restore the inoperable generator(s) to OPERABLE status prior to increasing $T_{\text {avg }}$ above $200^{\circ} \mathrm{F}$.

b. With one or more steam generators inoperable due to the water level being outside the limits, be in at least HOT STANDBY within 6 hours and in COLD SHUTDOWN within the next 30 hours.

\section{SURVEILLANCE REQUIREMENTS}

4.4.5.0 Each steam generator shall be demonstrated OPERABLE by performance of the following augmented inservice inspection program and the requirements of Specification 4.0.5.

4.4.5.1. Steam Generator Sample Selection and Inspection - Each steam generator shal7 be determined OPERABLE during shutdown by selecting and inspecting at least the minimum number of steam generators specified in Table 4.4-1.

4.4.5.2 Steam Generator Tube Sample Selection and Inspection - The steam generator tube minimum sample size, inspection result classification, and the corresponding action required shall be as specified in Table 4.4-2. The inservice inspection of steam generator tubes shall be performed at the frequencies specified in Specification 4.4.5.3 and the inspected tubes shall be verified acceptable per the acceptance criteria of Specification 4.4.5.4. The tubes selected for each inservice inspection shall include at least $3 \%$ of the total number of tubes in all steam generators; the tubes selected for these inspections shall be selected on a random basis except:

a. Where experience in similar plants with similar water chemistry indicates critical areas to be inspected, then at least $50 \%$ of the tubes inspected shall be from these critical areas. 
REACTOR COOLANT SYSTEM

SURVEILLANCE REQUIREMENTS (Continued)

b. The first sample of tubes selected for each inservice inspection (subsequent to the preservice inspection) of each steam generator shall include:

1. All nonplugged tubes that previously had detectable wall penetrations $(>20 \%)$.

2. Tubes in those areas where experience has indicated potential problems.

3. A tube inspection (pursuant to Specification 4.4.5.4.a.8) shall be performed on each selected tube. If any selected tube does not permit the passage of the eddy current probe for a tube inspection, this shall be recorded and an adjacent tube shall be selected and subjected to a tube inspection.

c. The tubes selected as the second and third samples (if required by Table 4.4-2) during each inservice inspection may be subjected to a partial tube inspection provided:

1. The tubes selected for these samples include the tubes from those areas of the tube sheet array where tubes with imperfections were previously found.

2. The inspections include those portions of the tubes where imperfections were previously found.

The results of each sample inspection shall be classified into one of the following three categories:

Category

C-1

C-2

\section{Inspection Results}

Less than $5 \%$ of the total tubes inspected are degraded tubes and none of the inspected tubes are defective.

One or more tubes, but not more than $1 \%$ of the total tubes inspected are defective, or between $5 \%$ and $10 \%$ of the total tubes inspected are degraded tubes. 
C-3

More than $10 \%$ of the total tubes inspected are degraded tubes or more than $1 \%$ of the inspected tubes are defective.

Note: In all inspections, previously degraded tubes must exhibit significant (>10\%) further wall penetrations to be included in the above percentage calculations.

4.4.5.3 Inspection Frequencies - The above required inservice inspections of steam generator tubes shall be performed at the following frequencies:

a. The first inservice inspection shall be performed after 6 Effective Ful1 Power Months but within 24 calendar months of initial criticality. Subsequent inservice inspections shall be performed at intervals of not less than 12 nor more than 24 calendar months after the previous inspection. If two consecutive inspections following service under AVT conditions, not including the preservice inspection, result in all inspection results falling into the $\mathrm{C}-1$ category or if two consecutive inspections demonstrate that previously observed degradation has not continued and no additional degradation has occurred, the inspection interval may be extended to a maximum of once per 40 months.

b. If the results of the inservice inspection of a steam generator conducted in accordance with Table 4.4-2 at 40 month intervals fall into Category $\mathrm{C}-3$, the inspection frequency shall be increased to at least once per 20 months. The increase in inspection frequency shall apply until the subsequent inspections satisfy the criteria of Specification 4.4.5.3.a; the interval may then be extended to a maximum of once per 40 months.

c. Additional, unscheduled inservice inspections shall be performed on each steam generator in accordance with the first sample inspection specified in Table 4.4-2 during the shutdown subsequent to any of the following conditions:

1. Primary-to-secondary tubes leaks (not including leaks originating from tube-to tube sheet welds) in excess of the limits of Specification 3.4.6.2.

2. A seismic occurrence greater than the Operating Basis Earthquake. 
REACTOR COOLANT SYSTEM

SURVEILLANCE REQUIREMENTS (Continued)

3. A loss-of-coolant accident requiring actuation of the engineered safeguards.

4. A main steam line or feedwater line break.

\subsubsection{Acceptance Criteria}

a. As used in this Specification:

1. Imperfection means an exception to the dimensions, finish or contour of a tube from that required by fabrication drawings or specifications. Eddy-current testing indications below $20 \%$ of the nominal tube wall thickness, if detectable, may be considered as imperfections.

2. Degradation means a service-induced cracking, wastage, wear or general corrosion occurring on either inside or outside of a tube.

3. Degraded Tube means a tube containing imperfections $\geq 20 \%$ of the nominal wall thickness caused by degradation.

4. \% Degradation means the percentage of the tube wall thickness affected or removed by degradation.

5. Defect means an imperfection of such severity that it exceeds the plugging limit. A tube containing a defect is defective.

6. Plugging Limit means the imperfection depth at or beyond which the tube shall be removed from service because it may become unserviceable prior to the next inspection and is equal to (40)\%* of the nominal tube wall thickness.

7. Unserviceable describes the condition of a tube if it leaks or contains a defect large enough to affect its structural integrity in the event of an Operating Basis Earthquake, a loss-of-coolant accident, or a steam line or feedwater line break as specified in 4.4.5.3.c, above.

8. Tube Inspection means an inspection of the steam generator tube from the point of entry completely to the point of exit.

ॠValue to be determined in accordance with the recommendations of Regulatory Guide 1.121 , August 1976. 
9. Preservice Inspection means an inspection of the full length of each tube in each steam generator performed by eddy current techniques prior to service to establish a baseline condition of the tubing. This inspection shall be performed after the field hydrostatic test and prior to initial POWER OPERATION using the equipment and techniques expected to be used during subsequent inservice inspections.

b. The steam generator shall be determined OPERABLE after completing the corresponding actions (plug all tubes exceeding the plugging limit and all tubes containing through-wall cracks) required by Table 4.4-2.

\subsubsection{Reports}

a. Following each inservice inspection of steam generator tubes, the number of tubes plugged in each steam generator shall be reporte $c$ to the Commission within 15 days.

b. The complete results of the steam generator tube inservice inspection shall be reported on an annual basis for the period in which the inspection was completed. This report shall include:

1. Number and extent of tubes inspected.

2. Location and percent of wa11-thickness penetration for each indication of an imperfection.

3. Identification of tubes plugged.

c. Results of steam generator tube inspections which fall into Category $\mathrm{C}-3$ and require prompt notification of the Commission shall be reported pursuant to Specification 6.9.1 prior to resumption of plant operation. The written followup of this report shall provide a description of investigations conducted to determine cause of the tube degradation and corrective measures taken to prevent recurrence.

4.4.5.6 The steam generator shall be demonstrated OPERABLE by verifying steam generator level to be within limits at least once per 12 hours. 
TABLE 4.4-1

\section{MINIMUM NUMBER OF STEAM GENERATORS TO BE}

INSPECTED DURING INSERVICE INSPECTION

\begin{tabular}{|c|c|c|c|c|c|c|}
\hline Preservice Inspection & \multicolumn{3}{|c|}{ No } & \multicolumn{3}{|c|}{ Yes } \\
\hline No. of Steam Generators per Unit & Two & Three & Four & Two & Three & Four \\
\hline First Inservice Inspection & \multicolumn{3}{|c|}{ All } & One & Two & Two \\
\hline Second \& Subsequent Inservice Inspections & \multicolumn{3}{|c|}{ One ${ }^{1}$} & One ${ }^{3}$ & $\mathrm{One}^{2}$ & $O n e^{3}$ \\
\hline
\end{tabular}

\section{Table Notation:}

1. The inservice inspection may be limited to one steam generator on a rotating schedule encompassing $3 \mathrm{~N} \%$ of the tubes (where $\mathrm{N}$ is the number of steam generators in the plant) if the results of the first or previous inspections indicate that all steam generators are performing in a like manner. Note that under some circumstances, the operating conditions in one or more steam generators may be found to be more severe than those in other steam generators. Under such circum stances the sampla sequence shall be modified to inspect the most severe conditions.

2. The other steam generator not inspected during the first inservice inspection shall be inspected. The third and subsequent inspections should follow the instructions described in 1 above.

3. Each of the other two steam generators not inspected during the first inservice inspections shall be inspected during the second and third inspections. The fourth and subsequent inspections shall follow the instructions described in 1 above. 
TABLE 4.4-2

STEAM GENERATOR TUBE INSPECTION

\begin{tabular}{|c|c|c|c|c|c|c|}
\hline \multicolumn{3}{|c|}{ IST SAMPLE INSPECTION } & \multicolumn{2}{|c|}{ 2ND SAMPLE INSPECTION } & \multicolumn{2}{|c|}{ 3RD SAMPLE INSPECTION } \\
\hline Sample Size & Result & Action Required & Result & Action Required & Result & Action Required \\
\hline \multirow{9}{*}{$\begin{array}{l}\text { A minimum of } \\
S \text { Tubes per } \\
\text { S. G. }\end{array}$} & $c-1$ & None & N/A & N/A & $N / A$ & N/A \\
\hline & \multirow[t]{5}{*}{$c-2$} & \multirow{5}{*}{$\begin{array}{l}\text { Plug defective tubes } \\
\text { and inspect additional } \\
2 \mathrm{~S} \text { tubes in this } \mathrm{S} . \mathrm{G} \text {. }\end{array}$} & $\mathrm{C}-1$ & None & N/A & N/A \\
\hline & & & \multirow{3}{*}{$\mathrm{C}-2$} & \multirow{3}{*}{$\begin{array}{l}\text { Plug defective tubes } \\
\text { and inspect additional } \\
4 \mathrm{~S} \text { tubes in this } \mathrm{S} \text {. G. }\end{array}$} & $\mathrm{C}-1$ & \begin{tabular}{|l|} 
None \\
\end{tabular} \\
\hline & & & & & $\mathrm{C}-2$ & \begin{tabular}{|l} 
Plug defective tubes \\
\end{tabular} \\
\hline & & & & & $C-3$ & $\begin{array}{l}\text { Perform action for } \\
\text { C-3 result of first } \\
\text { sample } \\
\end{array}$ \\
\hline & & & $C-3$ & $\begin{array}{l}\text { Perform action for } \\
\text { C-3 result of first } \\
\text { sample }\end{array}$ & $\mathrm{N} / \mathrm{A}$ & N/A \\
\hline & \multirow[t]{3}{*}{$\mathrm{C}-3$} & \multirow{3}{*}{$\begin{array}{l}\text { Inspect all tubes in } \\
\text { this S. G., plug de- } \\
\text { fective tubes and } \\
\text { inspect } 2 S \text { tubes in } \\
\text { each other S. G. } \\
\text { Prompt notification } \\
\text { to NRC pursuant } \\
\text { to specification } \\
6.9 .1\end{array}$} & \begin{tabular}{|l} 
All other \\
S. G.s are \\
C-1 \\
\end{tabular} & None & N/A & N/A \\
\hline & & & $\begin{array}{l}\text { Some S. G.s } \\
\text { C-2 but no } \\
\text { additional } \\
\text { S. G. are } \\
\mathrm{C}-3 \\
\end{array}$ & $\begin{array}{l}\text { Perform action for } \\
\text { C-2 result of second } \\
\text { sample }\end{array}$ & $N / A$ & N/A \\
\hline & & & $\begin{array}{l}\text { Additional } \\
\text { S. G. is C-3 }\end{array}$ & $\begin{array}{l}\text { Inspect all tubes in } \\
\text { each S. G. and plug } \\
\text { defective tubes. } \\
\text { Prompt notification } \\
\text { to NRC pursuant } \\
\text { to specification } \\
6.9 .1\end{array}$ & $N / A$ & N/A \\
\hline
\end{tabular}

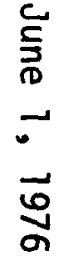

$S=3 \frac{N}{n} \% \begin{gathered}\text { Where } N \text { is the number of steam generators in the unit, and } n \text { is the number of steam generators inspected } \\ \text { during an inspection }\end{gathered}$ 


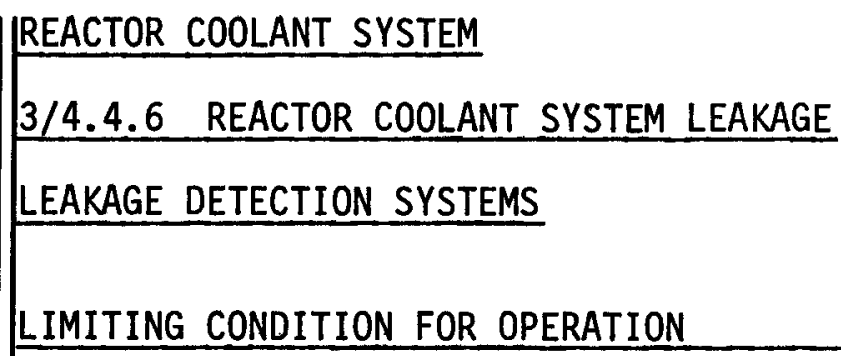

3.4.6.1 The following Reactor Coolant System leakage detection systems Sha11 be OPERABLE:

a. The containment atmosphere (gaseous or particulate) radioactivity monitoring system.

b. The containment sump level and flow monitoring system.

c. Either the (containment air cooler condensate flow rate) or a containment atmosphere (gaseous or particulate) radioactivity monitoring system.

APPLICABILITY: MODES $1,2,3$ and 4.

ACTION:

With only two of the above required leakage detection systems OPERABLE, operation may continue for up to 30 days provided grab samples are obtained and analyzed at least once per 24 hours when the required gaseous and/or particulate radioactivity monitoring system is inoperable; otherwise be in at least HOT STANDBY within the next 6 hours and in COLD SHUTDOWN within the following 30 hours.

SURVEILLANCE REQUIREMENTS

4.4.6.1 The leakage detection systems shall be demonstrated OPERABLE by: 
a. Containment atmosphere (gaseous and/or particulate) monituring system-performance of CHANNEL CHECK, CHANNEL CALIBRATION and CHANNEL FUNCTIONAL TEST at the frequencies specified in Table 4.3-3.

b. Containment sump level and flow monitoring system-performance of CHANNEL CALIBRATION at least once per 18 months.

c. (Specify appropriate surveillance tests depending upon the type of leakage detection system selected.) 
REACTOR COOLANT SYSTEM

OPERATIONAL LEAKAGE

LIMITING CONDITION FOR OPERATION

3.4.6.2 Reactor Coolant System leakage shall be limited to:

a. No PRESSURE BOUNDARY LEAKAGE.

b. 1 GPM UNIDENTIFIED LEAKAGE.

c. 1 GPM total primary-to-secondary leakage through steam generators and 500 gallons per day through the tubes of any one steam generator.

d. 10 GPM IDENTIFIED LEAKAGE from the Reactor Coolant System.

e. ( ) GPM CONTROLLED LEAKAGE at a Reactor Coolant System pressure of $(2230 \pm 20)$ psig.

APPLICABILITY: MODES $1,2,3$ and 4.

ACTION :

a. With any PRESSURE BOUNDARY LEAKAGE, be in at least HOT STANDBY within 6 hours and in COLD SHUTDOWN within the following 30 hours.

b. With any Reactor Coolant System leakage greater than any one of the above 1 imits, excluding PRESSURE BOUNDARY LEAKAGE, reduce the leakage rate to within limits within 4 hours or be in at least HOT STANDBY within the next 6 hours and in COLD SHUTDOWN within the following 30 hours.

SURVEILLANCE REQUIREMENTS

4.4.6.2 Reactor Coolant System leakages shall be demonstrated to be within each of the above limits by:

a. Monitoring the containment atmosphere (gaseous or particulate) radioactivity monitor at least once per 12 hours.

b. Monitoring the containment sump inventory and discharge at least once per 12 hours. 
c. Measurement of the CONTROLLED LEAKAGE to the reactor coolant pump seals when the Reactor Coolant System pressure is $(2230+20)$ psig at least once per 31 days with the modulating valve fully open.

d. Performance of a Reactor Coolant System water inventory balance at least once per 72 hours during steady state operation. 


\section{REACTOR COOLANT SYSTEM}

CHEMISTRY

LIMITING CONDITION FOR OPERATION

3.4.7 The Reactor Coolant System chemistry shall be maintained within the limits specified in Table 3.4-1.

APPLICABILITY: At al1 times.

ACTION:

MODES $1,2,3$ and 4 .

a. With any one or more chemistry parameter in excess of its Steady State Limit but within its Transient Limit, restore the parameter to within its Steady State Limit within 24 hours or be in at least HOT STANDBY within the next 6 hours and in COLD SHUTDOWN within the following 30 hours.

b. With any one or more chemistry parameter in excess of its Transient Limit, be in at least HOT STANDBY within 6 hours and in COLD SHUTDOWN within the following 30 hours.

At all other times:

With the concentration of either chloride or fluoride in the Reactor Coolant System in excess of its Steady State Limit for more than 24 hours or in excess of its Transient Limit, reduce the Reactor Coolant System pressure to < (500) psig, if applicable, and perform an engineering evaluation to determine the effects of the out-of-limit condition on the structural integrity of the Reactor Coolant System; determine that the Reactor Coolant System remains acceptable for continued operation prior to increasing the system pressure above (500) psig or prior to proceeding to MODE 4.

\section{SURVEILLANCE REQUIREMENTS}

4.4.7 The Reactor Coolant System chemistry shall be determined to be within the limits by analysis of those parameters at the frequencies specified in Table 4.4-3. 
TABLE 3.4-1

\section{REACTOR COOLANT SYSTEM}

\section{CHEMISTRY LIMITS}

PARAMETER

DISSOLVED OXYGEN*

CHLORIDE

FLUORIDE
STEADY STATE

LIMIT

$\leq 0.10 \mathrm{ppm}$

$\leq 0.15 \mathrm{ppm}$

$\leq 0.15 \mathrm{ppm}$
TRANS IENT

LIMIT

$\leq 1.00 \mathrm{ppm}$

$\leq 1.50 \mathrm{ppm}$

$\leq 1.50 \mathrm{ppm}$

*Limit not applicable with $\mathrm{T}_{\text {avg }} \leq 250^{\circ} \mathrm{F}$. 
TABLE 4.4-3

REACTOR COOLANT SYSTEM

\section{CHEMISTRY LIMITS SURVEILLANCE REQUIREMENTS}

PARAMETER

DISSOLVED OXYGEN*

CHLORIDE

FLUORIDE

${ }^{\star}$ Not required with $T_{\text {avg }} \leq 250^{\circ} \mathrm{F}$.
SAMPLE AND ANALYSIS FREQUENCY

At least once each 72 hours

At least once each 72 hours

At least once each 72 hours 
SPECIFIC ACTIVITY

LIMITING CONDITION FOR OPERATION

3.4.8 The specific activity of the primary coolant shall be limited to:

a. $\leq 1.0 \mu \mathrm{Ci} / \mathrm{gram}$ DOSE EQUIVALENT I-131.

b. $\leq 100 / \overline{\mathrm{E}} \mu \mathrm{Ci} / \mathrm{gram}$.

APPLICABILITY: MODES $1,2,3,4$ and 5.

ACTION:

MODES 1,2 and $3^{*}$.

a. With the specific activity of the primary coolant $>1.0 \mu \mathrm{Ci} / \mathrm{gram}$ DOSE EQUIVALENT I-131 but within the allowable limit (below and to the left of the line) shown on Figure 3.4-1, operation may continue for up to 48 hours provided that the cumulative operating time under these circumstances does not exceed 800 hours in any consecutive 12 months period. With the total cumulative operating time at a primary coolant specific activity $>1.0 \mu \mathrm{Ci} / \mathrm{gram}$ DOSE EQUIVALENT I-131 exceeding 500 hours in any consecutive six month period, prepare and submit a Special Report to the Commission pursuant to Specification 6.9.2 within 30 days indicating the number of hours of operation above this limit. The provisions of Specification 3.0.4 are not applicable.

b. With the specific activity of the primary coolant $>1.0 \mu \mathrm{Ci} / \mathrm{gram}$ DOSE EQUIVALENT I-131 for more than 48 hours during one continuous time interval or exceeding the limit line shown on Figure 3.4-1, be in at least HOT STANDBY with $\mathrm{T}_{\text {avg }}<(500)^{\circ} \mathrm{F}$ within 6 hours.

c. With the specific activity of the primary coolant $>100 / \overline{\mathrm{E}} \mu \mathrm{Ci} / \mathrm{gram}$, be in at least HOT STANDBY with $\mathrm{T}_{\text {avg }}<(500)^{\circ} \mathrm{F}$ within 6 hours.

MODES $1,2,3,4$ and 5 :

a. With the specific activity of the primary coolant $>1.0 \mu \mathrm{Ci} / \mathrm{gram}$ DOSE EQUIVALENT I-131 or $>100 / \bar{E} \mu \mathrm{Ci} / \mathrm{gram}$, perform the sampling and analys is requirements of item 4 a) of Table 4.4-4 until the specific activity of the primary coolant is restored to within its 1 imits. A REPORTABLE OCCURRENCE shall be prepared and submitted to the Commission pursuant to Specification 6.9.1. This report shall contain the results of the specific activity analyses together with the following information:

${ }^{* W i t h ~} \mathrm{~T}_{\text {avg }} \geq(500)^{\circ} \mathrm{F}$. 


\section{REACTOR COOLANT SYSTEM}

ACTION: (Continued)

1. Reactor power history starting 48 hours prior to the first sample in which the limit was exceeded.

2. Fuel burnup by core region.

3. Clean-up flow history starting 48 hours prior to the first sample in which the 1 imit was exceeded.

4. History of de-gassing operations, if any, starting 48 hours prior to the first sample in which the limit was exceeded.

5. The time duration when the specific activity of the primary coolant exceeded $1.0 \mu \mathrm{Ci} /$ gram DOSE EQUIVALENT I-131.

4.4.8 The specific activity of the primary coolant shall be determined to be within the limits by performance of the sampling and analysis program of Table 4.4-4. 
TABLE 4.4-4

是

\section{PRIMARY COOLANT SPECIFIC ACTIVITY SAMPLE}

\section{AND ANALYSIS PROGRAM}

TYPE OF MEASUREMENT

AND ANALYSIS

1. Gross Activity Determination

2. Isotopic Analysis for DOSE EQUIVALENT I-131 Concentration

$\frac{\omega}{+\infty}$

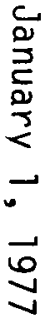

SAMPLE AND

ANALYSIS FREQUENCY

At least once each 72 hours

1 per 14 days

1 per 6 months*

a) Once per 4 hours, whenever the specific activity exceeds $1.0 \mu \mathrm{C} i$ /gram DOSE EQUIVALENT I-131 or $100 / \bar{E} \mu \mathrm{Ci} /$ gram.

b) One sample between 2 and 6 hours following a THERMAL POWER change exceeding 15 percent of the RATED THERMAL POWER within a one hour period.
MODES IN WHICH SAMPLE AND ANALYSIS REQUIRED

$1,2,3,4$

1

1

$1^{\#}, 2^{\#}, 3^{\#}, 4^{\#}, 5^{\#}$

$1,2,3$

\#Until the specific activity of the primary coolant system is restored within its 1 imits.

* Sample to be taken after a minimum of 2 EFPD and 20 days of POWER OPERATION have elapsed since the reactor was last subcritical for 48 hours or longer. 


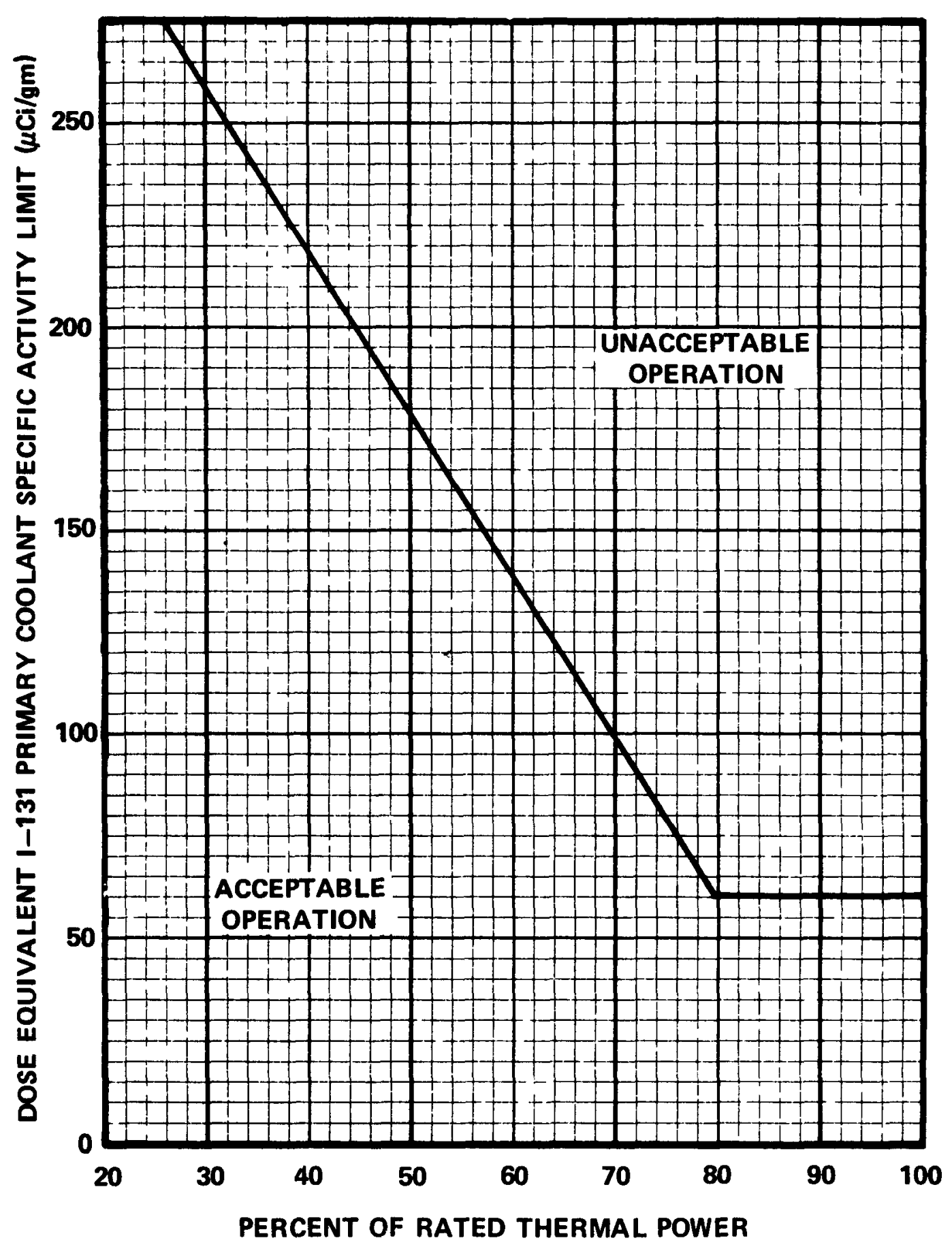

FIGURE 3.4-1

DOSE EQUIVALENT I-131 Primary Coolant Specific Activity Limit Versus Percent of RATED THERMAL POWER with the Primary Coolant Specific Activity $>1.0 \mu \mathrm{Ci} /$ gram Dose Equivalent I-131 
REACTOR COOLANT SYSTEM

3/4.4.9 PRESSURE/TEMPERATURE LIMITS

REACTOR COOLANT SYSTEM

LIMITING CONDITION FOR OPERATION

3.4.9.1 The Reactor Coolant System (except the pressurizer) temperature and pressure shall be limited in accordance with the limit lines shown on Figures 3.4-2 and 3.4-3 during heatup, cooldown, criticality, and inservice leak and hydrostatic testing with:

a. A maximum heatup of $(100)^{\circ} \mathrm{F}$ in any one hour period.

b. A maximum cooldown of $(100)^{\circ} \mathrm{F}$ in any one hour period.

APPLICABILITY: At all times.

ACTION:

With any of the above limits exceeded, restore the temperature and/or pressure to within the limits within 30 minutes; perform an engineering evaluation to determine the effects of the out-of-limit condition on the fracture toughness properties of the Reactor Coolant System; determine that the Reactor Coolant System remains acceptable for continued operation or be in at least HOT STANDBY within the next 6 hours and reduce RCS $\mathrm{T}$ and pressure to less than $200^{\circ} \mathrm{F}$ and $500 \mathrm{psig}$, respectively, within the following 30 hours.

SURVEILLANCE REQUIREMENTS

4.4.9.1.1 The Reactor Coolant System temperature and pressure shall be determined to be within the limits at least once per 30 minutes during system heatup, cooldown, and inservice leak and hydrostatic testing operations.

4.4.9.1.2 The reactor vessel material irradiation surveillance specimens shall be removed and examined, to determine changes in material properties, at the intervals shown in Table 4.4-5. The results of these examinations shall be used to update Figures 3.4-2 and 3.4-3. 


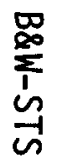

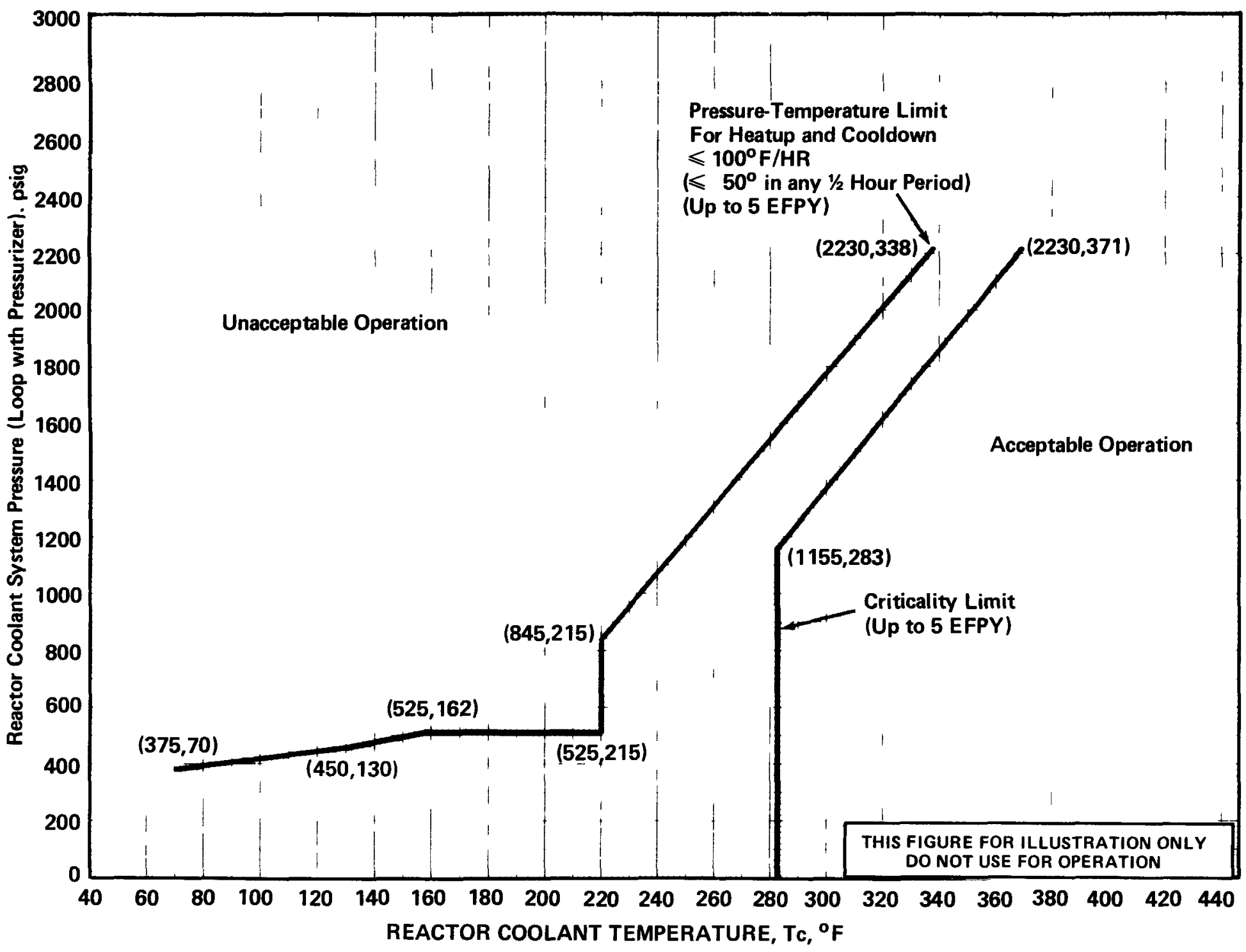

FIGURE 3.4-2. REACTOR COOLANT SYSTEM PRESSURE-TEMPERATURE LIMITS FOR HEATUP AND COOLDOWN AND CORE CRITICALITY 


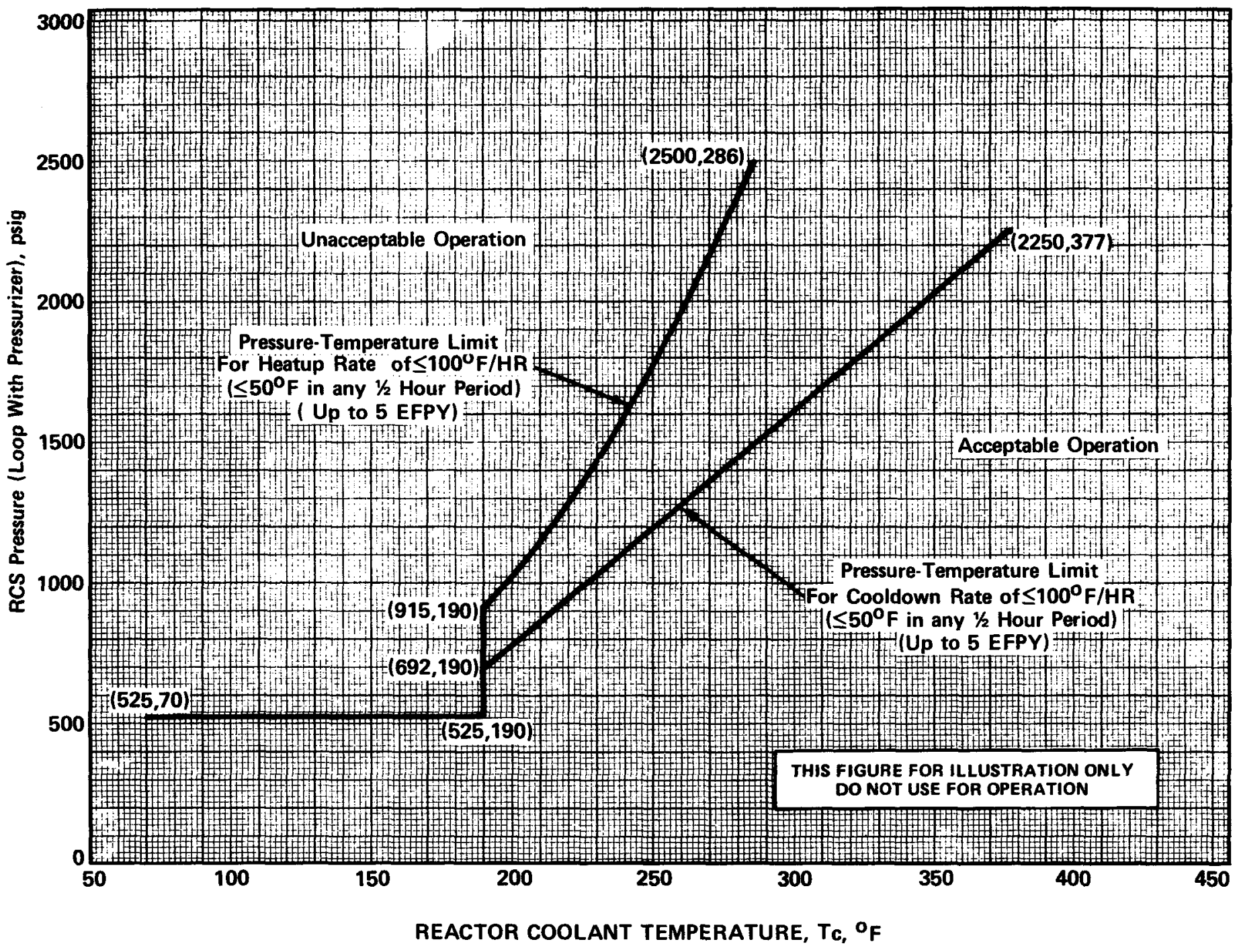

Figure 3.4-3

Reactor Coolant System Pressure Temperature Limits for Inservice Leak and Hydrostatic Tests 



\section{REACTOR COOLANT SYSTEM}

PRESSURIZER

LIMITING CONDITION FOR OPERATION

3.4.9.2 The pressurizer temperature shall be limited to:

a. A maximum heatup and cooldown of $100^{\circ} \mathrm{F}$ in any one hour period.

b. A maximum spray water temperature differential of $(410)^{\circ} \mathrm{F}$.

APPLICABILITY: At all times.

ACTION:

With the pressurizer temperature limits in excess of any of the above 1 imits, restore the temperature to within limits within 30 minutes; perform an engineering evaluation to determine the effects of the out-oflimit condition on the fracture toughness properties of the pressurizer; determine that the pressurizer remains acceptable for continued operation or be in at least HOT STANDBY within the next 6 hours and reduce pressurizer pressure to less than 500 psig, within the following 30 hours.

SURVEILLANCE REQUIREMENTS

4.4.9.2 The pressurizer temperature shall be determined to be within the limits at least once per 30 minutes during system heatup or cooldown. The spray water temperature differential shall be determined to be within the limit once per 12 hours during auxiliary spray operation. 
REACTOR COOLANT SYSTEM

3.4.10 STRUCTURAL INTEGRITY

ASME CODE CLASS 1,2 and 3 COMPONENTS

LIMITING CONDITION FOR OPERATION

3.4.10.1 The structural integrity of ASME Code Class 1,2 and 3 components shall be maintained in accordance with Specification 4.4.10.1.

APPLICABILITY: A11 MODES.

ACTION:

a. With the structural integrity of any ASME Code Class 1 component(s) not conforming to the above requirements, restore the structural integrity of the affected component(s) to within its limit or isolate the affected component(s) prior to increasing the Reactor Coolant System temperature more than $50^{\circ} \mathrm{F}$ above the minimum temperature required by NDT considerations.

b. With the structural integrity of any ASME Code Class 2 component(s) not conforming to the above requirements, restore the structural integrity of the affected component(s) to within its limit or isolate the affected component(s) prior to increasing the Reactor Coolant System temperature above $200^{\circ} \mathrm{F}$.

c. With the structural integrity of any ASME Code Class 3 component(s) not conforming to the above requirements, restore the structural integrity of the component(s) to within its limit or isolate the affected component(s) from service.

d. The provisions of Specification 3.0.4 are not applicable.

SURVE ILLANCE REQUIREMENTS

4.4.10.1 In addition to the requirements of Specification 4.0.5:

a. The reactor coolant pump flywheels shall be inspected per the recommendations of Regulatory Position C.4.b. of Regulatory Guide 1.14, Revision 1, August 1975. 
b. Each internals vent valve shall be demonstrated OPERABLE at least once per 18 months during shutdown, by:

1. Verifying through visual inspection that the valve body and valve disc exhibit no abnormal degradation.

2. Verifying the valve is not stuck in an open position.

3. Verifying through manual actuation that the valve is fully open when a force of $\leq(400)$ lbs. is applied vertically upward. 
3/4.5 EMERGENCY CORE COOLING SYSTEMS (ECCS)

CORE FLOODING TANKS

LIMITING CONDITION FOR OPERATION

3.5.1 Each reactor coolant system core flooding tank shall be OPERABLE with:

a. The isolation valve open.

b. A contained borated water volume between ( ) and ( ) cubic feet of borated water.

c. Between (2270) and ( ) ppm of boron.

d. A nitrogen cover-pressure of between (575) and (625) psig.

APPLICABILITY: MODES 1,2 and $3^{*}$.

ACTION:

a. With one core flooding tank inoperable, except as a result of a closed isolation valve, restore the inoperable tank to OPERABLE status within one hour or be in HOT SHUTDOWN within the next 12 hours.

b. With any core flooding tank inoperable due to the isolation valve being closed, either immediately open the isolation valve or be in HOT STANDBY within one hour and be in HOT SHUTDOWN within the next 12 hours.

SURVEILLANCE REQUIREMENTS

4.5.1:1 Each core flooding tank shall be demonstrated OPERABLE:

a. At least once per 12 hours by:

1. Verifying the contained borated water volume and nitrogen cover-pressure in the tanks.

2. Verifying that each tank isolation valve is open.

*With Reactor Coolant pressure $>(800)$ psig. 
EMERGENCY CORE COOLING SYSTEMS

SURVEILLANCE REQUIREMENTS (Continued)

b. At least once per 31 days and within 6 hours of each solution volume increase of $\geq$ ( $1 \%$ of tank volume), by verifying the boron concentration of the tank solution.

c. At least once per 31 days by verifying that power to the isolation valve operator is disconnected by removal of the breaker from the circuit.

d. At least once per 18 months by verifying that each core flooding tank isolation valve opens automatically and is interlocked against closing:

1. Whenever the Reactor Coolant System pressure exceeds psig.

2. Upon receipt of a (safety injection test) signal.

4.5.1.2. Each core flooding tank water level and pressure channel shall be demonstrated OPERABLE:

a. At least once per 31 days by the performance of a CHANNEL FUNCTIONAL TEST.

b. At least once per 18 months by the performance of a CHANNEL CALIBRATION. 


\section{EMERGENCY CORE COOLING SYSTEMS}

ECCS SUBSYSTEMS $-\mathrm{T}_{\mathrm{avg}} \geq(305)^{\circ} \mathrm{F}$

LIMITING CONDITION FOR OPERATION

3.5.2 Two independent ECCS subsystems shall be OPERABLE with each subsystem comprised of:

a. One OPERABLE high pressure injection (HPI) pump.

b. One OPERABLE low pressure injection (LPI) pump.

c. One OPERABLE decay heat cooler.

d. An OPERABLE flow path capable of taking suction from the borated water storage tank (BWST) on a safety injection signal and automatically transferring suction to the containment sump on a borated water storage tank low level signal during the recirculation phase of operation.

APPLICABILITY: MODES 1,2 and 3.

ACTION:

a. With one ECCS subsystem inoperable, restore the inoperable subsystem to OPERABLE status within 72 hours or be in HOT SHUTDOWN within the next 12 hours.

b. In the event the ECCS is actuated and injects water into the Reactor Coolant System, a Special Report shall be prepared and submitted to the Commission pursuant to Specification 6.9.2 within 90 days describing the circumstances of the actuation and the total accumulated actuation cycles to date. 
EMERGENCY CORE COOLING SYSTEMS

SURVEILLANCE REQUIREMENTS

4.5.2 Each ECCS subsystem shall be demonstrated OPERABLE:

a. At least once per 12 hours by verifying that the following valves are in the indicated positions with power to the valve operators removed:

Valve Number Valve Function Valve Position

a.

b.

c.

b. At least once per 31 days by:

1. Verifying that the LP injection cross-over valves are locked, sealed or otherwise secured in their throttled position.

2. Verifying that each valve (manual, power operated or automatic) in the flow path that is not locked, sealed or otherwise secured in position, is in its correct position.

c. By a visual inspection which verifies that no loose debris (rags, trash, clothing, etc.) is present in the containment which could be transported to the containment sump and cause restriction of the pump suction during LOCA conditions. This visual inspection shall be performed:

1. For all accessible areas of the containment prior to establishing CONTAINMENT INTEGRITY.

2. Of the areas affected within containment at the completion of each containment entry when CONTAINMENT INTEGRITY is established.

d. At least once per 18 months by:

1. Verifying automatic isolation and interlock action of the DHR system from the Reactor Coolant System when the Reactor Coolant System pressure is $\geq \ldots$ psig. 
EMERGENCY CORE COOLING SYSTEMS

SURVEILLANCE REQUIREMENTS (Continued)

2. A visual inspection of the containment emergency sump which verifies that the subsystem suction inlets are not restricted by debris and that the sump components (trash racks, screens, etc.) show no evidence of structural distress or corrosion.

3. Verifying a total leak rate $\leq$ (6) gallons per hour for the LPI system at:

a) Normal operating pressure of $\geq(350)$ psig for those parts of the system downstream of the pump suction isolation valve.

b) $\geq$ (55) psig for the piping from the containment emergency sump isolation valve to the pump suction isolation valve.

e. At least once per 18 months, during shutdown, by

1. Verifying that each automatic valve in the flow path actuates to its correct position on a (safety injection test) signal.

2. Verifying that each HPI and LPI pump test starts automatically upon receipt of a (safety injection test) signal.

f. By verifying that each of the following pumps develops the indicated discharge pressure on recirculation flow when tested pursuant to Specification 4.0.5.

1. High pressure injection pump $\geq \ldots$ psig.

2. Low pressure injection pump $\geq \ldots$ psig. 
*g. By verifying the correct position of each electrical and/or mechanical position stop for the following ECCS throttle valves:

1. Within 4 hours following completion of each valve stroking operation or maintenance on the valve when the ECCS subsystems are required to be OPERABLE.

2. At least once per 18 months.

HPI System

Valve Number

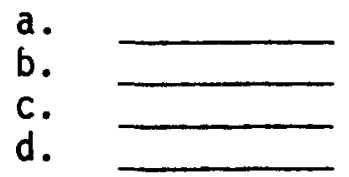

LPI System

Vaive Number

a.

b.

c.

d.

*h. By performing a flow balance test, during shutdown, following completion of modifications to the ECCS subsystems that alter the subsystem flow characteristics and verifying the following flow rates:

HPI System - Single Pump
a. Injection Leg $1, \geq$
b. Injection Leg $2, \geq$
c. Injection Leg $3, \geq$
d. Injection Leg $4, \geq$

$\mathrm{gpm}$
$-\mathrm{gpm}$
$\mathrm{gpm}$
$\mathrm{gpm}$ gpm $\mathrm{gpm}$ $\mathrm{gpm}$

LPI System - Single Pump

a. Injection Leg $1, \geq$

b. Injection Leg $2, \geq$

c. Injection Leg $3, \geq$

d. Injection Leg $4, \geq$

* Required if ECCS uses valves to throttle flow. 
EMERGENCY CORE COOLING SYSTEMS

ECCS SUBSYSTEMS - Tavg $<(305)^{\circ} \mathrm{F}$

LIMITING CONDITION FOR OPERATION

3.5.3 As a minimum, one ECCS subsystem comprised of the following shal1 be OPERABLE:

a. One OPERABLE high pressure injection (HPI) pump.

b. One OPERABLE -low pressure injection (LPI) pump.

c. One OPERABLE decay heat cooler.

d. An OPERABLE flow path capable of taking suction from the borated water storage tank (BWST) and transferring suction to the containment emergency sump.

APPLICABILITY: MODE 4.

ACTION:

a. With no ECCS subsystem OPERABLE because of the inoperability of either the HPI pump or the flow path from the borated water storage tank, restore at least one ECCS subsystem to OPERABLE status within one hour or be in COLD SHUTDOWN within the next 20 hours.

b. With no ECCS subsystem OPERABLE because of the inoperability of either the decay heat cooler or LPI pump, restore at least one ECCS subsystem to OPERABLE status or maintain the Reactor Coolant System $\mathrm{T}_{\text {avg }}$ less than $(305)^{\circ} \mathrm{F}$ by use of alternate heat removal methods. ${ }^{\text {avg }}$

c. In the event the ECCS is actuated and injects water into the reactor coolant system, a Special Report shall be prepared and submitted to the Commission pursuant to Specification 6.9.2 within 90 days describing the circumstances of the actuation and the total accumulated actuation cycles to date.

SURVEILLANCE REQUIREMENTS

4.5.3 The ECCS subsystems shall be demonstrated OPERABLE per the applicable Surveillance Requirements of (4.5.2). 
EMERGENCY CORE COOLING SYSTEMS

BORATED WATER STORAGE TANK

LIMITING CONDITION FOR OPERATION

3.5.4 The borated water storage tank (BWST) shall be OPERABLE with:

a. A contained borated water volume of between $(360,000)$ and ) gallons.

b. Between (1800) and ( ) ppm of boron.

c. A minimum water temperature of $(35)^{\circ} \mathrm{F}$.

APPLICABILITY: MODES $1,2,3$ and 4.

ACTION:

With the borated water storage tank inoperable, restore the tank to OPERABLE status within one hour or be in at least HOT STANDBY within the next 6 hours and in COLD SHUTDOWN within the following 30 hours.

SURVEILLANCE REQUIREMENTS

4.5.4 The BWST sha11 be demonstrated OPERABLE:

a. At least once per 7 days by:

1. Verifying the contained borated water volume in the tank.

2. Verifying the boron concentration of the water.

b. At least once per 24 hours by verifying the water temperature when (outside) air temperature $<35^{\circ} \mathrm{F}$. 
SECTION $3 / 4.6 \mathrm{~J}$

CONTAINMENT SYSTEMS SPECIFICATIONS

FOR

BABCOCK AND WILCOX

ATMOSPHERIC TYPE CONTAINMENT 


$3 / 4.6$ CONTAINMENT SYSTEMS
CONT.6.1 PRIMARY CONTAINMENT
LIMITING CONDITION FOR OPERATION

3.6.1.1 Primary CONTAINMENT INTEGRITY shall be maintained. APPLICABILITY: MODES $1,2,3$ and 4 .

ACTION:

Without primary CONTAINMENT INTEGRITY, restore CONTAINMENT INTEGRITY within one hour or be in at least HOT STANDBY within the next 6 hours and in COLD SHUTDOWN within the following 30 hours.

SURVEILLANCE REQUIREMENTS

4.5.1.1 Primary CONTAINMENT INTEGRITY shall be demonstrated:

a. At least once per 31 days by verifying that a11 penetrations* not capable of being closed by OPERABLE containment automatic isolation valves and required to be closed during accident conditions are closed by valves, blind flanges, or deactivated automatic valves secured in their positions, except as provided in Table 3.6-1 of Specification (3.6.4.1).

b. By verifying that each containment air lock if OPERABLE per Specification (3.6.1.3).

c. After each closing of the equipment hatch, by leak rate testing the equipment hatch seals with gas at $\mathrm{Pa}(50 \mathrm{psig})$ and verifying that when the measured leakage rate for these seals is added to the leakage rates determined pursuant to Specification 4.6.1.2.d for all other Type B and C penetrations, the combined leakage rate is $\leq 0.60 \mathrm{La}$.

*Except valves, blind flanges, and deactivated automatic valves which are located inside the containment and are locked, sealed, or otherwise secured in the closed position. These penetrations shall be verified closed during each COLD SHUTDOWN except that verification of these penetrations being closed need not be performed more often than once per 92 days. 
CONTAINMENT SYSTEMS

CONTAINMENT LEAKAGE

LIMITING CONDITION FOR OPERATION

3.6.1.2 Containment leakage rates shall be limited to:

a. An overall integrated leakage rate of:

1. $\leq L_{2},(0.20)$ percent by weight of the containment air per $\overline{2} 4$ hours at $P_{a},(50)$ psig, or

2. $\leq L_{t},(0.10)$ percent by weight of the containment air per 24 hours at a reduced pressure of $P_{t},(25)$ psig.

b. A combined leakage rate of $\leq 0.60 \mathrm{~L}$ for al1 penetrations and valves subject to Type $B$ and $C$ tests, when pressurized to $P_{a}$.

APPLICABILITY: MODES $1,2,3$ and 4.

ACTION:

(a) With the measured overall integrated leakage rate exceeding $0.75 \mathrm{~L}$ or $0.75 \mathrm{~L}$, as applicable, restore the overall integrated leakage rate to $\leq 0.75 \mathrm{~L}$ or $\leq 0.75 \mathrm{~L}$, as applicable, prior to increasing the Reactor ${ }^{a}$ Coolant system temperature above $200^{\circ} \mathrm{F}$.

(b) With the combined leakage rate for all penetrations and valves subject to Type $B$ and $C$ tests exceeding $0.60 \mathrm{~L}_{a}$, restore the leakage rate to within the limit prior to increasing the Reactor Coolant System temperature above $200^{\circ} \mathrm{F}$.

SURVEILLANCE REQUIREMENTS

4.6.1.2 The containment leakage rates sha11 be demonstrated at the following test schedule and shall be determined in conformance with the criteria specified in Appendix J of 10 CFR 50 using the methods and provisions of ANSI N45.4 - 1972:

a. Three Type A tests (Overa11 Integrated Containment Leakage Rate) shall be conducted at $40+10$ month intervals during shutdown at either $P_{a}$, (50) psig, or at $P_{t},(25)$ psig, during shall be conducted durring the shutdown for the 10-year plant inservice inspection. 
b. If any periodic Type $A$ test fails to meet either $.75 \mathrm{~L}$ or $.75 L_{t}$, the test schedule for subsequent Type $A$ test sha11 be reviewed and approved by the Commission. If two consecutive Type A tests fail to meet either $.75 \mathrm{~L}_{a}$ or $.75 \mathrm{~L}_{t}$, a Type $A$ test shall be performed at least every 18 months until two consecutive Type A tests meet either $.75 \mathrm{~L}_{\mathrm{a}}$ or $.75 \mathrm{~L}_{t}$ at which time the above test schedule may be resumed.

c. The accuracy of each Type A test shall be verified by a supplemental test which:

1. Confirms the accuracy of the Type A test by verifying that the difference between supplemental and Type $A$ test data is within $0.25 \mathrm{~L}_{a}$ or $0.25 \mathrm{~L}_{t}$.

2. Has a duration sufficient to establish accurately the change in leakage rate between the Type $A$ test and the supplemental test.

3. Required the quantity of gas injected into the containment or bled from the containment during the supplemental test to be equivalent to at least 25 percent of the total measured leakage at $\mathrm{P}_{\mathrm{a}},(50) \mathrm{psig}$, or $\mathrm{P}_{t},(25)$ psig.

d. Type $B$ and $C$ tests shall be conducted with gas at $P$ (50) psig at intervals no greater than 24 months except for tests involving:

1. Air locks.

2. Penetrations using continuous leakage monitoring systems.

3. Valves pressurized with fluid from a seal system.

e. Air locks shall be tested and demonstrated OPERABLE per Surveillance Requirement (4.6.1.3).

f. Type B periodic tests are not required for penetrations continuously monitored by the Containment Isolation Valve and Channel Weld Pressurization Systems, provided the systems are OPERABLE per Surveillance Requirement (4.6.1.4). 
g. Leakage from isolation valves that are sealed with fluid from a seal system may be excluded, subject to the provisions of Appendix J, Section III.C.3, when determining the combined leakage rate provided the seal system and valves are pressurized to at least $1.10 \mathrm{P}$, (55) psig, and the seal system capacity is adequate to maintain system pressure for at least 30 days.

h. Type $B$ tests for penetrations employing a continuous leakage monitoring system shall be conducted at $P_{\text {, }},(50)$ psig, at intervals no greater than once per 3 years.

i. All test leakage rates shall be calculated using observed data converted to absolute values. Error analyses shall be performed to select a balanced integrated leakage measurement system.

j. The provisions of Specification 4.0.2 are not applicable. 
CONTAINMENT SYSTEMS

CONTAINMENT AIR LOCKS

LIMITING CONDITION FOR OPERATION

3.6.1.3 Each containment air lock shall be OPERABLE with:

a. Both doors closed except when the air lock is being used for normal transit entry and exit through the containment, then at least one air lock door shall be closed.

b. An overall air lock leakage rate of $\leq 0.05 \mathrm{~L}_{a}$ at $\mathrm{P}_{\mathrm{a}},(50)$ psig. APPLICABILITY: MODES $1,2,3$ and 4 .

ACTION:

a. With one containment air lock door inoperable:

1. Maintain at least the OPERABLE air lock door closed and either restore the inoperable air lock door to OPERABLE status within 24 hours or lock the OPERABLE air lock door closed.

2. Operation may then continue until performance of the next required overall air lock leakage test provided that the OPERABLE air lock door is verified to be locked closed at least once per 31 days.

3. Otherwise, be in at least HOT STANDBY within the next 6 hours and in COLD SHUTDOWN within the following 30 hours.

4. The provisions of Specification 3.0.4 are not applicable.

b. With the containment air lock inoperable, except as the result of an inoperable air lock door, maintain at least one air lock door closed; restore the inoperable air lock to OPERABLE status within 24 hours or be in at least HOT STANDBY within the next 6 hours and in COLD SHUTDOWN within the following 30 hours.

*Exemption to Appendix "J" of 10 CFR 50. 
-

○

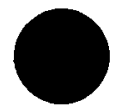


CONTAINMENT SYSTEMS

CONTAINMENT AIRLOCKS

SURVEILLANCE REQUIREMENTS

4.6.1.3 Each containment air'lock shall be demonstrated OPERABLE:

a. *After each opening, except when the air lock is being used for multiple entries, then at least once per 72 hours, by verfiying (no detectable) seal leakage by pressure decay when the volume between the door seals is pressurized to $\geq \mathrm{P}_{\mathrm{a}}$, (50) psig, for at least 15 minutes.

b. At least once per 6 months by conducting an overall air lock leakage test at $P_{3},(50)$ psig, and by verifying that the overall air lock leakage rate is within its 1 imit.

c. At least once per 6 months by verifying that only one door in each air lock can be opened at a time. 


\section{CONTAINMENT SYSTEMS}

CONTAINMENT ISOLATION VALVE AND CHANNEL WELD PRESSURIZATION SYSTEMS (OPTIONAL)

LIMITING CONDITION FOR OPERATION

3.6.1.4 The containment isolation valve and channel weld pressurization systems shall be OPERABLE.

APPLICABILITY: MODES $1,2,3$ and 4.

ACTION:

With the containment isolation valve or channel weld pressurization system inoperable, restore the inoperable system to OPERABLE status within 7 days or be in at least HOT STANDBY within the next 6 hours and in COLD SHUTDOWN within the following 30 hours.

SURVEILLANCE REQUIREMENTS

4.6.1.4.1 The containment isolation valve pressurization system shall be demonstrated OPERABLE at least once per 31 days by verifying that the system is pressurized to $\geq 1.10 \mathrm{P},(55) \mathrm{psig}$, and has adequate capacity to maintain system pressure for at least 30 days.

4.6.1.4.2 The containment channel weld pressurization system shall be demonstrated OPERABLE at least once per 31 days by verifying that the system is pressurized to $>\mathrm{P},(50) \mathrm{psig}$, and has adequate capacity to maintain system pressure for at least 30 days. 
CONTAINMENT SYSTEMS

INTERNAL PRESSURE

LIMITING CONDITION FOR OPERATION

3.6.1.5 Primary containment internal pressure shall be maintained between _ and _ psig.

APPLICABILITY: MODES $1,2,3$ and 4.

ACTION:

With the containment internal pressure outside of the limits above, restore the internal pressure to within the limits within 1 hour or be in at least HOT STANDBY within the next 6 hours and in COLD SHUTDOWN within the following 30 hours.

SURVEILLANCE REQUIREMENTS

4.6.1.5 The primary containment internal pressure shall be determined to within the limits at least once per 12 hours. 


\section{CONTAINMENT SYSTEMS \\ AIR TEMPERATURE}

LIMITING CONDITION FOR OPERATION

3.6.1.6 Primary containment average air temperature shall not exceed ${ }^{\circ} \mathrm{F}$.

APPLICABILITY: MODES $1,2,3$ and 4.

ACTION:

With the containment average air temperature $>\quad{ }^{\circ} \mathrm{F}$, reduce the average air temperature to within the limit within 8 hours, or be in at least HOT STANDBY within the next 6 hours and in COLD SHUTDOWN within the following 30 hours.

SURVEILLANCE REQUIREMENTS

4.6.1.6 The primary containment average air temperature shal1 be the arithmetical average of the temperatures at the following locations and shall be determined at least once per 24 hours:

Location

a.

b.

C.

d.

e. 
CONTAINMENT STRUCTURAL INTEGRITY (Prestressed concrete containment with ungrouted tendons and typical dome)

LIMITING CONDITIONS FOR OPERATION

3.6.1.7 The structural integrity of the containment shall be maintained at a level consistent with the acceptance criteria in Specification 4.6.1.7.

APPLICABILITY: MODES $1,2,3$ and 4.

ACTION:

With the structural integrity of the containment not conforming to the above requirements, restore the structural integrity to within the limits within 24 hours or be in at least HOT STANDBY within the next 6 hours and in COLD SHUTDOWN within the following 30 hours.

SURVEILLANCE REQUIREMENTS

4.6.1.7.1 Containment Tendons The containment tendons' structural integrity shall be demonstrated at the end of one, three and five years following the initial containment structural integrity test and at five year intervals thereafter. The tendons' structural integrity shall be demonstrated by:

a. Determining that a representative sample* of at least 21 tendons ( 6 dome, 5 vertical, and 10 hoop) each have a lift off force of between (minimum) and (maximum) pounds at the first year inspection. For subsequent inspections, the maximum allowable lift off force shall be decreased from the value determined at the first year inspection by the amount: $\log t$ and the minimum allowable lift off force shall be decreased from the value determined at the first year inspection by the amount: $\log t$ where $t$ is the time interval in years from initial tensioning of the tendon to the current testing date. This test shall include an unloading cycle in which each of these tendons is detensioned to determined if any wires or strands are broken or damaged. During retensioning of these tendons to loads not

*For each inspection, the tendons shall be selected on a random but representative basis so that the sample group will change somewhat for each inspection; however, to develop a history of tendon performance and to correlate the observed data, one tendon from each group (dome, vertical, and hoop) may be kept unchanged after the initial selection.
B\&W-ATMOSPHERIC
3/4 6-9JA1
June 1978 
to exceed their measured lift off forces, the change in load and elongation shall be measured simultaneously and the ratio of the change in load to the change in elongation shall be determined to be ___. If the lift off force or the change in elongation with Toad during the reloading cycle of any one tendon in the total sample population is out of the predicted bounds (less than minimum or greater than maximum), an adjacent tendon on each side of the defective tendon shall also be checked for lift off force and change in elongation. If both of these tendons are found acceptable, the surveillance program may proceed considering the single deficiency as unique and acceptable. More than one defective tendon out of the original sample population is evidence of abnormal degradation of the containment structure. Unless there is evidence of abnormal degradation of the containment structure during the first three tests of the tendons, the number of tendons checked for lift off force and change in elongation during subsequent tests may be reduced to a representative sample of at least 9 tendons ( 3 dome, 3 vertical and 3 hoop).

b. Removing one wire or strand from each of a dome, vertical and hoop tendon checked for a lift off force and determining that over the entire length of the removed wire or strand that:

1. The tendon wires or strands are free of corrosion, cracks and damage.

2. There are no changes in physical appearance of the sheathing filler grease.

3. A minimum tensile strength value of psi (guaranteed ultimate strength of the tendon material) for at least three wire or strand samples (one from each end and one at mid-length) cut from each removed wire or strand. Failure of any one of the wire or strand samples to meet the minimum tensile strength test is evidence of abnormal degradation of the containment structure. 
4.6.1.7.2 End Anchorages and Adjacent Concrete Surfaces The structural integrity of the end anchorages of all tendons inspected pursuant to Specification 4.6.1.7.1 and the adjacent concrete surfaces sha11 be demonstrated by determining through inspection that no apparent changes have occurred in the visual appearance of the end anchorage or the concrete crack patterns adjacent to the end anchorages. Inspections of the concrete shall be performed during the Type A containment leakage rate tests (reference Specification 4.6.7.2) while the containment is at its maximum test pressure.

4.6.1.7.3 Containment Surfaces The structural integrity of the exposed accessible interior and exterior surfaces of the containment, including the liner plate, shall be determined during the shutdown for each Type A containment leakage rate test (reference Specification 4.6 .1 .2 ) by a visual inspection of these surfaces and verifying no apparent changes in appearance or other abnormal degradation.

4.6.1.7.4 Reports Any abnormal degradation of the containment structure detected during the above required tests and inspections shall be reported to the Commission pursuant to Specification 6.9.1. This report shall include a description of the tendon condition, the condition of the concrete (especially at tendon anchorages), the inspection procedure, the tolerances on cracking, and the corrective actions taken. 


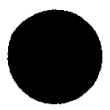

○

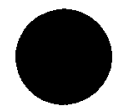


CONTAINMENT STRUCTURAL INTEGRITY (Prestressed concrete containment with ungrouted tendons and hemispherical dome)

LIMITING CONDITIONS FOR OPERATION

3.6.1.7 The structural integrity of the containment sha11 be maintained at a level consistent with the acceptance criteria in Specification 4.6.1.7.

APPLICABILITY: MODES $1,2,3$ and 4.

ACTION:

With the structural integrity of the containment not conforming to the above requirements, restore the structural integrity to within the limits within 24 hours or be in at least HOT STANDBY within the next 6 hours and in COLD SHUTDOWN within the following 30 hours.

SURVEILLANCE REQUIREMENTS

4.6.1.7.1 Containment Tendons. The containment tendons' structural integrity shall be demonstrated at the end of one, three and five years following the initial containment structural integrity test and at five year intervals thereafter. The tendons' structural integrity shall be demonstrated by:

a. Determining that a representative sample* of at least $4 \%$ but no less than 4 of the $U$ tendons each have a lift of force of between (minimum) and (maximum) pounds at the first year inspection and that a representative sample* of at least $4 \%$, but no less than 9 , of the hoop tendons each have a lift off force of between (minimum) and (maximum) pounds at the first year inspection. For subsequent inspections, the maximum allowable lift off forces shall be decreased from the value determined at the first year inspection by the amount: $\log t$ and the minimum allowable lift off force shall be decreased from the value determined at the first year inspection by the amount: $\log t$ where $t$ is the time interval in

*For each inspection, the tendons shall be selected on a random but representative basis so that the sample group will change somewhat for each inspection; however, to develop a history of tendon performance and to correlate the observed data, one tendon from each group ( $U$ and hoop) may be kept unchanged after the initial selection. 
years from initial tensioning of the tendon to the current testing date. This test shall include an unloading cycle in which each of these tendons is detensioned to determine if any wires or strands are broken or damaged. During retensioning of these tendons to loads not to exceed their measured lift off forces, the change in load and elongation shall be measured simultaneously and the ratio of the change in load to the change in elongation shall be determined to be + . If the lift off force or the change in elongation with load during the reloading cycle of any one tendon in the total sample population is out of the predicted bounds (less than minimum or greater than maximum), an adjacent tendon on each side of the defective tendon shall also be checked for lift off force and change in elongation. If both of these tendons are found acceptable, the surveillance program may proceed considering the single deficiency as unique and acceptable. More than one defective tendon out of abnormal degradation of the containment structure during the first three tests of the tendons, the number of tendons checked for lift off force and change in elongation during subsquent tests may be reduced to a representative sample of at least $2 \%$, but no less than 2, of the $U$ tendons an a representative sample of at least $2 \%$, but no less than 3 , of the hoop tendons.

b. Removing one wire or strand from one $U$ tendon and one hoop tendon checked for lift off force and determining that over the entire length of the removed wire or strand that:

1. The tendon wires or strands are free of corrosion, cracks and damage.

2. There are no changes in physical appearance of the sheathing filler grease.

3. A minimum tensile strength value of psi (guaranteed ultimate strength of the tendon material) for at least three wire or strand samples (one from each end and one at mid-length) cut from each removed wire or strand. Failure of any one of the wire or strand samples to meet the minimum tensile strength test is evidence of abnormal degradation of the containment structure. 
SURVEILLANCE REQUIREMENTS (Continued)

4.6.1.7.2 End Anchorages and Adjacent Concrete Surfaces The structural integrity of the end anchorages of all tendons inspected pursuant to Specification 4.6.1.7.1 and the adjacent concrete surfaces shall be demonstrated by determining through inspection that no apparent changes have occurred in the visual appearance of the end anchorage or the concrete crack patterns adjacent to the end anchorages. Inspections of the concrete shall be performed during the Type A containment leakage rate tests (reference Specification 4.6.1.2) while the containment is at its maximum test pressure.

4.6.1.7.3 Containment Surfaces The structural integrity of the exposed accessible interior and exterior surfaces of the containment, including the liner plate, shall be determined during the shutdown for each Type A containment leakage rate test (reference Specification 4.6 .1 .2 ) by a visual inspection of these surfaces and verifying no apparent changes in appearance or other abnormal degradation.

4.6.1.7.4 Reports Any abnormal degradation of the containment structure detected during the above required tests and inspections shall be reported to the Commission pursuant to Specification 6.9.1. The report shall include a description of the tendon condition, the condition of the concrete (especially at tendon anchorages), the inspection procedure, the tolerances on cracking, and the corrective actions taken. 
-
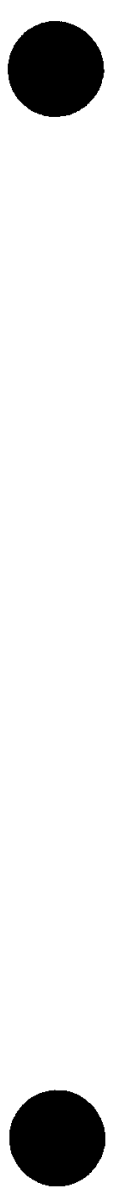
CONTAINMENT SYSTEMS

CONTAINMENT STRUCTURAL INTEGRITY (Reinforced concrete containment)

LIMITING CONDITION FOR OPERATION

3.6.1.7 The structural integrity of the containment shall be maintained at a level consistent with the acceptance criteria in Specification 4.6.1.7.

APPLICABILITY: MODES $1,2,3$ and 4 .

ACTION:

With the structural integrity of the containment not conforming to the above requirements, restore the structural integrity to within the limits within 24 hours or be in at least HOT STANDBY within the next 6 hours and in COLD SHUTDOWN within the following 30 hours.

SURVEILLANCE REQUIREMENTS

4.6.1.7.1 Containment Surfaces The structural integrity of the exposed accessible interior and exterior surfaces of the containment, including the liner plate, shall be determined during the shutdown for each Type A containment leakage rate test (reference Specification 4.6 .1 .2 ) by a visual inspection of these surfaces and verifying no apparent changes in appearance or other abnormal degradation.

4.6.1.7.2 Reports Any abnormal degradation of the containment structure detected during the above required inspections shall be reported to the Commission pursuant to Specification 6.9.1. This report shall include a description of the condition of the concrete, the inspection procedure, the tolerances on cracking, and the corrective actions taken. 
-

○

○ 
CONTAINMENT SYSTEMS

CONTAINMENT VENTILATION (OPTIONAL *)

LIMITING CONDITION FOR OPERATION

3.6.1.8 The containment purge supply and exhaust isolation valves shall be closed.

APPLICABILITY: MODES $1,2,3$, and 4 .

ACTION:

With one containment purge supply and/or one exhaust isolation valve open, close the open valve(s) within one hour or be in at least HOT STANDBY within the next 6 hours and in COLD SHUTDOWN within the following 30 hours.

SURVE ILLANCE REQUIREMENTS

4.6.1.8 The containment purge supply and exhaust isolation valves shall be determined closed at least once per 31 days.

*This specification may be modified if the facility design conforms to Branch Technical Position CSB 6-4 of the Standard Review Plan. 
0
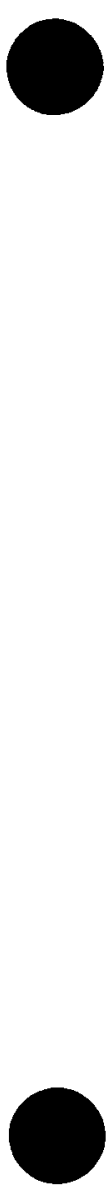


\section{CONTAINMENT SYSTEMS}

3/4.6.2 DEPRESSURIZATION AND COOLING SYSTEMS

CONTAINMENT SPRAY SYSTEM (Credit taken for iodine removal)

LIMITING CONDITION FOR OPERATION

3.6.2.1 At least two independent containment spray systems shall be OPERABLE with each spray system capable of taking suction from the BWST on a containment spray actuation signal and automatically transferring suction to the containment sump on a borated water storage tank low level signal. Each spray system flow path from the containment emergency sump shall be via an OPERABLE decay heat cooler.

APPLICABILITY: MODES $1,2,3$ and 4.

ACTION:

With one containment spray system inoperable, restore the inoperable spray system to OPERABLE status within 72 hours or be in at least HOT STANDBY within the next 6 hours and in COLD SHUTDOWN within the following 30 hours.

\section{SURVEILLANCE REQUIREMENTS}

4.6.2.1 Each containment spray system shall be demonstrated OPERABLE:

a. At least once per 31 days by verifying that each valve (manual, power operated or automatic) in the flow path that is not locked, sealed or otherwise secured in position, is in its correct position.

b. By verifying, that on recirculation flow, each pump develops a discharge pressure of $\geq$ Specification 4.0.5. psig when tested pursuant to

c. At least once per 18 months, during shutdown, by:

1. Verifying that each automatic valve in the flow path actuates to its correct position on a (containment spray test) signal.

2. Verifying that each spray pump starts automatically on a (containment spray test) signal. 
d. At least once per 18 months by verifying a total leak rate $\leq$ (6) gallons per hour for the system at:

1. Normal operating pressure of $>(350)$ psig for those parts of the system downstream of the pump suction isolation valve.

2. $\geq(55)$ psig for the piping from the containment emergency sump isolation valve to the pump suction isolation valve.

e. At least once per 5 years by performing an air or smoke flow test through each spray header and verifying each spray nozzle is unobstructed. 
CONTAINMENT SYSTEMS

3/4.6.2 DEPRESSURIZATION AND COOLING SYSTEMS

CONTAINMENT SPRAY SYSTEM (No credit taken for iodine removal)

LIMITING CONDITION FOR OPERATION

3.6.2.1 At least two independent containment spray systems shall be OPERABLE with each spray system capable of taking suction from the BWST on a containment spray actuation signal and automatically transferring suction to the containment sump on a borated water storage tank low level signal. Each spray system flow path from the containment emergency sump shall be via an OPERABLE decay heat cooler.

APPLICABILITY: MODES $1,2,3$ and 4.

ACTION:

a. With one containment spray system inoperable and at least (four) containment cooling fans OPERABLE, restore the inoperable spray system to OPERABLE status within 7 days or be in at least HOT STANDBY within the next 6 hours and in COLD SHUTDOWN within the following 30 hours.

b. With two containment spray systems inoperable and at least (four) containment cooling fans OPERABLE, restore at least one spray system to OPERABLE status within 72 hours or be in at least HOT STANDBY within the next 6 hours and in COLD SHUTDOWN within the following 30 hours. Restore both spray systems to OPERABLE status within 7 days of initial loss or be in at least HOT STANDBY within the next 6 hours and in COLD SHUTDOWN within the following 30 hours.

c. With one containment spray system inoperable and one group of required containment cooling fans inoperable, restore either the inoperable spray system or the inoperable group of cooling fans to OPERABLE status within 72 hours or be in at least HOT STANDBY within the next 6 hours and in COLD SHUTDOWN within the following 30 hours. Restore both the inoperable spray system and the inoperable group of cooling fans to OPERABLE status within 7 days of initial loss or be in at least HOT STANDBY within the next 6 hours and in COLD SHUTDOWN within the following 30 hours.

SURVEILLANCE REQUIREMENTS

4.6.2.1 Each containment spray system shall be demonstrated OPERABLE: 
a. At least once per 31 days be verifying that each valve (manual, power operated or automatic) in the flow path that is not locked, sealed or otherwise secured in position, is in its correct position.

b. By verifying, that on recirculation flow, each pump develops a discharge pressure of $\geq$ psig when tested pursuant to Specification 4.0.5.

c. At least once per 18 months, during shutdown, by:

1. Verifying that each automatic valve in the flow path actuates to its correct position on a (containment spray test) signal.

2. Verifying that each spray pump starts automatically on a (containment spray test) signal.

d. At least once per 18 months by verifying a total leak rate $\leq$ (6) gallons per hour for the system at:

1. Normal operating pressure of $>(350)$ psig for those parts of the system downstream of the pump suction isolation valve.

2. $>(55)$ psig for the piping from the containment emergency sump isolation valve to the pump suction isolation valve.

e. At least once per 5 years by performing an air or smoke flow test through each spray header and verifying each spray nozzle is unobstructed. 
CONTAINMENT SYSTEMS

SPRAY ADDITIVE SYSTEM (OPTIONAL)

LIMITING CONDITION FOR OPERATION

3.6.2.2 The spray additive system shall be OPERABLE with spray additive tanks containing at least:

a. A contained volume of between $(11,300)$ and ( ) gallons of solution containing between $(188,300)$ and () ppm of sodium hydroxide $(\mathrm{NaOH})$.

b. A contained volume of between $(12,500)$ and $(\quad)$ gallons of solution containing between $(287,000)$ and () $\mathrm{ppm}$ of sodium thiosulfate $\left(\mathrm{Na}_{2} \mathrm{~S}_{2} \mathrm{O}_{3}\right)$, between $(1,645)$ and () $\mathrm{ppm}$ of boron, and between $(5,700)$ and $(;)$ ppm of sodium hydroxide $(\mathrm{NaOH})$.

APPLICABILITY: MODES $1,2,3$ and 4.

ACTION:

With the spray additive system inoperable, restore the system to OPERABLE status within 72 hours or be in at least HOT STANDBY within the next 6 hours; restore the spray additive system to OPERABLE status within the next 48 hours or be in COLD SHUTDOWN within the next 30 hours.

SURVEILLANCE REQUIREMENTS

4.6.2.2 The spray additive system shall be demonstrated OPERABLE:

a. At least once per 31 days by verifying that each valve (manual, power operated or automatic) in the flow path that is not locked, sealed or otherwise secured in position, is in its correct position.

b. At least once per 6 months by:

1. Verifying the contained solution volume in the tanks.

2. Verifying the concentration of the $\mathrm{NaOH}$ and $\mathrm{Na}_{2} \mathrm{~S}_{2} \mathrm{O}_{3}$ solutions by chemical analysis. 
•
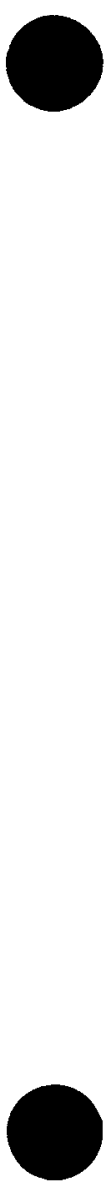
c. At least once per 18 months, during shutdown, by verifying that each automatic valve in the flow path actuates to its correct position on a containment spray test signal.

d. At least once per 5 years by verifying each solution flow rate (to be determined during pre-operational tests) from the following drain connections in the spray additive system:
1. (Drain line location) $\pm$ gpm.
2. (Drain line location) $\pm$ gpm. 
•
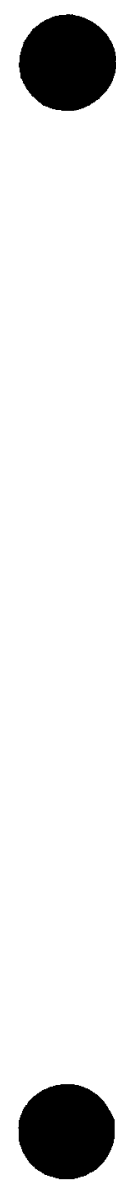
CONTAINMENT SYSTEMS

CONTAINMENT COOLING SYSTEM (OPTIONAL) (Credit taken for iodine removal by spray systems)

LIMITING CONDITION FOR OPERATION

3.6.2.3 At least (two) independent groups of containment cooling fans shall be OPERABLE with (two) fan systems to each group. (Equivalent to $100 \%$ cooling capacity.)

APPLICABILITY: MODES $1,2,3$ and 4 .

ACTION:

a. With one group of the above required containment cooling fans inoperable and both containment spray systems OPERABLE, restore the inoperable group of cooling fans to OPERABLE status within 7 days or be in at least HOT STANDBY within the next 6 hours and in COLD SHUTDOWN within the following 30 hours.

b. With two groups of the above required containment cooling fans inoperable and both containment spray systems OPERABLE, restore at least one group of cooling fans to OPERABLE status within 72 hours or be in at least HOT STANDBY within the next 6 hours and in COLD SHUTDOWN with in the following 30 hours. Restore both above required groups of cooling fans to OPERABLE status within 7 days of initial loss or be in at least HOT STANDBY within the next 6 hours and in COLD SHUTDOWN within the following 30 hours.

c. With one group of the above required containment cooling fans inoperable and one containment spray system inoperable, restore the inoperable spray system to OPERABLE status within 72 hours or be in at least HOT STANDBY within the next 6 hours and in COLD SHUTDOWN within the following 30 hours. Restore the inoperable group of containment cooling fans to OPERABLE status within 7 days of initial loss or be in at least HOT STANDBY within the next 6 hours and in COLD SHUTDOWN within the following 30 hours.

SURVEILLANCE REQUIREMENTS

4.6.2.3 Each group of containment cooling fans shall be demonstrated OPE ABLE:

a. At least once per 31 days on a STAGGERED TEST BASIS by: 
1. Starting (unless al ready operating) each unit from the control room.

2. Verifying that each unit operates for at least 15 minutes.

3. Verifying a cooling water flow rate of $\geq \ldots$ gpm to each unit cooler.

b. At least once per 18 months by verifying that each unit starts automatically (on low speed) upon receipt of a test signal. 
CONTAINMENT SYSTEMS

CONTAINMENT COOLING SYSTEM (OPTIONAL) (No credit taken for iodine removal by spray systems)

LIMITING CONDITION FOR OPERATION

3.6.2.3 At least (two) independent groups of containment cooling fans shall be OPERABLE with (two) fan systems to each group. (Equivalent to $100 \%$ cooling capacity.)

APPLICABILITY: MODES $1,2,3$ and 4.

ACTION:

a. With one group of the above required containment cooling fans inoperable and both containment spray systems OPERABLE, restore the inoperable group of cooling fans to OPERABLE status within 7 days or be in at least HOT STANDBY within the next 6 hours and in COLD SHUTDOWN within the following 30 hours.

b. With two groups of the above required containment cooling fans inoperable and both containment spray systems OPERABLE, restore at least one group of cooling fans to OPERABLE status within 72 hours or be in at least HOT STANDBY within the next 6 hours and in COLD SHUTDOWN within the following 30 hours. Restore both above required groups of cooling fans to OPERABLE status within 7 days of initial loss or be in at least HOT STANDBY within the next 6 hours and in COLD SHUTDOWN within the following 30 hours.

c. With one group of the above required containment cooling fans inoperable and one containment spray system inoperable, restore either the inoperable group of containment cooling fans or the inoperable spray system to OPERABLE status within 72 hours or be in at least HOT STANDBY within the next 6 hours and in COLD SHUTDOWN within the following 30 hours. Restore both the inoperable group of containment cooling fans and the inoperable spray system to OPERABLE status within 7 days of initial loss or be in at least HOT STANDBY within the next 6 hours and in COLD SHUTDOWN within the following 30 hours.

SURVEILLANCE REQUIREMENTS

4.6.2.3 Each group of containment cooling fans shall be demonstrated OPERABLE:

a. At least once per 31 days on a STAGGERED TEST BASIS by: 
1. Starting (unless already operating) each unit from the control room.

2. Verifying that each unit operates for at least 15 minutes.

3. Verifying a cooling water flow rate of $\geq \ldots$ gpm to each unit cooler.

b. At least once per 18 months by verifying that each unit starts automatically (on low speed) upon receipt of a test signal. 
3/4.6.3 IODINE CLEANUP SYSTEM (OPTIONAL)

LIMITING CONDITION FOR OPERATION

3.6.3.1 Two independent containment iodine cleanup systems shall be OPERABLE.

APPLICABILITY: MODES $1,2,3$ and 4.

ACTION:

With one iodine cleanup system inoperable, restore the inoperable system to OPERABLE status within 7 days or be in at least HOT STANDBY within the next 6 hours and in COLD SHUTDOWN within the following 30 hours.

SURVEILLANCE REQUIREMENTS

4.6.3.1 Each iodine cleanup system shal1 be demonstrated OPERABLE:

a. At least once per 31 days on a STAGGERED TEST BASIS by initiating, from the control room, flow through the HEPA filters and charcoal adsorbers and verifying that the system operates for at least 10 hours with the heaters on.

b. At least once per 18 months or (1) after any structural maintenance on the HEPA filter or charcoal adsorber housings, or (2) following painting, fire or chemical release in any ventilation zone communicating with the system by:

1. Verifying that the cleanup system satisfies the in-place testing acceptance criteria and uses the test procedures of Regulatory Positions C.5.a, C.5.C and C.5.d of Regulatory Guide 1.52, Revision 2, March 1978, and the system flow rate is _ cfm $\pm 10 \%$.

2. Verifying within 31 days after removal that a laboratory analysis of a representative carbon sample obtained in accordance with Regulatory Position C.6.b of Regulatory Guide 1.52, Revision 2, March 1978, meets the laboratory testing criteria of Regulatory Position C.6.a of Regulatory Guide 1.52, Revision 2, March 1978. 
3. Verifying a system flow rate of _cfm $\pm 10 \%$ during system operation when tested in accordance with ANSI N510-1975.

c. After every 720 hours of charcoal adsorber operation by verifying within 31 days after removal that a laboratory analys is of a representative carbon sample obtained in accordance with Regulatory Position C.6.b of Regulatory Guide 1.52, Revision 2, March 1978, meets the laboratory testing criteria of Regulatory Position C.6.a of Regulatory Guide 1.52, Revision 2, March 1978.

d. At least once per 18 months by:

1. Verifying that the pressure drop across the combined HEPA filters and charcoal adsorber banks is < (6) inches Water Gauge while operating the system at a flow rate of $\mathrm{cfm} \pm 10 \%$.

2. Verifying that the system starts on either a safety injection test signal or on a containment pressure-high test signal.

3. Verifying that the filter cooling bypass valves can be opened by operator action.

4. Verifying that the heaters dissipate $+$ kw when tested in accordance with ANSI $\bar{N} 510-1975$.

e. After each complete or partial replacement of a HEPA filter bank by verifying that the HEPA filter banks remove $\geq(99.95) \%$ * of the DOP when they are tested in-place in accordance with ANSI N510-1975 while operating the system at a flow rate of cfm $\pm 10 \%$.

f. After each complete or partial replacement of a charcoal adsorber bank by verifying that the charcoal adsorbers remove $>99.95 \%$ of a halogenated hydrocarbon refrigerant test gas when they are tested in-place in accordance with ANSI N510-1975 while operating the system at a flow rate of $\mathrm{cfm} \pm 10 \%$.

*99.95\% applicable when a filter efficiency of $99 \%$ is assumed in the safety analyses; $99 \%$ when a filter efficiency of $90 \%$ is assumed. 
CONTAINMENT SYSTEMS

3/4.6.4 CONTAINMENT ISOLATION VALVES

LIMITING CONDITION FOR OPERATION

3.6.4.1 The containment isolation valves specified in Table 3.6-1 shall be OPERABLE with isolation times as shown in Table 3.6-1.

APPLICABILITY: MODES $1,2,3$ and 4.

ACTION:

With one or more of the isolation valve(s) specified in Table 3.6-1 inoperable, maintain at least one isolation valve OPERABLE in each affected penetration that is open and either:

a. Restore the inoperable valve(s) to OPERABLE status within 4 hours, or

b. Isolate each affected penetration within 4 hours by use of at least one deactivated automatic valve secured in the isolation position, or

c. Isolate each affected penetration within 4 hours by use of at least one closed manual valve or blind flange, or

d. Be in at least HOT STANDBY within the next 6 hours and in COLD SHUTDOWN within the following 30 hours.

SURVEILLANCE REQUIREMENTS

4.6.4.1.1 The isolation valves specified in Table 3.6-1 shall be demonstrated OPERABLE prior to returning the valve to service after maintenance, repair or replacement work is performed on the valve or its associated actuator, control or power circuit by performance of a cycling test and verification of isolation time. 
4.6.4.1.2 Each isolation valve specified in Table 3.6-1 shall be demonstrated OPERABLE during the COLD SHUTDOWN or REFUELING MODE at least once per 18 months by:

a. Verifying that on a containment isolation test signal, each automatic isolation valve actuates to its isolation position.

b. Verifying that on a containment radiation-high test signal, each purge and exhaust automatic valve actuates to its isolation position.

4.6.4.1.3 The isolation time of each power operated or automatic valve of Table 3.6-1 shall be determined to be within its limit when tested pursuant to Specification $4 \cdot 0.5$. 
TABLE 3.6-1

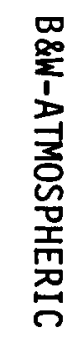

CONTAINMENT ISOLATION VALVES

VALVE NUMBER

FUNCTION

ISOLATION TIME

( ) seconds

A. CONTAINMENT ISOLATION

1.

2.

B. CONTAINMENT PURGE

AND EXHAUST

1.

2.

c. MANUAL

1.

2.

号 D. OTHER

: 1.

2.

* May be opened on an intermittent basis under administrative control.

\#Not subject to Type $C$ leakage tests. 
3/4.6.5 COMBUSTIBLE GAS CONTROL

HYDROGEN ANALYZERS

LIMITING CONDITION FOR OPERATION

3.6.5.1 Two independent containment hydrogen analyzers shall be OPERABLE.

APPLICABILITY: MODES 1 and 2.

ACTION:

With one hydrogen analyzer inoperable, restore the inoperable analyzer to OPERABLE status within 30 days or be in at least HOT STANDBY within the next 6 hours.

\section{SURVEILLANCE REQUIREMENTS}

4.6.5.1 Each hydrogen analyzer shall be demonstrated OPERABLE at least once per 92 days on a STAGGERED TEST BASIS by performing a CHANNEL CALIBRATION using sample gases containing:

a. One volume percent hydrogen, balance nitrogen.

b. Four volume percent hydrogen, balance nitrogen. 


\section{CONTAINMENT SYSTEMS}

ELECTRIC HYDROGEN RECOMBINERS - W

LIMITING CONDITION FOR OPERATION

3.6.5.2 Two independent containment hydrogen recombiner systems shall be OPERABLE.

APPLICABILITY: MODES 1 and 2.

ACTION:

With one hydrogen recombiner system inoperable, restore the inoperable system to OPERABLE status within 30 days or be in at least HOT STANDBY within the next 6 hours.

SURVEILLANCE REQUIREMENTS

4.6.5.2 Each hydrogen recombiner system shall be demonstrated OPERABLE:

a. At least once per 6 months by verifying during a recombiner system functional test that the minimum heater sheath temperature increases to $>700^{\circ} \mathrm{F}$ within 90 minutes and is maintained for at least 2 hours.

b. At least once per 18 months by:

1. Performing a CHANNEL CALIBRATION of all recombiner instrumentation and control circuits.

2. Verifying through a visual examination that there is no evidence of abnormal conditions within the recombiners (i.e., loose wiring or structural connections, deposits of foreign materials, etc.).

3. Verifying during a recombiner system functional test that the heater sheath temperature increases to $\geq 1200^{\circ} \mathrm{F}$ within 5 hours and is maintained for at least 4 hours.

4. Verifying the integrity of the heater electrical circuits by performing a continuity and resistance to ground test following the above required functional test. The resistance to ground for any heater phase shall be $\geq 10,000$ ohms. 
CONTAINMENT SYSTEMS

HYDROGEN PURGE CLEANUP SYSTEM (If less than 2 hydrogen recombiners available)

LIMITING CONDITION FOR OPERATION

3.6.5.3 A containment hydrogen purge cleanup system shall be OPERABLE and capable of being powered from a minimum of one OPERABLE emergency bus.

APPLICABILITY: MODES 1 and 2.

ACTION:

With the containment hydrogen purge cleanup system inoperable, restore the hydrogen purge cleanup system to OPERABLE status within 30 days or be in at least HOT STANDBY with in the next 6 hours.

\section{SURVEILLANCE REQUIREMENTS}

4.6.5.3 The hydrogen purge cleanup system shall be demonstrated OPERABLE:

a. At least once per 31 days by initiating, from the control room, flow through the HEPA filters and charcoal adsorbers and verifying that the system operates for at least 10 hours with the heaters on.

b. At least once per 18 months or (1) after any structural maintenance on the HEPA filter or charcoal adsorber housings, or

(2) following painting, fire or chemical release in any venti-

lation zone communicating with the system by:

1. Verifying that the cleanup system satisfies the in-place testing acceptance criteria and uses the test procedures of Regulatory Positions C.5.a, C.5.C and C.5.d of Regulatory Guide 1.52, Revision 2, March 1978, and the system flow rate is $\mathrm{cfm} \pm 10 \%$.

2. Verifying within 31 days after removal that a laboratory analysis of a representative carbon sample obtained in accordance with Regulatory Position C.6.b of Regulatory Guide 1.52, Revision 2, March 1978, meets the laboratory testing criteria of Regulatory Position C.6.a of Regulatory Guide 1.52, Revision 2, March 1978. 
CONTAINMENT SYSTEMS

SURVEILLANCE REQUIREMENTS (Continued)

3. Verifying a system flow rate of _ cfm $\pm 10 \%$ during system operation when tested in accordance with ANSI N510-1975.

c. After every 720 hours of charcoal adsorber operation by verifying within 31 days after removal that a laboratory analysis of a representative carbon sample obtained in accordance with Regulatory Position C.6.b of Regulatory Guide 1.52, Revision 2, March 1978, meets the laboratory testing criteria of Regulatory Position C.6.a of Regulatory Guide 1.52, Revision 2, March 1978.

d. At least once per 18 months by:

1. Verifying that the pressure drop across the combined HEPA filters and charcoal adsorber banks is < (6) inches Water Gauge while operating the system at a flow rate of $\mathrm{cfm} \pm 10 \%$.

2. Verifying that the filter cooling bypass valves can be manually opened.

3. Verifying that the heaters dissipate $+\frac{}{\mathrm{kw}}$ when tested in accordance with ANSI $\sqrt{510-1975}$.

e. After each complete or partial replacement of a HEPA filter bank by verifying that the HEPA filter banks remove $\geq(99.95) \% *$ of the DOP when they are tested in-place in accordance with ANSI N510-1975 while operating the system at a flow rate of $\mathrm{cfm} \pm 10 \%$.

f. After each complete or partial replacement of a charcoal adsorber bank by verifying that the charcoal adsorbers remove $>99.95 \%$ of a halogenated hydrocarbon refrigerant test gas when they are tested in-place in accordance with ANSI N510-1975 while operating the system at a flow rate of $\mathrm{cfm} \pm 10 \%$.

ॠ99.95\% applicable when a filter efficiency of $99 \%$ is assumed in the safety analyses; $99 \%$ when a filter efficiency of $90 \%$ is assumed. 
CONTAINMENT SYSTEMS

HYDROGEN MIXING SYSTEM (OPTIONAL)

LIMITING CONDITION FOR OPERATION

3.6.5.4 Two independent hydrogen mixing systems shall be OPERABLE. APPLICABILITY: MODES 1 and 2.

ACTION:

With one hydrogen mixing system inoperable, restore the inoperable system to OPERABLE status within 30 days or be in at least HOT STANDBY within the next 6 hours.

SURVEILLANCE REQUIREMENTS

4.6.5.4 Each hydrogen mixing system shall be demonstrated OPERABLE:

a. At least once per 92 days on a STAGGERED TEST BASIS by:

1. Starting each system from the control room.

2. Verifying that the system operates for at least 15 minutes.

b. At least once per 18 months by verifying a system flow rate of at least cfm. 


\section{CONTAINMENT SYSTEMS}

3/4.6.6 PENETRATION ROOM EXHAUST AIR CLEANUP SYSTEM (OPTIONAL)

LIMITING CONDITION FOR OPERATION

3.6.6.1 Two independent containment penetration room exhaust air cleanup systems shall be OPERABLE.

APPLICABILITY: MODES 1,2 and 3.

ACTION:

With one containment penetration room exhaust air cleanup system inoperable, restore the inoperable system to OPERABLE status within 7 days or be in at least HOT STANDBY within the next 6 hours and in COLD SHUTDOWN within the following 30 hours.

SURVEILLANCE REQUIREMENTS

4.6.6.1 Each containment penetration room exhaust air cleanup system shall be demonstrated OPERABLE:

a. At least once per 31 days on a STAGGERED TEST BASIS by initiating, from the control room, flow through the HEPA filters and charcoal adsorbers and verifying that the system operates for at least 10 hours with the heaters on.

b. At least once per 18 months or (1) after any structural maintenance on the HEPA filter or charcoal adsorber housings, or (2) following painting, fire or chemical release in any ventilation zone communicating with the system by:

1. Verifying that with the system operating at a flow rate of $\quad \mathrm{cfm}+10 \%$ and exhausting through the HEPA filters and charcoal adsorbers, the total bypass flow of the system to the facility vent, including leakage through the system diverting valves, is $<1 \%$ when the system is tested by admitting cold DOP at the system intake. (For systems with diverting valves.) 
2. Verifying that the cleanup system satisfies the in-place testing acceptance criteria and uses the test procedures of Regulatory Positions C.5.a, C.5.C and C.5.d of Regulatory Guide 1.52, Revision 2, March 1978, and the system flow rate is $\mathrm{cfm} \pm 10 \%$.

3. Verifying within 31 days after removal that a laboratory analysis of a representative carbon sample obtained in accordance with Regulatory Position C.6.b of Regulatory Guide 1.52, Revision 2, March 1978, meets the Taboratory testing criteria of Regulatory Position C.6.a of Regulatory Guide 1.52, Revision 2, March 1978.

4. Verifying a system flow rate of _cfm $\pm 10 \%$ during system operation when tested in accordance with ANSI N510-1975.

c. After every 720 hours of charcoal adsorber operation by verifying within 31 days after removal that a laboratory analys is of a representative carbon sample obtained in accordance with Regulatory Position C.6.b of Regulatory Guide 1.52, Revision 2, March 1978, meets the 1aboratory testing criteria of Regulatory Position C.6. a of Regulatory Guide 1.52, Revision 2, March 1978.

d. At least once per 18 months by:

1. Verifying that the pressure drop across the combined HEPA filters and charcoal adsorber banks is $<(6)$ inches water Gauge while operating the system at a flow rate of $\mathrm{cfm}$ $\pm 10 \%$.

2. Verifying that the system starts on a safety injection test signal.

3. Verifying that the filter cooling bypass valves can be manually opened. when tested in accordance with ANSI $\sqrt{510-197} \overline{5}$. 
e. After each complete or partial replacement of a HEPA filter bank by verifying that the HEPA filter banks remove $\geq(99.95) \%$ * $\mid$ of the DOP when they are tested in-place in accordance with ANSI N510-1975 while operating the system at a flow rate of $\mathrm{cfm} \pm 10 \%$.

f. After each complete or partial replacement of a charcoal adsorber bank by verifying that the charcoal adsorbers remove $\geq 99.95 \%$ of a halogenated hydrocarbon refrigerant test gas when they are tested in-place in accordance with ANSI N510-1975 while operating the system at a flow rate of $\mathrm{cfm} \pm 10 \%$.

*99.95\% applicable when a filter efficiency of $99 \%$ is assumed in the safety analyses; $99 \%$ when a filter efficiency of $90 \%$ is assumed. 
CONTAINMENT SYSTEMS

3/4.6.7 VACUUM RELIEF VALVES (OPTIONAL)

LIMITING CONDITION FOR OPERATION

3.6.7.1 The primary containment to atmosphere vacuum relief valves shall be OPERABLE with an actuation setpoint of $\leq$ psid.

APPLICABILITY: MODES $1,2,3$ and 4.

ACTION:

With one primary containment to atmosphere vacuum relief valve inoperable, restore the valve to OPERABLE status within 4 hours or be in at least HOT STANDBY within the next 6 hours and in COLD SHUTDOWN within the following 30 hours.

SURVEILLANCE REQUIREMENTS

4.6.7.1 No additional Surveillance Requirements other than those required by Specification 4.0.5. 
SECTION $3 / 4.6 \mathrm{~L}$

CONTAINMENT SYSTEMS SPECIFICATIONS

FOR

BABCOCK AND WILCOX

DUAL TYPE CONTAINMENT 
3/4.6 CONTAINMENT SYSTEMS

3/4.6.1 PRIMARY CONTAINMENT

CONTAINMENT INTEGRITY

LIMITING CONDITION FOR OPERATION

3.6.1.1 Primary CONTAINMENT INTEGIRTY shall be maintained.

APPLICABILITY: MODES $1,2,3$ and 4.

ACTION:

Without primary CONTAINMENT INTEGRITY, restore CONTAINMENT INTEGRITY within one hour or be in at least HOT STANDBY within the next 6 hours and in COLD SHUTDOWN within the following 30 hours.

SURVEILLANCE REQUIREMENTS

4.6.1.1 Primary CONTAINMENT INTEGRITY shall be demonstrated:

a. At least once per 31 days by verifying that all penetrations* not capable of being closed by OPERABLE containment automatic isolation valves and required to be closed during accident conditions are closed by valves, blind flanges, or deactivated automatic valves secured in their positions, except as provided in Table 3.6-2 of Specification 3.6.4.1.

b. By verifying that each containment air lock is OPERABLE per Specification (3.6.1.3).

c. After each closing of the equipment hatch, by leak rate testing the equipment hatch seals with gas at $\mathrm{Pa}(50 \mathrm{psig})$ and verifying that when the measured leakage rate for these seals is added to the leakage rates determined pursuant to Specification 4.6.1.2.d for all other Type B and C penetrations, the combined leakage rate is $\leq 0.60 \mathrm{La}$.

FExcept valves, blind flanges, and deactivated automatic valves which are located inside the containment and are locked, sealed or otherwise secured in the closed position. These penetrations shall be verified closed during each COLD SHUTDOWN except that such verification need not be performed more often than once per 92 days. 
CONTAINMENT LEAKAGE

LIMITING CONDITION FOR OPERATION

3.6.1.2 Containment leakage rates shall be limited to:

a. An overall integrated leakage rate of:

1. $\leq L_{0},(0.20)$ percent by weight of the containment air per 24 hours at $P_{a}$, (50) psig, or

2. $\leq L_{t},(0.10)$ percent by weight of the containment air per $\overline{2} 4$ hours at a reduced pressure of $P_{t},(25)$ psig.

b. A combined leakage rate of $\leq 0.60 \mathrm{~L}$ for all penetrations and valves subject to Type $B$ and $C$ tests, when pressurized to $P_{a}$.

c. A combined leakage rate of $\leq(0.10) L$ for all penetrations identified in Table 3.6-1 as secondary containment bypass leakage paths, when pressurized to $\mathrm{P}_{\mathrm{a}}$.

APPLICABILITY: MODES $1,2,3$ and 4.

ACTION:

(a) With the measured overall integrated leakage rate exceeding $0.75 \mathrm{~L}_{\mathrm{a}}$ or $0.75 \mathrm{~L}_{t}$, as applicable, restore the overall integrated ${ }^{a}$ leakage rate to $\leq 0.75 \mathrm{~L}_{a}$ or $\leq 0.75 \mathrm{~L}_{t}$, as applicable, prior to increasing the Reactor ${ }^{a}$ Coolant System temperature above $200^{\circ} \mathrm{F}$.

(b) With the combined leakage rate for all penetrations and valves subject to Type $B$ and $C$ tests exceeding $0.60 \mathrm{~L}$, restore the leakage rate to within the limit prior to increasing the Reactor Coolant System temperature above $200^{\circ} \mathrm{F}$.

(c) With the combined bypass leakage rate exceeding $(0.10) \mathrm{L}_{\text {a }}$, restore the leakage rate to within the limit prior to increasing the Reactor Coolant System temperature above $200^{\circ} \mathrm{F}$.

\section{SURVEILLANCE REQUIREMENTS}

4.6.1.2 The containment leakage rates shall be demonstrated at the following test schedule and shall be determined in conformance with the criteria specified in Appendix $J$ of 10 CFR 50 using the methods and provisions of ANSI N45.4 - (1972):

B\&W-DUAL 
a. Three Type A tests (Overall Integrated Containment Leakage Rate) shall be canducted at $40+10$ month intervals during shutdown at either $P_{a},(50) p s i \bar{g}$, or at $P_{t},(25)$ psig, during each 10 year service period. The third test of each set shall be conducted during the shutdown for the 10-year plant inservice inspection.

b. If any periodic Type $A$ test fails to meet either $.75 \mathrm{~L}$ or $.75 \mathrm{~L}_{t}$, the test schedule for subsequent Type $A$ tests $\xi$ hall be reviewed and approved by the Commission. If two consecutive Type A tests fail to meet either $.75 \mathrm{~L}_{a}$ or $.75 \mathrm{~L}_{t}$, a Type $A$ test shall be performed at least every 18 months $t$, antil two consecutive Type A tests meet either $.75 \mathrm{~L}_{\mathrm{a}}$ or $.75 \mathrm{~L}_{t}$ at which time the above test schedule may be resumed.

c. The accuracy of each Type A test shall be verified by a supplemental test which:

1. Confirms the accuracy of the Type $A$ test by verifying that the difference between supplemental and Type $A$ test data is within $0.25 \mathrm{~L}_{a}$ or $0.25 \mathrm{~L}_{\mathrm{t}}$.

2. Has a duration sufficient to establish accurately the change in leakage rate between the Type $A$ test and the supplemental test.

3. Requires the quantity of gas injected into the containment or bled from the containment during the supplemental test to be equivalent to at least 25 percent of the total measured leakage at $P_{a},(50) \mathrm{psig}$, or $P_{t},(25) \mathrm{psig}$.

d. Type $B$ and $C$ tests shall be conducted with gas at $P,(50)$ psig, at intervals no greater than 24 months except for têsts involving:

1. Air locks.

2. Penetrations using continuous leakage monitoring systems.

3. Valves pressurized with fluid from a seal system.

e. The combined bypass leakage rate shall be determined to be < $(0.10) L_{a}$ by applicable Type $B$ and $C$ tests at least once every 24 months except for penetrations which are not individually testable; penetrations not individually testable shall be determined to have no detectable leakage when tested with soap bubbles while the containment is pressurized to $\mathrm{P}_{\mathrm{a}},(50)$ psig, during each Type A test. 
f. Air locks shall be tested and demonstrated OPERABLE per Surveillance Requirement (4.6.1.3).

g. Type B periodic tests are not required for penetrations continuously monitored by the Containment Isolation Valve and Channel Weld Pressurization Systems, provided the systems are OPERABLE per Surveillance Requirement (4.6.1.4).

h. Leakage from isolation valves that are sealed with fluid from a seal system may be excluded, subject to the provisions of Appendix J, Section III.C.3, when determining the combined leakage rate provided the seal system and valves are pressurized to at least $1.10 \mathrm{P},(55) \mathrm{psig}$, and the seal system capacity is adequate to mafntain system pressure for at least 30 days.

i. Type $B$ tests for penetrations employing a continuous leakage monitoring system shall be conducted at $P_{a}$, (50) psig, at intervals no greater than once per 3 years.

j. All test leakage rates shall be calculated using observed data converted to absolute values. Error analyses shall be performed to select a balanced integrated leakage measurement system.

k. The provisions of Specification 4.0.2 are not applicable. 
TABLE 3.6-1

SECONDARY CONTAINMENT BYPASS LEAKAGE PATHS

PENETRATION

RELEASE LOCATION

$\frac{\omega}{f}$

ì

몽

言

$\omega$

$\stackrel{\circ}{\circ}$

$\stackrel{\vec{\sigma}}{-5}$ 
CONTAINMENT SYSTEMS

CONTAINMENT AIR LOCKS

LIMITING CONDITION FOR OPERATION

3.6.1.3 Each containment air lock shall be OPERABLE with:

a. Both doors closed except when the air lock is being used for normal transit entry and exit through the containment, then at least one air lock door shall be closed.

b. An overall air lock leakage rate of $\leq 0.05 \mathrm{~L}_{\mathrm{a}}$ at $\mathrm{P}_{\mathrm{a}},(50) \mathrm{psig}$. APPLICABILITY: MODES $1,2,3$ and 4.

ACTION:

a. With one containment air lock door inoperable:

1. Maintain at least the OPERABLE air lock door closed and either restore the inoperable air lock door to OPERABLE status within 24 hours or lock the OPERABLE air lock door closed.

2. Operation may then continue until performance of the next required overall air lock leakage test provided that the OPERABLE air lock door is verified to be locked closed at least once per 31 days.

3. Otherwise, be in at least HOT STANDBY within the next 6 hours and in COLD SHUTDOWN within the following 30 hours.

4. Th provisions of Specification 3.0.4 are not applicable.

b. With the containment air lock inoperable, except as the result of an inoperable air lock door, maintain at least one air lock door closed; restore the inoperable air lock to OPERABLE status within 24 hours or be in at least HOT STANDBY within the next 6 hours and on COLD. SHUTDOWN within the following 30 hours. 
4.6.1.3 Each containment air lock shall be demonstrated OPERABLE:

a. *After each opening, except when the air lock is being used for multiple entries, then at least once per 72 hours, by verifying (no detectable) seal leakage by pressure decay when the volume between the door seals is pressurized to $\geq \mathrm{P}_{\mathrm{a}}$, (50) psig, for at least 15 minutes.

b. At least once per 6 months by conducting an overall air lock leakage test at $P_{2},(50)$ psig, and by verifying that the overall air lock leakage rate is within its limit.

c. At least once per 6 months by verifying that only one door in each air lock can be opened at a time.

ॠ Exemption to Appendix "J" of 10 CFR 50. 
0

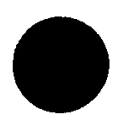

○ 
CONTAINMENT ISOLATION VALVE AND CHANNEL WELD PRESSURIZATION SYSTEMS (OPTIONAL)

LIMITING CONDITION FOR OPERATION

3.6.1.4 The containment isolation valve and channel weld pressurization systems sha11 be OPERABLE.

APPLICABILITY: MODES $1,2,3$ and 4.

ACTION:

With the containment isolation valve or channel weld pressurization system inoperable, restore the inoperable system to OPERABLE status within 7 days or be in at least HOT STANDBY within the next 6 hours and in COLD SHUTDOWN within the following 30 hours.

SURVEILLANCE REQUIREMENTS

4.6.1.4.1 The containment isolation valve pressurization system shall be demonstrated OPERABLE at least once per 31 days by verifying that the system is pressurized to $\geq 1.10 \mathrm{P}_{2},(55) \mathrm{psig}$, and has adequate capacity to maintain system pressure for at least 30 days.

4.6.1.4.2 The containment channel weld pressurization system shall be demonstrated OPERABLE at least once per 31 days by verifying that the system is pressurized to $\geq 1.0 \mathrm{P}(50) \mathrm{psig}$, and has adequate capacity to maintain system pressure for $\mathrm{gt}$ least 30 days. 
CONTAINMENT SYSTEMS

INTERNAL PRESSURE

LIMITING CONDITION FOR OPERATION

3.6.1.5 Primary containment internal pressure shall be maintained between and psig.

APPLICABILITY: MODES 1, 2, 3 and 4.

ACTION:

With the containment internal pressure outside of the limits above, restore the internal pressure to within the limits within 1 hour or be in at least HOT STANDBY within the next 6 hours and in COLD SHUTDOWN within the following 30 hours.

SURVEILLANCE REQUIREMENTS

4.6.1.5 The primary containment internal pressure shall be determined to within the limits at least once per 12 hours. 
CONTAINMENT SYSTEMS

AIR TEMPERATURE

LIMITING CONDITION FOR OPERATION

3.6.1.6 Primary containment average air temperature shall not exceed ${ }^{\circ} \mathrm{F}$.

APPLICABILITY: MODES $1,2,3$ and 4.

ACTION:

With the containment average air temperature $>\quad{ }^{\circ} \mathrm{F}$, reduce the average air temperature to within the limit within 8 hours, or be in at least HOT STANDBY within the next 6 hours and in COLD SHUTDOWN within the following 30 hours.

SURVEILLANCE REQUIREMENTS

4.6.1.6 The primary containment average air temperature shall be the arithmetical average of the temperatures at the following locations and shall be determined at least once per 24 hours:

Location

a.

b.

c.

d.

e. 
CONTAINMENT VESSEL STRUCTURAL INTEGRITY

LIMITING CONDITIONS FOR OPERATION

3.6.1.7 The structural integrity of the containment vessel shall be maintained at a level consistent with the acceptance criteria in Specification 4.6.1.7.

APPLICABILITY: MODES $1,2,3$ and 4.

ACTION:

With the structural integrity of the containment vessel not conforming to the above requirements, restore the structural integrity to within the limits prior to increasing the Reactor Coolant System temperature above $200^{\circ} \mathrm{F}$.

SURVEILLANCE REQUIREMENTS

4.6.1.7 The structural integrity of the containment vessel shall be determined during the shutdown for each Type A containment leakage rate test (reference Specification 4.6 .1 .2 ) by a visual inspection of the accessible interior and exterior surfaces of the vessel and verifying no apparent changes in appearance of the surfaces or other abnormal degradation. Any abnormal degradation of the containment vessel detected during the above required inspections shall be reported to the commission pursuant to Specification 6.9.1. 


\section{CONTAINMENT SYSTEMS}

CONTAINMENT VENTILATION SYSTEM (OPTIONAL*)

LIMITING CONDITION FOR OPERATION

3.6.1.8 The contatinment purge supply and exhaust isolation valves shall be closed.

APPEICABILITY: MODES $1,2,3$, and 4 .

ACTION:

With one containment purge supply and/or one exhaust isolation valve open, close the open valve(s) within one hour or be in at least HOT STANDBY within the next 6 hours and in COLD SHUTDOWN within the following 30 hours.

SURVEILLANCE REQUIREMENTS

4.6.1.8 The containment purge supply and exhaust isolation valves shall be determined closed at least once per 31 days.

This specification may be modified if the facility design conforms to Branch Technical Position CSB 6-4 of the Standard Review Plan. 
•
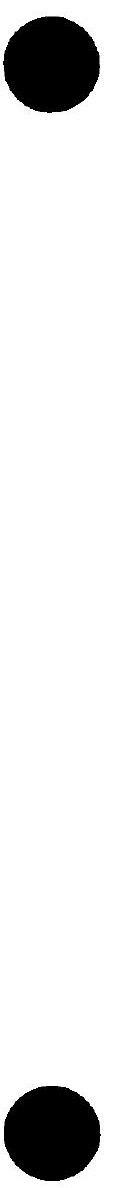
CONTAINMENT SYSTEMS

3/4.6.2 DEPRESSURIZATION AND COOLING SYSTEMS

CONTAINMENT SPRAY SYSTEM (Credit taken for iodine removal)

LIMITING CONDITION FOR OPERATIUN

3.6.2.1 At least two independent containment spray systems shall be OPERABLE with each spray system capable of taking suction from the BWST on a containment spray actuation signal and automatically transferring suction to the containment emergency sump on a borated water storage tank low level signal. Each spray system flow path from the containment emergency sump shall be via an OPERABLE decay heat cooler.

APPLICABILITY: MUDES 1, 2, 3 and 4.

ACTION:

With one containment spray system inoperable, restore the inoperable spray system to OPERABLE status within 72 hours or be in at least HOT STANDBY within the next 6 hours and in COLD SHUTDOWN within the following 30 hours.

SURVEILLANCE REQUIREMENTS

4.6.2.1 Each containment spray system shall be demonstrated OPERABLE:

a. At least once per 31 days by verifying that each valve (manual, power operated or automatic) in the flow path that is not locked, sealed or otherwise secured in position, is in its correct position.

b. By verifying, that on recirculation flow, each pump develops a discharge pressure $\geq$ Specification $4 \cdot 0.5$. psig when tested pursuant to

c. At least once per 18 months, during shutdown, by:

1. Verifying that each automatic valve in the flow path actuates to its correct position on a containment spray test signal.

2. Verifying that each spray pump starts automatically on a (containment spray test) signal. 


\section{CONTAINMENT SYSTEMS}

SURVEILLANCE REQUIREMENTS (Continued)

d. At least once per 18 months by verifying a total leak rate $\leq$ (6) gallons per hour for the system at:

1. Normal operating pressure of $>(350)$ psig for those parts of the system downstream of the pump suction isolation valve.

2. $\geq(55)$ psig for the piping from the containment emergency sump isolation valve to the pump suction isolation valve.

e. At least once per 5 years by performing an air or smoke flow test through each spray header and verifying each spray nozzle is unobstructed. 
CONTAINMENT SYSTEMS

3/4.6.2 DEPRESSURIZATION AND COOLING SYSTEMS

CONTAINMENT SPRAY SYSTEM (No credit taken for iodine removal)

LIMITING CONDITION FOR OPERATION

3.6.2.1 At least two independent containment spray systems shall be OPERABLE with each spray system capable of taking suction from the BWST on a containment spray actuation signal and automatically transferring suction to the containment emergency sump on a borated water storage tank low level signal. Each spray system flow path from the containment emergency sump shall be via an OPERABLE decay heat cooler.

APPLICABILITY: MODES $1,2,3$ and 4.

ACTION:

a. With one containment spray system inoperable and at least (four) containment cooling fans OPERABLE, restore the inoperable spray system to OPERABLE status within 7 days or be in at least HOT STANDBY within the next 6 hours and in COLD SHUTDOWN within the following 30 hours.

b. With two containment spray systems inoperable and at least (four) containment cooling fans OPERABLE, restore at least one spray system to OPERABLE status within 72 hours or be in at least HOT STANDBY within the next 6 hours and in COLD SHUTDOWN within the following 30 hours. Restore both spray systems to OPERABLE status within 7 days of initial loss or be in at least HOT STANDBY within the next 6 hours and in COLD SHUTDOWN within the following 30 hours.

c. With one containment spray system inoperable and one group of required containment cooling fans inoperable, restore either the inoperable spray system or the inoperable group of cooling fans to OPERABLE status within 72 hours or be in at least HOT STANDBY within the next 6 hours and in COLD SHUTDOWN within the following 30 hours. Restore both the inoperable spray system and the inoperable group of cooling fans to OPERABLE status within 7 days of initial loss or be in at least HOT STANDBY within the next 6 hours and in COLD SHUTDOWN within the following 30 hours.

SURVEILLANCE REQUIREMENTS

4.6.2.1 Each containment spray system shall be demonstrated OPERABLE: 
a. At least once per 31 days be verifying that each valve (manual, power operated or automatic) in the flow path that is not locked, sealed or otherwise secured in position, is in its correct position.

b. By verifying, that on recirculation flow, each pump develops a discharge pressure of $\geq$ Specification $4 \cdot 0.5$. psig when tested pursuant to

c. At least once per 18 months, during shutdown, by:

1. Verifying that each automatic valve in the flow path actuates to its correct position on a (containment spray test) signal.

2. Verifying that each spray pump starts automatically on a (containment spray test) signal.

d. At least once per 18 months by verifying a total leak rate $\leq$ (6) gallons per hour for the system at:

1. Normal operating pressure of $\geq(350)$ psig for those parts of the system downstream of the pump suction isolation valve.

2. $\geq(55)$ psig for the piping from the containment emergency sump isolation valve to the pump suction isolation valve.

e. At least once per 5 years by performing an air or smoke flow test through each spray header and verifying each spray nozzle is unobstructed. 


\section{CONTAINMENT SYSTEMS}

SPRAY ADDITIVE SYSTEM (OPTIONAL)

LIMITING CONDITION FOR OPERATION

3.6.2.2 The spray additive system shall be OPERABLE with:

a. A spray additive tank containing a volume of between and gallons of between $\mathrm{NaOH} \overline{\mathrm{sol}}$ ution. and percent by weight

b. At least two spray additive pumps capable of adding $\mathrm{NaOH}$ solution from the chemical additive tank to a containment spray system pump flow.

APPLICABILITY: MODES $1,2,3$ and 4.

ACTION:

With any spray additive system inoperable, restore the system to OPERABLE status within 72 hours or be in at least HOT STANDBY within the next 6 hours; restore the spray additive system to OPERABLE status within the next 48 hours or be in COLD SHUIDOWN within the next 30 hours.

SURVEILLANCE REQUIREMENTS

4.6.2.2 The spray additive system shall be demonstrated OPERABLE:

a. At least once every 31 days by verifying that each valve (manual, power operated or automatic) in the flow path that is not locked, sealed or otherwise secured in position, is in its correct position.

b. At least once per 6 months by:

1. Verifying the contained solution volume in the tank.

2. Verifying the concentration of the $\mathrm{NaOH}$ solution by chemical analysis.

c. At least once per 18 months, during shutdown, by verifying that each automatic valve in the flow path actuates to its correct position on a containment spray test signal. 
d. At least once per 5 years by verifying each solution flow rate (to be determined during pre-operational tests) from the following drain connections in the spray additive system:

1. (Drain line location) $+$ gpm.

2. (Drain line location) $\pm$ gpm. 
CONTAINMENT SYSTEMS

CONTAINMENT COOLING SYSTEM (OPTIONAL) (No credit taken for iodine removal by spray systems)

LIMITING CONDITION FOR OPERATION

3.6.2.3 At least (two) independent groups of containment cooling fans shall be OPERABLE with (two) fan systems to each group. (Equivalent to $100 \%$ cooling capacity.)

APPLICABILITY: MODES $1,2,3$ and 4.

ACTION:

a. With one group of the above required containment cooling fans inoperable and both containment spray systems OPERABLE, restore the inoperable group of cooling fans to OPERABLE status within 7 days or be in at least HOT STANDBY within the next 6 hours and in COLD SHUTDOWN within the following 30 hours.

b. With two groups of the above required containment cooling fans inoperable, and both containment spray systems OPERABLE, restore at least one group of cooling fans to OPERABLE status within 72 hours or be in at least HOT STANDBY within the next 6 hours and in COLD SHUTDOWN within the following 30 hours. Restore both above required groups of cooling fans to OPERABLE status within 7 days of initial loss or be in at least HOT STANDBY within the next 6 hours and in COLD SHUTDOWN within the following 30 hours.

c. With one group of the above required containment cooling fans inoperable and one containment spray system inoperable, restore either the inoperable group of containment cooling fans or the inoperable spray system to OPERABLE status within 72 hours or be in at least HOT STANDBY within the next 6 hours and in COLD SHUTDOWN within the following 30 hours.

SURVEILLANCE REQUIREMENTS

4.6.2.3 Each group of containment cooling fans shall be demonstrated OPERABLE : 
a. At least once per 31 days on a STAGGEREU TEST BASIS by:

1. Starting (unless already operating) each unit from the control room.

2. Verifying that each unit operates for at least 15 minutes.

3. Verifying a cooling water flow rate of $\geq \ldots$ gpm to each unit cooler.

b. At least once per 18 months by verifying that each unit starts automatically (on low speed) upon receipt of a test signa 1 . 
CONTAIMMENT COOLING SYSTEM (OPTIONAL) (No credit taken for iodine removal by spray systems)

LIMITIING CONDITION FOR OPERATION

3.6.2.3 At least (two) independent groups of containment cooling fans shal1 be OPERABLE with (two) fan systems to each group. (Equivalent to $100 \%$ cooling capacity.)

APPLICABILITY: MODES $1,2,3$ and 4.

ACTION:

a. With one group of the above required containment cooling fans inoperable and both containment spray systems OPERABLE, restore the inoperable group of cooling fans to OPERABLE status within 7 days or be in at least HOT STANDBY within the next 6 hours and in COLD SHUTDOWN within the following 30 hours.

b. With two groups of the above required containment cooling fans inoperable, and both containment spray systems OPERABLE, restore at least one group of cooling fans to OPERABLE status within 72 hours or be in at least HOT STANDBY within the next 6 hours and in COLD SHUTDOWN within the following 30 hours. Restore both above required groups of cooling fans to OPERABLE status within 7 days of initial loss or be in at least HOT STANDBY within the next 6 hours and in COLD SHUTDOWN within the following 30 hours.

c. With one group of the above required containment cooling fans inoperable and one containment spray system inoperable, restore either the inoperable group of containment cooling fans or the inoperable spray system to OPERABLE status within 72 hours or be in at least HOT STANDBY within the next 6 hours and in COLD SHUTDOWN within the following 30 hours. Restore both the inoperable group of containment cooling fans and the inoperable spray system to OPERABLE status within 7 days of initial loss or be in at least HOT STANDBY within the next 6 hours and in COLD SHUTDOWN within the following 30 hours.

SURVEILLANCE REQUIREMENTS

4.6.2.3 Each group of containment cooling fans shall be demonstrated OPERABLE: 
a. At least once per 31 days on a STAGGERED TEST BASIS by:

1. Starting (unless already operating) each unit from the control room.

2. Verifying that each unit operates for at least 15 minutes.

3. Verifying a cooling water flow rate of $\geq \ldots$ gpm to each unit cooler.

b. At least once per 18 months by verifying that each unit starts automatically (on low speed) upon receipt of a signal. 
CONTAINMENT SYSTEMS

3/4.6.3 IODINE CLEANUP SYSTEM (OPTIONAL)

LIMITING CONDITION FOR OPERATION

3.6.3.1 Two independent containment iodine cleanup systems shall be OPERABLE.

APPLICABILITY: MODES $1,2,3$ and 4.

ACTION:

With one iodine cleanup system inoperable, restore the inoperable system to OPERABLE status within 7 days or be in at least HOT STANDBY within the next 6 hours and in COLD SHUTDOWN within the following 30 hours.

\section{SURVEILLANCE REQUIREMENTS}

4.6.3.1 Each iodine cleanup system shall be demonstrated OPERABLE:

a. At least once per 31 days on a STAGGERED TEST BASIS by initiating, from the control room, flow through the HEPA filters and charcoal adsorbers and verifying that the system operates for at least 10 hours with the heaters on.

b. At least once per 18 months or (1) after any structural maintenance on the HEPA filter or charcoal adsorber housings, or (2) following painting, fire or chemical release in any ventilation zone communicating with the system by:

1. Verifying that the cleanup system satisfies the in-place testing acceptance criteria and uses the test procedures of Regulatory Positions C.5.a, C.5.C and C.5.d of Regulatory Guide 1.52, Revision 2, March 1978, and the system flow rate is $\mathrm{cfm} \pm 10 \%$.

2. Verifying within 31 days after removal that a laboratory analysis of a representative carbon sample obtained in accordance with Regulatory Position C.6.b of Regulatory Guide 1.52, Revision 2, March 1978, meets the laboratory testing criteria of Regulatory Position C.6.a of Regulatory Guide 1.52, Revision 2, March 1978.

3. Verifying a system flow rate of $\mathrm{cfm} \pm 10 \%$ during system operation when tested in accordance with ANSI N510-1975. 
c. After every 720 hours of charcoal adsorber operation by verifying within 31 days after removal that a laboratory analys is of a representative carbon sample obtained in accordance with Regulatory Position C.6.b of Regulatory Guide 1.52, Revision 2, March 1978, meets the laboratory testing criteria of Regulatory Position C.6.a of Regulatory Guide 1.52, Revision 2, March 1978.

d. At least once per 18 months by:

1. Verifying that the pressure drop across the combined HEPA filters and charcoal adsorber banks is < (6) inches Water Gauge while operating the system at a flow rate of $\mathrm{cfm} \pm 10 \%$.

2. Verifying that the system starts on either a safety injection test signal or on a containment pressure-high test signal.

3. Verifying that the filter cooling bypass valves can be opened by operator action.

4. Verifying that the heaters dissipate + $\mathrm{kw}$ when tested in accordance with ANS $\overline{\mathrm{I}} \mathbf{N 5 1 0 - 1 9 7 5}$.

e. After each complete or partial replacement of a HEPA filter bank by verifying that the HEPA filter banks remove $\geq(99.95) \%$ * of the DOP when they are tested in-place in accordance with ANSI N510-1975 while operating the system at a flow rate of $\mathrm{cfm} \pm 10 \%$.

f. After each complete or partial replacement of a charcoal adsorber bank by verifying that the charcoal adsorbers remove $>99.95 \%$ of a halogenated hydrocarbon refrigerant test gas when they are tested in-place in accordance with ANSI N510-1975 while operating the system at a flow rate of $\mathrm{cfm} \pm 10 \%$.

*99.95\% applicable when a filter efficiency of $99 \%$ is assumed in the safety analyses; $99 \%$ when a filter efficiency of $90 \%$ is assumed. 
CONTAINMENT SYSTEMS

3/4.6.4 CONTAINMENT ISOLATION VALVES

LIMITING CONDITION FOR OPERATION

3.6.4.1 The containment isolation valves specified in Table 3.6-2

shall be OPERABLE with isolation times as shown in Table 3.6-2.

APPLICABILITY: MODES $1,2,3$ and 4.

ACTION:

With one or more of the isolation valve(s) in Table 3.6-2 inoperable, maintain at least one isolation valve OPERABLE in each affected penetration that is open and either:

a. Restore the inoperable valve(s) to OPERABLE status within 4 hours, or

b. Isolate each affected penetration within 4 hours by use of at least one deactivated automatic valve secured in the isolation position, or

c. Isolate each affected penetration within 4 hours by use of at least one closed manual valve or blind flange, or

d. Be in at least HOT STANDBY within the next 6 hours and in COLD SHUTDOWN within the following 30 hours.

SURVEILLANCE REQUIREMENTS

4.6.4.1.1 The isolation valves specified in Table $3.6-2$ shall be demonstrated OPERABLE prior to returning the valve to service after maintenance, repair or replacement work is performed on the valve or its associated actuator, control or power circuit by performance of a cycling test and verification of isolation time. 
4.6.4.1.2 Each isolation valve specified in Table 3.6-2 shall be demonstrated OPERABLE during the COLD SHUTDOWN or REFUELING MODE at least once per 18 months by:
a. Verifying that on a containment isolation test signal, each automatic isolation valve actuates to its isolation position.
b. Verifying that on a Containment Purge and Exhaust isolation test signal, each Purge and Exhaust automatic valve actuates to its isolation position.

4.6.4.1.3 The isolation time of each power operated or automatic valve of Table 3.6-2 shall be determined to be within its 1 imit when tested pursuant to Specification 4.0.5. 
TABLE 3.6-2

A. CONTAINMENT ISOLATION

1.

2.

B. CONTAINMENT PURGE

AND EXHAUST

$\underset{\infty}{\omega}$

1 .

2.

C. MANUAL

1.

2.

D. OTHER

1 .

高 2 .

$\stackrel{\vec{\omega}}{\infty}$

* May be opened on an intermittent basis under administrative control.

\# Not subject to Type $C$ leakage tests. 
CONTAINMENT SYSTEMS

3/4.6.5 COMBUSTIBLE GAS CONTROL

HYDROGEN ANALYZERS

LIMITING CONDITION FOR OPERATION

3.6.5.1 Two independent containment hydrogen analyzers shall be OPERABLE.

APPLICABILITY: MODES 1 and 2.

ACTION:

With one hydrogen analyzer inoperable, restore the inoperable analyzer to OPERABLE status within 30 days or be in at least HOT STANDBY within the next 6 hours.

SURVEILLANCE REQUIREMENTS

4.6.5.1 Each hydrogen analyzer shal1 be demonstrated OPERABLE at least once per 92 days on a STAGGERED TEST BASIS by performing a CHANNEL

CALIBRATION using sample gases containing:

a. One volume percent hydrogen, balance nitrogen.

b. Four volume percent hydrogen, balance nitrogen. 
ELECTRIC HYDROGEN RECOMBINERS - W

LIMITING CONDITION FOR OPERATION

3.6.5.2 Two independent containment hydrogen recombiner systems shall be OPERABLE.

APPLICABILITY: MODES 1 and 2.

ACTION:

With one hydrogen recombiner system inoperable, restore the inoperable system to OPERABLE status within 30 days or be in at least HOT STANDBY within the next 6 hours.

SURVEILLANCE REQUIREMENTS

4.6.5.2 Each hydrogen recombiner system shall be demonstrated OPERABLE:

a. At least once per 6 months by verifying during a recombiner system functional test that the minimum heater sheath temperature increases to $>700^{\circ} \mathrm{F}$ with in 90 minutes and is maintained for at least 2 hours.

b. At least once per 18 months by:

1. Performing a CHANNEL CALIBRATION of all recombiner instrumentation and control circuits.

2. Verifying through a visual examination that there is no evidence of abnomal conditions within the recombiners (i.e., loose wiring or structural connections, deposits of foreign materials, etc.).

3. Verifying during a recombiner system functional test that the heater sheath temperature increases to $>1200^{\circ} \mathrm{F}$ within 5 hours and is maintained for at least 4 hours.

4. Verifying the integrity of the heater electrical circuits by performing a continuity and resistance to ground test following the above required functional test. The resistance to ground for any heater phase shall be $\geq 10,000$ ohms. 


\section{CONTAINMENT SYSTEMS}

HYDROGEN PURGE CLEANUP SYSTEM (If less than two hydrogen recombiners available)

LIMITING CONDITION FOR OPERATION

3.6.5.3 A containment hydrogen purge cleanup system shall be OPERABLE and capable of being powered from a minimum of one OPERABLE emergency bus.

APPLICABILITY: MODES 1 and 2.

ACTION:

With the containment hydrogen purge cleanup system inoperable, restore the hydrogen purge cleanup system to OPERABLE status within 30 days or be at least in HOT STANDBY within the next 6 hours.

\section{SURVEILLANCE REQUIREMENTS}

4.6.5.3 The hydrogen purge cleanup system shall be demonstrated OPERABLE :

a. At least once per 31 days by initiating, from the control room, flow through the HEPA filters and charcoal adsorbers and verifying that the system operates for at least 10 hours with the heaters on.

b. At least once per 18 months or (1) after any structural maintenance on the HEPA filter or charcoal adsorber housings, or

(2) following painting, fire or chemical release in any ventilation zone communicating with the system by:

1. Verifying that the cleanup system satisfies the in-place testing acceptance criteria and uses the test procedures of Regulatory Positions C.5.a, C.5.C and C.5.d of Regulatory Guide 1.52, Revision 2, March 1978, and the system flow rate is $\mathrm{cfm}+10 \%$.

2. Verifying within 31 days after removal that a laboratory analysis of a representative carbon sample obtained in accordance with Regulatory Position C.6.b of Regulatory Guide 1.52, Revision 2, March 1978, meets the laboratory testing criteria of Regulatory Position C.6.a of Regulatory Guide 1.52, Revision 2, March 1978.

3. Verifying a system flow rate of _cfm $\pm 10 \%$ during system operation when tested in accordance with ANSI N510-1975. 
c. After every 720 hours of charcoal adsorber operation by verifying within 31 days after removal that a laboratory analysis of a representative carbon sample obtained in accordance with Regulatory Position C.6.b of Regulatory Guide 1.52, Revision 2, March 1976, meets the laboratory testing criteria of Regulatory Position C.6.a of Regulatory Guide 1.52, Revision 2, March 1978.

d. At least once per 18 months by:

1. Verifying that the pressure drop across the combined HEPA filters and charcoal adsorber banks is < (6) inches Water Gauge while operating the system at a flow rate of $\mathrm{cfm}$ $+10 \%$.

2. Verifying that the filter cooling bypass valves can be manually opened. 3. Verifying that the heaters dissipate
when tested in ac ordance with ANSI $N \overline{510-197} \frac{+}{5}$.

e. After each complete or partial replacement of a HEPA filter Bank by verifying that the HEPA filter banks remove $\geq(99.95) \%$ * of the DOP when they are tested in-place in accordance with ANSI N510-1975 while operating the system at a flow rate of $\mathrm{cfm} \pm 10 \%$.

f. After each complete or partial replacement of a charcoal adsorber bank by verifying that the charcoal adsorbers remove $\geq 99.95 \%$ of a halogenated hydrocarbon refrigerant test gas when they are tested in-place in accordance with ANSI N5101975 while operating the system at a flow rate of $\mathrm{cfm} \pm$ $10 \%$.

*99.95\% applicable when a filter efficiency of $99 \%$ is assumed in the safety analyses; $99 \%$ when a filter efficiency of $90 \%$ is assumed. 


\section{CONTAINMENT SYSTEMS}

HYDROGEN MIXING SYSTEM (OPTIONAL)

LIMITING CONDITION FOR OPERATION

3.6.5.4 Two independent hydrogen mixing systems shall be OPERABLE. APPLICABILITY: MODES 1 and 2.

ACTION:

With one hydrogen mixing system inoperable, restore the inoperable system to OPERABLE status within 30 days or be in at least HOT STANDBY within the next 6 hours.

SURVEILLANCE REQUIREMENTS

4.6.5.4 Each hydrogen mixing system shal1 be demonstrated OPERABLE:

a. At least once per 92 days on a STAGGERED TEST BASIS by:

1. Verifying that the system can be started on operator action in the control room.

2. Verifying that the system operates for at least 15 minutes.

b. At least once per 18 months by verifying a system flow rate of at least cfm. 
CONTAINMENT SYSTEMS

3/4.6.6 PENETRATION ROOM EXHAUST AIR CLEANUP SYSTEM (OPTIONAL)

LIMITING CONDITION FOR OPERATION

3.6.6.1 Two independent containment penetration room exhaust air cleanup systems shall be OPERABLE.

APPLICABILITY: MODES 1,2 and 3.

ACTION:

With one contaiment penetration room exhaust air cleanup system inoperable, restore the inoperable system to OPERABLE status within 7 days or be in at least HOT STANDBY within the next 6 hours and in COLD SHUTDOWN within the following 30 hours.

SURVEILLANCE REQUIREMENTS

4.6.6.1 Each containment penetration room exhaust air cleanup system shall be demonstrated OPERABLE:

a. At least once per 31 days on a STAGGERED TEST BASIS by initiating, from the control room, flow through the HEPA filters and charcoal adsorbers and verifying that the system operates for at least 10 hours with the heaters on.

b. At least once per 18 months or (1) after any structural maintenance on the HEPA filter or charcoal adsorber housings, or

(2) following painting, fire or chemical release in any ventilation zone communicating with the system by:

1. Verifying that with the system operating at a flow rate of $\quad \mathrm{cfm}+10 \%$ and exhausting through the HEPA filters and charcoal adsorbers, the total bypass flow of the system to the facility vent, including leakage through the system diverting valves, is $<1 \%$ when the system is tested by admitting cold DOP at the system intake. (For systems with diverting valves.)

2. Verifying that the cleanup system satisfies the in-place testing acceptance criteria and uses the test procedures 
of Regulatory Positions C.5.a, C.5.C and C.5.d of Regulatory Guide 1.52, Revision 2, March 1978, and the system flow rate is $\mathrm{cfm}+10 \%$.

3. Verifying within 31 days after removal that a laboratory analysis of a representative carbon sample obtained in accordance with Regulatory Position C.6.b of Regulatory Guide 1.52, Revision 2, March 1978, meets the laboratory testing criteria of Regulatory Position C.6.a of Regulatory Guide 1.52, Revision 2, March 1978.

4. Verifying a system flow rate of $\mathrm{cfm} \pm 10 \%$ during system operation when tested in accordance with ANSI N510-1975.

c. After every 720 hours of charcoal adsorber operation by verifying within 31 days after removal that a laboratory analys is of a representative carbon sample obtained in accordance with Regulatory Position C.6.b of Regulatory Guide 1.52, Revision 2, March 1978, meets the laboratory testing criteria of Regulatory Position C.6.a of Regulatory Guide 1.52, Revision 2, March 1978.

d. At least once per 18 months by:

1. Verifying that the pressure drop across the combined HEPA filters and charcoal adsorber banks is < (6) inches Water Gauge while operating the system at a flow rate of $\mathrm{cfm}$ $+10 \%$.

2. Verifying that the system starts on a safety injection test signal.

3. Verifying that the filter cooling bypass valves can be manually opened.

4. Verifying that the heaters dissipate $+\ldots$ when tested in accordance with ANSI $\sqrt{510-197} \overline{5}$. 
e. After each complete or partial replacement of a HEPA filter bank by verifying that the HEPA filter banks remove $\geq(99.95) \%$ * of the DOP when they are tested in-place in accordance with ANSI N510-1975 while operating the system at a flow rate of $\mathrm{cfm} \pm 10 \%$.

f. After each complete or partial replacement of a charcoal adsorber bank by verifying that the charcoal adsorbers remove $\geq 99.95 \%$ of a halogenated hydrocarbon refrigerant test gas when they are tested in-place in accordance with ANSI N5101975 while operating the system at a flow rate of $\mathrm{cfm} \pm$ $10 \%$.

*99.95\% applicable when a filter efficiency of $99 \%$ is assumed in the safety analyses; $99 \%$ when a filter efficiency of $90 \%$ is assumed. 
3/4.6.7 VACUUM RELIEF VALVES (OPTIONAL)

LIMITING CONDITION FOR OPERATION

3.6.7.1 The primary containment to atmosphere vacuum relief valves sha11 be OPERABLE with an actuation setpoint of $\leq$ psid.

APPLICABILITY: MODES $1,2,3$ and 4.

ACTION:

With one primary containment to atmosphere vacuum relief valve inoperable, restore the valve to OPERABLE status within 4 hours or be in at least HOT STANDBY within the next 6 hours and in COLD SHUTDOWN within the following 30 hours.

SURVEILLANCE REQUIREMENTS

4.6.7.1 No additional Surveillance Requirements other than those required by Specification 4.0.5. 
CONTAINMENT SYSTEMS

3/4.6.8 SECONDARY CONTAINMENT

SHIELD BUILDING AIR CLEANUP SYSTEM

LIMITING CONDITION FOR OPERATION

3.6.8.1 Two independent shield building air cleanup systems shall be OPERABLE.

APPLICABILITY: MODES $1,2,3$ and 4 .

ACTION:

With one shield building air cleanup system inoperable, restore the inoperable system to OPERABLE status within 7 days or be in at least HOT STANDBY within the next 6 hours and in COLD SHUTDOWN within the following 30 hours.

SURVEILLANCE REQUIREMENTS

4.6.8.1 Each shield building air cleanup system shall be demonstrated OPERABLE:

a. At least once per 31 days on a STAGGERED TEST BASIS by initiating, from the control room, flow through the HEPA filters and charcoal adsorbers and verifying that the system operates for at least 10 hours with the heaters on.

b. At least once per 18 months or (1) after any structural maintenance on the HEPA filter or charcoal adsorber housings, or (2) following painting, fire or chemical release in any ventilation zone communicating with the system by:

1. Verifying that with the system operating at a flow rate of $\quad \mathrm{cfm} \pm 10 \%$ and exhausting through the HEPA filters and charcoal adsorbers, the total bypass flow of the system to the facility vent, including leakage through the system diverting valves, is $\leq 1 \%$ when the system is tested by admitting cold DOP at the system intake. (For systems with diverting valves.) 
2. Verifying that the cleanup system satisfies the in-place testing acceptance criteria and uses the test procedures of Regulatory Positions C.5.a, C.5.C and C.5.d of Regulatory Guide 1.52, Revision 2, March 1978, and the system flow rate is $\mathrm{cfm} \pm 10 \%$.

3. Verifying within 31 days after removal that a laboratory analysis of a representative carbon sample obtained in accordance with Regulatory Position C.6.b of Regulatory Guide 1.52, Revision 2, March 1978, meets the laboratory testing criteria of Regulatory Position C.6.a of Regulatory Guide 1.52, Revision 2, March 1978.

4. Verifying a system flow rate of $\mathrm{cfm}+10 \%$ during system operation when tested in accordance with ANSI N510-1975.

c. After every 720 hours of charcoal adsorber operation by verifying within 31 days after removal that a laboratory analys is of a representative carbon sample obtained in accordance with Regulatory Position C.6.b of Regulatory Guide 1.52, Revision 2 , March 1978, meets the laboratory testing criteria of Regulatory Position C.6.a of Regulatory Guide 1.52, Revision 2, March 1978.

d. At least once per 18 months by:

1. Verifying that the pressure drop across the combined HEPA filters and charcoal adsorber banks is < (6) inches Water Gauge while operating the system at a flow rate of __ cfm $+10 \%$.

2. Verifying that the system starts automatically on any containment isolation test signal.

3. Verifying that the filter cooling bypass valves can be manually opened.

4. Verifying that each system produces a negative pressure of $>(0.25)$ inches W.G. in the annulus within (1) minute after a start signal.

5. Verifying that the heaters dissipate when tested in accordance with ANSI $\sqrt{510-197} \overline{5}$. $\mathrm{kW}$ 
e. After each complete or partial replacement of a HEPA filter bank by verifying that the HEPA filter banks remove $\geq(99.95) \%$ * of the DOP when they are tested in-place in accordance with ANSI N510-1975 while operating the system at a flow rate of $\mathrm{cfm} \pm 10 \%$.

f. After each complete or partial replacement of a charcoal adsorber bank by verifying that the charcoal adsorbers remove $\geq 99.95 \%$ of a halogenated hydrocarbon refrigerant test gas when they are tested in-place in accordance with ANSI N5101975 while operating the system at a flow rate of $\mathrm{cfm} \pm$ $10 \%$.

*99.95\% applicable when a filter efficiency of $99 \%$ is assumed in the safety analyses; $99 \%$ when a filter efficiency of $90 \%$ is assumed. 
CONTAINMENT SYSTEMS

SHIELD BUILDING INTEGRITY

LIMITING CONDITION FOR OPERATION

3.6.8.2 SHIELD BUILDING INTEGRITY shall be maintained.

APPLICABILITY: MODES $1,2,3$ and 4.

ACTION:

Without SHIELD BUILDING INTEGRITY, restore SHIELD BUILDING INTEGRITY within 24 hours or be in at least HOT STANDBY within the next 6 hours and in COLD SHUTDOWN within the following 30 hours.

SURVEILLANCE REQUIREMENTS

3.6.8.2 SHIELD BUILDING INTEGRITY shall be demonstrated at least once per 31 days by verifying that each door in each access opening is closed except when the access opening is being used for normal transit entry and exit, then at least one door shall be closed. 
CONTAINMENT SYSTEMS

SHIELD BUILDING STRUCTURAL INTEGRITY

LIMITING CONDITION FOR OPERATION

3.6.8.3 The structural integrity of the shield building shall be maintained at a level consistent with the acceptance criteria in Specification 4.6.8.3.

APPLICABILITY: MODES $1,2,3$ and 4.

ACTION:

With the structural integrity of the shield building not conforming to the original acceptance standards, restore the structural integrity to within the limits prior to increasing the Reactor Coolant System temperature above $200^{\circ} \mathrm{F}$.

SURVEILLANCE REQUIREMENTS

4.6.8.3 The structural integrity of the shield building shall be determined during the shutdown for each Type A containment leakage rate test (reference Specification 4.6 .1 .2 ) by a visual inspection of the accessible interior and exterior surfaces of the shield building and verifying no apparent changes in appearance of the concrete surfaces or other abnormal degradation. Any abnormal degradation of the shield building detected during the above required inspections shall be reported to the Commission pursuant to Specification 6.9.1. 
$3 / 4.7$ PLANT SYSTEMS

3/4.7.1 TURBINE CYCLE

SAFETY VALVES

LIMITING CONDITION FOR OPERATION

3.7.1.1 All main steam line code safety valves shall be OPERABLE with lift settings as specified in Table 3.7-4.

APPLICABILITY: MODES 1,2 and 3.

ACTION:

With one or more main steam line code safety valves inoperable, operation in MODES 1,2 and 3 may proceed provided, that within 4 hours, either the inoperable valve is restored to OPERABLE status or the Nuclear Overpower Trip Setpoint is reduced per Table 3.7-1; otherwise, be in at least HOT STANDBY within the next 6 hours and in COLD SHUTDOWN within the following 30 hours. The provisions of Specification 3.0.4 are not applicable.

SURVEILLANCE REQUIREMENTS

4.7.1.1 No additional Surveillance Requirements other than those required by Specification 4.0 .5 . 
TABLE 3.7-1

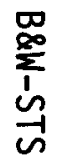

MAXIMUM ALLOWABLE NUCLEAR OVERPOWER TRIP SETPOINT WITH INOPERABLE STEAM LINE SAFETY VALVES

Maximum Number of Inoperable Safety

Valves on Any Steam Generator

1

2

3

Maximum Allowable Nuclear

Overpower Trip Setpoint

(Percent of RATED THERMAL POWER)

$\stackrel{\omega}{a}$

ñ

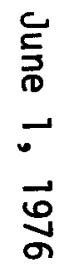


TABLE $3.7-4$

\section{STEAM LINE SAFETY VALVES PER STEAM GENERATOR}

VALVE NUMBER

a.

b.

c.

d.

$\stackrel{\omega}{\phi}$

'́

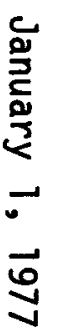

LIFT SETTING $( \pm 1 \%)^{*}$

psig

psig

psig

psig

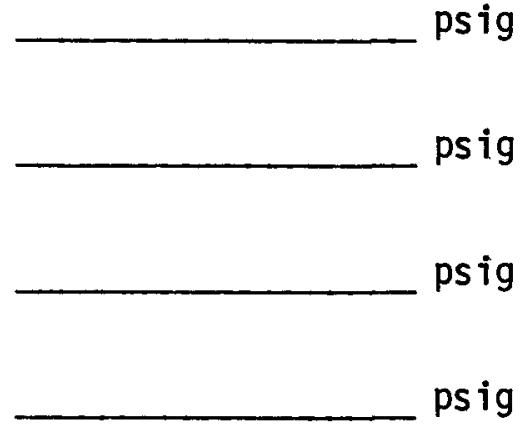

ORIFICE SIZE

*The lift setting pressure shall correspond to ambient conditions of the valve at nominal operating temperature and pressure. 
PLANT SYSTEMS

ALXILIARY FEEDWATER SYSTEM

LIMITING CONDITION FOR OPERATION

3.7.1.2 Two independent steam generator auxiliary feedwater pumps and associated flow paths shall be OPERABLE with:

a. One auxiliary feedwater pump capable of being powered from an OPERABLE emergency bus.

b. One auxiliary feedwater pump capable of being powered from an OPERABLE steam supply system.

APPLICABILITY: MODES 1,2 and 3 .

ACTION:

With one auxiliary feedwater system inoperable, restore the inoperable system to OPERABLE status within 72 hours or be in HOT SHUTDOWN within the next 12 hours.

SURVEILLANCE REQUIREMENTS

4.7.1.2 Each auxiliary feedwater system shall be demonstrated OPERABLE:

a. At least once per 31 days by:

1. Verifying that each motor driven pump develops a discharge pressure of $\geq$ psig at a flow of $\geq$ gpm.

2. Verifying that each steam turbine driven pump develops a discharge pressure of $\geq \quad$ psig at a flow of $\geq \quad \mathrm{gpm}$ when the secondary steam supply pressure is greater than psig.

3. Verifying that each valve (manual, power operated or automatic) in the flow path that is not locked, sealed or otherwise secured in position, is in its correct position. 


\section{PLANT SYSTEMS}

SURVEILLANCE REQUIREMENTS (Continued)

b. At least once per 18 months, during shutdown, by:

1. Verifying that each automatic valve in the flow path actuates to its correct position on an auxiliary feedwater actuation test signal.

2. Verifying that each pump starts automatically upon receipt of an (auxiliary feedwater actuation test) signal. 


\section{PLANT SYSTEMS}

CONDENSATE STORAGE TANK

LIMITING CONDITION FOR OPERATION

3.7.1.3 The condensate storage tank (CST) shall be OPERABLE with a minimum contained volume of gallons of water.

APPLICABILITY: MODES 1,2 and 3.

ACTION:

With the condensate storage tank inoperable, within 4 hours either:

a. Restore the CST to OPERABLE status or be in HOT SHUTDOWN within the next 12 hours, or

b. Demonstrate the OPERABILITY of the (alternate source) as a backup supply to the auxiliary feedwater system and restore the condensate storage tank to OPERABLE status within 7 days or be in HOT SHUTDOWN within the next 12 hours.

SURVEILLANCE REQUIREMENTS

4.7.1.3.1 The condensate storage tank shall be demonstrated OPERABLE at least once per 12 hours by verifying the contained water volume to be within its limits when the tank is the supply source for the auxiliary feedwater pumps.

4.7.1.3.2 The (alternate water source) shall be demonstrated OPERABLE at least once per 12 hours by (method dependent upon alternate source) whenever the (alternate water source) is the supply source for the auxiliary feedwater pumps. 


\section{PLANT SYSTEMS}

ACTIVITY

3.7.1.4 The specific activity of the secondary coolant system shall be $\leq 0.10 \mu \mathrm{Ci} / \mathrm{gram}$ DOSE EQUIVALENT I- 131 .

APPLICABILITY: MODES $1,2,3$ and 4 .

ACTION:

With the specific activity of the secondary coolant system $>0.10 \mu \mathrm{Ci} / \mathrm{gram}$ DOSE EQUIVALENT I-131, be in at least HOT STANDBY within 6 hours and in COLD SHUTDOWN within the following 30 hours.

4.7.1.4 The specific activity of the secondary coolant system shall be determined to be within the limit by performance of the sampling and analysis program of Table 4.7-2. 


\section{TABLE 4.7-2}

SECONDARY COOLANT SYSTEM SPECIFIC ACTIVITY

SAMPLE AND ANALYSIS PROGRAM

TYPE OF MEASUREMENT AND ANALYSIS

1. Gross Activity Determination

2. Isotopic Analysis for DOSE EQUIVALENT I-131 Concentration
SAMPLE AND

ANALYSIS FREQUENCY

At least once per 72 hours

a) 1 per 31 days, whenever the gross activity determination indicates iodine concentrations greater than 10\% of the allowable limit.

b) 1 per 6 months, whenever the gross activity determination indicates iodine concentrations below $10 \%$ of the allowable limit. 


\section{PLANT SYSTEMS}

MAIN STEAM LINE ISOLATION VALVES

LIMITING CONDITION FOR OPERATION

3.7.1.5 Each main steam line isolation valve shall be OPERABLE.

APPLICABILITY: MODES 1,2 and 3.

ACTION:

MODE 1 - With one main steam line isolation valve inoperable, POWER OPERATION may continue provided the inoperable valve is either restored to OPERABLE status or closed within 4 hours. Otherwise, be in HOT SHUTDOWN within the next 12 hours.

MODES 2

and 3 - With one main steam line isolation valve inoperable, subsequent operation in MODES 1,2 or 3 may proceed provided:

a. The inoperable isolation valve is maintained closed. Otherwise, be in HOT SHUTDOWN within the next 12 hours.

b. The provisions of Specification 3.0.4 are not applicable.

SURVEILLANCE REQUIREMENTS

4.7.1.5 Each main steam line isolation valve shall be demonstrated OPERABLE by verifying full closure within to Specification 4.0 .5 . seconds when tested pursuant 


\section{PLANT SYSTEMS}

SECONDARY WATER CHEMISTRY

LIMITING CONDITION FOR OPERATION

3.7.1.6 The secondary water chemistry shall be maintained within the limits of Table 3.7-2.

APPLICABLITY: MODES 1,2 and 3.

ACTION:

(To be determined in a manner set forth in the bases and to be imposed by a change to this Specification.)

4.7.1.6 The secondary water chemistry shall be determined to be within the limits by analysis of those parameters at the frequencies specified in Table 4.7-3. 
TABLE 3.7-2

\section{SECONDARY WATER CHEMISTRY LIMITS}

Water Sample Location

$\star$

$\omega$
$I$
$I$

흠

\section{Parameters*}

\#Sample locations, parameters and limits to be established in approximatley 6 months following issuance of the full power license based upon test program described in bases. 
TABLE $4.7-3$

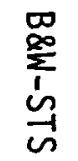

SECONDARY WATER CHEMISTRY SURVEILLANCE REQUIREMENTS

Water sample

Location

\section{Parameters*}

$\star$

$\stackrel{\omega}{\infty}$

$\frac{1}{N}$

$\stackrel{c}{\grave{5}}$

$-$

\#Sample Tocations, parameters and frequencies to be established in approximately 6 months following issuance of the full power 1 icense based upon test program described in bases.

$\vec{v}$ 


\section{PLANT SYSTEMS}

3/4.7.2 STEAM GENERATOR PRESSURE/TEMPERATURE LIMITATION

LIMITING CONDITION FOR OPERATION

3.7.2.1 The temperature of the secondary coolant in the steam generators shail be $>(110)^{\circ} \mathrm{F}$ when the pressure of the secondary coolant in the steam generator is > (237) psig.

APPLICABILITY: At all times.

ACTION:

With the requirements of the above specification not satisfied:

a. Reduce the steam generator pressure to $\leq(237)$ psig within 30 minutes.

b. Perform an engineering evaluation to determine the effect of overpressurization on the structural integrity of the steam generator. Determine that the steam generator remains acceptable for continued operation prior to increasing its pressure above (237) psig.

SURVEILLANCE REQUIREMENTS

4.7.2.1 The temperature of the secondary coolant in each steam generator shall be determined to be $>(110)^{\circ} \mathrm{F}$ at least once per hour when secondary pressure in the steam generator is $>(237)$ psig and $\mathrm{T}_{\text {avg }}$ is $<200^{\circ} \mathrm{F}$. 
PLANT SYSTEMS

3/4.7.3 COMPONENT COOLING WATER SYSTEM

LIMITING CONDITION FOR OPERATION

3.7.3.1 Two independent component cooling water loops shall be OPERABLE. APPLICABILITY: MODES $1,2,3$ and 4.

ACTION:

With one component cooling water loop inoperable, restore the inoperable loop to OPERABLE status within 72 hours or be in at least HOT STANDBY within the next 6 hours and in COLD SHUTDOWN within the following 30 hours.

\section{SURVEILLANCE REQUIREMENTS}

4.7.3.1 Each component cooling water loop sha11 be demonstrated OPERABLE:

a. At least once per 31 days by verifying that each valve (manual, power operated or automatic) servicing safety related equipment that is not locked, sealed or otherwise secured in position, is in its correct position.

b. At least once per 18 months, during shutdown, by:

1. Verifying that each automatic valve in the flow path actuates to its correct position on an ESFAS test signal.

2. Verifying that each component cooling water emergency pump starts automatically on an ESFAS test signal. 
PLANT SYSTEMS

3/4.7.4 SERVICE WATER SYSTEM

LIMITING CONDITION FOR OPERATION

3.7.4.1 Two independent service water loops shall be OPERABLE.

APPLICABILITY: MODES $1,2,3$ and 4.

ACTION:

With one service water loop inoperable, restore the inoperable loop to OPERABLE status within 72 hours or be in at least HOT STANDBY within the next 6 hours and in COLD SHUTDOWN within the following 30 hours.

SURVEILLANCE REQUIREMENTS

4.7.4.1 Each service water loop shall be demonstrated OPERABLE:

a. At least once per 31 days by verifying that each valve (manual, power operated or automatic) servicing safety related equipment that is not locked, sealed or otherwise secured in position, is in its correct position.

b. At least once per 18 months, during shutdown, by:

1. Verifying that each automatic valve in the flow path actuates to its correct position on an ESFAS test signal.

2. Verifying that each service water emergency pump starts automatically on an ESFAS test signal. 
PLANT SYSTEMS

3/4.7.5 ULTIMATE HEAT SINK (OPTIONAL)

LIMITING CONDITION FOR OPERATION

3.7.5.1 The ultimate heat sink shall be OPERABLE with:

a. A minimum water level at or above elevation (__ Mean Sea Leve1, USGS datum.

b. An average water temperature of $\leq(\ldots)^{\circ} \mathrm{F}$.

APPLICABILITY: MODES 1,2, 3 and 4 .

ACTION:

With the requirements of the above specification not satisfied, be in at least HOT STANDBY within 6 hours and in COLD SHUTDOWN within the following 30 hours.

SURVEILLANCE REQUIREMENTS

4.7.5.1 The ultimate heat sink shall be determined OPERABLE at least once per 24 hours by verifying the average water temperature and water level to be within their limits. 
PLANT SYSTEMS

3/4.7.6 FLOOD PROTECTION (OPTIONAL*)

LIMITING CONDITION FOR OPERATION

3.7.6.1 Flood protection shall be provided for all safety related systems, components and structures when the water level of the (usually the ultimate heat sink) exceeds ___ Mean Sea Level USGS datum, at

APPLICABILITY: At all times.

ACTION:

With the water level at __ above elevation __ Mean Sea Level USGS datum:

a. (Be in at least HOT STANDBY within 6 hours and in at least COLD SHUTDOWN within the following 30 hours.)

b. Initiate and complete within hours, the following flood protection measures.

1. (Plant dependent)

2. (Plant dependent)

SURVEILLANCE REQUIREMENTS

4.7.6.1 The water level at shall be determined to be within the limit by:

a. Measurement at least once per 24 hours when the water level is below elevation Mean Sea Leve1 USGS datum, and

b. Measurement at least once per 2 hours when the water level is equal to or above elevation Mean Sea Level USGS datum.

This specification not required if the facility design has adequate passive flood control protection features sufficient to accommodate the Design Basis Flood identified in Regulatory Guide 1.59, August 1973. 


\section{PLANT SYSTEMS}

\section{3/4.7.7 CONTROL ROOM EMERGENCY AIR CLEANUP SYSTEM}

LIMITING CONDITION FOR OPERATION

3.7.7.1 Two independent control room emergency air cleanup systems shal1 be OPERABLE.

APPLICABILITY: MODES $1,2,3$ and 4.

ACTION:

Wi th one control room emergency air cleanup system inoperable, restore the inoperable system to OPERABLE status within 7 days or be in at least HOT STANDBY within the next 6 hours and in COLD SHUTDOWN within the following 30 hours.

SURVEILLANCE REQUIREMENTS

4.7.7.1 Each control room emergency air cleanup system shall be demonstrated OPERABLE:

a. At least once per 12 hours by verifying that the control room air temperature is $\leq(120)^{\circ} \mathrm{F}$.

b. At least once per 31 days on a STAGGERED TEST BASIS by initiating, from the control room, flow through the HEPA filters and charcoal adsorbers and verifying that the system operates for at least 10 hours with the heaters on.

c. At least once per 18 months or (1) after any structural maintenance on the HEPA filter or charcoal adsorber housings, or (2) following painting, fire or chemical release in any ventilation zone communicating with the system by: 


\section{PLANT SYSTEMS}

SURVEILLANCE REQUIREMENTS (Continued)

1. Verifying that with the system operating at a flow rate of $\mathrm{cfm} \pm 10 \%$ and exhausting through the HEPA filters and charcoal adsorbers, the total bypass flow of the system to the facility vent, including leakage through the system diverting valves, is $\leq 1 \%$ when the system is tested by admitting cold DOP at the system intake. (For systems with diverting valves.)

2. Verifying that the cleanup system satisfies the in-place testing acceptance criteria and uses the test procedures of Regulatory Positions C.5.a, C.5.C and C.5.d of Regulatory Guide 1.52, Revision 2, March 1978, and the system flow rate is cfm $+10 \%$.

3. Verifying within 31 days after removal that a laboratory analysis of a representative carbon sample obtained in accordance with Regulatory Position C.6.b of Regulatory Guide 1.52, Revision 2, March 1978, meets the laboratory testing criteria of Regulatory Position C.6.a of Regulatory Guide 1.52, Revision 2, March 1978.

4. Verifying a system flow rate of _cfm $+10 \%$ during system operation when tested in accordance with ANSI N510-1975.

d. After every 720 hours of charcoal adsorber operation by verifying within 31 days after removal that a laboratory analys is of a representative carbon sample obtained in accordance with Regulatory Position C.6.b of Regulatory Guide 1.52, Revision 2, March 1978, meets the laboratory testing criteria of Regulatory Position C.6.a of Regulatory Guide 1.52, Revision 2, March 1978.

e. At least once per 18 months by:

1. Verifying that the pressure drop across the combined HEPA filters and charcoal adsorber banks is < (6) inches Water Gauge while operating the system at a flow rate of cfm $\pm 10 \%$.

2. Verifying that on a containment isolation test signal and chlorine detection test signal, the system automatically switches into a recirculation mode of operation with flow through the HEPA filters and charcoal adsorber banks. 
3. Verifying that the system maintains the control room at a positive pressure of $\geq(1 / 4)$ inch W.G. relative to the outside atmosphere during system operation.

4. Verifying that the heaters dissipate $+\ldots$ when tested in accordance with ANSI $N \overline{510-1975}$.

f. After each complete or partial replacement of a HEPA filter bank by verifying that the HEPA filter banks remove $\geq(99.95) \%$ * of the DOP when they are tested in-place in accordance with ANSI N510-1975 while operating the system at a flow rate of $\mathrm{cfm} \pm 10 \%$.

9. After each complete or partial replacement of a charcoal adsorber bank by verifying that the charcoal adsorbers remove $\geq 99.95 \%$ of a halogenated hydrocarbon refrigerant test gas when they are tested in-place in accordance with ANSI N510-1975 while operating the system at a flow rate of cfm $\pm 10 \%$.

ॠ99.95\% applicable when a filter efficiency of $99 \%$ is assumed in the safety analyses; $99 \%$ when a filter efficiency of $90 \%$ is assumed. 
PLANT SYSTEMS

3/4.7.8 ECCS PUMP ROOM EXHAUST AIR CLEANUP SYSTEM

LIMITING CONDITION FOR OPERATION

3.7.8.1 Two independent ECCS pump room exhaust cleanup systems trains shall be OPERABLE.

APPLICABILITY: MODES $1,2,3$ and 4.

ACTION:

With one ECCS pump room exhaust air cleanup system inoperable, restore the inoperable system to OPERABLE status within 7 days or be in at least HOT STANDBY within the next 6 hours and in COLD SHUTDOWN within the following 30 hours.

\section{SURVEILLANCE REQUIREMENTS}

4.7.8.1 Each ECCS pump room exhaust air cleanup system shall be demonstrated OPERABLE:

a. At least once per 31 days on a STAGGERED TEST BASIS by initiating, from the control room, flow through the HEPA filters and charcoal adsorbers and verifying that the system operates for at least 10 hours with the heaters on.

b. At least once per 18 months or (1) after any structural maintenance on the HEPA filter or charcoal adsorber housings, or (2) following painting, fire or chemical release in any ventilation zone communicating with the system by:

1. Verifying that with the system operating at a flow rate of $\quad \mathrm{cm}+10 \%$ and exhausting through the HEPA filters and charcoal adsorbers, the total bypass flow of the system to the facility vent, including leakage through the system diverting valves, is $\leq 1 \%$ when the system is tested by admitting cold DOP at the system intake. (For systems with diverting valves.) 
2. Verifying that the cleanup system satisfies the in-place testing acceptance criteria and uses the test procedures of Regulatory Positions C.5.a, C.5.C and C.5.d of Regulatory Guide 1.52, Revision 2, March 1978, and the system flow rate is cfm $+10 \%$.

3. Verifying within 31 days after removal that a laboratory analysis of a representative carbon sample obtained in accordance with Regulatory Position C.6.b of Regulatory Guide 1.52, Revision 2, March 1978, meets the laboratory testing criteria of Regulatory Position C.6.a of Regulatory Guide 1.52, Revision 2, March 1978.

4. Verifying a system flow rate of cfm $+10 \%$ during system operation when tested in accordance with ANSI N510-1975.

c. After every 720 hours of charcoal adsorber operation by verifying within 37 days after removal that a laboratory analysis of a representative carbon sample obtained in accordance with Regulatory Position C.6.5 of Regulatory Guide 1.52, Revision 2, March 1978, meets the laboratory testing criteria of Regulatory Position C.6.a of Regulatory Guide 1.52, Revision 2, March 1978.

d. At least once per 18 months by:

1. Verifying that the pressure drop across the combined HEPA filters and charcoal adsorber banks is $<(6)$ inches water Gauge while operating the system at a flow rate of $\mathrm{cfm}$ $\pm 10 \%$.

2. Verifying that the system starts on a safety injection test signal.

3. Verifying that the filter cooling bypass valves can be manually opened.

4. Verifying that the heaters dissipate $t+\mathrm{kw}$ when tested in accordance with ANSI $\sqrt{510-1975}$. 


\section{PLANT SYSTEMS}

SURVEILLANCE REQUIREMENTS (Continued)

e. After each complete or partial replacement of a HEPA filter bank by verifying that the HEPA filter banks remove $\geq(99.95) \% *$ of the DOP when they are tested in-place in accordance with ANSI N510-1975 while operating the system at a flow rate of $c f m \pm 10 \%$.

f. After each complete or partial replacement of a charcoal adsorber bank by verifying that the charcoal adsorbers remove $>99.95 \%$ of a halogenated hydrocarbon refrigerant test gas when they are tested in-place in accordance with ANSI N510-1975 while operating the system at a flow rate of $c f m \pm 10 \%$.

*99.95\% applicable when a filter efficiency of $99 \%$ is assumed in the safety analyses; $99 \%$ when a filter efficiency of $90 \%$ is assumed. 
PLANT SYSTEMS

3/4.7.9 HYDRAULIC SNUBBERS

LIMITING CONDITION FOR OPERATION

3.7.9.1 All hydraulic snubbers listed in Table 3.7-3 shall be OPERABLE.

APPLICABILITY: MODES $1,2,3$ and 4.

ACTION:

With one or more hydraulic snubbers inoperable, replace or restore the inoperable snubber(s) to OPERABLE status within 72 hours or be in at least HOT STANDBY within the next 6 hours and in COLD SHUTDOWN within the following 30 hours.

SURVEILLANCE REQUIREMENTS

4.7.9.1 Hydraulic snubbers will be demonstrated OPERABLE by performance of the following augmented inservice inspection program and the requirements of Specification 4.0.5.

a. Each hydraulic snubber with seal material fabricated from ethylene propylene or other materials demonstrated compatible with the operating environment and approved as such by the NRC, shall be determined OPERABLE at least once after not less than 4 months but within 6 months of initial criticality and in accordance with the inspection schedule of Table 4.7-4 thereafter, by a visual inspection of the snubber. Visual inspections of the snubbers shall include, but are not necessarily 1 imited to, inspection of the hydraulic fluid reservoirs, fluid connections, and linkage connections to the piping and anchors. Initiation of the Table 4.7-4 inspection schedule shall be made assuming the unit was previously at the 6 month inspection interval.

b. Each hydraulic snubber with seal material not fabricated from ethylene propylene or other materials demonstrated compatible with the operating environment shall be determined OPERABLE at least once per 31 days by a visual inspection of the snubber. Visual inspections of the snubbers shall include, but are not necessarily limited to, inspection of the hydraulic fluid reservoirs, fluid connections, and linkage connections to the piping and anchors. 


\section{PLANT SYSTEMS}

HYDRAULIC SNUBBERS (Continued)

SURVEILLANCE REQUIREMENTS (Continued)

c. At least once per 18 months during shutdown a representative sample of at least 10 hydraulic snubbers or at least $10 \%$ of all snubbers listed in Table 3.7-3, whichever is less, shall be selected and functionally tested to verify correct piston movement, lock up and bleed. Snubbers greater than 50,000 1bs capacity may be excluded from functional testing requirements. Snubbers selected for functional testing shall be selected on a rotating basis. Snubbers identified in Table 3.7-3 as either "Especially Difficult to Remove" or in "High Radiation Zones" may be exempted from functional testing provided these snubbers were demonstrated OPERABLE during previous functional tests. Snubbers found inoperable during functional testing shall be restored to OPERABLE status prior to resuming operation. For each snubber found inoperable during these functional tests, an additional minimum of $10 \%$ of a 11 snubbers or 10 snubbers, whichever is less, shall also be functionally tested until no more failures are found or all snubbers have been functionally tested. 
TABLE 3.7-3

\section{SAFETY RELATED HYDKAULIC SNUBBERS*}

SNUBBER

NO.

\section{ACCESSIBLE OR INACCESSIBLE $(A$ or $I)$ \\ HIGH RADIATION ZONE DURING SHUTDOWN**}

ESPECIALLY DIFFICULT

TO REMOVE

\# Snubbers may be added to safety related systems without prior License Amendment to Table 3.7-3 provided that a revision to Table 3.7-3 is included with the next License Amendment request.

$\frac{\complement}{5}$

* Modifications to this column due to changes in high radiation areas may be made without prior license amendment provided a revision to Table 3.7-3 is included with the next License Amendment request. 
TABLE 4.7-4

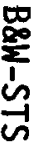

\section{HYDRAULIC SNUBBER INSPECTION SCHEDULE}

NUMBER OF SNUBBERS FOUND INOPERABLE

NEXT REQUIRED

DURING INSPECTION OR DURING INSPECTION INTERVAL *

INSPECTION INTERVAL **

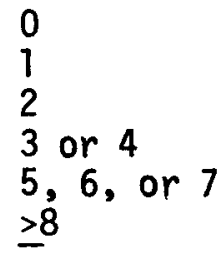

18 months $+25 \%$

12 months $+25 \%$

6 months $\mp 25 \%$

124 days $\mp 25 \%$

62 days $\mp 25 \%$

31 days $\mp 25 \%$

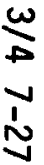

* Snubbers may be categorized into two groups, "accessible" and "inaccessible". This categorization shall be based upon the snubber's accessibility for inspection during reactor operation. These two groups may be inspected independently according to the above schedule.

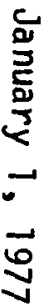

** The required inspection interval shall not be lengthened more than one step at a time and the provisions of Specification 4.0 .2 are not applicable. 
PLANT SYSTEMS

3/4.7.10 SEALED SOURCE CONTAMINATION

LIMITING CONDITION FOR OPERATION

3.7.10.1 Each sealed source containing radioactive material either in excess of 100 microcuries of beta and/or gamma emitting material or 5 microcuries of alpha emitting material shall be free of $\geq 0.005$ microcuries of removable contamination.

APPLICABILITY: At all times.

ACTION:

a. Each sealed source with removable contamination in excess of the above limit shall be immediately withdrawn from use and:

1. Either decontaminated and repaired, or

2. Disposed of in accordance with Commission Regulations.

b. The provisions of Specifications 3.0.3 and 3.0.4 are not applicable.

SURVEILLANCE REQUIREMENTS

4.7.10.1.1 Test Requirements - Each sealed source shall be tested for leakage and/or contamination by:
a. The licensee, or
b. Other persons specifically authorized by the Commission or an Agreement State.

The test method shall have a detection sensitivity of at least 0.005 microcuries per test sample.

4.7.10.1.2 Test Frequencies - Each category of sealed sources (excluding startup sources and fission detectors previously subjected to core flux) shall be tested at the frequency described below.

a. Sources in use - At least once per six months for all sealed sources containing radioactive material:

B\&W-STS

$3 / 4 \quad 7-28$

June 1978 


\section{PLANT SYSTEMS}

SURVEILLANCE REQUIREMENTS (Continued)

1. With a half-life greater than 30 days (excluding Hydrogen 3 ) and

2. In any form other than gas.

b. Stored sources not in use - Each sealed source and fission detector shall be tested prior to use or transfer to another licensee unless tested within the previous six months. Sealed sources and fission detectors transferred without a certificate indicating the last test date shall be tested prior to being placed into use.

c. Startup sources and fission detectors - Each sealed startup source and fission detector shall be tested within 31 days prior to being subjected to core flux or installed in the core and following repair or maintenance to the source.

4.7.10.1.3 Reports - A report shall be prepared and submitted to the Commission on an annual basis if sealed source or fission detector leakage tests reveal the presence of $>0.005$ microcuries of removable contamination. 
PLANT SYSTEMS

3/4.7.11 FIRE SUPPRESSION SYSTEMS

FIRE SUPRESSION WATER SYSTEM

LIMITING CONDITION FOR OPERATION

3.7.11.1 The fire suppression water system shal1 be OPERABLE with;

a. (Two) high pressure pumps, each with a capacity of gpm, with their discharge aligned to the fire suppression header,

b. Separate water supplies, each with a minimum contained volume of gallons, and

c. An OPERABLE flow path capable of taking suction from the tank and the tank and transferring the water through distribution piping with OPERABLE sectionalizing control or isolation valves to the yard hydrant curb valves and the first valve ahead of the water flow alarm device on each sprinkler, hose standpipe or spray system riser required to be OPERABLE per Specifications 3.7.11.2 and 3.7.11.6.

APPLICABILITY: At all times.

ACTION:

a. With one pump and/or one water supply inoperable, restore the inoperable equipment to OPERABLE status within 7 days or, in 1 ieu of any other report required by Specification 6.9.1, prepare and submit a Special Report to the Commission pursuant to Specification 6.9.2 within the next 30 days outlining the plans and procedures to be used to provide for the loss of redundancy in this system. The provisions of Specifications 3.0 .3 and 3.0.4 are not applicable.

b. With the fire suppression water system otherwise inoperable:

1. Establish a backup fire suppression water system within 24 hours, and

2. Submit a Special Report in accordance with Specification 6.9.2;

a) By telephone within 24 hours,

b) Confirmed by telegraph, mailgram or facsimile transmission no later than the first working day following the event, and 
PLANT SYSTEMS

LIMITING CONDITION FOR OPERATION (Continued)

c) In writing within 14 days following the event, outlining the action taken, the cause of the inoperability and the plans and schedule for restoring the system to OPERABLE status.

SURVEILLANCE REQUIREMENTS

4.7.11.1.1 The fire suppression water system shall be demonstrated OPERABLE:

a. At least once per 7 days by verifying the contained water supply volume.

b. At least once per 31 days on a STAGGERED TEST BASIS by starting each pump and operating it for at least (15) minutes on recirculation flow.

c. At least once per 31 days by verifying that each valve (manual, power operated or automatic) in the flow path is in its correct position.

d. (At least once per 6 months by performance of a system flush.)

e. At least once per 12 months by cycling each testable valve in the flow path through at least one complete cycle of full travel.

f. At least once per 18 months by performing a system functional test which includes simulated automatic actuation of the system throughout its operating sequence, and:

1. Verifying that each automatic valve in the flow path actuates to its correct position,

2. Verifying that each pump develops at least (2500) gpm at a system head of (250) feet,

3. Cycling each valve in the flow path that is not testable during plant operation through at least one complete cycle of full travel, and

4. Verifying that each high pressure pump starts (sequentially) to maintain the fire suppression water system pressure $\geq$ _psig. 
PLANT SYSTEMS

SURVEILLANCE REQUIREMENTS (Continued)

g. At least once per 3 years by performing a flow test of the system in accordance with Chapter 5, Section 11 of the Fire Protection Handbook, 14th Edition, published by the National Fire Protection Association.

4.7.11.1.2 The fire pump diesel engine shall be demonstrated OPERABLE:

a. At least once per 31 days by verifying;

1. The fuel storage tank contains at least___ gallons of fuel, and

2. The diesel starts from ambient conditions and operates for at least 20 minutes.

b. At least once per 92 days by verifying that a sample of diesel fuel from the fuel storage tank, obtained in accordance with ASTM-D270-65, is within the acceptable limits, specified in Table 1 of ASTM D975-74 when checked for viscosity, water and sediment.

c. At least once per 18 months, during shutdown, by:

1. Subjecting the diesel to an inspection in accordance with procedures prepared in conjunction with its manufacturer's recommendations for the class of service, and

2. Verifying the diesel starts from ambient conditions on the auto-start signal and operates for $\geq 20$ minutes while loaded with the fire pump.

4.7.11.1.3 The fire pump diesel starting 24 volt battery bank and charger shall be demonstrated OPERABLE.

a. At least once per 7 days by verifying that:

1. The electrolyte level of each battery is above the plates, and

2. The overall battery voltage is $\geq 24$ volts. 
b. At least once per 92 days by verifying that the specific gravity is appropriate for continued service of the battery.

c. At least once per 18 months by verifying that:

1. The batteries, cell plates and battery racks show no visual indication of physical damage or abnormal deterioration, and

2. The battery-to-battery and terminal connections are clean, tight, free of corrosion and coated with anticorrosion material. 
PLANT SYSTEMS

SPRAY AND/OR SPRINKLER SYSTEMS

LIMITING CONDITION FOR OPERATION

3.7.11.2 The following spray and/or sprinkler systems shall be OPERABLE:

a. (Plant dependent - to be listed by name and location.)

b.

c.

$\therefore$

APPLICABILITY: Whenever equipment in the spray/sprinkler protected areas is required to be OPERABLE.

ACTION:

a. With one or more of the above required spray and/or sprinkler systems inoperable, establish a continuous fire watch with backup fire suppression equipment for the unprotected area(s) within 1 hour; restore the system to OPERABLE status within 14 days or, in lieu of any other report required by Specification 6.9.1, prepare and submit a Special Report to the Commission pursuant to Specification 6.9 .2 within the next 30 days outlining the action taken, the cause of the inoperability and the plans and schedule for restoring the system to OPERABLE status.

b. The provisions of Specification 3.0 .3 and 3.0.4 are not applicable.

SURVEILLANCE REQUIREMENTS

4.7.11.2 Each of the above required spray and/or sprinkler systems shall be demonstrated OPERABLE:

a. At least once per 12 months by cycling each testable valve in the flow path through at least one complete cycle of full travel.

b. At least once per 18 months:

1. By performing a system functional test which includes simulated automatic actuation of the system, and:

a) Verifying that the automatic valves in the flow path actuate to their correct positions on a test signal, and 


\section{PLANT SYSTEMS}

SURVEILLANCE REQUIREMENTS (Continued)

b) Cycling each valve in the flow path that is not testable during plant operation through at least one complete cycle of full travel.

2. By inspection of the spray headers to verify their integrity, and

3. By inspection of each nozzle to verify no blockage.

c. At least once per 3 years by performing an air flow test through each open head spray/sprinkler header and verifying each open head spray/ sprinkler nozzle is unobstructed. 
PLANT SYSTEMS

LOW PRESSURE $\mathrm{CO}_{2}$ SYSTEMS

LIMITING CONDITION FOR OPERATION

3.7.11.3 The following low pressure $\mathrm{CO}_{2}$ systems shall be OPERABLE with a minimum level of

storage $\operatorname{tank}(s)$. and a minimum pressure of in the associated

a. (Plant dependent - to be listed by name and location.)

b.

c.

APPLICABILITY: Whenever equipment in the low pressure $\mathrm{CO}_{2}$ protected areas is required to be OPERABLE.

ACTION:

a. With one or more of the above required low pressure $\mathrm{CO}_{2}$ systems inoperable, establish a continuous fire watch with backup fire suppression equipment for the unprotected area(s) within 1 hour; restore the system to OPERABLE status within 14 days or, in lieu of any other report required by Specification 6.9.1, prepare and submit a Special Report to the Commission pursuant to Specification 6.9.2 within the next 30 days outlining the action taken, the cause of the inoperability and the plans and schedule for restoring the system to OPERABLE status.

b. The provisions of Specification 3.0.3 and 3.0.4 are not applicable.

SURVEILLANCE REQUIREMENTS

4.7.11.3 Each of the above required low pressure $\mathrm{CO}_{2}$ systems shall be demonstrated OPERABLE:

a. At least once per 7 days by verifying $\mathrm{CO}_{2}$ storage tank level and pressure, and

b. At least once per 18 months by verifying:

1. The system valves and associated ventilation dampers actuate manually and automatically, upon receipt of a simulated actuation signal, and

2. Flow from each nozzle during a "Puff Test." 
PLANT SYSTEMS

HIGH PRESSURE $\mathrm{CO}_{2}$ SYSTEMS

LIMITING CONDITION FOR OPERATION

3.7.11.4 The following high pressure $\mathrm{CO}_{2}$ systems shall be OPERABLE with the storage tanks having at least $90 \%$ of full charge weight.

a. (Plant dependent - to be listed by name and location.)

b.

c.

APPLICABILITY: Whenever equipment in the high pressure $\mathrm{CO}_{2}$ protected areas is required to be OPERABLE.

\section{ACTION:}

a. With one or more of the above required high pressure $\mathrm{CO}_{2}$ systems inoperable, establish a continuous fire watch with backup fire suppression equipment for the unprotected area(s) within 1 hour; restore the system to OPERABLE status within 14 days or, in 1 ieu of any other report required by Specification 6.9.1, prepare and submit a Special Report to the Commission pursuant to Specification 6.9.2 within the next 30 days outlining the action taken, the cause of the inoperability and the plans and schedule for restoring the system to OPERABLE status.

b. The provisions of Specifications 3.0 .3 and 3.0.4 are not applicable.

SURVEILLANCE REQUIREMENTS

4.7.11.4 Each of the above required high pressure $\mathrm{CO}_{2}$ systems shall be demonstrated OPERABLE:

a. At least once per 6 months by verifying $\mathrm{CO}_{2}$ storage tank weight.

b. At least once per 18 months by:

1. Verifying the system, including associated ventilation dampers, actuates manualiy and automaticaliy, upon receipt of a simulated test signal, and

2. Performance of a flow test through headers and nozzles to assure no blockage. 
PLANT SYSTEMS

HALON SYSTEMS

LIMITING CONDITION FOR OPERATION

3.7.11.5 The following Halon systems shall be OPERABLE with the storage tanks having at least $95 \%$ of full charge weight and $90 \%$ of full charge pressure.

a. (Plant dependent - to be listed by name and location.)

b.

c.

APPLICABILITY: Whenever equipment in the Halon protected areas is required to be OPERABLE.

\section{ACTION:}

a. With one or more of the above required Halon systems inoperable, establish a continuous fire watch with backup fire suppression equipment for the unprotected area(s) within 1 hour; restore the system to OPERABLE status within 14 days or, in 1 ieu of any other report required by Specification 6.9.1, prepare and submit a Special Report to the Commission pursuant to Specification 6.9.2 within the next 30 days outlining the action taken, the cause of the inoperability and the plans and schedule for restoring the system to OPERABLE status.

b. The provisions of Specifications 3.0.3 and 3.0.4 are not applicable.

\section{SURVEILLANCE 'REQUIREMENTS}

4.7.11.5 Each of the above required Halon systems shall be demonstrated OPERABLE:

a. At least once per 6 months by verifying Halon storage tank weight and pressure.

b. At least once per 18 months by:

1. Verifying the system, including associated ventilation dampers, actuates manually and automatically, upon receipt of a simulated test signal, and

2. Performance of a flow test through headers and nozzles to assure no blockage. 
PLANT SYSTEMS

FIRE HOSE STATIONS

LIMITING CONDITIONS FOR OPERATION

3.7.11.6 The fire hose stations shown in Table 3.7-4 shall be OPERABLE.

APPLICABILITY: Whenever equipment in the areas protected by the fire hose stations is required to be OPERABLE.

ACTION:

a. With one or more of the fire hose stations shown in Table 3.7-4 inoperable, route an additional equivalent capacity fire hose to the unprotected area(s) from an OPERABLE hose station within 1 hour.

b. The provisions of Specifications 3.0.3 and 3.0.4 are not applicable.

SURVEILLANCE REQUIREMENTS

4.7.11.6 Each of the fire hose stations shown in Table 3.7-4 shall be demonstrated OPERABLE:

a. At least once per 31 days by visual inspection of the station to assure all required equipment is at the station.

b. At least once per 18 months by:

1. Removing the hose for inspection and re-racking, and

2. Replacement of all degraded gaskets in couplings.

c. At least once per 3 years by:

1. Partially opening each hose station valve to verify valve OPERABILITY and no flow blockage.

2. Conducting a hose hydrostatic test at a pressure at least 50 psig greater than the maximum pressure available at that hose station. 
TABLE 3.7-4

FIRE HOSE STATIONS 
PLANT SYSTEMS

3/4.7.12 PENETRATION FIRE BARRIERS

LIMITING CONDITIONS FOR OPERATION

3.7.12 Al1 penetration fire barriers protecting safety related areas shall be functional.

APPLICABILITY: At al1 times.

ACTION:

a. With one or more of the above required penetration fire barriers non-functional, establish a continuous fire watch on at least one side of the affected penetration within 1 hour.

b. The provisions of Specifications 3.0.3 and 3.0.4 are not applicable.

SURVEILLANCE REQUIREMENTS

4.7.12 The above required penetration fire barriers shall be verified to be functional;

a. At least once per 18 months by a visual inspection

b. Prior to returning a penetration fire barrier to functional status following repairs or maintenance by performance of a visual inspection of the affected penetration fire barrier(s). 
-
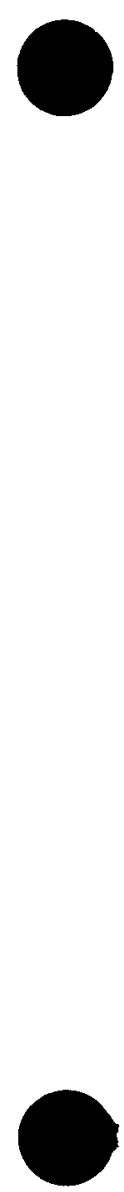


\section{$3 / 4.8$ ELECTRICAL POWER SYSTEMS \\ 3/4.8.1 A.C. SOURCES \\ OPERATING \\ LIMITING CONDITION FOR OPERATION}

3.8.1.1 As a minimum, the following A.C. electrical power sources shall be OPERABLE:

a. Two physically independent circuits between the offsite transmission network and the onsite Class IE distribution system.

b. Two separate and independent diesel generators each with:

1. Separate day and engine-mounted fuel tanks containing a minimum volume of gallons of fuel.

2. A separate fuel storage system containing a minimum volume of __ gallons of fuel.

3. A separate fuel transfer pump.

APPLICABILITY: MODES $1,2,3$ and 4.

ACTION:

a. With either an offsite circuit or diesel generator of the above required $A$.C. electrical power sources inoperable, demonstrate the OPERABILITY of the remaining A.C. sources by performing Surveillance Requirements 4.8.1.1.1.a and 4.8.1.1.2.a.4 within one hour and at least once per 8 hours thereafter; restore at least two offsite circuits and two diesel generators to OPERABLE status within 72 hours or be in at least HOT STANDBY within the next 6 hours and in COLD SHUTDOWN within the following 30 hours.

b. With one offsite circuit and one diesel generator of the above required A.C. electrical power sources inoperable, demonstrate the OPERABILITY of the remaining A.C. sources by performing Surveillance Requirements 4.8.1.1.1.a and 4.8.1.1.2.a.4 within one hour and at least once per 8 hours thereafter; restore at least one of the inoperable sources to OPERABLE status within 12 hours or be in at least HOT STANDBY within the next 6 hours and in COLD SHUTDOWN within the following 30 hours. Restore at least two offsite circuits and two diesel generators to OPERABLE status within 72 hours from the time of initial loss 
ELECTRICAL POWER SYSTEMS

ACTION (Continued)

or be in at least HOT STANDBY within the next 6 hours and in COLD SHUTDOWN within the following 30 hours.

c. With two of the above required offsite A.C. circuits inoperable, demonstrate the OPERABILITY of two diesel generators by performing Surveillance Requirement 4.8.1.1.2.a.4 within one hour and at least once per 8 hours thereafter, unless the diesel generators are already operating; restore at least one of the inoperable offsite sources to OPERABLE status within 24 hours or be in at least HOT STANDBY within the next 6 hours. With only one offsite source restored, restore at least two offsite circuits to OPERABLE status within 72 hours from time of initial loss or be in at least HOT STANDBY within the next 6 hours and in COLD SHUTDOWN within the following 30 hours.

d. With two of the above required diesel generators inoperable, demonstrate the OPERABILITY of two offsite A.C. circuits by performing Surveillance Requirement 4.8.1.1.1.a within one hour and at least once per 8 hours thereafter; restore at least one of the inoperable diesel generators to. OPERABLE status within 2 hours or be in at least HOT STANDBY within the next 6 hours and in COLD SHUTDOWN within the following 30 hours. Restore at least two diesel generators to OPERABLE status within 72 hours from time of initial loss or be in at least HOT STANDBY within the next 6 hours and in COLD SHUTDOWN within the following 30 hours.

SURVEILLANCE REQUIREMENTS

4.8.1.1.1 Each of the above required independent circuits between the offsite transmission network and the onsite Class IE distribution system shall be:

a. Determined OPERABLE at least once per 7 days by verifying correct breaker alignments, indicated power availability, and

b. Demonstrated OPERABLE at least once per 18 months during shutdown by transferring (manually and automatically) unit power supply from the normal circuit to the alternate circuit.

4.8.1.1.2 Each diesel generator shall be demonstrated OPERABLE:

a. In accordance with the frequency specified in Table 4.8-1 on a STAGGERED TEST BASIS by: 
1. Verifying the fuel volume in the day and engine-mounted fuel tank.

2. Verifying the fuel volume in the fuel storage tank.

3. Verifying the fuel transfer pump can be started and transfers fuel from the storage system to the day and engine-mounted tank.

4. Verifying the diesel starts from ambient condition and accelerates to at least (900) rpm in $\leq(10)$ seconds.

5. Verifying the generator is synchronized, loaded to $\geq$ (continuous rating) $\mathrm{kw}$ in $\leq(60)$ seconds, and operates for $\geq 60$ minutes.

6. Verifying the diesel generator is aligned to provide standby power to the associated emergency busses.

7. Verifying that the automatic load sequence timer(s) is OPERABLE with the interval between each load block within $\pm 10 \%$ of its design interval.

b. At least once per 92 days by verifying that a sample of diesel fuel obtained in accordance with ASTM-D270-65, from the fuel storage tank is within the acceptable limits specified in Table 1 of ASTM D975-74 when checked for viscosity, water and sediment.

c. At least once per 18 months during shutdown by:

1. Subjecting the diesel to an inspection in accordance with procedures prepared in conjunction with its manufacturer's recommendations for this class of standby service.

2. Verifying the generator capability to reject a load of $\geq$ (largest single emergency load) kw while maintaining voltage at ___ volts and frequency at $\mathrm{Hz}$.

3. Verifying the generator capability to reject a load of $\geq$ (continuous rating) $\mathrm{kw}$ without exceeding $75 \%$ of the difference between nominal speed and the overspeed trip setpoint, or $15 \%$ above nominal, whichever is lower. 
4. Simulating a loss of offsite power by itself, and:

a) Verifying de-energization of the emergency busses and load shedding from the emergency busses.

b) Verifying the diesel starts from ambient condition on the auto-start signal, energizes the emergency busses with permanently connected loads, energizes the auto-connected shutdown loads through the load sequencer and operates for $\geq 5$ minutes while its generator is loaded with the shutdown loads.

5. Verifying that on an ESF actuation test signal (without loss of offsite power) the diesel generator starts on the auto-start signal and operates on standby for $\geq 5$ minutes.

6. Verifying that on a simulated loss of the diesel generator (with offsite power not available), the loads are shed from the emergency busses and that subsequent loading of the diesel generator is in accordance with design requirements.

7. Simulating a loss of offsite power in conjunction with an ESF actuation test signal, and

a) Verifying de-energization of the emergency busses and load shedding from the emergency busses.

b) Verifying the diesel starts from ambient condition on the auto-start signal, energizes the emergency busses with permanently connected loads, energizes the auto-connected emergency (accident) loads through the load sequencer and operates for $\geq 5$ minutes while its generator is loaded with the emergency loads.

c) Verifying that al1 diesel generator trips, except engine overspeed and generator differential, are automatically bypassed upon loss of voltage on the emergency bus concurrent with a safety injection actuation signal.

8. Verifying the diesel generator operates for at least 24 hours. During the first 2 hours of this test, the diesel generator shall be loaded to $\geq$ (2-hour rating) $\mathrm{kw}$ and during the remaining 22 hours of this test, 
the diesel generator shall be loaded to $>$ (continuous rating) kw. Within 5 minutes after completing this 24 hour test, repeat Specification 4.8.1.1.2.c.5.

9. Verifying that the auto-connected loads to each diesel generator do not exceed the 2000 hour rating of kw.

10. Verifying the diesel generator's capability to:

a) Synchronize with the offsite power source while the generator is loaded with its emergency loads upon a simulated restoration of offsite power,

b) Transfer its loads to the offsite power source, and

c) Proceed through its shutdown sequence.

11. Verifying that with the diesel generator operating in a test mode (connected to its bus), a simulated safety injection test overrides the test mode by:

a) Returning the diesel generator to standby operation, and

b) Automatically energizing the emergency loads with offsite power.

12. Verifying that the fuel transfer pump transfers fuel from each fuel storage tank to the day and engine-mounted tank of each diesel via the installed cross connection lines.

d. At least once per 10 years or after any modifications which could affect diesel generator interdependence by starting both diesel generators simultaneously, during shutdown, and verifying that both diesel generators accelerate to at least (900) rpm in $\leq(10)$ seconds.

4.8.1.1.3 Reports - All diesel generator failures, valid or non-valid, shall be reported to the Commission pursuant to Specification 6.9.1. If the number of failures in the last 100 valid tests (on a per nuclear unit basis) is $\geq 7$, the report shall be supplemented to include the additional information recommended in Regulatory Position C.3.b of Regulatory Guide 1.108, Revision 1, August 1977. 
TABLE 4.8-1

\section{DIESEL GENERATOR TEST SCHEDULE}

Number of Failures In

Last 100 Valid Tests*

$\leq 1$

2

3

$\leq 4$
Test Frequency

At least once per 31 days

At least once per 14 days

At least once per 7 days

At least once per 3 days

*Criteria for determining number of failures and number of valid tests shall be in accordance with Regulatory Position C.2.e. of Regulatory Guide 1.108, Revision 1, August 1977, where the 1ast 100 tests are determined on a per nuclear unit basis. For the purposes of this test schedule, only valid tests conducted after the OL issuance date shall be induded in the computation of the "last 100 valid tests". Entry into this test schedule shall be made at the 31 day test frequency. 


\section{ELECTRICAL POWER SYSTEMS}

SHUTDOWN

LIMITING CONDITION FOR OPERATION

3.8.1.2 As a minimum, the following A.C. electrical power sources shall be OPERABLE:

a. One circuit between the offsite transmission network and the onsite Class IE distribution system.

b. One diesel generator with:

1. Day and engine-mounted fuel tanks containing a minimum volume of gallons of fuel.

2. A fuel storage system containing a minimum volume of gallons of fuel.

3. A fuel transfer pump.

APPLICABILITY: MODES 5 and 6.

ACTION:

With less than the above minimum required A.C. electrical power sources OPERABLE, suspend all operations involving CORE ALTERATIONS or positive reactivity changes.

SURVEILLANCE REQUIREMENTS

4.8.1.2 The above required A.C. electrical power sources shall be demonstrated OPERABLE by the performance of each of the Surveillance Requirements of 4.8.1.1.1 and 4.8.1.1.2 (except for requirement

4.8.1.1.2a.5) and 4.8.1.1.3. 
ELECTRICAL POWER SYSTEMS

3/4.8.2 ONSITE POWER DISTRIBUTION SYSTEM

A.C. DISTRIBUTION - OPERATING

LIMITING CONDITION FOR OPERATION

3.8.2.1 The following A.C. electrical busses shall be OPERABLE and energized with tie breakers open between redundant busses:

(4160) volt Emergency Bus \#

(4160) volt Emergency Bus \#

(480)

volt Emergency Bus \#

(480)

volt Emergency Bus \#

(240)

volt A.C. Vital Bus \#

(240)

volt A.C. Vital Bus \#

(120)

volt A.C. Vital Bus \#

(120)

volt A.C. Vital Bus \#

(120)

volt A.C. Vital Bus \#

(120)

volt A.C. Vital Bus \#

APPLICABILITY: MODES 1, 2, 3 and 4.

ACTION:

With less than the above complement of A.C. busses OPERABLE, restore the inoperable bus to OPERABLE status within 8 hours or be in at least HOT STANDBY within the next 6 hours and in COLD SHUTDOWN within the following 30 hours.

SURVEILLANCE REQUIREMENTS

4.8.2.1 The specified A.C. busses shall be determined OPERABLE with tie breakers open between redundant busses at least once per 7 days by verifying correct breaker alignment and indicated power availability. 
ELECTRICAL POWER SYSTEMS

A.C. DISTRIBUTION - SHUTDOWN

LIMITING CONDITION FOR OPERATION

3.8.2.2 As a minimum, the following A.C. electrical busses shall be OPERABLE:

1 - (4160) volt Emergency Bus

1 - (480) volt Emergency Bus

1 - (240) volt A. C. Vital Bus

2 - (120) volt A.C. Vital Busses.

APPLICABILITY: MODES 5 and 6.

ACTION:

With less than the above complement of A.C. busses OPERABLE and energized, establish CONTAINMENT INTEGRITY within 8 hours.

SURVEILLANCE REQUIREMENTS

4.8.2.2 The specified A.C. busses shall be determined OPERABLE at least once per 7 days by verifying correct breaker alignment and indicated power availability. 
ELECTRICAL POWER SYSTEMS

D.C. DISTRIBUTION - OPERATING

LIMITING CONDITION FOR OPERATION

3.8.2.3 The following D.C. bus trains shall be energized and OPERABLE with tie breakers between bus trains open:

TRAIN "A" consisting of (250/125)-volt D.C. bus No. 1, (250/125)-volt D.C. battery bank No. 1 and a full capacity charger.

TRAIN "B" consisting of (250/125)-volt D.C. bus No. 2, (250/125)-volt D.C. battery bank No. 2 and a full capacity charger.

APPLICABILITY: MODES 1, 2, 3 and 4.

ACTION:

a. With one (250/125)-volt D.C. bus inoperable, restore the inoperable bus to OPERABLE status within 2 hours or be in at least HOT STANDBY within the next 6 hours and in COLD SHUTDOWN within the following 30 hours.

b. With one (250/125)-volt D.C. battery and/or its charger inoperable, restore the inoperable battery and/or charger to OPERABLE status within 2 hours or be in at least HOT STANDBY within the next 6 hours and in COLD SHUTDOWN within the following 30 hours.

SURVEILLANCE REQUIREMENTS

4.8.2.3.1 Each D.C. bus train shall be determined OPERABLE and energized with tie breakers open at least once per 7 days by verifying correct breaker alignment and indicated power avajlability.

4.8.2.3.2 Each (250/125)-volt battery bank and charger shall be demonstrated OPERABLE:

a. At least once per 7 days by verifying that:

1. The electrolyte level of each pilot cell is between the minimum and maximum level indication marks. 
ELECTRICAL POWER SYSTEMS

SURVEILLANCE REQUIREMENTS (Continued)

2. The pilot cell specific gravity, corrected to $(77)^{\circ} \mathrm{F}$ and full electrolyte level, is $\geq$

3. The pilot cell voltage is $\geq$ volts.

4. The overall battery voltage is $\geq(250 / 125)$ volts.

b. At least once per 92 days by verifying that:

1. The voltage of each connected cell is $>$ volts under float charge and has not decreased more than volts from the value observed during the original acceptance test.

2. The specific gravity, corrected to $(77)^{\circ} \mathrm{F}$ and full electrolyte level, of each connected cell is $\geq$ and has not decreased more than during the previous test. from the value observed

3. The electrolyte level of each connected cell is between the minimum and maximum level indication marks.

c. At least once per 18 months by verifying that:

1. The cells, cell plates and battery racks show no visual indication of physical damage or deterioration.

2. The cell-to-cell and terminal connections are clean, tight and coated with anti-corrosion material.

3. The resistance of each cell-to-cell and terminal connection is $\leq 0.01$ ohms.

4. The battery charger will supply at least minimum of volts for at least 8 hours. amperes at a

d. At least once per 18 months, during shutdown, by verifying that the battery capacity is adequate to supply and maintain in OPERABLE status all of the actual emergency loads for (8) hours when the battery is subjected to a battery service test.

e. At least once per 60 months, during shutdown, by verifying that the battery capacity is at least $80 \%$ of the manufacturer's rating when subjected to a performance discharge test. This performance discharge test shall be performed subsequent to the satisfactory completion of the required battery service test. 
ELECTRICAL POWER SYSTEMS

D.C. DISTRIBUTION - SHUTDOWN

LIMITING CONDITION FOR OPERATION

3.8.2.4 As a minimum, the following D.C. electrical equipment and bus shal1 be energized and OPERABLE:

1 - (250/125)-volt D.C. bus.

1 - (250/125)-volt battery bank and charger supplying the above D.C. bus.

APPLICABILITY: MODES 5 and 6.

ACTION:

With less than the above complement of D.C. equipment and bus OPERABLE, establ ish CONTAINMENT INTEGRITY within 8 hours.

SURVEILLANCE REQUIREMENTS

4.8.2.4.1 The above required (250/125)-volt D.C. bus shall be determined OPERABLE and energized at least once per 7 days by verifying correct breaker alignment and indicated power availability.

4.8.2.4.2 The above required (250/125)-volt battery bank and charger shall be demonstrated OPERABLE per Surveillance Requirement 4.8.2.3.2. 


\section{3/4.9 REFUELING OPERATIONS \\ BORON CONCENTRATION \\ LIMITING CONDITION FOR OPERATION}

3.9.1 With the reactor vessel head unbolted or removed, the boron concentration of all filled portions of the Reactor Coolant System and the refueling canal shall be maintained uniform and sufficient to ensure that the more restrictive of the following reactivity. conditions is met:

a. Either a $K_{\text {ff }}$ of 0.95 or less, which includes a $1 \% \Delta \mathrm{k} / \mathrm{k}$ conservative affowance for uncertainties, or

b. A boron concentration of $\geq(1850) \mathrm{ppm}$, which includes a $50 \mathrm{ppm}$ conservative allowance for uncertainties.

APPLICABILITY: MODE 6 *.

ACTION:

With the requirements of the above specification not satisfied, immediately suspend all operations involving CORE ALTERATIONS or positive reactivity changes and initiate and continue boration at $\geq() \mathrm{gpm}$ of () $\mathrm{ppm}$ boron or its equivalent until $\mathrm{K} f$ is reduced to $\leq 0.95$ or the boron concentration is restored to $\geq\left(\left\{\frac{850)}{\mathrm{ppm}}\right.\right.$, whichever is the more restrictive: The provisions of Specification 3.0.3 are not applicable.

SURVEILLANCE REQUIREMENTS

4.9.1.1 The more restrictive of the above two reactivity conditions shall be determined prior to:

a. Removing or unbolting the reactor vessel head.

b. Withdrawal of any safety or regulating rod in excess of 3 feet from its fully inserted position within the reactor pressure vessel.

4.9.1.2 The boron concentration of the reactor coolant system and the refueling canal shall be determined by chemical analysis at least once each 72 hours.

*The reactor shall be maintained in MODE 6 when the reactor vessel head is unbolted or removed. 
REFUELING OPERATIONS

INSTRUMENTATION

LIMITING CONDITION FOR OPERATION

3.9.2 As a minimum, two source range neutron flux monitors shall be operating, each with continuous visual indication in the control room and one with audible indication in the containment and the control room.

APPLICABILITY: MODE 6.

ACTION:

a. With one of the above required monitors inoperable immediately suspend all operations involving CORE ALTERATIONS or positive reactivity changes.

b. With both of the required monitors inoperable, determine the boron concentration of the reactor coolant system at least once per 12 hours.

c. The provisions of specification 3.0.3 are not applicable.

SURVEILLANCE REQUIREMENTS

4.9.2 Each source range neutron flux monitor shall be demonstrated OPERABLE by performance of:

a. A CHANNEL CHECK at least once per 12 hours.

b. A CHANNEL FUNCTIONAL TEST at least once per 7 days.

c. A CHANNEL FUNCTIONAL TEST within 8 hours prior to the initial start of CORE ALTERATIONS. 


\section{REFUELING OPERATIONS}

DECAY TIME

LIMITING CONDITION FOR OPERATION

3.9.3 The reactor shall be subcritical for at least (100) hours.

APPLICABILITY: During movement of irradiated fuel in the reactor pressure vesse1.

ACTION:

With the reactor subcritical for less than (100) hours, suspend all operations involving movement of irradiated fuel in the reactor pressure vessel. The provisions of Specification 3.0.3 are not applicable.

4.9.3 The reactor shall be determined to have been subcritical for at least (100) hours by verification of the date and time of subcriticality prior to movement of irradiated fuel in the reactor pressure vessel. 
REFUELING OPERATIONS

CONTAINMENT PENETRATIONS

LIMITING CONDITION FOR OPERATION

3.9.4 The containment penetrations shall be in the following status:

a. The equipment door closed and held in place by a minimum of four bolts:

b. A minimum of one door in each airlock closed.

c. Each penetration providing direct access from the containment atmosphere to the outside atmosphere shall be either:

1. Closed by an isolation valve, blind flange, or manual valve, or

2. Be capable of being closed by an OPERABLE automatic containment purge and exhaust isolation valve.

APPLICABILITY: During CORE ALTERATIONS or movement of irradiated fuel within the containment.

ACTION:

With the requirements of the above specification not satisfied, immediately suspend all operations involving CORE ALTERATIONS or movement of irradiated fuel in the containment. The provisions of Specification 3.0 .3 are not applicable.

SURVEILLANCE REQUIREMENTS

4.9.4 Each of the above required containment penetrations shall be determined to be either in its closed/isolated condition or capable of being closed by an OPERABLE automatic containment purge and exhaust valve within 100 hours prior to the start of and at least once per 7 days during CORE ALTERATIONS or movement of irradiated fuel in the containment by:

a. Verifying the penetrations are in their isolated condition, or

b. Testing the containment purge and exhaust valves per the applicable portions of Specification (4.6.4.1.2). 


\section{REFUELING OPERATIONS}

COMMUNICATIONS

LIMITING CONDITION FOR OPERATION

3.9.5 Direct communications shall be maintained between the control room and personnel at the refueling station.

APPLICABILITY: During CORE ALTERATIONS.

ACTION:

When direct communications between the control room and personnel at the refueling station cannot be maintained, suspend all CORE ALTERATIONS. The provisions of Specification 3.0.3 are not applicable.

4.9.5 Direct communications between the control room and personnel at the refueling station shall be demonstrated within one hour prior to the start of and at least once per 12 hours during CORE ALTERATIONS. 
REFUELING OPERATIONS

FUEL HANDLING BRIDEE OPERABILITY

LIMITING CONDITION FOR OPERATION

3.9.6 The fuel handling bridges shall be used for movement of control rods or fuel assemb1ies and sha11 be OPERABLE with:

a. A hoist minimum capacity of ___ pounds.

b. A hoist overload cutoff limit of __ pounds.

APPLICABILITY: During movement of control rods or fuel assemblies within the reactor pressure vesse?.

ACTION:

With the requirements for bridge OPERABILITY not satisfied, suspend use of any inoperable bridge from operations involving the movement of control rods or fuel assemblies within the reactor pressure vessel. The provisions of Specification 3.0.3 are not applicable.

SURVEILLANCE REQUIREMENTS

4.9.6 Each fuel handling bridge used for movement of control rods or fuel assemblies within the reactor pressure vessel shall be demonstrated OPERABLE within 100 hours prior to the start of moving control rods or fuel assemblies by performing a hoist load test of at least pounds and demonstrating an automatic load cutoff when the hoist load exceeds pounds. 


\section{REFUELING OPERATIONS}

CRANE TRAVEL - SPENT FUEL STORAGE POOL BUILDING

3.9.7 Loads in excess of pounds shall be prohibited from travel over fuel assemblies in the storage pool. APPLICABILITY: With fuel assemblies and water in the storage pool. ACTION:

With the requirements of the above specification not satisfied, place the crane load in a safe condition. The provisions of Specification 3.0.3 are not applicable.

SURVEILLANCE REQUIREMENTS

4.9.7 Crane interlocks and/or physical stops which prevent crane travel with loads in excess of demonstrated OPERABLE within 7 days prior to crane operation and at least once per 7 days during crane operation. 
REFUELING OPERATIONS

COOLANT CIRCULATION

LIMITING CONDITION FOR OPERATION

3.9.8 At least one decay heat removal loop shall be in operation. APPLICABILITY: MODE 6.

ACTION:

a. With less than one decay heat removal loop in operation, except as provided in b below, suspend all operations involving an increase in the reactor decay heat load or a reduction in boron concentration of the Reactor Coolant System. Close all containment penetrations providing direct access from the containment atmosphere to the outside atmosphere within 4 hours.

b. The decay heat removal loop may be removed from operation for up to 1 hour per 8 hour period during the performance of CORE ALTERATIONS in the vicinity of the reactor pressure vessel (hot) legs.

c. The provisions of Specification 3.0.3 are not applicable.

4.9.8 A decay heat removal loop shall be demonstrated to be operating and circulating reactor coolant at a flow rate of $\geq(2800) \mathrm{gpm}$ at least once per 24 hours. 
REFUELING OPERATIONS

CONTAINMENT PURGE AND EXHAUST ISOLATION SYSTEM

LIMITING CONDITION FOR OPERATION

3.9.9 The containment purge and exhaust isolation system shall be OPERABLE.

APPLICABILITY: MODE 6 .

ACTION:

With the containment purge and exhaust isolation system inoperable, close each of the purge and exhaust penetrations providing direct access from thel ontainment atmosphere to the outside atmosphere. The provisions of Specifications 3.0.3 and 3.0.4 are not applicable.

SURVEILLANCE REQUIREMENTS

4.9.9 The containment purge and exhaust isolation system shall be demonstrated OPERABLE within 100 hours prior to the start of and at least once per 7 days during CORE ALTERATIONS by verifying that containment purge and exhaust isolation occurs on manual initiation and on a high radiation test signal from each of the containment radiation monitoring instrumentation channels. 


\section{REFUEL ING OPERATIONS}

WATER LEVEL - REACTOR VESSEL

LIMITING CONDITION FOR OPERATION

3.9.10 As a minimum, 23 feet of water shall be maintained over the top of irradiated fuel assemblies seated within the reactor pressure vessel.

APPLICABILITY: During movement of fuel assemblies or control rods within the reactor pressure vessel while in MODE 6 .

ACTION:

With the requirements of the above specification not satisfied, suspend all operation involving movement of fuel assemblies or control rods within the reactor pressure vessel. The provisions of Specification 3.0.3 are not applicable.

4.9.10 The water level shall be determined to be at least its minimum required depth within 2 hours prior to the start of and at least once per 24 hours during movement of fuel assemblies or control rods within the reactor pressure vessel. 


\section{REFUELING OPERATIONS \\ STORAGE POOL WATER LEVEL \\ LIMITING CONDITION FOR OPERATION}

3.9.11 As a minimum, 23 feet of water shal1 be maintained over the top of irradiated fuel assemblies seated in the storage racks.

APPLICABILITY: Whenever irradiated fuel assemblies are in the storage pool.

ACTION:

With the requirement of the specification not satisfied, suspend all movement of fuel and crane operations with loads in the fuel storage area and restore the water level to within its limit within 4 hours. The provisions of Specification 3.0.3 are not applicable.

SURVEILLANCE REQUIREMENTS

4.9.11 The water level in the storage pool shall be determined to be at least its minimum required depth at least once per 7 days when irradiated fuel assemblies are in the fuel storage pool. 
REFUELING OPERATIONS

STORAGE POOL AIR CLEANUP SYSTEM

LIMITING CONDITION FOR OPERATION

3.9.12 Two independent fuel storage pool air cleanup systems shall be OPERABLE.

APPLICABILITY: Whenever irradiated fuel is in the storage pool.

ACTION:

a. With one fuel storage pool air cleanup system inoperable, fuel movement within the storage pool or crane operation with loads over the storage pool may proceed provided the OPERABLE fuel storage pool air cleanup system is in operation and discharging through at least one train of HEPA filters and charcoal adsorbers.

b. With no fuel storage pool air cleanup system OPERABLE, suspend all operations involving movement of fuel within the storage pool or crane operation with loads over the storage pool until at least one fuel storage pool air cleanup system is restored to OPERABLE status.

c. The provisions of Specifications 3.0 .3 and 3.0.4 are not applicable.

SURVEILLANCE REQUIREMENTS

4.9.12 The above required fuel storage pool air cleanup systems shall be demonstrated OPERABLE:

a. At least once per 31 days on a STAGGERED TEST BASIS by initiating, from the control room, flow through the HEPA filters and charcoal adsorbers and verifying that the system operates for at least 10 hours with the heaters on.

b. At least once per 18 months or (1) after any structural maintenance on the HEPA filter or charcoal adsorber housings, or (2) following painting, fire or chemical release in any ventilation zone communicating. with the system by: 
REFUELING OPERATIONS

SURVEILLANCE REQUIREMENTS (Continued)

1. Verifying that with the system operating at a flow rate of $\quad \mathrm{cfm} \pm 10 \%$ and exhausting through the HEPA filters and charcoal adsorbers, the total bypass flow of the system to the facility vent, including leakage through the system diverting valves, is $\leq 1 \%$ when the system is tested by admitting cold DOP at the system intake. (For systems with diverting valves.)

2. Verifying that the cleanup system satisfies the in-place testing acceptance criteria and uses the test procedures of Regulatory Positions C.5.a, C.5.C and C.5.d of Regulatory Guide 1.52, Revision 2, March 1978, and the system flow rate is $\mathrm{cfm} \pm 10 \%$.

3. Verifying within 31 days after removal that a laboratory analysis of a representative carbon sample obtained in accordance with Regulatory Position C.6.b of Regulatory Guide 1.52, Revision 2, March 1978, meets the laboratory testing criteria of Regulatory Position C.6.a of Regulatory Guide 1.52, Revision 2, March 1978.

4. Verifying a system flow rate of $\mathrm{cfm}+10 \%$ during system operation when tested in accordance with ANSI N510-1975.

c. After every 720 hours of charcoal adsorber operation by verifying within 31 days after removal that a laboratory analysis of a representative carbon sample obtained in accordance with Regulatory Position C.6.b of Regulatory Guide 1.52, Revision 2 , March 1978, meets the laboratory testing criteria of Regulatory Position C.6.a of Regulatory Guide 1.52, Revision 2, March 1978.

d. At least once per 18 months by:

1. Verifying that the pressure drop across the combined HEPA filters and charcoal adsorber banks is < (6) inches Water Gauge while operating the system at a flow rate of $\mathrm{cfm}$ $\pm 10 \%$.

2. Verifying that on a high radiation test signal, the system automatically starts (unless already operating) and directs its exhaust flow through the HEPA filters and charcoal adsorber banks. 
REFUELING OPERATIONS

SURVEILLANCE REQUIREMENTS (Continued)

3. Verifying that the system maintains the spent fuel storage pool area at a negative pressure of $\geq(1 / 4)$ inches Water Gauge relative to the outside atmosphere during system operation.

4. Verifying that the filter cooling bypass valves can be manually opened.

5. Verifying that the heaters dissipate $+\ldots$ when tested in accordance with ANSI $\sqrt{510-797} \overline{5}$.

e. After each complete or partial replacement of a HEPA filter bank by verifying that the HEPA filter banks remove $\geq(99.95) \% * \quad \mid$ of the DOP when they are tested in-place in accordance with ANSI N510-1975 while operating the system at a flow rate of $\mathrm{cfm} \pm 10 \%$.

f. After each complete or partial replacement of a charcoal adsorber bank by verifying that the charcoal adsorbers remove $\geq 99.95 \%$ of a halogenated hydrocarbon refrigerant test gas when they are tested in-place in accordance with ANSI N510-1975 while operating the system at a flow rate of $\mathrm{cfm} \pm 10 \%$.

ॠ99.95\% app Ticable when a filter efficiency of $99 \%$ is assumed in the safety analyses; $99 \%$ when a filter efficiency of $90 \%$ is assumed. 


\section{3/4.10 SPECIAL TEST EXCEPTIONS}

GROUP HEIGHT, INSERTION AND POWER DISTRIBUTION LIMITS

LIMITING CONDITION FOR OPERATION

3.10.1 The group height, insertion and power distribution limits of Specifications $3.1 .3 .1,3.1 .3 .2,3.1 .3 .6,3.1 .3 .7,3.1 .3 .8,3.2 .1$ and 3.2.4 may be suspended during the performance of PHYSICS TESTS provided:

a. The THERMAL POWER is maintained $\leq 85 \%$ of RATED THERMAL POWER.

b. The Nuclear Overpower Trip Setpoint is $\leq 10 \%$ of Rated Thermal Power higher than the THERMAL POWER at which the test is performed, with a maximum setting of $90 \%$ of RATED THERMAL POWER.

c. The limits of Specifications 3.2.2 and 3.2.3 are maintained and determined at the frequencies specified in 4.10 .1 .2 below.

APPLICABILITY: MODE 1 .

ACTION:

With any of the limits of Specifications 3.2 .2 or 3.2 .3 being exceeded while the requirements of Specifications $3.1 .3 .1,3.1 .3 .2,3.1 .3 .6$, 3.1.3.7, 3.1.3.8, 3.2.1 or 3.2.4 are suspended, either:

a. Reduce THERMAL POWER sufficiently to satisfy the ACTION requirements of Specifications 3.2 .2 and 3.2.3, or

b. Be in at least HOT STANDBY within 6 hours.

SURVEILLANCE REQUIREMENTS

4.10.1.1 The Nuclear Overpower Trip Setpoint shall be determined to be set within the limits specified within 8 hours prior to the initiation of and at least once per 8 hours during PHYSICS TESTS.

4.10.1.2 The Surveillance Requirements of Specifications 4.2.2 and 4.2.3 shall be performed at least once per two hours during PHYSICS TESTS. 
SPECIAL TEST EXCEPTIONS

PHYSICS TESTS

LIMITING CONDITION FOR OPERATION

3.10.2 The Timitations of Specifications 3.1.1.3, 3.1.3.1, 3.1.3.2, 3.1.3.6, 3.1.3.7, and 3.1.3.8 may be suspended during the performance of PHYSICS TESTS provided:

a. The THERMAL POWER does not exceed $5 \%$ of RATED THERMAL POWER.

b. The reactor trip setpoints on the OPERABLE Nuclear Overpower Channels are set at $\leq 25 \%$ of RATED THERMAL POWER.

c. The nuclear instrumentation Source Range and Intermediate Range high startup rate control rod withdrawal inhibit are OPERABLE.

APPLICABILITY: MODE 2.

ACTION:

With the THERMAL POWER $>5 \%$ of RATED THERMAL POWER, immediately open the control rod drive trip breakers.

SURVEILLANCE REQUIREMENTS

4.10.2.1 The THERMAL POWER shall be determined to be $<5 \%$ of RATED THERMAL POWER at least once per hour during PHYSICS TESTTS.

4.10.2.2 Each Source and Intermediate Range and Nuclear Overpower Channel shall be subjected to a CHANNEL FUNCTIONAL TEST within 12 hours prior to initiating PHYSICS TESTS. 
SPECIAL TEST EXCEPTION (OPTIONAL)

REACTOR COOLANT LOOPS

LIMITING CONDITION FOR OPERATION

3.10.3 The 1 imitations of Specification 3.4.1 may be suspended during the performance of startup and PHYSICS TESTS provided:

a. The THERMAL POWER does not exceed $5 \%$ of RATED THERMAL POWER, and

b. The reactor trip setpoints on the OPERABLE Nuclear Overpower channels are set $\leq 25 \%$ of RATED THERMAL POWER.

APPLICABILITY: During startup and PHYSICS TESTS.

ACTION:

With the THERMAL POWER greater than $5 \%$ of RATED THERMAL POWER, immediately open the control rod drive trip breakers.

\section{SURVEILLANCE REQUIREMENTS}

4.10.3.1 The THERMAL POWER shall be determined to be $<5 \%$ of RATED THERMAL POWER at least once per hour during startup and PHYSICS TESTS.

4.10.3.2 Each Nuclear Overpower Channel shall be subjected to a CHANNEL FUNCTIONAL TEST within 12 hours prior to initiating startup or PHYSICS TESTS. 
SPECIAL TEST EXCEPTICN

SHUTDOWN MARGIN

LIMITING CONDITION FOR OPERATION

3.10.4 The SHUTDOWN MARGIN requirement of Specification 3.1.1.1 may be suspended for measurement of control rod worth and shutdown margin provided:

a. Reactivity equivalent to at least the highest estimated control rod worth is available for trip insertion from OPERABLE control $\operatorname{rod}(s)$.

b. All axial power shaping rods are withdrawn to at least $90 \%$ (indicated position) and OPERABLE.

APPLICABILITY: MODE 2.

ACTION:

a. With any safety or regulating control rod not fully inserted and with less than the above reactivity equivalent available for trip insertion or the axial power shaping rods not within their withdrawal limits, immediately initiate and continue boration at $>() \mathrm{gpm}$ of () $\mathrm{ppm}$ boric acid solution or its equivalent until the SHUTDOWN MARGIN required by Specification 3.1.1.1 is restored.

b. With all safety or regulating control rods fully inserted and the reactor subcritical by less than the above reactivity equivalent, immediately initiate and continue boration at $\geq() \mathrm{gpm}$ of ( ) ppm boric acid solution or its equivalent until the SHUTDOWN MARGIN required by Specification 3.1.1.1 is restored.

\section{SURVEILLANCE REQUIREMENTS}

4.10.4.1 The position of each safety, regulating, and axial power shaping rod either partially or fully withdrawn shall be determined at least once per 2 hours.

4.10.4.2 Each safety or regulating control rod not fully inserted shall be demonstrated capable of ful 1 insertion when tripped from at least the $50 \%$ withdrawn position within 24 hours prior to reducing the SHUTDOWN MARGIN to less than the 1imits of Specification 3.1.1.1.

4.10.4.3 The axial power shaping rods shall be demonstrated OPERABLE by moving each axial power shaping rod $\geq 6.5 \%$ (indicated position) within 4 hours prior to reducing the SHUTDOWN MARGIN to less than the limits of Specification 3.1.1.1. 


\section{BASES}

FOR

LIMITING CONDITIONS FOR OPERATION

AND

SURVEILLANCE REQUIREMENTS 
-
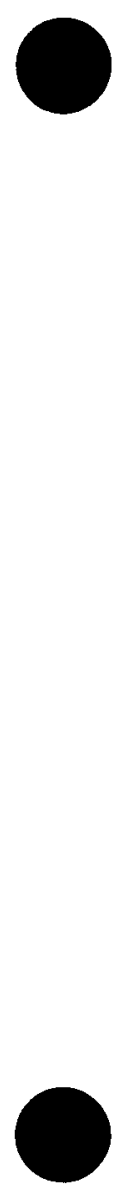
NOTE

The summary statements contained in this section provide the bases for the specifications of Sections 3.0 and 4.0 and are not considered a part of these technical specifications as provided in 10 CFR 50.36. 
-
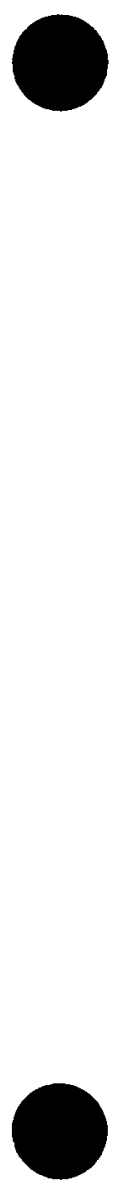
The specifications of this section provide the general requirements applicable to each of the Limiting Conditions for Operation and Surveillance Requirements within Section $3 / 4$.

3.0.1 This specification defines the applicability of each specification in terms of defined OPERATIONAL MODES or other speciffed conditions and is provided to delineate specifically when each specification is applicable.

3.0.2 This specification defines those conditions necessary to constitute compliance with the terms of an individual Limiting Condition for Operation and associated ACTION requirement.

3.0.3 This specification delineates the ACTION to be taken for circumstances not directly provided for in the ACTION statements and whose occurrence would violate the intent of the specification. For example, Specification (3.5.1) calls for each Reactor Coolant System core flooding tank to be OPERABLE and provides explicit ACTION requirements when one tank is inoperable. Under the terms of Specification 3.0.3, if more than one tank is inoperable, the facility is required to be in at least HOT STANDBY within 1 hour and in COLD SHUTDOWN within the following 30 hours.

3.0.4 This specification provides that entry into an OPERATIONAL MODE or other specified applicability condition must be made with (a) the full complement of required systems, equipment or components OPERABLE and (b) all other parameters as specified in the Limiting Conditions for Operation being met without regard for allowable deviations and out of service provisions contained in the ACTION statements.

The intent of this provision is to insure that facility operation is not initiated with either required equipment or systems inoperable or other specified limits being exceeded.

Exceptions to this provision have been provided for a limited number of specifications when startup with inoperable equipment would not affect plant safety. These exceptions are stated in the ACTION statements of the appropriate specifications. 
4.0.1 This specification provides that surveillance activities necessary to insure the Limiting Conditions for Operation are met and will be performed during the OPERATIONAL MODES or other conditions for which the Limiting Conditions for Operation are applicable. Provisions for additional surveillance activities to be performed without regard to the applicable OPERATIONAL MODES or other conditions are provided in the individual Surveillance Requirements. Surveillance Requirements for SPECIAL TEST EXCEPTIONS need only be performed when the SPECIAL TEST EXCEPTION is being utilized as an exception to an individual specification.

\subsubsection{The provisions of this specification provide allowable toler-} ances for performing suveillance activities beyond those specified in the nominal surveillance interval. These tolerances are necessary to provide operational flexibility because of scheduling and performance considerations. The phrase "at least" associated with a surveillance frequency does not negate this allowable tolerance value and permits the performance of more frequent surveillance activities.

The tolerance values, taken either individually or consecutively over 3 test intervals, are sufficiently restrictive to ensure that the reliability associated with the surveillance activity is not significantly degraded beyond that obtained from the nominal specified interval.

\subsubsection{The provisions of this specification set forth the criteria} for determination of compliance with the OPERABILITY requirement $s$ of the Limiting Conditions for Operations. Under this criteria, equipment, systems or components are assumed to be OPERABLE if the associated surveillance activities have been satisfactorily perofmred within the specified time interval. Nothing in this provision is to be contrued as defining equipment, systems or components OPERABLE, when such items are found or known to be inoperable although still meeting the Surveillance Requirments.

\subsubsection{Thi specification ensures that the surveillance activities} associated with a Limiting Condition for Operation have been performed within the specified time interval prior to entry into an OPERATIONAL MODE or other applicable condition. The intent of this provision is to enslure that surveillance activities have been satisfactorily demonstrated on a current basis as required to meet the OPERABILITY requirements of the Limiting Condition for Operation. 
Under the terms of this specification, for example, during initial plant startup or following extended plant outages, the applicable surveillance activities must be performed within the stated surveillance interval prior to placing or returning the system or equipment into OPERABLE status.

4.0.5 This specification ensures that inservice inspection of ASME Code Class 1,2 and 3 components and inservice testing of ASME Code Class 1 , 2 and 3 pumps and valves will be performed in accordance with a periodically updated version of Section XI of the ASME Boiler and Pressure Vesse1 Code and Addenda as required by 10 CFR $50.55 \mathrm{a}$. Rel ief from any of the above requirements has been provided in writing by the Commission and is not a part of these technical specifications.

This specification includes a clarification of the frequencies for performing the inservice inspection and testing activities required by Section XI of the ASME Boiler and Pressure Vessel Code and applicable Addenda. This clarification is provided to ensure consistency in survelllance intervals throughout these Technical Specifications and to remove any ambiguities relative to the frequencies for performing the required inservice inspection and testing activities.

Under the terms of this specification, the more restrictive requirements of the Technical Specifications take precedence over the ASME Boiler and Pressure Vessel Code and applicable Addenda. For example, the requirements of Specification 4.0.4 to perform surveillance activities prior to entry into an OPERATIONAL MODE or other specified applicability condition takes precedence over the ASME Boiler and Pressure Vessel Code provision which allows pumps to be tested up to one week after return to normal operation and for example, the Technical Specification definition of OPERABLE does not grant a grace period before a device that is not capable of performing its specified functions is declared inoperable and takes precedence over the ASME Boiler and Pressure Vessel provision, which allows a valve to be incapable of performing its specified function for up to 24 hours before being declared inoperable. 
๑
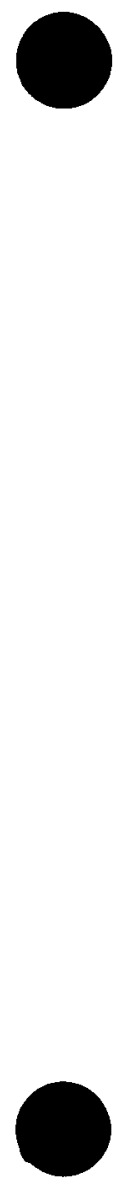
3/4.1.1 BORATION CONTROL

\section{3/4.1.1.1 SHUTDOWN MARGIN}

A sufficient SHUTDOWN MARGIN ensures that 1) the reactor can be made subcritical from all operating conditions, 2) the reactivity transients associated with postulated accident conditions are controllable within acceptable limits, and 3) the reactor will be maintained sufficiently subcritical to preclude inadvertent criticality in the shutdown condition. During Modes 1 and 2 the SHUTDOWN MARGIN is known to be within limits if all control rods are OPERABLE and withdrawn to or beyond the insertion 1 imits.

SHUTDOWN MARGIN requirements vary throughout core life as a function of fuel depletion, RCS boron concentration and RCS Tayg. The most restrictive condition occurs at EOL, with $T_{\text {ay }}$ at no ${ }^{\text {ayd }}$ ad operating temperature, and is associated with a postulaled steam line break accident and resulting uncontrolled RCS cooldown. In the analys is of this accident a minimum SHUTDOWN MARGIN of $(0.30) \% \Delta k / k$ is required to control the reactivity transient. Accordingly, the SHUTDOWN MARGIN required is based upon this limiting condition and is consistent with FSAR safety analysis assumptions.

\section{3/4.1.1.2 BORON DILUTION}

A minimum flow rate of at least (2800) GPM provides adequate mixing, prevents stratification and ensures that reactivity changes will be gradual through the Reactor Coolant System in the core during boron concentration reductions in the Reactor Coolant System. A flow rate of at least (2800) GPM will circulate an equivalent Reactor Coolant System volume of $(13,300)$ cubic feet in approximately 30 minutes. The reactivity change rate associated with boron concentration reduction will be within the capability for operator recognition and control.

\section{3/4.1.1.3 MODERATOR TEMPERATURE COEFFICIENT}

The limitations on moderator temperature coefficient (MTC) are provided to ensure that the assumptions used in the accident and transient analyses remain valid through each fuel cycle. The surveillance requirement for measurement of the MTC each fuel cycle are adequate to confirm the MTC value since this coefficient changes slowly due principally to the reduction in RCS boron concentration associated with fuel burnup. The confirmation that the measured MTC value is within its limit provides assurance that the coefficient will be maintained within acceptable values throughout each fuel cycle. 
REACTIVITY CONTROL SYSTEMS

BASES

3/4.1.1.4 MINIMUM TEMPERATURE FOR CRITICALITY

This specification ensures that the reactor will not be made critical with the Reactor Coolant System average temperature less than $525^{\circ} \mathrm{F}$.

This limitation is required to ensure 1) the moderator temperature coefficient is within its analyzed temperature range, 2) the protective instrumentation is within its normal operating range, 3 ) the pressurizer is capable of being in an OPERABLE status with a steam bubble, and 4) the reactor pressure vessel is above its minimum RT ${ }_{N D T}$ temperature.

\section{2/4.1.2 BORATION SYSTEMS}

The boron injection system ensures that negative reactivity control is available during each mode of facility operation. The components required to perform this function include 1) borated water sources, 2) makeup or DHR pumps, 3) separate flow paths, 4) boric acid pumps, 5) associated heat tracing systems, and 6) an emergency power supply from OPERABLE emergency busses.

With the RCS average temperature above $200^{\circ} \mathrm{F}$, a minimum of two separate and redundant boron injection systems are provided to ensure single functional capability in the event an assumed failure renders one of the systems inoperable. Allowable out-of-service periods ensure that minor component repair or corrective action may be completed without undue risk to overall facility safety from injection system failures during the repair period.

The boration capability of either system is sufficient to provide a SHUTDOWN MARGIN from expected operating conditions of $\Delta k / k$ after xenon decay and cooldown to $200^{\circ} \mathrm{F}$. The maximum expected boration capability requirement occurs at EOL from full power equilibrium xenon conditions and requires either gallons of acid storage tanks or gallons of borated water storage $\overline{\text { tank. }}$.

The requirements for a minimum contained volume of $(402,500)$ gallons of borated water in the borated water storage tank ensures the capability for borating the RCS to the desired level. The specified quantity of borated water is consistent with the ECCS requirements of Specification 3.5.4. Therefore, the larger volume of borated water is specifies.

With the RCS temperature below $200^{\circ} \mathrm{F}$, one injection system is acceptable without single failure consideration on the basis of the 
REACTIVITY CONTROL SYSTEMS

BASES

3/4.1.2 BORATION SYSTEMS (Continued)

stable reactivity condition of the reactor and the additional restrictions prohibiting CORE ALTERATIONS and positive reactivity change in the event the single injection system becomes inoperable.

The boron capability required below $200^{\circ} \mathrm{F}$ is sufficient to provide a SHUTDOWN MARGIN of $1 \% \Delta \mathrm{k} / \mathrm{k}$ after xenon decay and cooldown from $200^{\circ} \mathrm{F}$ to $140^{\circ} \mathrm{F}$. This condition requires either () gallons of $(12,250) \mathrm{ppm}$ borated water from the boric acid storage system or ( ) gallons of (1800) ppm borated water from the borated water storage tank.

The contained water volume limits include allowance for water not available because of discharge line location and other physical characteristics. The limits on contained water volume, and boron concentration ensure a pH value of between (8.5) and (11.0) of the solution sprayed within containment after a design basis accident. The pH band minimizes the evolution of iodine and minimizes the effect of chloride and caustic stress corrosion cracking on mechanical systems and components.

The OPERABILITY of one boron injection system during REFUELING ensures that this system is available for reactivity control while in MODE 6.

\section{3/4.1.3 MOVABLE CONTROL ASSEMBLIES}

The specifications of this section (1) ensure that acceptable power distribution limits are maintained, (2) ensure that the minimum SHUTDOWN MARGIN is maintained, and (3) limit the potential effects of rod misalignment on associated accident analyses. OPERABILITY of the control rod position indicators is required to determine control rod positions and thereby ensure compliance with the control rod alignment and insertion limits.

The ACTION statements which permit limited variations from the basic requirements are accompanied by additional restrictions which ensure that the original design criteria are met. For example, misalignment of a safety or regulating rod requires a restriction in THERMAL POWER. In addition, those accident analyses affected by a misaligned rod are reevaluated to confirm that the results remain valid during future operation.

The position of a rod declared inoperable due to misalignment should not be included in computing the average group position for determining the OPERABILITY of rods with lesser misalignments. 
3/4.1.3 MOVABLE CONTROL ASSEMBLIES (Continued)

The maximum rod drop time permitted is consistent with the assumed rod drop time used in the safety analyses. Measurement with $T$

$\geq(525)^{\circ} \mathrm{F}$ and with reactor coolant pumps operating ensures that $\mathrm{l}_{\mathrm{g}}$ measured drop times will be representative of insertion times experienced during a reactor trip at operating conditions.

Control rod positions and OPERABILITY of the rod position indicators are required to be verified on a nominal basis of once per 12 hours with frequent verifications required if an automatic monitoring channel is inoperable. These verification frequencies are adequate for assuring that the applicable LCO's are satisfied.

The limitation on THERMAL POWER based on xenon reactivity is necessary to ensure that power peaking limits are not exceeded even with specified rod insertion limits satisfied. 
$3 / 4.2$ POWER DISTRIBUTION LIMITS

\section{BASES}

The specifications of this section provide assurance of fuel integrity during Condition I (Normal Operation) and II (Incidents of Moderate Frequency) events by: (a) maintaining the minimum DNBR in the core $\geq(1.32 / 1.30)$ during normat operation and during short term transients, (b) maintaining the peak linear power density $<\quad \mathrm{kw} / \mathrm{ft}$ during normal operation, and (c) maintaining the peak power density $\leq(23.5) \mathrm{kW} / \mathrm{ft}$ during short term transients. In addition, the above criteria must be met in order to meet the assumptions used for the loss-of-coolant accidents.

The power-imbalance envelope defined in Figures (3.2-1 and 3.2-2), and the insertion 1 imit curves, Figures $(3.1-1,3.1-2,3.1-3,3.1-4$ and 3.1-5), are based on LOCA analyses which have defined the maximum linear heat rate such that the maximum clad temperature will not exceed the Final Acceptance Criteria of $2200^{\circ} \mathrm{F}$ following a LOCA. Operation outside of the power-imbalance envelope alone does not constitute a situation that would cause the Final Acceptance Criteria to be exceeded should a LOCA occur. The power-imbalance envelope represents the boundary of operation limited by the Final Acceptance Criteria only if the control rods are at the insertion limits, as defined by Figures (3.1-1,3.1-2,3.1-3,3.1-4 and 3.1-5), and if a (4) percent QUADRANT POWER TILT exists. Additional conservatism is introducted by application of:

a. Nuclear uncertainty factors.

b. Thermal calibration uncertainty.

c. Fuel densification effects.

d. Hot rod manufacturing tolerance factors.

The ACTION statements which permit limited variations from the basic requirements are accompanied by additional restrictions which ensures that the original criteria are met.

The definitions of certain design limit nuclear power peaking factors as used in these specifications are as follows:

$F_{Q} \quad$ Nuclear Heat Flux Hot Channel Factor, is defined as the maximum local fuel rod linear power density divided by the average fuel rod linear power density, assuming nominal fuel pellet and rod dimensions. 
POWER DISTRIBUTION LIMITS

BASES

$F^{N} \quad$ Nuclear Enthalpy Rise Hot Channel Factor, is defined as the

$\Delta H$ ratio of the integral of linear power along the rod on which minimum DNBR occurs to the average rod power.

It has been determined by extensive analysis of possible operating power shapes that the design limits on nuclear power peaking and on minimum DNBR at full power are met, provided:

$$
F_{Q} \leq(2.56) ; \quad F_{\Delta H}^{N} \leq(1.71)
$$

Power Peaking is not a directly observabie quantity and therefore limits have been established on the bases of the AXIAL POWER IMBALANCE produced by the power peaking. It has been determined that the above hot channel factor limits will be met provided the following conditions are maintained.

1. Control rods in a single group move together with no individual rod insertion differing by more than \pm()$\%$ (indicated position) from the group average height.

2. Regulating rod groups are sequenced with overlapping groups as required in Specification 3.1.3.6.

3. The regulating rod insertion limits of Specification 3.1.3.6 are maintained.

4. AXIAL POWER IMBALANCE 1 imits are maintained. The AXIAL POWER IMBALANCE is a measure of the difference in power between the top and bottom halves of the core. Calculations of core average axial peaking factors for many plants and measurements from operating plants under a variety of operating conditions have been correlated with AXIAL POWER IMBALANCE. The correlation shows that the design power shape is not exceeded if the AXIAL POWER IMBALANCE is maintained between + (10) percent and - (15) percent at RATED THERMAL POWER.

The design limit power peaking factors are the most restrictive calculated at full power for the range from all control rods fully withdrawn to minimum allowable control rod insertion and are the core DNBR design basis. Therefore, for operation at a fraction of RATED THERMAL POWER, the design ? imits are met. When using incore detectors to make power distribution maps to determine $F_{Q}$ and $F_{\Delta H}^{N}$ :

a. The measurement of total peaking factor, $F_{0}^{\text {Meas }}$, shall be increased by (3) percent to account for manufacturing tolerances and further increased by (5) percent to account for measurement error. 
POWER DISTRIBUTION LIMITS

BASES

b. The measurement of enthalpy rise hot channel factor, $F_{1}^{N}$, shall be increased by (4) percent to account for measurement error.

For Condition II events, the core is protected from exceeding (23.5) $\mathrm{kw} / \mathrm{ft}$ locally, and from going below a minimum DNBR of $(1.32 / 1.30)$, by automatic protection on power, AXIAL POWER IMBALANCE, pressure and temperature. Only conditions I through 3, above, are mandatory since the AXIAL POWER IMBALANCE is an explicit input to the Reactor Protection System.

The QUADRANT POWER TILT limit assures that the radial power distribution satisfies the design values used in the power capability analysis. Radial power distribution measurements are made during startup testing and periodically during power operation.

The QUADRANT POWER TILT limit of $(4) \%$ at which corrective action is required provides DNB and linear heat generation rate protection with $x-y$ plane power tilts. A limiting tilt of $(4.5) \%$ can be tolerated before the margin for uncertainty in $F_{0}$ is depleted. The limit of (4)\% was selected to provide an allowance for the uncertainty associated with the indicated power tilt. In the event the tilt is not corrected, the margin for uncertainty on $F_{0}$ is reinstated by reducing the power by 2 percent for each percent of eilt in excess of $(4) \%$.

\section{3/4.2.5 DNB PARAMETERS}

The limits on the DNB related parameters assure that each of the parameters are maintained within the normal steady state envelope of operation assumed in the transient and accident analyses. The limits are consistent with the FSAR initial assumptions and have been analytically demonstrated adequate to maintain a minimum DNBR of $(1.30)$ throughout each analyzed transient.

The 12 hour periodic surveillance of these parameters through instrument readout is sufficient to ensure that the parameters are restored within their limits following load changes and other expected transient operation. The 18 month periodic measurement of the RCS total flow rate is adequate to detect flow degradation and ensure correlation of the flow indication channels with measured flow such that the indicated percent flow will provide sufficient verification of flow rate on a 12 hour basis. 
$3 / 4.3$ INSTRUMENTATION

BASES

3/4.3.1 and 3/4.3.2 REACTOR PROTECTION SYSTEM (RPS) AND ENGINEERED

SAFETY FEATURES ACTUATION SYSTEM (ESFAS) INSTRUMENTATION

The OPERABILITY of the RPS and ESFAS instrumentation systems ensure that 1$)$ the associated ESFAS action and/or RPS trip will be initiated when the parameter monitored by each channel or combination thereof exceeds its setpoint, 2) the specified coincidence logic is maintained, 3) sufficient redundancy is maintained to permit a channel to be out of service for testing or maintenance, and 4) sufficient system functional capability is available for RPS and ESFAS purposes from diverse parameters.

The OPERABILITY of these systems is required to provide the overall reliability, redundance and diversity assumed available in the facility design for the protection and mitigation of accident and transient conditions. The integrated operation of each of these systems is consistent with the assumptions used in the accident analyses.

The surveillance requirements specified for these systems ensure that the overall system functional capability is maintained comparable to the original design standards. The periodic surveillance tests performed at the minimum frequencies are sufficient to demonstrate this capability.

The measurement of response time at the specified frequencies provides assurance that the RPS and ESFAS action function associated with each channel is completed within the time limit assumed in the safety analyses. No credit was taken in the analyses for those channels with response times indicated as not applicable.

Response time may be demonstrated by any series of sequential, overlapping or total channel test measurements provided that such test demonstrate the total channel response time as defined. Sensor response time verification may be demonstrated by either 1) in place, onsite or offsite test measurements or 2) utilizing replacement sensors with certified response times. 
3/4.3 INSTRUMENTATION

BASES

3/4.3.3 MONITORING INSTRUMENTATION

3/4.3.3.1 RADIATION MONITORING INSTRUMENTATION

The OPERABILITY of the radiation monitoring channels ensures that

1) the radiation levels are continually measured in the areas served

by the individual channels and 2) the alarm or automatic action is

initiated when the radiation level trip setpoint is exceeded.

\section{3/4.3.3.2 INCORE DETECTORS}

The OPERABILITY of the incore detectors ensures that the measurements obtained from use of this system accurately represent the spatial neutron flux distribution of the reactor core. See Bases Figures 3-1 and 3-2 for examples of acceptable minimum incore detector arrangements.

\section{3/4.3.3.3 SEISMIC INSTRUMENTATION}

The OPERABILITY of the seismic instrumentation ensures that sufficient capability is available to promptly determine the magnitude of a seismic event so that the response of those features important to safety may be evaluated. This capability is required to permit comparison of the measured response to that used in the design basis for the facility to determine if plant shutdown is required pursuant to Appendix "A" of 10 CFR Part 100. This instrumentation is consistent with the recommendations of Regulatory Guide 1.12 "Instrumentation for Earthquakes," Apri1 1974.

\section{3/4.3.3.4 METEOROLOGICAL INSTRUMENTATION}

The OPERABILITY of the meteorological instrumentation ensures that sufficient meteorological data is available for estimating potential radiation doses to the public as a result of routine or accidental release of radioactive materials to the atmosphere. This capability is required to evaluate the need for initiating protective measures to protect the health and safety of the public. This instrumentation is consistent with the recommendations of Regulatory Guide 1.23 "Onsite Meteorological Programs," February 1972.

\section{3/4.3.3.5 REMOTE SHUTDOWN INSTRUMENTATION}

The OPERABILITY of the remote shutdown instrumentation ensures that sufficient capability is available to permit shutdown and maintenance of B\&W-STS 
$3 / 4.3$ INSTRUMENTATION
BASES

REMOTE SHUTDOWN INSTRUMENTATION (Continued)

HOT STANDBY of the facility from locations outside of the control room. This capability is required in the event control room habitability is lost and is consistent with General Design Criteria 19 of Appendix "A", 10 CFR 50.

\section{3/4.3.3.6 POST-ACCIDENT INSTRUMENTATION}

The OPERABILITY of the post-accident instrumentation ensures that sufficient information is available on selected plant parameters to monitor and assess these variables following an accident. This capability is consistent with the recommendations of Regulatory Guide 1.97, "Instrumentation for Light-Water Cooled Nuclear Power Plants to Assess Plant Conditions During and Following an Accident," December 1975.

3/4.3.3.7 CHLORINE DETECTION SYSTEMS

The OPERABILITY of the chlorine detection systems ensures that an accidental chlorine release will be detected promptly and the control room emergency ventilation system will automatically isolate the control room and initiate its operation in the recirculation mode to provide the required protection. The chlorine detection systems required by this specification are consistent with the recommendations of Regulatory Guide 1.95, "Protection of Nuclear Power Plant Control Room Operations Against an Accidental Chlorine Release," February 1975.

\section{3/4.3.3.8 FIRE DETECTION INSTRUMENTATION}

OPERABILITY of the fire detection instrumentation ensures that adequate warning capability is available for the prompt detection of fires. This capability is required in order to detect and locate fires in their early stages. Prompt detection of fires will reduce the potential for damage to safety related equipment and is an integral element in the overall facility fire protection program.

In the event that a portion of the fire detection instrumentation is inoperable, the establishment of frequent fire patrols in the affected areas is required to provide detection capability until the inoperable instrumentation is restored to OPERABILITY. 


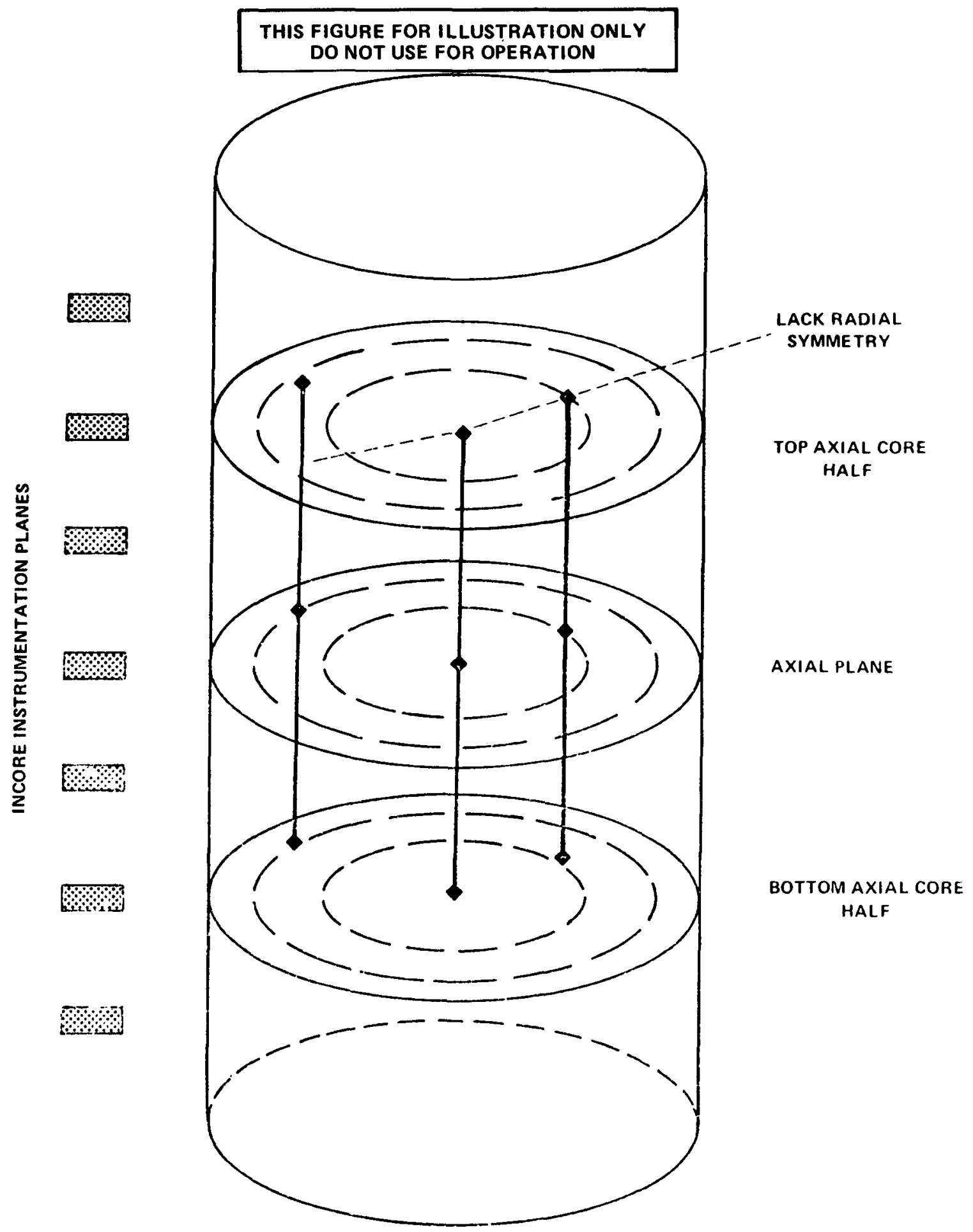

Bases Figure 3-1 Incore Instrumentation Specification Acceptable Minimum AXIAL POWER IMBALANCE Arrangement 


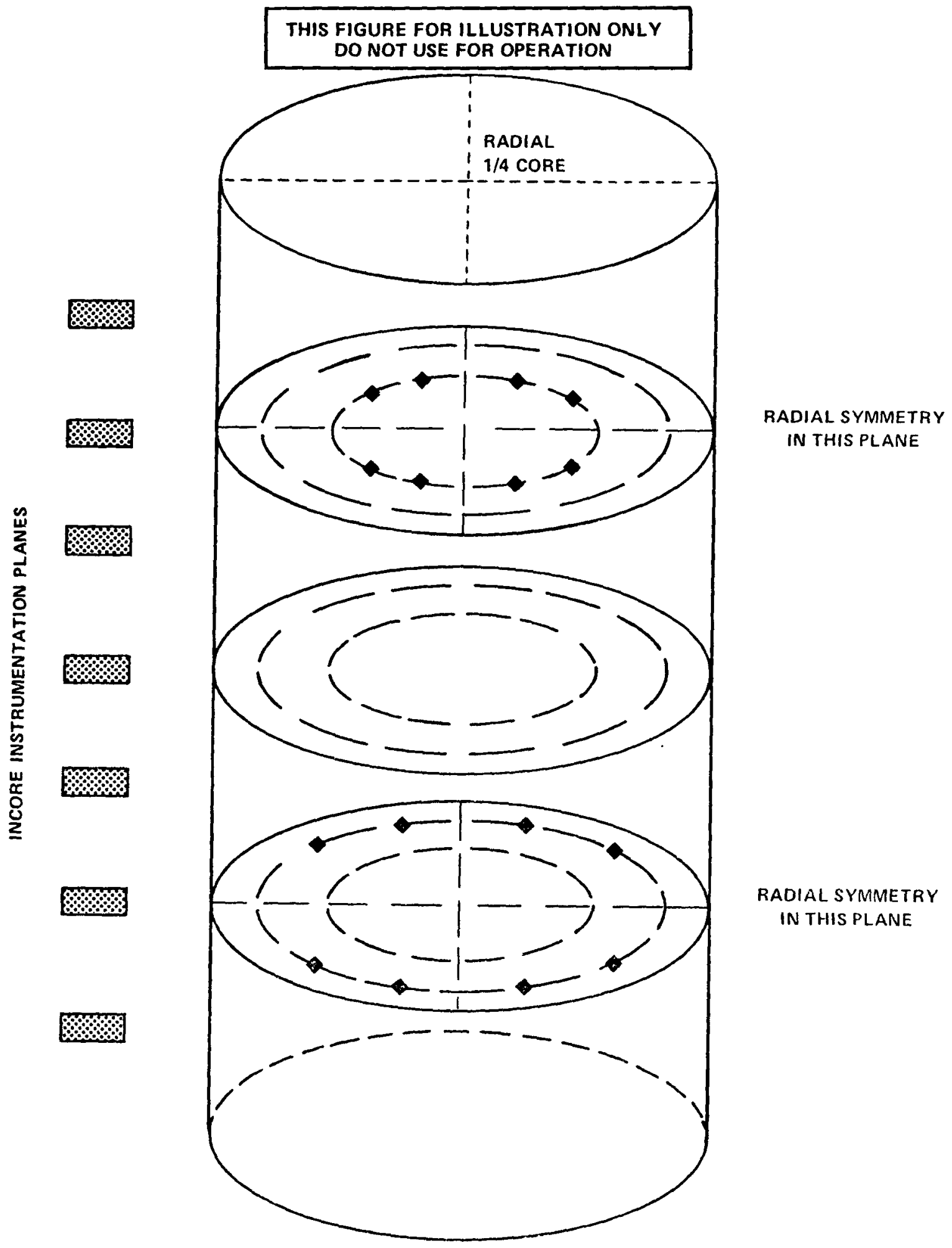

Bases Figure 3-2 Incore Instrumentation Specification Acceptable Minimum QUADRANT POWER TILT Arrangement 


\section{3/4.3.4 TURB INE OVERSPEED PROTECTION}

This specification is provided to ensure that the turbine overspeed protection instrumentation and the turbine speed control valves are OPERABLE and wil1 protect the turbine from excessive overspeed. Protection from turbine excessive overspeed is required since excessive overspeed of the turbine could generate potentially damaging missiles which could impact and damage safety related components, equipment or structures. 
$3 / 4.4 \quad$ REACTOR COOLANT SYSTEM

BASES

3/4.4.1 REACTOR COOLANT LOOPS

The plant is designed to operate with both reactor coolant loops in operation, and maintain DNBR above (1.32/1.30) during all normal operations and anticipated transients. With one reactor coolant pump not in operation in one or both loops, THERMAL POWER is restrlcted by the Nuclear Overpower Based on RCS Flow and AXIAL POWER IMBALANCE and the Nuclear Overpower Based on Pump Monitors trip, ensuring that the DNBR will be maintained above $(1.32 / 1.30)$ at the maximum possible THERMAL POWER for the number of reactor coolant pumps in operation or the local quality at the point of minimum DNBR equal to $(22 / 15) \%$, whichever is more restrictive.

A single reactor coolant loop provides sufficient heat removal capability for removing core decay heat while in HOT STANDBY; however, single failure considerations require placing a DHR loop into operation in the shutdown cooling mode if component repairs and/or corrective actions cannot be made within the allowable out-of-service time.

\section{$3 / 4.4 .2$ and $3 / 4.4 .3$ SAFETY VALVES}

The pressurizer code safety valves operate to prevent the RCS from being pressurized above its Safety Limit of (2750) psig. Each safety valve is designed to relieve 1bs per hour of saturated steam at the valve's setpoint.

The relief capacity of a single safety valve is adequate to relieve any overpressure condition which could occur during shutdown. In the event that no safety valves are OPERABLE, an operating DHR 10op, connected to the RCS, provides overpressure relief capability and will prevent RCS overpressurization.

During operation, all pressurizer code safety valves must be OPERABLE to prevent the RCS from being pressurized above its safety 1 imit of (2750) psig. The combined relief capacity of all of these valves is greater than the maximum surge rate resulting from any transient.

Demonstration of the safety valves' lift settings will occur only during shutdown and will be performed in accordance with the provisions of Section XI of the ASME Boiler and Pressure Code. 
REACTOR COOLANT SYSTEM

BASES

\section{3/4.4.4 PRESSURIZER}

A steam bubble in the pressurizer ensures that the RCS is not a hydraulically solid system and is capable of accommodating pressure surges during operation. The steam bubble also protects the pressurizer code safety valves and power operated relief valves against water relief.

The low level limit is based on providing enough water volume to prevent a pressurizer low level or a reactor coolant system low pressure condition that would actuate the Reactor Protection System or the Engineered Safety Feature Actuation System as a result of a reactor scram. The high level limit is based on providing enough steam volume to prevent a pressurizer high level as a result of any transient.

The power operated relief valves and steam bubble function to relieve RCS pressure during all design transients. Operation of the power operated relief valves minimizes the undesirable opening of the spring-loaded pressurizer code safety valves.

\section{3/4.4.5 STEAM GENERATORS}

The Surveillance Requirements for inspection of the steam generator tubes ensure that the structural integrity of this portion of the RCS will be maintained. The program for inservice inspection of steam generator tubes is based on a modification of Regulatory Guide 1.83, Revision 1. Inservice inspection of steam generator tubing is essential in order to maintain surveillance of the conditions of the tubes in the event that there is evidence of mechanical damage or progressive degradation due to design, manufacturing errors, or inservice conditions that lead to corrosion. Inservice inspection of steam generator tubing also provides a means of characterizing the nature and cause of any tube degradation sc that corrective measures can be taken.

The plant is expected to be operated in a manner such that the secondary coolant will be maintained within those chemistry limits found to result in negligible corrosion of the steam generator tubes. If the secondary coolant chemistry is not maintained within these chemistry limits, localized corrosion may likely result in stress corrosion cracking. The extent of cracking during plant operation would be limited by the limitation of steam generator tube leakage between the primary coolant system and the secondary coolant system (primary-to-secondary leakage $=1 \mathrm{GPM}$ ). Cracks having a primary-to-secondary leakage less than this limit during operation will have an adequate margin of safety to withstand the loads 
REACTOR COOLANT SYSTEM

BASES

imposed during normal operation and by postulated accidents. Operating plants have demonstrated that primary-to-secondary leakage of $1 \mathrm{GPM}$ can be detected by monitoring the secondary coolant. Leakage in excess of this limit will require plant shutdown and an unscheduled inspection, during which the leaking tubes will be located and plugged.

Wastage-type defects are unlikely with proper chemistry treatment of the secondary coolant. However, even if a defect should develop in service, it will be found during scheduled inservice steam generator tube examinations. Plugging will be required for $(40) \%$ of the tube nominal wall thickness. Steam generator tube inspections of operating plants have demonstrated the capability to reliably detect degradation that has penetrated $20 \%$ of the original tube wall thickness.

Whenever the results of any steam generator tubing inservice inspection fall into Category $\mathrm{C}-3$, these results will be promptly reported to the Commission pursuant to Specification 6.9.1 prior to resumption of plant operation. Such cases will be considered by the Commission on a case-by-case basis and may result in a requirement for analysis, laboratory examinations, tests, additional eddy-current inspection, and revision of the Technical Specifications, if necessary.

The steam generator water level limits are consistent with the initial assumptions in the FSAR. 
REACTOR COOLANT SYSTEM

BASES

3/4.4.6 REACTOR COOLANT SYSTEM LEAKAGE

3/4.4.6.1 LEAKAGE DETECTION SYSTEMS

The RCS leakage detection systems required by this specification are provided to detect and monitor leakage from the Reactor Coolant Pressure Boundary. These detection systems are consistent with the recommendations of Regulatory Guide 1.45, "Reactor Coolant Pressure Boundary Leakage Detection Systems," May 1973.

\section{3/4.4.6.2 OPERATIONAL LEAKAGE}

PRESSURE BOUNDARY LEAKAGE of any magnitude is unacceptable since it may be indicative of an impending gross failure of the pressure boundary. Therefore, the presence of any PRESSURE BOUNDARY LEAKAGE requires the unit to be promptly placed in COLD SHUTDOWN.

Industry experience has shown that, while a limited amount of leakage is expected from the RCS, the UNIDENTIFIED LEAKAGE portion of this can be reduced to a threshold value of less than 1 GPM. This threshold value is sufficiently low to ensure early detection of additional leakage.

The total steam generator tube leakage limit of 1 GPM for all steam generators ensures that the dosage contribution from tube leakage will be limited to a small fraction of Part 100 limits in the event of either a steam generator tube rupture or steam line break. The 1 GPM 1 imit is consistent with the assumptions used in the analysis of these accidents. The (0.5) GPM leakage limit per steam generator ensures that steam generator tube entegrity is maintained in the event of a main steam line rupture or under LOCA conditions.

The 10 GPM IDENTIFIED LEAKAGE 1 imitation provides allowance for a 1 imited amount of leakage from known sources whose presence will not interfere with the detection of UNIDENTIFIED LEAKAGE by the leakage detection systems.

The CONTROLLED LEAKAGE limit of ( ) GPM restricts operation with a total RCS leakage to all RC pump seals in excess of ( ) GPM. 
REACTOR COOLANT SYSTEM

BASES

\section{$3 / 4.4 .7$ CHEMISTRY}

The limitations on Reactor Coolant System chemistry ensure that corrosion of the Reactor Coolant System is minimized and reduce the potential for Reactor Coolant System leakage or failure due to stress corrosion. Maintaining the chemistry within the Steady State Limits shown on Table 3.4-1 provides adequate corrosion protection to ensure the structural integrity of the Reactor Coolant System over the life of the plant. The associated effects of exceeding the oxygen, chloride and fluoride limits are time and temperature dependent. Corrosion studies show that operation may be continued with contaminant concentration levels in excess of the Steady State Limits, up to the Transient Limits, for the specified limited time intervals without having a significant effect on the structural integrity of the Reactor Coolant System. The time interval permitting continued operation within the restrictions of the Transient Limits provides time for taking corrective actions to restore the contaminant concentrations to within the Steady State Limits.

The surveillance requirements provide adequate assurance that concentrations in excess of the limits will be detected in sufficient time to take corrective action.

\section{3/4.4.8 SPECIFIC ACTIVITY}

The limitations on the specific activity of the primary coolant ensure that the resulting 2 hour doses at the site boundary will not exceed an appropriately small fraction of the Part 100 limit following a steam generator tube rupture accident in conjunction with an assumed steady state primary-to-secondary steam generator leakage rate of 1.0 GPM. The values for the 1 imits on specific activity represent interim limits based upon a parametric evaluation by the NRC of typical site locations. These values are conservative in the specific site parameters of the site, such as site boundary location and meteorological conditions, were not considered in this evaluation. The NRC is finalizing site specific criteria which will be used as the basis for the reevaluation of the specific activity limits of this site. This reevaluation may result in higher limits. 
The ACTION statement permitting POWER OPERATION to continue for limited time periods with the primary coolant's specific activity $>1.0$ $\mu \mathrm{Ci} / \mathrm{gram}$ DOSE EQUIVALENT I-131, but within the allowable limit shown on Figure 3.4-1, accommodates possible iodine spiking phenomenon which may occur following changes in THERMAL POWER. Operation with specific activity levels exceeding $1.0 \mu \mathrm{Ci} / \mathrm{gram}$ DOSE EQUIVALENT I-131 but within the limits shown on Figure 3.4-1 must be restricted to no more than 800 hours per year (approximately 10 percent of the units yearly operating time) since the activity levels allowed by Figure 3.4-1 increase the 2 hour thyroid dose at the site boundary by a factor of up to 20 following a postulated steam generator tube rupture. Reporting any cumulative operating time over 500 hours in any 6 consecutive month period with $>1.0 \mu \mathrm{Ci} / \mathrm{gram}$ DOSE EQUIVALENT I-131 wi11 alert the NRC to the situation and allow sufficient time for evaluation and appropriate action before reaching the 800 hour 1 imit.

Reducing $\mathrm{T}_{\text {ayg }}$ to $<(500)^{\circ} \mathrm{F}$ prevents the release of activity should a steam generator tube rupture since the saturation pressure of the primary coolant is below the lift pressure of the atmospheric steam relief valves.

The surveillance requirements provide adequate assurance that excessive specific activity levels in the primary coolant will be detected in sufficient time to take corrective action. Information obtained on iodine spiking will be used to assess the parameters associated with spiking phenomena. A reduction in frequency of isotopic analyses following power changes may be permissible if justified by the data obtained.

\section{3/4.4.9 PRESSURE/TEMPERATURE LIMITS}

All components in the Reactor Coolant System are designed to withstand the effects of cyclic loads due to system temperature and pressure changes. These cyclic loads are introduced by normal load transients, reactor trips, and startup and shutdown operations. The various categories of load cycles used for design purposes are provided in Section () of the FSAR. During heatup and cooldown, the rates of temperature and pressure changes are limited so that the maximum specified heatup and cooldown rates are consistent with the design assumptions and satisfy the stress limits for cyclic operation.

During heatup, the thermal gradients in the reactor vessel wall produce thermal stresses which vary from compressive at the inner wall to tensile at the outer wall. These thermal induced compressive stresses tend to alleviate the tensile stresses induced by the internal pressure. Therefore, a pressure-temperature curve based on steady state conditions (i.e., no thermal stresses) represents a lower bound of all similar curves for finite heatup rates when the inner wall of the vessel is treated as the governing location. 


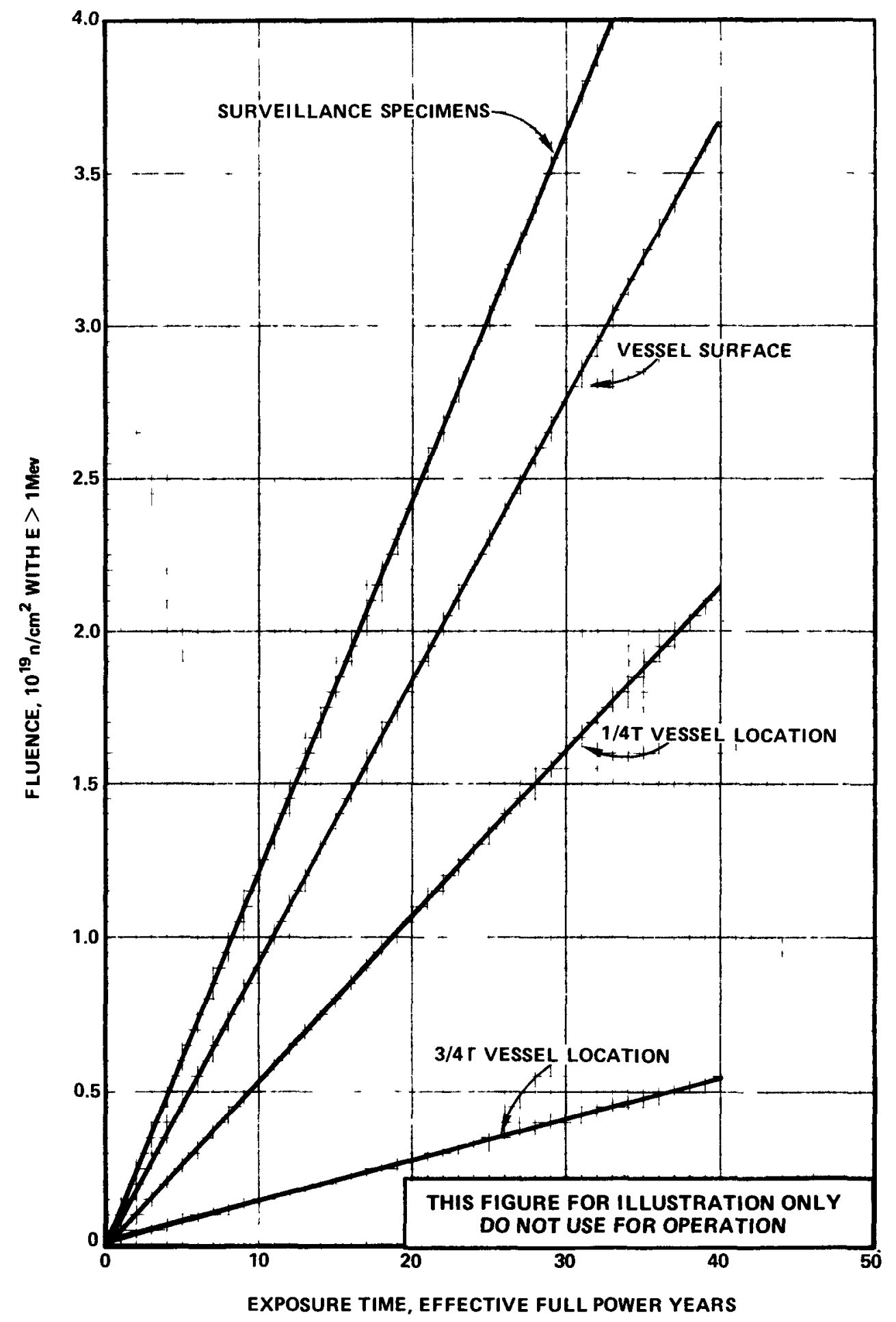

Bases Figure 4-1 Fast Neutron Fluence (E $>1 \mathrm{mev}$ ) as a Function of Full Power Service Life 


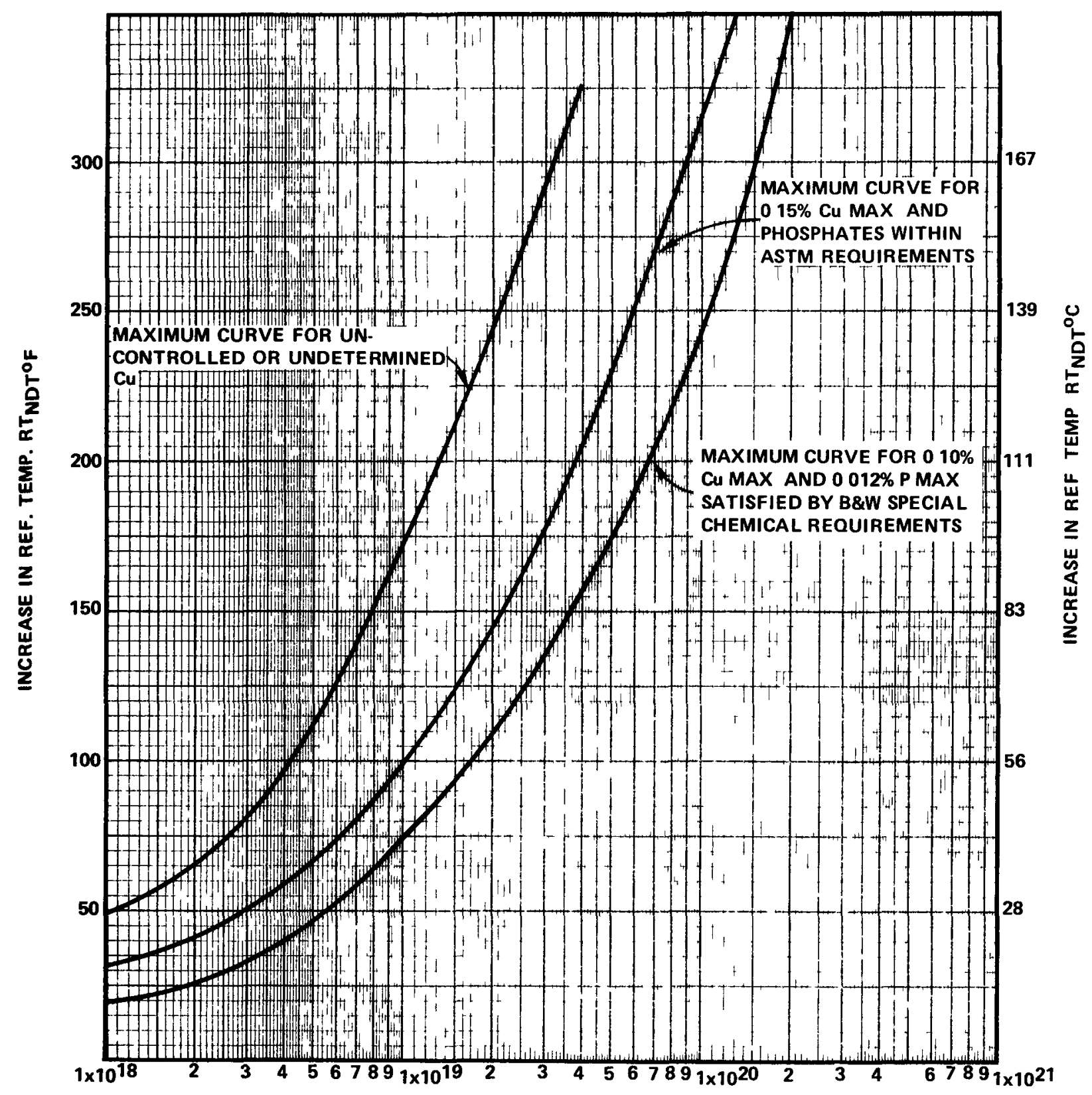

NEUTRON FLUENCE $\mathrm{n} / \mathrm{cm}^{2}$ WITH E $>1$ Mev

Bases Figure 4-2 Effect of Fluence and Copper Content on Shift of RT NDT for Reactor Vessel Steels Exposed to $550^{\circ} \mathrm{F}$ Temperature 


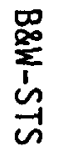

BASES TABLE 4-1

REACTOR VESSEL TOUGHNESS

\begin{tabular}{|c|c|c|c|c|c|c|c|c|}
\hline & COMP & MATERIAL & $\mathrm{CU}$ & $P$ & NDTT & $\begin{array}{l}50 \text { FT-LB/ } 35 \\
\text { MIL TEMP F }\end{array}$ & $\mathrm{RT}_{\text {NDT }}$ & $\begin{array}{l}\text { MIN. UPPER SHELF } \\
\text { FT-LB } \\
\end{array}$ \\
\hline COMPONENT & CODE & TYPE & $\%$ & $\%$ & $F$ & TRANS & $F$ & TRANS \\
\hline
\end{tabular}

$\infty$
$\omega$
$b$
$b$

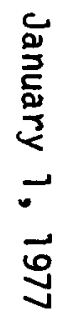


REACTOR COOLANT SYSTEM

BASES

The heatup analysis also covers the determination of pressuretemperature limitations for the case in which the outer wall of the vessel becomes the controlling location. The thermal gradients established during heatup produce tensile stresses at the outer wall of the vessel. These stresses are additive to the pressure induced tensile stresses which are already present. The thermal induced stresses at the outer wall of the vessel are tensile and are dependent on both the rate of heatup and the time along the heatup ramp; therefore, a lower bound curve similar to that described for the heatup of the inner wall cannot be defined. Consequently, for the cases in which the outer wall of the vessel becomes the stress controlling location, each heatup rate of interest must be analyzed on an individual basis.

The heatup limit curves, Figures (3.4-2) and (3.4-3), are composite curves which were prepared by determining the most conservative case, with either the inside or outside wall controlling, for any heatup rate up to $100^{\circ} \mathrm{F}$ per hour. The cooldown limit curves, Figures (3.4-2) and (3.4-3) are composite curves which were prepared based upon the same type analys is with the exception that the controlling location is always the inside wall where the cooldown thermal gradients tend to produce tensile stresses while producing compressive stresses at the outside wall. The heatup and cooldown curves were prepared based upon the most limiting value of the predicted adjusted reference temperature at the end of (2) EFPY.

The reactor vessel materials have been tested to determine their

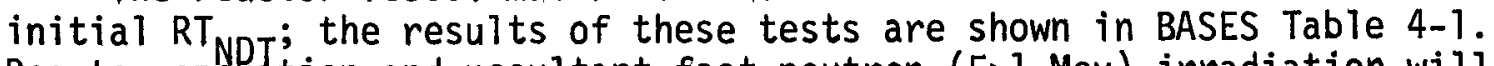
Reactor operation and resultant fast neutron ( $E>1$ Mev) irradiation will cause an increase in the RT ${ }_{\text {NRT }}$. Therefore, an adjusted reference temperature, based upon the fillence and copper content of the material in question, can be predicted using BASES Figures 4-1 and 4-2. The heatup and cooldown limit curves, of Figures (3.4-2) and (3.4-3) include predicted adjustments for this shift in RT as adjustments for possible errors in the pressure and temperature sensing ins truments.

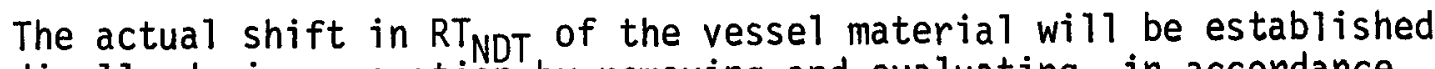
periodically during operation by removing and evaluating, in accordance with ASTM E185-73, reactor vessel material irradiation surveillance specimens installed near the inside wall of the reactor vessel in the core area. Since the neutron spectra at the irradiation samples and vessel inside the radius are essentially identical, the measured transition shift for a sample can applied with confidence to the adjacent section of the reactor vessel. The heatup and cooldown curves must be 
REACTOR COOLANT SYSTEM

BASES

recalculated when the $\triangle R T_{\text {NDT }}$ determined from the surveillance capsule is different from the calculated $\triangle \mathrm{RT}_{\mathrm{NDT}}$ for the equivalent capsule radiation exposure.

The pressure and temperature 1 imits shown on Figures 3.4-2 and 3.4-3 for reactor criticality and for inservice leak and hydrostatic testing have been provided to assure compliance with the minimum temperature requirements of Appendix G to 10 CFR 50.

The number of reactor vessel irradiation surveillance specimens and the frequencies for removing and testing these specimens are provided in Table 4.4-3 to assure compliance with the requirements of Appendix $H$ to 10 CFR Part 50.

The limitations imposed on pressurizer heatup and cooldown and spray water temperature differential are provided to assure that the pressurizer is operated within the design criteria assumed for the fatigue analys is performed in accordance with the ASME code requirements.

3/4.4.10 STRUCTURAL INTEGRITY

The inservice inspection and testing programs for ASME Code Class 1, 2 and 3 components ensure that the structural integrity and operational readiness of these components will be maintained at an acceptable level throughout the life of the plant. These programs are in accordance with Section XI of the ASME Boiler and Pressure Vessel Code and applicable Addenda as required by 10 CFR Part $50.55 \mathrm{a}(\mathrm{g})$ except where specified written relief has been granted by the Commission pursuant to 10 CFR Part 50.55a (g) (6) (i).

The internals vent valves are provided to relieve the pressure generated by steaming in the core following a LOCA so that the core remains sufficiently covered. Inspection and manual actuation of the internals vent valves 1) ensure OPERABILITY, 2) ensure that the valves are not stuck open during normal operation, and 3) demonstrates that the valves are fully open at the force equivalent to the differential pressure assumed in the safety analysis.

Components of the reactor coolant system were designed to provide access to permit inservice inspections in accordance with Section XI of the ASME Boiler and Pressure Vessel Code, Edition and Addenda through 
๑

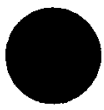


3/4.5 EMERGENCY CORE COOLING SYSTEMS (ECCS)

BASES

\section{3/4.5.1 CORE FLOODING TANKS}

The OPERABILITY of each core flooding tank ensures that a sufficient volume of borated water will be inmediately forced into the reactor vessel in the event the RCS pressure falls below the pressure of the tanks. This initial surge of water into the vessel provides the initial cooling mechanism during large RCS pipe ruptures.

The limits on volume, boron concentration and pressure ensure that the assumptions used for core flooding tank injection in the safety analysis are met.

The tank power operated isolation valves are considered to be "operating bypasses" in the context of IEEE Std. 279-1971, which requires that bypasses of a protective function be removed automatically whenever permissive conditions are not met. In addition, as these tank isolation vaives fail to meet single failure criteria, removal of power to the valves is required.

The limits for operation with a core flooding tank inoperable for any reason except an isolation valve closed minimizes the time exposure of the plant to a LOCA event occurring concurrent with failure of an additional tank which may result in unacceptable peak cladding temperatures. If a closed isolation valve cannot be immediately opened, the full capability of one tank is not available and prompt action is required to place the reactor in a mode where this capability is not required. 
EMERGENCY CORE COOLING SYSTEMS

BASES

$3 / 4.5 .2$ and $3 / 4.5 .3$ ECCS SUBSYSTEMS

The OPERABILITY of two independent ECCS subsystems with RCS average temperature $>(305)^{\circ} \mathrm{F}$ ensures that sufficient emergency core cooling capability will be available in the event of a LOCA assuming the loss of one subsystem through any single failure consideration. Either subsystem operating in conjunction with the core flooding tanks is capable of supplying sufficient core cooling to maintain the peak cladding temperatures within acceptable limits for all postulated break sizes ranging from the double ended break of the largest RCS cold leg pipe downward. In addition, each ECCS subsystem provides long term core cooling capability in the recirculation mode during the accident recovery period.

With the RCS temperature below $(305)^{\circ} \mathrm{F}$, one OPERABLE ECCS subsystem is acceptable without single failure consideration on the basis of the stable reactivity condition of the reactor and the limited core cooling requirements.

The Surveillance Requirements provided to ensure OPERABILITY of each component ensures, that, at a minimum, the assumptions used in the safety analyses are met and that subsystem OPERABILITY is maintained. Power is required to be removed from any valve which fails to meet single failure criteria. The decay heat removal system leak rate surveillance requirements assure that the leakage rates assumed for the system during the recirculation phase of the low pressure injection will not be exceeded.

Surveillance requirements for throttle valve position stops and flow balance testing provide assurance that proper ECCS flows will be maintained in the event of a LOCA. Maintenance of proper flow resistance and pressure drop in the piping system to each injection point is necessary to: (1) prevent total pump flow from exceeding runout conditions when the system is in its minimum resistance configuration, (2) provide the proper flow split between injection points in accordance with the assumptions used in the ECCS-LOCA analyses, and (3) provide an acceptable level of total ECCS flow to all injection points equal to or above that assumed in the ECCSLOCA analyses. 
EMERGENCY CORE COOLING SYSTEMS

BASES

3/4.5.4 BORATED WATER STORAGE TANK

The OPERABILITY of the borated water storage tank (BWST) as part of the ECCS ensures that a sufficient supply of borated water is available for injection by the ECCS in the event of a LOCA. The limits on BWST minimum volume and boron concentration ensure that 1) sufficient water is available within containment to permit recirculation cooling flow to the core, and 2) the reactor will remain subcritical in the cold condition following mixing of the BWST and the RCS water, volumes with all control rods inserted except for the most reactive control as sembly. These assumptions are consistent with the LOCA analyses.

The contained water volume limit includes an allowance for water not usable because of tank discharge line location or other physical characteristics. The limits on contained water volume, and boron concentration ensure a pH value of between (8.5) and (ii.0) of the solution sprayed within containment after a design basis accident. The pH band minimizes the evolution of iodine and minimizes the effect of chloride and caustic stress corrosion cracking on mechanical systems and components. 
•

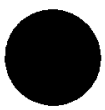

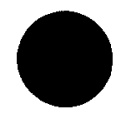




\section{BASES}

FOR

SECTION $3 / 4.6 \mathrm{~J}$

CONTAINMENT SYSTEMS SPECIFICATIONS

FOR

BABCOCK AND WILCOX STS

ATMOSPHERIC TYPE CONTAINMENT 
•

$\bullet$

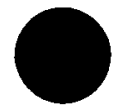


$3 / 4.6 \quad$ CONTAINMENT SYSTEMS
BASES

3/4.6.1 PRIMARY CONTAINMENT

3/4.6.1.1 CONTAINMENT INTEGRITY

Primary CONTAINMENT INTEGRITY ensures that the release of radioactive materials from the containment atmosphere will be restricted to those leakage paths and associated leak rates assumed in the safety analyses. This restriction, in conjunction with the leakage rate limitation, will limit the site boundary radiation doses to within the limits of 10 CFR 100 during accident conditions. .

\section{3/4.6.1.2 CONTAINMENT LEAKAGE}

The limitations on containment leakage rates ensure that the total containment leakage volume will not exceed the value assumed in the safety analyses at the peak accident pressure of psig, $P$. As an added conservatism, the measured overall integrated Teakage rate is further limited to $\leq 0.75 \mathrm{~L}_{\alpha}$ or $\leq 0.75 \mathrm{~L}_{t}$, as applicable, during performance of the periodic tests to account for possible degradation of the containment leakage barriers between leakage tests.

The surveillance testing for measuring leakage rates are consistent with the requirements of Appendix " $\mathrm{J}$ " of 10 CFR 50.

\section{3/4.6.1.3 CONTAINMENT AIR LOCKS}

The limitations on closure and leak rate for the containment air locks are required to meet the restrictions on CONTAINMENT INTEGRITY and containment leak rate given. Surveillance testing of the air lock seals provide assurance that the overall air lock leakage will not become excessive due to seal damage during the intervals between air lock leakage tests.

\section{3/4.6.1.4 CONTAINMENT ISOLATION VALVE AND CHANNEL WELD PRESSURIZATION SYSTEMS (OPTIONAL)}

The OPERABILITY of the isolation valve and containment channel weld pressurization systems is required to meet the restrictions on overall containment leak rate assumed in the accident analysis. The Surveillance Requirements for determining OPERABILITY are consistent with Appendix " $\mathrm{J"}$ of 10 CFR 50. 


\section{3/4.6.1.5 INTERNAL PRESSURE}

The limitations on containment internal pressure ensure that 1) the containment structure is prevented from exceeding its design negative pressure differential with respect to the outside atmosphere of (3.0) psig and 2) the containment peak pressure does not exceed the design pressure of (54) psig during LOCA conditions.

The maximum peak pressure obtained from a LOCA event is (45) psig. The limit of (3) psig for initial positive containment pressure will limit the total pressure to (48) psig which is less than the design pressure and is consistent with the safety analyses.

\section{3/4.6.1.6 AIR TEMPERATURE}

The limitations on containment average air temperature ensure that the overall containment average air temperature does not exceed the initial temperature condition assumed in the accident analysis for a LOCA.

\section{3/4.6.1.7 CONTAINMENT STRUCTURAL INTEGRITY}

\section{(Prestressed concrete containment with ungrouted tendons.)}

This limitation ensures that the structural integrity of the containment will be maintained comparable to the original design standards for the life of the facility. Strctural integrity is required to ensure that the containment will withstand the maximum pressure of (48) psig in the event of a LOCA. The measurement of containment tendon lift off force, the tensile tests of the tendon wires or strands, the visual examination of tendons, anchorages and exposed interior and exterior surfaces of the containment, and the Type A leakage test are sufficient to demonstrate this capability. (The tendon wire or strand samples will also be subjected to stress cycling tests and to accelerated corrosion tests to simulate the tendon's operating conditions and enviornment.)

The surveillance requirements for demonstrating the containment's structural integrity are in compliance with the recommendations of Regulatory Guide 1.35 "Inservice Surveillance of Ungrouted Tendons in Prestressed Concrete Containment Structures", January 1976.

(Reinforced concrete containment.)

This limitation ensures that the structural integrity of the containment will be maintained comparable to the original design standards for the life of the facility. Structural integrity is required to ensure that the containment will withstand the maximum pressure of (48) psig in the event of a LOCA. A visual inspection in conjunction with the Type A leakage tests is sufficient to demonstrate this capability. 


\section{3/4.6.1.8 CONTAINMENT VENT ILATION SYSTEM}

The containment purge supply and exhaust isolation valves are required to be closed during plant operation since these valves have not been demonstrated capable of closing during a LOCA. Maintaining these valves closed during plant operations ensures that excessive quantities of radioactive materials will not be released via the conta inment purge system.

3/4.6.2 DEPRESSURIZATION AND COOLING SYSTEMS

\section{3/4.6.2.1 CONTAINMENT SPRAY SYSTEM}

The OPERABILITY of the containment spray system ensures that containment depressurization and cooling capability will be available in the event of a LOCA. The pressure reduction and resultant lower containment leakage rate are consistent with the assumptions used in the safety analyses. The leak rate surveillance requirements assure that the leakare rates assumed for the system during the recirculation phase will not be exceeded.

(Credit taken for iodine removal)

The containment spray system and the containment cooling system are redundant to each other in providing post accident cooling of the containment atmosphere. However, the containment spray system also provides a mechanism for removing iodine from the containment atmosphere and therefore the time requirements for restoring an inoperable spray system to OPERABLE status have been maintained consistent with that assigned other inoperable ESF equipment.

(No credit taken for iodine removal)

The containment spray system and the containment cooling system are redundant to each other in providing post accident cooling of the containment atmosphere. Since no credit has been taken for iodine removal by the containment spray system, the allowable out of service time requirements for the containment spray system and containment cooling system have been interrelated and adjusted to reflect this additional redundancy in cooling capability. 
CONTAINMENT SYSTEMS

BASES

\section{3/4.6.2.2 SPRAY ADDITIVE SYSTEM (OPTIONAL)}

The OPERABILITY of the spray additive system ensures that sufficient $\mathrm{NaOH}$ and $\mathrm{Na}_{2} \mathrm{~S}_{2} \mathrm{O}_{3}$ are added to the containment spray in the event of a LOCA. The mifimum $\mathrm{Na}_{2} \mathrm{~S}_{2} \mathrm{O}_{3}$ yolume and concentration ensures sufficient $\mathrm{Na}_{2} \mathrm{~S}_{2} \mathrm{O}_{3}$ is available to remove organic iodine from the containment atmosphere and return it to the spray water. The limits on contained sodium hydroxide solution volume and concentration, and contained sodium thiosulfate solution volume and concentration ensure a $\mathrm{pH}$ value of between (8.5) and (11.0) of the solution sprayed within containment after a desian basis accident. The $\mathrm{pH}$ band minimizes the evolution of iodine and minimizes the effect of chloride and caustic stress corrosion cracking on mechanical systems and components. The contained water volume limit includes an allowance for water not usable because of tank discharge line location or other physical characteristics. These assumptions are consistent with the iodine removal efficiency assumed in the safety analyses.

\section{3/4.6.2.3 CONTAINMENT COOLING SYSTEM (OPTIONAL)}

The OPERABILITY of the containment cooling system ensures that 1) the containment air temperature will be maintained within limits during normal operation, and 2) adequate heat removal capacity is available when operated in conjunction with the containment spray systems during post-LOCA conditions.

(Credit taken for iodine removal by spray systems)

The containment cooling system and the containment spray system are redundant to each other in providing post accident cooling of the containment atmosphere. As a result of this redundancy in cooling capability, the allowable out of service time requirements for the containment cooling system have been appropriately adjusted. However, the allowable out of service time requirements for the containment spray system have been maintained consistent with that assigned other inoperable ESF equipment since the containment spray system also provides a mechanism for removing iodine from the containment atmosphere.

(No credit taken for iodine removal by spray systems)

The containment cooling system and the containment spray system are redundant to each other in providing post accident cooling of the containment atmosphere. Since no credit has been taken for iodine removal by the containment spray system, the allowable out of service time requirements for the contaimment cooling system and containment spray system have been interrelated and adjusted to reflect this additional redundancy in cooling capacity. 
CONTAINMENT SYSTEMS

BASES

3/4.6.3 IODINE CLEANUP SYSTEM (OPTIONAL)

The OPERABILITY of the containment iodine cleanup system ensures that sufficient iodine removal capability will be available in the event of a LOCA. The reduction in containment iodine inventory reduces the resulting site boundary radiation doses associated with containment leakage. The operation of this system and resultant iodine removal capacity are consistent with the assumptions used in the LOCA analyses.

\section{3/4.6.4 CONTAINMENT ISOLATION VALVES}

The OPERABILITY of the containment isolation valves ensures that the containment atmosphere will be isolated from the outside environment in the event of a release of radioactive material to the containment atmosphere or pressurization of the containment. Containment isolation within the time limits specified ensures that the release of radioactive material to the environment will be consistent with the assumptions used in the analyses for a LOCA.

\section{3/4.6.5 COMBUSTIBLE GAS CONTROL}

The OPERABILITY of the equipment and systems required for the detection and control of hydrogen gas ensures that this equipment will be available to maintain the hydrogen concentration within containment below its flammable limit during post-LOCA conditions. Either recombiner unit (or the purge cleanup system) is capable of controlling the expected hydrogen generation associated with 1) zirconium-water reactions, 2) radiolytic decomposition of water, and 3) corrosion of metals within containment. These hydrogen control systems are consistent with the recommendations of Regulatory Guide 1.7, "Control of Combustible Gas Concentrations in Containment Following a LOCA," March 1971.

The hydrogen mixing systems are provided to ensure adequate mixing of the containment atmosphere following a LOCA. This mixing action will prevent localized accumulations of hydrogen from exceeding the flammable limit.

\section{3/4.6.6 PENETRATION ROOM EXHAUST AIR CLEANUP SYSTEM (OPTIONAL)}

The OPERABILITY of the penetration room exhaust air cleanup system ensures that radioactive materials leaking from the containment atmosphere through containment penetrations following a LOCA are filtered and adsorbed prior to reaching the environment. The operation of this system and the resultant effect on offsite dosage calculations was assumed in the LOCA analyses. 
3/4.6.7 VACUUM RELIEF VALVES (OPTIONAL)

The OPERABILITY of the primary containment-to-atmosphere vacuum relief valves ensures that the containment internal pressure does not become more negative than psig. This condition is necessary to prevent exceeding the containment design limit for internal vacuum of psig. 


\section{BASES}

FOR

SECTION 3/4.6L

CONTAINMENT SYSTEMS SPECIFICATIONS

FOR

BABCOCK AND WILCOX STS

DUAL TYPE CONTAINMENTS 
○
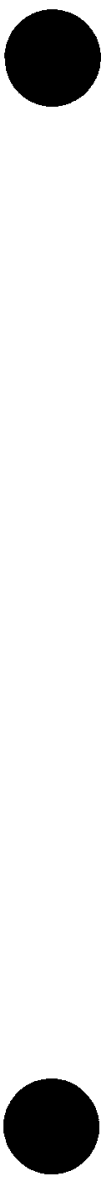
$3 / 4.6$ CONTAINMENT SYSTEMS

BASES

3/4.6.1 PRIMARY CONTAINMENT

3/4.6.1.1 CONTAINMENT INTEGRITY

Primary CONTAINMENT INTEGRITY ensures that the release of radioactive materials from the containment atmosphere will be restricted to those leakage paths and associated leak rates assumed in the safety analyses. This restriction, in conjunction with the leakage rate limitation, will limit the site boundary radiation doses to within the limits of 10 CFR 100 during accident conditions.

\section{3/4.6.1.2 CONTAINMENT LEAKAGE}

The 1 imitations on containment leakage rates ensure that the total containment leakage volume will not exceed the value assumed in the safety analyses at the peak accident pressure of psig, $P_{\text {a A A an }}$ added conservatism, the measured overall integrated Teakage rate is further limited to $\leq 0.75 \mathrm{~L}_{\text {o }}$ or $\leq \mathrm{L}_{t}$, as applicable, during performance of the periodic tests to account for possible degradation of the containment leakage barriers between leakage tests.

The surveillance testing for measuring leakage rates are consistent with the requirements of Appendix "J" of 10 CFR 50.

\section{3/4.6.1.3 CONTAINMENT AIR LOCKS}

The limitations on closure and leak rate for the containment air locks are required to meet the restrictions on CONTAINMENT INTEGRITY and containment leak rate. Surveillance testing of the air lock seals provide assurance that the overall air lock leakage will not become excessive due to seal damage during the intervals between air lock leakage tests.

3/4.6.1.4 CONTAINMENT ISOLATION VALVE AND CHANNEL WELD PRESSURIZATION SYSTEMS (OPTIONAL)

The OPERABILITY of the isolation valve and containment channel weld pressurization systems is required to meet the restrictions on overall containment leak rate assumed in the accident analyses. The Surveillance Requirements for determining OPERABILITY are consistent with Appendix " $\mathrm{J}$ " of 10 CFR 50 . 


\section{3/4.6.1.5 INTERNAL PRESSURE}

The limitations on containment internal pressure ensure that 1) the containment structure is prevented from exceeding its design negative pressure differential with respect to the annulus atmosphere of $(1.0)$ psi and 2) the containment peak pressure does not exceed the design pressure of (90) psig during LOCA conditions.

The maximum peak pressure obtained from a LOCA event is (35) psig. The limit of (2) psig for initial positive containment pressure will limit the total pressure to (37) psig which is less than the design pressure and is consistent with the safety analyses.

\section{3/4.6.1.6 AIR TEMPERATURE}

The limitations on containment average air temperature ensure that the overall containment average air temperature does not exceed the initial temperature condition assumed in the accident analys is for a LOCA.

\section{3/4.6.1.7 CONTAINMENT VESSEL STRUCTURAL INTEGRITY}

This limitation ensures that the structural integrity of the containment steel vessel will be maintained comparable to the original design standards for the life of the facility. Structural integrity is required to ensure that the vessel will withstand the maximum pressure of (40) psig in the event of a LOCA. A visual inspection in conjunction with Type A leakage tests is sufficient to demonstrate this capability.

\section{3/4.6.1.8 CONTAINMENT, VENTILATION SYSTEM}

The containment purge supply and exhaust isolation valves are required to be closed during plant operation since these valves have not been demonstrated capable of closing during a LOCA. Maintaining these valves closed during plant operations ensures that excessive quantities of radioactive materials will not be released via the containment purge system.

\section{3/4.6.2 DEPRESSURIZATION AND COOLING SYSTEMS}

\section{3/4.6.2.1 CONTAINMENT SPRAY SYSTEM}

The OPERABILITY of the containment spray system ensures that containment depressurization and cooling capability will be available in the event of a LOCA. The pressure reduction and resultant lower containment leakage rate are consistent with the assumptions used in the safety analyses. The leak rate surveillance requirements assure that the leakage assumed for the system during the recirculation phase will not be exceeded.

B\&W-STS

B $3 / 4$ 6-2L June 1978 
CONTAINMENT SYSTEMS

BASES

(Credit taken for iodine removal)

The containment spray system and the containment cooling system are redundant to each other in providing post accident cooling of the containment atmosphere. However, the containment spray system also provides a mechanism for removing iodine from the containment atmosphere and therefore the time requirements for restoring an inoperable spray system to OPERABLE status have been maintained consistent with that assigned other inoperable ESF equipment.

(No credit taken for iodine removal)

The containment spray system and the containment cooling system are redundant to each other in providing post accident cooling of the containment atmosphere. Since no credit has been taken for iodine removal by the containment spray system, the allowable out of service time requirements for the containment spray system and containment cooling system have been interrelated and adjusted to reflect this additional redundancy in cooling capability.

\section{3/4.6.2.2 SPRAY ADDITIVE SYSTEM (OPTIONAL)}

The OPERABILITY of the spray additive system ensures that sufficient $\mathrm{NaOH}$ is added to the containment spray in the event of a LOCA. The limits on contained sodium hydroxide solution volume and concentration ensure a $\mathrm{pH}$ value of between (8.5) and (11.0) of the solution sprayed within containment after a design basis accident. The pH band minimizes the evolution of iodine and minimizes the effect of chloride and caustic stress corrosion cracking on mechanical systems and components. The contained water volume limit includes an allowance for water not usable because of tank discharge location or other physical characteristics. These assumptions are consistent with the iodine removal efficiency assumed in the safety analyses.

\section{3/4.6.2.3 CONTAINMENT COOLING SYSTEM (OPTIONAL)}

The OPERABILITY of the containment cooling system ensures that 1) the containment air temperature will be maintained within limits during normal operation, and 2) adequate heat removal capacity is available when operated in conjunction with the containment spray systems during post-LOCA conditions. 
| CONTAINMENT SYSTEMS

BASES

(Credit taken for iodine removal by spray systems)

The containment cooling system and the containment spray system are redundant to each other in providing post accident cooling of the containment atmosphere. As a result of this redundancy in cooling capability, the allowable out of service time requirements for the containment cooling system have been appropriately adjusted. However, the allowable out of service time requirements for the containment spray system have been maintained consistent with that assigned other inoperable ESF equipment since the containment spray system also provides a mechanism for removing iodine from the containment atmosphere.

(No credit taken for iodine removal by spray systems)

The containment cooling system and the containment spray system are redundant to each other in providing post accident cooling of the containment atmosphere. Since no credit has been taken for iodine removal by the containment spray system, the allowable out of service time requirements for the containment cooling system and containment spray system have been interrelated and adjusted to reflect this additional redundancy in cooling capacity.

\section{3/4.6.3 IODINE CLEANUP SYSTEM (OPTIONAL)}

The OPERABILITY of the containment jodine cleanup system ensures that sufficient iodine removal capability will be available in the event of a 2OCA. The reduction in containment iodine inventory reduces the resulting site boundary radiation doses associated with containment leakage. The pperation of this system and resultant iodine removal capacity are consistent with the assumptions used in the LOCA analyses.

\section{3/4.6.4 CONTAINMENT ISOLATION VALVES}

The OPERABILITY of the containment isolation valves ensures that the containment atmosphere will be isolated from the outside environment in the event of a release of radioactive material to the containment atmosphere or pressurization of the containment. Containment isolation within the time limits specified ensures that the release of radioactive material to the environment will be consistent with the assumptions used in the analyses for a LOCA. 


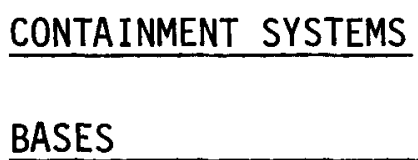

3/4.6.5 COMBUSTIBLE GAS CONTROL

The OPERABILITY of the equipment and systems required for the detection and control of hydrogen gas ensures that this equipment will be available to maintain the hydrogen concentration within containment below its flammable limit during post-LOCA conditions. Either recombiner unit (or the purge cleanup system) is capable of controlling the expected hydrogen generation associated with 1) zirconium-water reactions, 2) radiolytic decomposition of water, and 3) corrosion of metals within containment. These hydrogen control systems are consistent with the recommendations of Regulatory Guide 1.7, "Control of Combustible Gas Concentrations in Containment Following a LOCA," March 1971.

The hydrogen mixing systems are provided to ensure adequate mixing of the containment atmosphere following a LOCA. This mixing action will prevent localized accumulations of hydrogen from exceeding the flammable limit.

3/4.6.6 PENETRATION ROOM EXHAUST AIR CLEANUP SYSTEM (OPTIONAL)

The OPERABILITY of the penetration room exhaust air cleanup system ensures that radioactive materials leaking from the containment atmosphere through containment penetrations following a LOCA are filtered prior to reaching the environment. The operation of this system and the resultant effect on offsite dosage calculations was assumed in the LOCA analyses.

\section{3/4.6.7 VACUUM RELIEF VALVES (OPTIONAL)}

The OPERABILITY of the primary containment-to-atmosphere vacuum relief valves ensures that the containment internal pressure differential does not become more negative than (_) psi. This condition is necessary to prevent exceeding the containment design limit for internal pressure differential of (1.0) psi.

\section{3/4.6.8 SECONDARY CONTAINMENT}

\section{3/4.6.8.1 SHIELD BUILDING AIR CLEANUP SYSTEM}

The OPERABILITY of the shield building air cleanup systems ensures that containment vessel leakage occurring during LOCA conditions into the annulus will be filtered through the HEPA filters and charcoal adsorber trains prior to discharge to the atmosphere. This requirement is necessary to meet the assumptions used in the safety analyses and limit the site boundary radiation doses to within the limits of 10 CFR 100 during LOCA conditions. 


\section{CONTAINMENT SYSTEMS}

BASES

\section{3/4.6.8.2 SHIELD BUILDING INTEGRITY}

Shield building integrity ensures that the release of radioactive materials from the primary containment atmosphere will be restricted to those leakage paths and associated leak rates assumed in the safety analyses. This restriction, in conjunction with operation of the secondary containment ventilation system, will limit the site boundary radiation doses to within the limits of 10 CFR 100 during accident conditions.

\section{3/4.6.8.3 SHIELD BUILDING STRUCTURAL INTEGRITY}

This limitation ensures that the structural integrity of the containment shield building will be maintained comparable to the original design standards for the life of the facility. Structural integrity is required to provide 1) protection for the steel vessel from external missiles, 2) radiation shielding in the event of a LOCA, and 3) an annulus surrounding the steel vessel that can be maintained at a negative pressure during accident conditions. A visual inspection is sufficient to demonstrate this capability. 
$3 / 4.7$ PLANT SYSTEMS

BASES

\section{3/4.7.1 TURBINE CYCLE}

\section{3/4.7.1.1 SAFETY VALVES}

The OPERABILITY of the main steam line code safety valves ensures that the secondary system pressure will be limited to within $110 \%$ of its design pressure of ( ) psig during the most severe anticipated system operational transient. The maximum relieving capacity is associated with a turbine trip from 100\% RATED THERMAL POWER coincident with an assumed loss of condenser heat sink (i.e., no steam bypass to the condenser).

The specified valve lift settings and relieving capacities are in accordance with the requirements of Section III of the ASME Boiler and Pressure Vessel Code, (1971) Edition. The total relieving capacity for all valves on all of the steam lines is () $1 \mathrm{bs} / \mathrm{hr}$ which is () percent of the total secondary steam flow of () $1 \mathrm{bs} / \mathrm{hr}$ at $100 \%$ RATED THERMAL POWER. A minimum of 2 OPERABLE safety vaives per steam generator ensures that sufficient relieving capacity is available for the allowable THERMAL POWER restriction in Table 3.7-1.

STARTUP and/or POWER OPERATION is allowable with safety valves inoperable within the 1 imitations of the ACTION requirements on the basis of the reduction in secondary system steam flow and THERMAL POWER required by the reduced reactor trip settings of the Nuclear Overpower channels. The reactor trip setpoint reductions are derived on the following bases:

$$
S P=\frac{(X)-(Y)(V)}{X} \times(105.5)
$$

where:

$S P=$ reduced Nuclear Overpower Trip Setpoint in percent of RATED THERMAL POWER

$V=$ maximum number of inoperable safety valves per steam generator

$(105.5)=$ Nuclear Overpower Trip Setpoint specified in Table 2.2.1

$X=$ Total relieving capacity of all safety valves per steam generator in $1 \mathrm{bs} /$ hour

$Y=$ Maximum relieving capacity of any one safety valve in lbs/hour 


\section{3/4.7.1.2 AUXILIARY FEEDWATER SYSTEMS}

The OPERABILITY of the auxiliary feedwater systems ensures that the Reactor Coolant System can be cooled down to less than $(305)^{\circ} \mathrm{F}$ from normal operating conditions in the event of a total loss of offsite power.

Each electric driven auxiliary feedwater pump is capable of delivering a total feedwater flow of (350) gpm at a pressure of (1133) psig to the entrance of the steam generators. Each steam driven auxiliary feedwater pump is capable of delivering a total feedwater flow of (700) gpm at a pressure of (1133) psig to the entrance of the steam generators. This capacity is sufficient to ensure that adequate feedwater flow is available to remove decay heat and reduce the Reactor Coolant System temperature to less than $(305)^{\circ} \mathrm{F}$ where the Decay Heat Removal System may be placed into operation.

\section{3/4.7.1.3 CONDENSATE STORAGE TANK}

The OPERABILITY of the condensate storage tank with the minimum water volume ensures that sufficient water is available for cooldown of the Reactor Coolant System to less than $(305)^{\circ} \mathrm{F}$ in the event of a total loss of offsite power or of the main feedwater system. The minimum water volume is sufficient to maintain the RCS at HOT STANDBY conditions for ( ) hours with steam discharge to atmosphere concurrent with loss of offsite power. The contained water volume limit includes an allowance for water not usable because of tank discharge line location or other physical characteristics.

\section{3/4.7.1.4 ACTIVITY}

The 1 imitations on secondary system specific activity ensure that the resultant offsite radiation dose will be 1 imited to a small fraction of 10 CFR Part 100 limits in the event of a steam line rupture. This dose includes the effects of a coincident $1.0 \mathrm{GPM}$ primary to secondary tube leak in the steam generator of the affected steam line. These values are consistent with the assumptions used in the safety analyses.

\section{3/4.7.1.5 MAIN STEAM LINE ISOLATION VALVES}

The OPERABILITY of the main steam line isolation valves ensures that no more than one steam generator will blowdown in the event of a steam line rupture. This restriction is required to 1) minimize the 
BASES

positive reactivity effects of the Reactor Coolant System cooldown associated with the blowdown, and 2) limit the pressure rise within containment in the event the steam line rupture occurs within containment. The OPERABILITY of the main steam isolation valves within the closure times of the surveillance requirements are consistent with the assumptions used in the safety analyses.

\section{3/4.7.1.6 SECONDARY WATER CHEMISTRY}

A test program will be conducted during approximately the first 6 months following initial criticality to establish the appropriate limits on the secondary water chemistry parameters and to determine the appropriate frequencies for monitoring these parameters. The results of this test program will be submitted to the Commission for review. The Commission will then issue a revision to this specification specifying the limits on the parameters and the frequencies for monitoring these parameters.

The test program will include an analysis of the chemical constitutents of the condenser cooling water at the point of intake. The analysis shall identify the various traces of ions which upon concentration in the condensate may have the potential for inducement for stress corrosion in the steam generator tubing. The test program shall also evaluate the efficiency of the water treatment systems in the facility for removal of such ions and the potential for addition of other ions resulting from the treatment method. The test program shall analyze concentration phenomena and the concentration rates in the steam generator and the secondary water system and shall consider concentration in the recirculating cooling water system.

\section{3/4.7.2 STEAM GENERATOR PRESSURE/TEMPERATURE LIMITATION}

The limitation on steam generator pressure and temperature ensures that the pressure induced stresses in the steam generators do not exceed the maximum allowable fracture toughness stress limits. The limitations of $(70)^{\circ} \mathrm{F}$ and (200) psig are based on a steam generator RT NDT of ()$^{\circ} \mathrm{F}$ and are sufficient to prevent brittle fracture.

\section{3/4.7.3 COMPONENT COOLING WATER SYSTEM}

The OPERABILITY of the component cooling water system ensures that sufficient cooling capacity is available for continued operation of safety related equipment during normal and accident conditions. The redundant cooling capacity of this system, assuming a single failure, is consistent with the assumptions used in the safety analyses.

B\&W-STS

B $3 / 47-3$

June 1,1976 
PLANT SYSTEMS

BASES

\section{3/4.7.4 SERVICE WATER SYSTEM}

The OPERABILITY of the service water system ensures that sufficient cooling capacity is available for continued operation of safety related equipment during normal and accident conditions. The redundant cooling capacity of this system, assuming a single failure, is consistent with the assumptions used in the safety analyses.

\section{3/4.7.5 ULTIMATE HEAT SINK (OPTIONAL)}

The limitations on the ultimate heat sink level and temperature ensure that sufficient cooling capacity is available to either 1) provide normal cooldown of the facility, or 2) to mitigate the effects of accident conditions within acceptable limits.

The limitations on minimum water level and maximum temperature are based on providing a 30 day cooling water supply to safety related equipment without exceeding their design basis temperature and is consistent with the recommendations of Regulatory Guide 1.27, "Ultimate Heat Sink for Nuclear Plants", March 1974.

\section{3/4.7.6 FLOOD PROTECTION (OPTIONAL)}

The limitation on flood protection ensures that facility protective actions will be taken (and operation will be terminated) in the event of flood conditions. The limit of elevation () Mean Sea Level is based on the maximum elevation at which facility flood control measures provide protection to safety related equipment.

\section{3/4.7.7 CONTROL ROOM EMERGENCY AIR CLEANUP SYSTEM}

The OPERABILITY of the control room emergency air cleanup system ensures that 1) the ambient air temperature does not exceed the allowable temperature for continuous duty rating for the equipment and instrumentation cooled by this system and 2) the control room will remain habitable for operations personnel during and following all credible accident conditions. The OPERABILITY of this system in conjunction with control room design provisions is based on limiting the radiation exposure to personnel occupying the control room to 5 rem or less whole body, or its equivalent. This limitation is consistent with the requirements of General Design Criterion 19 of Appendix "A", 10 CFR 50. 
PLANT SYSTEMS

BASES

\section{3/4.7.8 ECCS PUMP ROOM EXHAUST AIR CLEANUP SYSTEM (OPTIONAL)}

The OPERABILITY of the ECCS pump room exhaust air cleanup system ensures that radioactive materials leaking from the ECCS equipment within the pump room following a LOCA are filtered prior to reaching the environment. The operation of this system and the resultant effect on offsite dosage calculations were assumed in the safety analyses.

\section{$3 / 4.7 .9$ HYDRAULIC SNUBBERS}

The hydraulic snubbers are required OPERABLE to ensure that the structural integrity of the reactor coolant system and all other safety related systems is maintained during and following a seismic or other event initiating dynamic loads. The only snubbers excluded from this inspection program are those installed on nonsafety related systems and then only if their failure or failure of the system on which they are installed, would have no adverse effect on any safety related system.

The inspection frequency applicable to snubbers containing seals fabricated from materials which have been demonstrated compatible with their operating environment is based upon maintaining a constant level of snubber protection. Therefore, the required inspection interval varies inversely with the observed snubber failures. The number of inoperable snubbers found during an inspection of these snubbers determines the time interval for the next required inspection of these snubbers. Inspections performed before that interval has elapsed may be used as a new reference point to determine the next inspection. However, the results of such early inspections performed before the original required time interval has elapsed (nominal time less $25 \%$ ) may not be used to lengthen the required inspection interval. Any inspection whose results require a shorter inspection interval will override the previous schedule.

To provide further assurance of snubber reliability, a representative sample of the installed snubbers will be functionaliy tested during plant shutdowns at 18 month intervals. These tests will include stroking of the snubbers to verify proper piston movement, lock-up and bleed. Observed failures of these sample snubbers will require functional testing of additional units. To minimize personnel exposures, snubbers installed in areas that have high radiation fields during shutdown or in especially difficult to remove locations may be exempted from these functional testing requirements provided the OPERABILITY of these snubbers was demonstrated during functional testing at either the completion of their fabrication or at a subsequent date. 
PLANT SYSTEMS

BASES

\section{3/4.7.10 SEALED SOURCE CONTAMINATION}

The limitations on removable contamination for sources requiring leak testing, including alpha emitters, is based on 10 CFR 70.39 (c) limits for plutonium. This limitation will ensure that leakage from byproduct, source, and special nuclear material sources will not exceed allowable intake values.

\section{$3 / 4.7 .11$ FIRE SUPPRESSION SYSTEMS}

The OPERABILITY of the fire suppression systems ensures that adequate fire suppression capability is available to confine and extinquish fires occuring in any portion of the facility where safety related equipment is located. The fire suppression system consists of the water system, spray and/or sprinkler, $\mathrm{CO}_{2}$, Halon and fire hose stations. The collective capability of the fire suppression systems is adequate to minimize potential damage to safety related equipment and is a major element in the facility fire protection program.

In the event that portions of the fire suppression systems are inoperable, alternate backup fire fighting equipment is required to be made ayailable in the affected areas until the inoperable equipment is restored to service.

In the event the fire suppression water system becomes inoperable, imnediate corrective measures must be taken since this system provides the major fire suppression capability of the plant. The requirement for a twenty-four hour report to the Commission provides for prompt evaluation of the acceptability of the corrective measures to provide adequate fire suppression capability for the continued protection of the nuclear plant.

\section{3/4.7.12 PENETRATION FIRE BARRIERS}

The functional integrity of the penetration fire barriers ensures that fires will be confined or adequately retarded from spreading to adjacent portions of the facility. This design feature minimizes the possibility of a single fire rapidly involving several areas of the facility prior to detection and extinguishment. The penetration fire barriers are a passive element in the facility fire protection program and are subject to periodic inspections.

During periods of time when the barriers are not functional, a continuous fire watch is required to be maintained in the vicinity of the affected barrier until the barrier is restored to functional status. 
3/4.8 ELECTRICAL POWER SYSTEMS

BASES

The OPERABILITY of the A.C. and D.C. power sources and associated distribution systems during operation ensures that sufficient power will be available to supply the safety related equipment required for 1 ) the safe shutdown of the facility and 2) the mitigation and control of accident conditions within the facility. The minimum specified independent and redundant A.C. and D.C. power sources and distribution systems satisfy the requirements of General Design Criterion 17 of Appendix "A" to 10 CFR 50 .

The ACTION requirements specified for the levels of degradation of the power sources provide restriction upon continued facility operation commensurate with the level of degradation. The OPERABILITY of the power sources are consistent with the initial condition assumptions of the safety analyses and are based upon maintaining at least one redundant set of onsite A.C. and D.C. power sources and associated distribution systems OPERABLE during accident conditions coincident with an assumed loss of offsite power and single failure of the other onsite A.C. source.

The OPERABILITY of the minimum specified A.C. and D.C. power sources and associated distribution systems during shutdown and refueling ensures that 1) the facility can be maintained in the shutdown or refueling condition for extended time periods and 2) sufficient instrumentation and control capability is available for monitoring and maintaining the unit status.

The Surveillance Requirements for demonstrating the OPERABILITY of the diesel generators are in accordance with the recommendations of Regulatory Guide 1.9 "Selection of Diesel Generator Set Capacity for Standby Power Supplies", March 10, 1971, and 1.108 "Periodic Testing of Diesel Generator Units Used as Onsite Electric Power Systems at Nuclear Power Plants," Revision 1, August 1977. 
$\bullet$
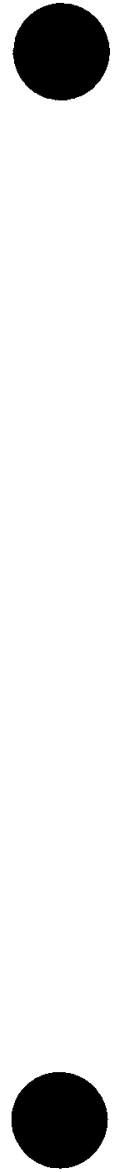


\section{3/4.9 REFUELING OPERATIONS}

BASES

\section{3/4.9.1 BORON CONCENTRATION}

The 1 imitations on reactivity conditions during REFUELING ensure that: 1) the reactor will remain subcritical during CORE ALTERATIONS, and 2) a uniform boron concentration is maintained for reactivity control in the water volumes having direct access to the reactor vessel. These limitations are consistent with the initial conditions assumed for the boron dilution incident in the accident analysis.

\section{3/4.9.2 INSTRUMENTATION}

The OPERABILITY of source range neutron flux monitors ensures that redundant monitoring capability is available to detect changes in the reactivity condition of the core.

\section{3/4.9.3 DECAY TIME}

The minimum requirement for reactor subcriticality prior to movement of irradiated fuel assemblies in the reactor pressure vessel ensures that sufficient time has elapsed to allow the radioactive decay of the short lived fission products. This decay time is consistent with the assumptions used in the safety analyses.

\section{3/4.9.4 CONTAINMENT PENETRATIONS}

The requirements on containment penetration closure and OPERABILITY ensure that a release of radioactive material within containment will be restricted from leakage to the environment. The OPERABILITY and closure requirements are sufficient to restrict radioactive material release from a fuel element rupture based upon the lack of containment pressurization potential while in the REFUELING MODE.

\section{3/4.9.5 COMMUNICATIONS}

The requirement for communications capability ensures that refueling station personnel can be promptly informed of significant changes in the facility status or core reactivity condition during CORE ALTERATIONS. 
REFUELING OPERATIONS

BASES

3/4.9.6 FUEL HANDLING BRIDGE OPERABILITY

The OPERABILITY requirements of the hoist bridges used for movement of fuel assemblies ensures that: 1) fuel handling bridges will be used for movement of control rods and fuel assemblies, 2) each hoist has sufficient load capacity to lift a fuel element, and 3) the core internals and pressure vessel are protected from excessive lifting force in the event they are inadvertently engaged during lifting operations.

\section{3/4.9.7 CRANE TRAVEL - SPENT FUEL STORAGE BUILDING}

The restriction on movement of loads in excess of the nominal weight of a fuel and control rod assembly and associated handling tool over other fuel assemblies in the storage pool ensures that in the event this load is dropped (1) the activity release will be limited to that contained in a single fuel assembly, and (2) any possible distortion of fuel in the storage racks will not result in a critical array. This assumption is consistent with the activity release assumed in the accident analyses.

\section{3/4.9.8 COOLANT CIRCULATION}

The requirement that at least one decay heat removal loop be in operation ensures that ( 1 ) sufficient cooling capacity is available to remove decay heat and maintain the water in the reactor pressure vessel below $140^{\circ} \mathrm{F}$ as required during the REFUELING MODE, and (2) sufficient coolant circulation is maintained through the reactor core to minimize the effect of a boron dilution incident and prevent boron stratification.

\section{3/4.9.9 CONTAINMENT PURGE AND EXHAUST ISOLATION SYSTEM}

The OPERABILITY of this system ensures that the containment purge and exhaust penetrations will be automatically isolated upon detection of high radiation levels within the containment. The OPERABILITY of this system is required to restrict the release of radioactive material from the containment atmosphere to the environment.

3/4.9.10 and 3/4.9.11 WATER LEVEL - REACTOR VESSEL AND STORAGE POOL WATER LEVEL

The restrictions on minimum water level ensure that sufficient water depth is available to remove $99 \%$ of the assumed $10 \%$ iodine gap activity released from the rupture of an irradiated fuel assembly. The minimum water depth is consistent with the assumptions of the safety analysis. 


\section{REFUELING OPERATIONS}

BASES

3/4.9.12 STORAGE POOL AIR CLEANUP SYSTEM

The requirements on the storage pool air cleanup system to be operating or OPERABLE ensure that all radioactive material released from an irradiated fuel assembly will be filtered through the HEPA filters and charcoal adsorber prior to discharge to the atmosphere. The OPERABILITY of this system and the resulting iodine removal capacity are consistent with the assumptions of the safety analyses. 
•
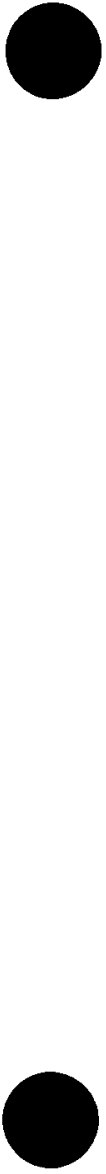


\section{$3 / 4.10$ SPECIAL TEST EXCEPTIONS}

BASES

3/4.10.1 GROUP HEIGHT, INSERTION AND POWER DISTRIBUTION LIMITS

This special test exception permits individual control rods to be positioned outside of their specified group heights and insertion limits and to be assigned to other than specified control rod groups, and permits AXIAL POWER IMBALANCE and QUADRANT POWER TILT limits to be exceeded during the performance of such PHYSICS TESTS as those required to 1) measure control rod worth, 2) determine the reactor stability index and damping factor under xenon oscillation conditions and 3 ) calibrate AXIAL POWER IMBALANCE and QUADRANT POWER TILT instrumentation.

\section{3/4.10.2 PHYSICS TESTS}

This special test exception permits PHYSICS TESTS to be performed at less than or equal to $5 \%$ of RATED THERMAL POWER and is required to verify the fundamental nuclear characteristics of the reactor core and related instrumentation.

\section{3/4.10.3 REACTOR COOLANT LOOPS}

This special test exception permits reactor criticality under various flow conditions and is required in order to perform certain startup and PHYSICS TESTS while at low THERMAL POWER levels.

\section{3/4.10.4 SHUTDOWN MARGIN}

This special test exception provides that a minimum amount of control rod worth is immediately available for reactivity control when tests are performed for control rod worth measurement. This special test exception is required to permit the periodic verification of the actual versus predicted core reactivity condition occurring as a result of fuel burnup or fuel cycling operations. 
๑

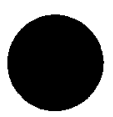

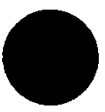


SECTION 5.0

DESIGN FEATURES 
O
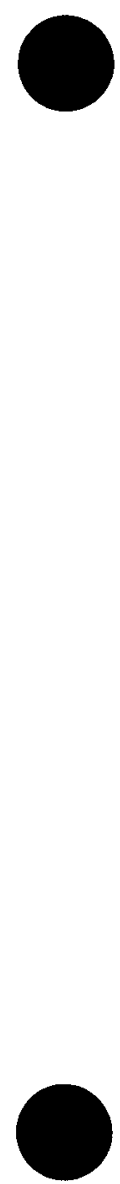


\subsection{SITE}

\section{EXCLUSION AREA}

5.1.1 The exclusion area is shown on Figure 5.1-1.

LOW POPULATION ZONE

5.1.2 The low population zone is shown on Figure 5.1-2.

\subsection{CONTAINMENT}

\section{CONFIGURATION}

5.2.1 The reactor containment building is a steel lined, reinforced concrete building of cylindrical shape, with a dome roof and having the following design features:

a. Nominal inside diameter $=$ feet.

b. Nominal inside height $=$ feet.

c. Minimum thickness of concrete walls = feet.

d. Minimum thickness of concrete roof $=$ feet.

e. Minimum thickness of concrete floor pad $=$ feet.

f. Nominal thickness of steel liner $=\ldots$ inches.

g. Net free volume $=$ cubic feet. 
This figure shall consist of a map of the site area and provide at a minimum, the information described in Section (2.1.2) of the FSAR and the meteorological tower location.

\section{EXCLUSION AREA}

FIGURE $5.1-1$ 
This figure shall consist of a map of the site area showing the Low Population Zone (LPZ) boundary. Features such as towns, roads and recreational areas shall be indicated in sufficient detail to allow identification of significant shifts in population distribution within the LPZ.

\section{LOW POPULATION ZONE}

FIGURE 5.1-2 
DESIGN PRESSURE AND TEMPERATURE

5.2.2 The reactor containment building is designed and shall be maintained for a maximum internal pressure of psig and a temperature of ${ }_{\mathrm{F}}$.

\subsection{REACTOR CORE}

\section{FUEL ASSEMBLIES}

5.3.1 The reactor core shall contain fuel assemblies with each fuel assembly containing. fuel rods clad with (Zircaloy -4 ). Each fuel rod shall have a nominal active fuel length of inches and contain a maximum total weight of loading shall have a maximum enrichment of grams uranium. The initial core Reload fuel shall be similar in physical design to the initial core loading and shall have a maximum enrichment of weight percent U-235.

The first cycle fuel loading shall contain assemblies with each assembly containing up to of sintered $\mathrm{Al}_{2} \mathrm{O}_{3}-\mathrm{B}_{4} \mathrm{C}$ clad with Zircaloy-4. burnable poison rod burnable poison rods

\section{CONTROL RODS}

5.3.2 The reactor core shall contain safety and regulating and axial power shaping (APSR) controt rods. The safety and regulating control rods shall contain a nominal 134 inches of absorber material. The APSR's shall contain a nominal 36 inches of absorber material at their lower ends. The nominal values of absorber material shall be 80 percent silver, 15 percent indium and 5 percent cadmium. All control rods shall be clad with stainless steel tubing. 


\subsection{REACTOR COOLANT SYSTEM}

DESIGN PRESSURE AND TEMPERATURE

5.4.1 The reactor coolant system is designed and shall be maintained:

a. In accordance with the code requirements specified in Section. (5.2) of the FSAR, with allowance for normal degradation pursuant to applicable Surveillance Requirements.

b. For a pressure of psig, and

c. For a temperature of ${ }^{\circ} \mathrm{F}$, except for the pressurizer and pressurizer surge line which is ${ }^{\circ} \mathrm{F}$.

VOLUME

5.4.2 The total water and steam volume of the reactor coolant system is \pm cubic feet at a nominal $\mathrm{T}_{\text {avg }}$ of $(525)^{\circ} \mathrm{F}$.

5.5 METEOROLOGICAL TOWER LOCATION

5.5.1 The meteorological tower shall be located as shown on Figure $(5.1-1)$.

5.6 FUEL STORAGE

CRITICALITY

5.6.1 The new and spent fuel storage racks are designed and shall be maintained with a nominal inch center-to-center distance between fuel assemblies placed in the storage racks to ensure a $k$ ff equivalent to $\leq 0.95$ with the storage pool filled with unborated wafter. The $k_{\text {f }}$ of 0.95 includes a conservative allowance of $(2.6) \% \Delta k / k$ for uncertainties as described in Section (9.1) of the FSAR. If new fuel for the first core loading is stored dry in the spent fuel storage racks with a nominal inch center-to-center distance between fuel assemblies, then $k_{\text {eff }}$ sha11 not exceed $(0.98)$ when aqueous foam moderation is assumed.

DRAINAGE

5.6.2 The spent fuel storage pool is designed and shall be maintained to prevent inadvertent draining of the pool below elevation 


\section{CAPACITY}

5.6.3 The spent fuel storage pool is designed and shall be maintained with a storage capacity 1 imited to no more than fuel assemblies.

\subsection{COMPONENT CYCLIC OR TRANSIENT LIMIT}

5.7.1 The components identified in Table 5.7-1 are designed and shall be maintained within the cyclic or transient limit of Table 5.7-1. 
Component or System

1. Reactor Coolant System

2. Reactor Coolant System

3. Reactor Coolant System

4. Reactor Coolant System

5. Reactor Coolant System

6. Reactor Coolant System

7. Once Through Steam Generator

8. Once Through Steam Generator

9. Once Through Steam Generator
Cycle or Transient Limit

(240) Heatup and Cooldown Cycles

(160) Step Load Reduction Cycles (Resulting from turbine trip)

(150) Step Load Reduction Cycles (Resulting from electrical load rejection)

(40) Reactor Trip Cycles (Resulting from loss of electric power to all $\mathrm{RC}$ pumps)

(160) Reactor Trip Cycles (Resulting from turbine trip without automatic control action)

(40) Reactor Trip Cycles (Resulting from rod withdrawal accident)

(88) Reactor Trip Cycles (Resulting from complete loss of all main feedwater)

(40) Reactor Trip Cycles (Resulting from loss of station power)

(20) Reactor Trip Cycles (Resulting from loss of feedwater to one steam generator)
Design Cycle or Transient $\left(70^{\circ} \mathrm{F}\right.$ to $557^{\circ} \mathrm{F}$ to $\left.70^{\circ} \mathrm{F}\right)$

( $100 \%$ to $8 \%$ RTP*)

( $100 \%$ to $8 \%$ RTP*)

Reactor Trip

Reactor Trip

Reactor Trip

Reactor Trip

Reactor Trip

Reactor Trip

*RATED THERMAL POWER 
TABLE 5.7-1 (Continued)

Component or System

10. Once Through

Steam Generator

11. Reactor Coolant System

12. Reactor Coolant System

13. Reactor Coolant System

14. Once Through Steam Generator

15. Reactor Coolant System

16. Reactor Coolant System
Cycle or Transient Limit Design Cycle or Transient

(10) Reactor Trip Cycles Reactor Trip (Resulting from stuck open turbine bypass valve)

(80) Rapid Depressurization (2200 psig to 300 psig in one hour)

(20) Change of Flow Cycles Loss of one or more RC pumps

(20) Hydrostatic Test

(35) Hydrostatic Tests

(480) Test Transients

(240) Test Transients
Pressurized to $\geq$ (3125) psig

Pressurized to $\geq$ (3125) psig

High Pressure Injection Test

Core Flooding Check Valve Test 
STANDARD

TECHNICAL SPECIFICATIONS

SECTION 6.0

ADMINISTRATIVE CONTROLS 
○
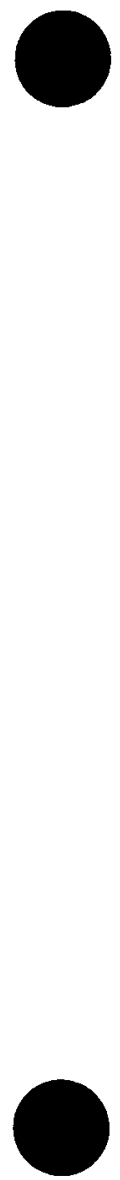


\subsection{RESPONSIBILITY}

6.1.1 The (Plant Superintendent) shall be responstble for overall unit operation and shall delegate in writing the succession to this responsibility during his absence.

\subsection{ORGANIZATION}

OFFSITE

6.2.1 The offsite organization for unit management and technical support shal1 be as shown on figure 6.2-1.

\section{UNIT STAFF}

6.2.2 The Unit organization shall be as shown on figure $6.2-2$ and:

a. Each on duty shift shall be composed of at least the minimum shift crew composition shown in Table 6.2-1.

b. At least one licensed Operator shall be in the control room when fuel is in the reactor.

c. At least two licensed Operators shall be present in the control room during reactor start-up, scheduled reactor shutdown and during recovery from reactor trips.

d. An individual qualified in radiation protection procedures shall be on site when fuel is in the reactor.

e. A11 CORE ALTERATIONS shall be directly supervised by either a licensed Senior Reactor Operator or Senior Reactor Operator Limited to Fuel Handing who has no other concurrent responsibilities during this operation.

f. A site Fire Brigade of at least 5 members shall be maintained onsite at all times. The Fire Brigade shall not include (3) members of the minimum shift crew necessary for safe shutdown of the unit and any personnel required for other essentlal functions during a fire emergency. 
This figure shall show the organizational structure and lines of responstbility for the offst te groups that provide technical and management support for the unit. The organizational arrangement for performance and monitoring Quality Assurance activities should also be indicated.

Figure 6.2-1

OFFSITE ORGANIZATION 
This figure shall show the organizational structure and 1 ines of responsibllity for the unit staff.

Positions to be staffed by itcensed personnel should be indicated.

Figure 6.2-2

UNIT ORGANIZATION 
TABLE $6.2-1$

MINIMUM SHIFT CREW COMPOSITION\#

\begin{tabular}{|l|c|c|}
\hline \multirow{2}{*}{$\begin{array}{l}\text { LICENSE } \\
\text { CATEGORY }\end{array}$} & \multicolumn{2}{|c|}{ APPL ICABLE MODES } \\
\cline { 2 - 3 } & $1,2,3 \& 4$ & $5 \& 6$ \\
\hline SOL & 1 & $1 *$ \\
\hline OL & 2 & 1 \\
\hline Non-Licensed & 2 & 1 \\
\hline
\end{tabular}

* Does not include the licensed Senior Reactor Operator or Senior Reactor Operator Limited to Fuel Handling, supervising CORE ALTERATIONS.

\#Shift crew composition may be less than the minimum requirements for a period of time not to exceed 2 hours in order to accommodate unexpected absence of on duty shift crew members provided immediate action is taken to restore the shift crew composition to within the minimum requirements of Table 6.2-1. 


\subsection{UNIT STAFF QUALIFICATIONS}

Minimum qualifications for members of the unit staff may be specified by use of an overall qualification statement referencing ANSI N18.1-1971 or alternately by specifying individual position qualifications. Generally, the first method is preferable; however, the second method is adaptable to those unit staffs requiring special qualification statements because of a unique organizational structure.

6.3.1 Each member of the unit staff shall meet or exceed the minimum qualifications of ANSI N18.1-1971 for comparable positions, except for the (Radiation Protection Manager) who shall meet or exceed the qualifications of Regulatory Guide 1.8, September 1975.

\subsection{TRAINING}

6.4.1 A retraining and replacement training program for the unit staff shall be maintained under the direction of the (position title) and shall meet or exceed the requirements and recommendations of Section 5.5 of ANSI N18.1-1971 and Appendix "A" of 10 CFR Part 55.

6.4.2 A training program for the Fire Brigade shall be maintained under the direction of the (position title) and shall meet or exceed the requirements of Section 27 of the NFPA Code-1975, except for Fire Brigade training sessions which shall be held at least once per 92 days.

\subsection{REVIEW AND AUDIT}

The method by which independent review and audit of facility operations is accomplished may take one of several forms. The licensee may either assign this function to an organizational unit separate and independent from the group having responsibility for unit operation or may utilize a standing committee composed of individuals from within and outside the licensee's organization.

Irrespective of the method used, the licensee shall specify the details of each functional element provided for the independent review and audit process as illustrated in the following example specifications.

\subsubsection{UNIT REVIEW GROUP (URG)}

\section{FUNCTION}

6.5.1.1 The (Unit Review Group) shall function to advise the (Plant Superintendent) on all matters related to nuclear safety. 
COMPOSITION

6.5.1.2 The (Unit Review Group) shall be composed of the:

Chairman:

Member:

Member:

Member:

Member:

Member:

Member:
(Plant Superintendent)

(Operations Supervisor)

(Technical Supervisor)

(Ma intenance Supervisor)

(Plant Instrument and Control Engineer)

(Plant Nuclear Engineer)

(Health Physicist)

\section{ALTERNATES}

6.5.1.3 All alternate members shall be appointed in writing by the (URG) Chairman to serve on a temporary basis; however, no more than two alternates shall participate as voting members in (URG) activities at any one time.

\section{MEETING FREQUENCY}

6.5.1.4 The (URG) shall meet at least once per calendar month and as convened by the (URG) Chairman or his designated alternate.

\section{QUORUM}

6.5.1.5 The minimum quorum of the (URG) necessary for the performance of the (URG) responsibility and authority provision of these technical specifications shall consist of the Chairman or his designated alternate and four members including alternates.

\section{RESPONS IBILITIES}

6.5.1.6 The (Unit Review Group) shall be responsible for:

a. Review of 1) all procedures required by Specification 6.8 and changes thereto, 2) any other proposed procedures or changes thereto as determined by the (Plant Superintendent) to affect nuclear safety.

b. Review of all proposed tests and experiments that affect nuclear safety. 
c. Review of all proposed changes to Appendix "A" Technical Specifications.

d. Review of all proposed changes or modifications to unit systems or equipment that affect nuclear safety.

e. Investigation of all violations of the Technical Specifications including the preparation and forwarding of reports covering evaluation and recommendations to prevent recurrence to the (Superintendent of Power Plants) and to the (Company Nuclear Review and Audit Group).

f. Review of events requiring 24 hour written notification to the Commission.

g. Review of unit operations to detect potential nuclear safety hazards.

h. Performance of special reviews, investigations or analyses and reports thereon as requested by the (Plant Superintendent) or the (Company Nuclear Review and Audit Group).

i. Review of the Security Plan and implementing procedures and shall submit recommended changes to the (Company Nuclear Review and Audit Group).

j. Review of the Emergency Plan and implementing procedures and shall submit recommended changes to the (Company Nuclear Review and Audit Group).

AUTHORITY

6.5.1.7 The (Unit Review Group) shal1:

a. Recommend in writing to the (Plant Superintendent) approval or disapproval of items considered under 6.5.1.6(a) through (d) above.

b. Render determinations in writing with regard to whether or not each item considered under 6.5.1.6(a) through (e) above constitutes an unreviewed safety question.

c. Provide written notification within 24 hours to the (Superintendent of Power Plants) and the (Company Nuclear Review and Audit Group) of disagreement between the (URG) and the (Plant Superintendent); however, the (Plant Superintendent) shall have responsibility for resolution of such disagreements pursuant to 6.1 .1 above. 
RECORDS

6.5.1.8 The (Unit Review Group) shall maintain written minutes of each (URG) meeting that, at a minimum, document the results of all (URG) activities performed under the responsibility and authority provisions of these technical specifications. Copies shall be provided to the (Superintendent of Power Plants) and the (Company Nuclear Review and Audit Group).

\subsubsection{COMPANY NUCLEAR REVIEW AND AUDIT GROUP (CNRAG)}

\section{FUNCTION}

6.5.2.1 The (Company Nuclear Review and Audit Group) shall function to provide independent review and audit of designated activities in the areas of:
a. nuclear power plant operations
b. nuclear engineering
c. chemistry and radiochemistry
d. metallurgy
e. instrumentation and control
f. radiological safety
g. mechanical and electrical engineering
h. quality assurance practices
i. (other appropriate fields associated with the unique char- acteristics of the nuclear power plant) 
COMPOSITION

6.5.2.2 The (CNRAG) shall be composed of the:

Director: (Position Title)

Member:

Member:

Member:

(Position Title)

(Position Title)

Member: (Position Title)

(Position Title)

\section{ALTERNATES}

6.5.2.3 All alternate members shall be appointed in writing by the (CNRAG) Director to serve on a temporary basis; however, no more than two alternates shall participate as voting members in (CNRAG) activities at any one time.

\section{CONSULTANTS}

6.5.2.4 Consultants shall be utilized as determined by the (CNRAG) Director to provide expert advice to the (CNRAG).

\section{MEETING FREQUENCY}

6.5.2.5 The (CNRAG) shall meet at least once per calendar quarter during the initial year of unit operation following fuel loading and at least once per six months thereafter.

\section{QUORUM}

6.5.2.6 The minimum quorum of the (CNRAG) necessary for the performance of the (CNRAG) review and audit functions of these technical specifications shall consist of the Director or his designated alternate and lat least 4 CNRAG) members including alternates. No more than a minority of the quorum shall have line responsibility for operation of the unit. 


\section{REVIEW}

6.5.2.7 The (CNRAG) shall review:

a. The safety evaluations for 1) changes to procedures, equipment or systems and 2) tests or expertments completed under the provision of Section 50.59, 10 CFR, to verlfy that such actions did not constitute an unreviewed safety question.

b. Proposed changes to procedures, equipment or systems which involve an unreviewed safety question as defined in Section $50.59,10$ CFR.

c. Proposed tests or experiments which involve an unreviewed safety question as defined in Section 50.59, 10 CFR.

d. Proposed changes to Technical Specifications or this Operating License.

e. Violations of codes, regulations, orders, Techntcal Spectfications, 1 icense requirements, or of internal procedures or instructions having nuclear safety signtficance.

f. Significant operating abnormalities or deviations from normal and expected performance of unit equipment that affect nuclear safety.

g. Events requiring 24 hour written notification to the Commission.

h. All recognized indications of an unantfcipated defictency in some aspect of design or operation of structures, systems, or components that could affect nuclear safety.

i. Reports and meetings minutes of the (Unit Review Group). 


\section{AUDITS}

6.5.2.8 Audits of unit activities shall be performed under the cognizance of the (CNRAG). These audits shall encompass:

a. The conformance of unit operation to provisions contained within the Technical Specifications and applicable license conditions at least once per 12 months.

b. The performance, training and qualifications of the entire unit staff at least once per 12 months.

c. The results of actions taken to correct deficiencies occurring in unit equipment, structures, systems or method of operation that affect nuclear safety at least once per 6 months.

d. The performance of activities required by the Operational Quality Assurance Program to meet the criteria of Appendix "B", 10 CFR 50, at least once per 24 months.

e. The Emergency Plan and implementing procedures at least once per 24 months.

f. The Security Plan and implementing procedures at least once per 24 months.

g. Any other area of unit operation considered appropriate by the (CNRAG) or the (Vice President Operations).

h. The Fire Protection Program and implementing procedures at least once per 24 months.

i. An independent fire protection and loss prevention inspection and audit shall be performed annually utilizing either qualified offsite licensee personnel or an outside fire protection firm.

j. An inspection and audit of the fire protection and loss prevention program shall be performed by an outside qualified fire consultant at intervals no greater than 3 years.

AUTHORITY

6.5.2.9 The (CNRAG) shall report to and advise the (Vice President Operations) on those areas of responsibility specified in sections 6.5.2.7 and 6.5.2.8. 


\section{RECORDS}

6.5.2.10 Records of (CNRAG) activities shal1 be prepared, approved and distributed as indicated below:

a. Minutes of each (CNRAG) meeting shall be prepared, approved and forwarded to the (Vice President-Operations) within 14 days following each meeting.

b. Reports of reviews encompassed by Section 6.5.2.7 above, shall be prepared, approved and forwarded to the (Vice PresidentOperations) within 14 days following completion of the review.

c. Audit reports encompassed by Section 6.5 .2 .8 above, shall be forwarded to the (Vice President-Operations) and to the management positions responsible for the areas audited within 30 days after completion of the audit.

\subsection{REPORTABLE OCCURRENCE ACTION}

6.6.1 The following actions shall be taken for REPORTABLE OCCURRENCES:

a. The Commission shall be notified and/or a report submitted pursuant to the requirements of Specification 6.9.

b. Each REPORTABLE OCCURRENCE requiring 24 hour notification to the Commission shall be reviewed by the (URG) and submitted to the (CNRAG) and the (Superintendent of Power plants). 


\subsection{SAFETY LIMIT VIOLATION}

6.7.1 The following actions shall be taken in the event a Safety Limit is violated:

a. The unit shall be placed in at least HOT STANDBY within one hour.

b. The Safety Limit violation shall be reported to the Commission, the (Superintendent of Power Plants) and to the (CNRAG) within 24 hours.

c. A Safety Limit Violation Report shall be prepared. The report shall be reviewed by the (URG). This report shall describe (1) applicable circumstances preceding the violation, (2) effects of the violation upon facility components, systems or structures, and (3) corrective action taken to prevent recurrence.

d. The Safety Limit Violation Report shall be submitted to the Commission, the (CNRAG) and the (Superintendent of Power Plants) within 14 days of the violation.

\section{$\underline{6.8}$ PROCEDURES}

6.8.1 Written procedures shall be established, implemented and maintained covering the activities referenced below:

a. The applicable procedures recommended in Appendix "A" of Regulatory Guide 1.33, Revision 2, February 1978.

b. Refueling operations.

c. Surveillance and test activities of safety related equipment.

d. Security Plan implementation.

e. Emergency Plan implementation.

f. Fire Protection Program implementation.

6.8.2 Each procedure of 6.8.1 above, and changes thereto, shall be reviewed by the (URG) and approved by the (Plant Superintendent) prior to implementation and reviewed periodically as set forth in administrative procedures. 
6.8.3 Temporary changes to procedures of 6.8 .1 above may be made provided:

a. The intent of the originial procedure is not altered.

b. The change is approved by two members of the plant management staff, at least one of whom holds a Senior Reactor Operator's License on the unit affected.

c. The change is documented, reviewed by the (URG) and approved by the (Plant Superintendent) within 14 days of implementation.

\subsection{REPORTING REQUIREMENTS}

ROUTINE REPORTS AND REPORTABLE OCCURRENCES

6.9.1 In addition to the applicable reporting requirements of Title 10 , Code of Federal Regulations, the following reports shall be submitted to the Director of the Regional Office of Inspection and Enforcement unless otherwise noted.

\section{STARTUP REPORT}

6.9.1.1 A summary report of plant startup and power escalation testing shall be submitted following (1) receipt of an operating license, (2) amendment to the license involving a planned increase in power level, (3) installation of fuel that has a different design or has been manufactured by a different fuel supplier, and (4) modifications that may have significantly altered the nuclear, thermal, or hydraulic performance of the plant.

6.9.1.2 The startup report shall address each of the tests fdentified in the FSAR and shall include a description of the measured values of the operating conditions or characteristics obtained during the test program and a comparison of these values with design predictions and specifications. Any corrective actions that were required to obtain satłsfactory bperation shall also be described. Any additional specific details required in license conditions based on other cormitments shall be included in this report.

6.9.1.3 Startup reports shall be submitted within (1) 90 days following completion of the startup test program, (2) 90 days following resumption or commencement of commercial power operation, or (3) 9 months following initial criticality, whichever is earliest. If the Startup Report does hot cover all three events (1.e., initial criticality, completion of startup test program, and resumption or commencement of commercial operation) supplementary reports shall be submitted at least every three montis until all three events have been completed. 
ANNUAL REPORTS $1 /$

6.9.1.4 Annual reports covering the activities of the unit as described below for the previous calendar year shall be submitted prior to March 1 of each year. The initial report shall be submitted prior to March 1 of the year following initial criticality.

6.9.1.5 Reports required on an annual basis shall include:

a. A tabulation on an annual basis of the number of station, utility, and other personnel (including contractors) receiving exposures greater than $100 \mathrm{mrem} / \mathrm{yr}$ and their associated manrem exposure according to work and job functions, $=$ e.g., reactor operations and surveillance, inservice inspection, routine maintenance, special maintenance (describe maintenance), waste processing, and refueling. The dose assignments to various duty functions may be estimated based on pocket dosimeter, TLD, or film badge measurements. Small exposures totalling less than 20 percent of the individual total dose need not be accounted for. In the aggregate, at least 80 percent of the total whole body dose received from external sources should be assigned to specific major work functions.

b. The results of steam generator tube inservice inspections performed during the report period. (CE, W \& B\&W units only).

c. The results of the core barrel movement monitoring activities performed during the report period. (CE units only).

d. (Any other unit unique reports required on an annual basis.)

I/A single submittal may be made for a multiple unit station. The submittal should combine those sections that are common to all units at the station.

$2 /$ This tabulation supplements the requirements of $\$ 20.407$ of 10 CFR Part 20. 
6.9.1.6 Routine reports of operating statistics and shutdown experience shall be submitted on a monthly basis to the Director, Office of Management and Program Analysis U.S. Nuclear Regulatory Commission, Washington, D.C. 20555, with a copy to the Regional Offfce of Inspection and Enforcement, no later than the 15th of each month following the calendar month covered by the report.

\section{REPORTABLE OCCURRENCES}

6.9.1.7 The REPORTABLE OCCURRENCES of Specifications 6.9.1.8 and 6.9.1.9 below, including corrective actions and measures to prevent recurrence, shall be reported to the NRC. Supplemental reports may be required to fully describe final resolution of occurrence. In case of corrected or supplemental reports, a licensee event report shall be completed and reference shall be made to the original report date.

\section{PROMPT NOTIFICATION WITH WRITTEN FOLLOWUP}

6.9.1.8 The types of events 1 is ted below shall be reported within 24 hours by telephone and confirmed by telegraph, mailgram, or facsimile transmission to the Director of the Regional office, or his designate no later than the first working day following the event, with a written followup report within 14 days. The written followup report shall include, as a minimum, a completed copy of a licensee event report form. Information provided on the licensee event report form shall be supplemented, as needed, by additional narrative material to provide complete explanation of the circumstances surrounding the event.

a. Failure of the reactor protection system or other systems subject to limiting safety system settings to initiate the required protective function by the time a monitored parameter reaches the setpoint specified as the limiting safety system setting in the technical specifications or fallure to complete the required protective function.

D. Operation of the unit or affected systems when any parameter or operation subject to a 1 imiting condition for operation is less conservative than the least conservative aspect of the i imiting condition for operation established in the technical speciftcations.

c. Abnormal degradation discovered in fuel cladding, reactor coolant pressure boundary, or primary contalmment. 
d. Reactivity anomalies involving disagreement with the predicted value of reactivity balance under steady state conditions during power operation greater than or equal to $1 \% \Delta \mathrm{k} / \mathrm{k}$; a calculated reactivity balance indicating a SHUTDOWN MARGIN less conservative than specified in the technical spectfications; short-term reactfvity increases that correspond to a reactor period of less than 5 seconds or, if subcritical, an unplanned reactivity insertion of more than $0.5 \% \Delta k / k$; or occurrence of any unplanned criticaltty.

e. Failure or malfunction of one or more components which prevents or could prevent, by itself, the fulfillment of the functional requirements of system(s) used to cope with accidents analyzed in the SAR.

f. Personnel error or procedural inadequacy which prevents or could prevent, by itself, the fulfillment of the functtonal requirements of systems required to cope with accidents analyzed in the SAR.

g. Conditions arising from natural or man-made events that, as a direct result of the event require unit shutdown, operation of safety systems, or other protective measures required by technical specifications.

h. Errors discovered in the transient or accident analyses or in the methods used for such analyses as described in the safety analysis report or in the bases for the technical specifications that have or could have permitted reactor operation in a manner less conservative than assumed in the analyses.

1. Performance of structures, systems, or components that requires remedial action or corrective measures to prevent operation in a manner less conservative than assumed in the accident analyses in the safety analysis report or technical spectfications bases; or discovery during unit 1ife of conditions not specifically considered in the safety analysis report or technical specifications that require remedial action or corrective measures to prevent the existence or development of an unsafe condition.

THIRTY DAY WRITTEN REPORTS

6.9.1.9 The types of events listed below shall be the subject of written reports to the Director of the Regional Office within thirty days of 
occurrence of the event. The written report shall include, as a minimum, a completed copy of a licensee event report form. Information provided on the licensee event report form shall be supplemented, as needed, by additional narrative material to provide complete explanation of the circumstances surrounding the event.

a. Reactor protection system or engineered safety feature instrument settings which are found to be less conservative than those estabiished by the technical specifications but which do not prevent the fulfillment of the functional requirements of affected systems.

b. Conditions leading to operation in a degraded mode permitted by a limiting condition for operation or plant shutdown required by a limiting condition for operation.

c. Obseryed inadequacies in the implementation of administrative or procedural controls which threaten to cause reduction of degree of redundancy provided in reactor protection systems or engineered safety feature systems.

d. Abnormal degradation of systems other than those specified in $6,9.7 .8$. c above designed to contain radioactive material resulting from the fission process.

SPECIAL REPORTS

Special reports may be required covering inspections, test and maintenance activities. These special reports are determined on an individual basis for each unit and their preparation and submittal are designated in the Technical Specifications.

6.9.2 Special reports shall be submitted to the Director of the Office of Inspection and Enforcement Regional Office within the time period specified for each report. 
6.10 RECORD RETENTION

In addition to the applicable record retention requirements of Title 10 , Code of Federal Regulations, the following records shall be retained for at least the minimum period indicated.

6.10.1 The following records shall be retained for at least five years:

a. Records and logs of unit operation covering time interval at each power level.

b. Records and logs of principal maintenance activities, inspections, repair and replacement of principal items of equipment related to nuclear safety.

c. All REPORTABLE OCCURRENCES submitted to the Commission.

d. Records of surveillance activities, inspections and calibrations required by these Technical Specifications.

e. Records of changes made to the procedures required by Specification 6.8.1.

f. Records of radioactive shipments.

g. Records of sealed source and fission detector leak tests and results.

h. Records of annual physical inventory of all sealed source material of record.

6.10.2 The following records shall be retained for the duration of the Unit Operating License:

a. Records and drawing changes reflecting unit design modifications made to systems and equipment described in the Final Safety Analys is Report.

b. Records of new and irradiated fuel inventory, fuel transfers and assembly burnup histories.

c. Records of radiation exposure for all individuals entering radiation control areas.

d. Records of gaseous and liquid radioactive material released to the environs. 
e. Records of transient of operational cycles for those unit components identified in Table 5.7-1.

f. Records of reactor tests and experiments.

g. Records of training and qualification for current members of the unit staff.

h. Records of in-service inspections performed pursuant to these Technical Specifications.

i. Records of Quality Assurance activities required by the QA Manual.

j. Records of reviews performed for changes made to procedures or equipment or reviews of tests and experiments pursuant to 10 CFR 50.59 .

k. Records of meetings of the (URG) and the (CNRAG).

\subsection{RADIATION PROTECTION PROGRAM}

Procedures for personnel radiation protection shall be prepared cons istent with the requirements of 10 CFR Part 20 and shall be approved, maintained and adhered to for all operations involving personnel radiation exposure.

\subsection{HIGH RADIATION AREA (OPTIONAL)}

6.12.1 In lieu of the "control device" or "alarm signal" required by paragraph $20.203(\mathrm{c})(2)$ of 10 CFR 20 , each high radiation area in which the intensity of radiation is greater than $100 \mathrm{mrem} / \mathrm{hr}$ but less than $1000 \mathrm{mrem} / \mathrm{hr}$ shall be barricaded and conspicuously posted as a high radiation area and entrance thereto shall be controlled by requiring issuance of a Radiation Work Permit*. Any individual or group of individuals permitted to enter such areas shall be provided with or accompanied by one or more of the following:

a. A radiation monitoring device which continuously indicates the radiation dose rate in the area.

*Health Physics personnel or personnel escorted by Health Physics personnel in accordance with approved emergency procedures shall be exempt from the RWP issuance requirement during the performance of their assigned radiation protection duties, provided they comply with approved radiation protection procedures for entry into high radiation areas. 
b. A radiation monitoring device which continuously integrates the radiation dose rate in the area and alarms when a preset integrated dose is received. Entry into such areas with this monitoring device may be made after the dose rate level in the area has been established and personnel have been made knowledgeable of them.

c. An individual qualified in radiation protection procedures who is equipped with a radiation dose rate monitoring device. This individual shall be responsible for providing positive control over the activities within the area and shall perform periodic radiation surveillance at the frequency specified by the facility Health Physicist in the Radiation Work Permit.

6.12.2 The requirements of 6.12 .1 , above, shall also apply to each high radiation area in which the intensity of radiation is greater than $1000 \mathrm{mrem} / \mathrm{hr}$. In addition, locked doors shall be provided to prevent unauthorized entry into such areas and the keys shall be maintained under the administrative control of the Shift Foreman on duty and/or the Plant Health Physicist. 